Portland State University

PDXScholar

\title{
Factors That Motivate Washington State Teachers to Participate in Professional Growth and Development
}

\author{
Dolores Adan Heisinger \\ Portland State University
}

Follow this and additional works at: https://pdxscholar.library.pdx.edu/open_access_etds

Part of the Educational Assessment, Evaluation, and Research Commons, and the Educational Leadership Commons

Let us know how access to this document benefits you.

\section{Recommended Citation}

Heisinger, Dolores Adan, "Factors That Motivate Washington State Teachers to Participate in Professional Growth and Development" (1994). Dissertations and Theses. Paper 4753.

https://doi.org/10.15760/etd.6637

This Dissertation is brought to you for free and open access. It has been accepted for inclusion in Dissertations and Theses by an authorized administrator of PDXScholar. Please contact us if we can make this document more accessible: pdxscholar@pdx.edu. 
FACTORS THAT MOTIVATE WASHINGTON STATE TEACHERS TO PARTICIPATE IN PROFESSIONAL GROWTH AND DEVELOPMENT

by

DOLORES ADAN HEISINGER

A dissertation submitted in partial fulfillment of the requirements for the degree of

\author{
DOCTOR OF EDUCATION \\ in \\ EDUCATIONAL LEADERSHIP: \\ PUBLIC SCHOOL ADMINISTRATION \\ AND SUPERVISION
}

\author{
Portland State University \\ and \\ University of Oregon
}

1994 


\section{DISSERTATION APPROVAL}

The abstract and dissertation of Dolores Adan Heisinger for the Doctor of Education in Educational Leadership: Public School Administration and Supervision were presented January 13,1994 , and accepted by the dissertation committee and the doctoral program

COMMITTEE APPROVALS:

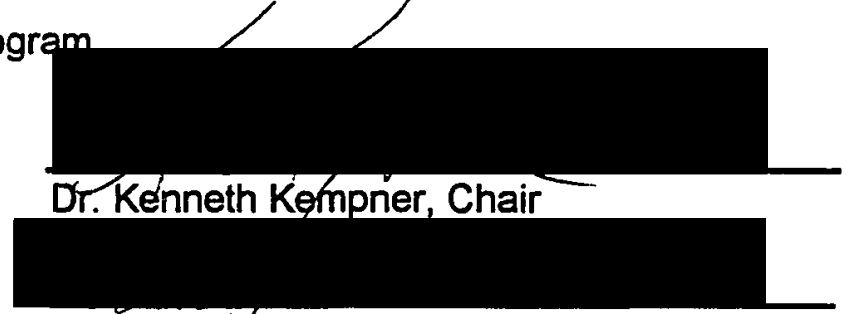

Dr. Amy Driscoli

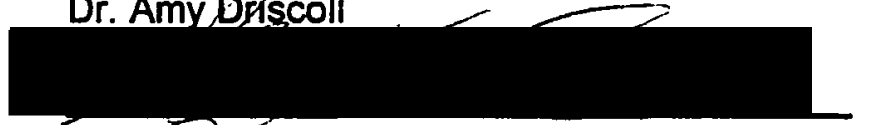

Dr. Mlary Kínnick

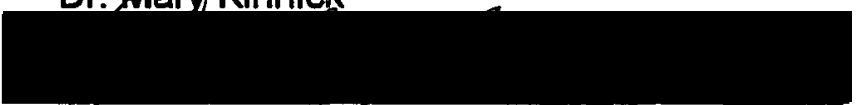

Gr. David C. Berliner

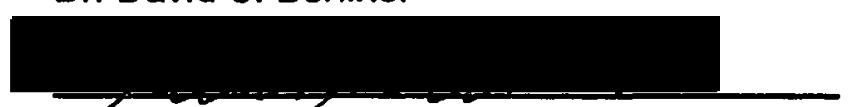

Dr. Walter G. Ellis

Representative of the Office of

Graduate Studies

DOCTORAL PROGRAM APPROVAL:

David A. Krug, Acting Bean

School of Education

ACCEPTED FOR PORTLAND STATE UNIVERSITY BY THE LIBRARY

on 18 Ylaxch 1994 


\begin{abstract}
An abstract of the dissertation of Dolores Adan Heisinger for the Doctor of Education in Educational Leadership: Public School Administration and Supervision presented January 13, 1994.
\end{abstract}

Title: Factors that Motivate Washington State Teachers to Participate in Professional Growth and Development

The major focus of this study was the identification of factors that motivate teachers to participate in professional growth and development activities. Although teachers may be motivated to participate in staff development for different reasons, it was hypothesized that common factors forming an identifiable incentive profile could be found. Within the focus of the study, three primary questions were asked: a) What are the needs, incentives or motivators that influence teachers to further their professional development?; b) What are the relative strengths of the various needs, incentives or motivators?; and c) How do the incentive structures of teachers differ based on a set of demographic variables and attributes?

Answers to Question (1) were formulated in the process of conducting a literature review of staff development, general motivation theory and teacher 
motivation theory, and while developing the research instruments used in the study. Questions (2) and (3) were answered by analyzing the results of the research instruments after they were administered in survey format to study respondents.

The study instruments (Work Motivation Profile and Staff Development Motivation Profile) utilized the technique of paired comparisons. Respondents were asked to weight two statements that corresponded to levels of Maslow's (1954) and Herzberg's (1959) five-tiered motivation constructs.

The analysis unit examined in the research study consisted of all teachers, kindergarten through twelfth grade, in the state of Washington during the time period 1986-1987. A systematic sample of 2000 was drawn from the approximately 39,500 teachers in the state. Of the 2,000 surveys mailed to teachers, 770 were usable for the study.

There were four major findings from the study: (a) The strongest need that prompted teachers in this sample to participate in professional growth and development activities was the intrinsic motivation of Self-Actualization. The second greatest source of motivation was Social needs; (b) Basic, Stadus, or Security needs were secondary motivators. (c) Years of experience, major work assignment, size of school district and proportion of household income attributable to school district salary had significant, though weak, effects on the need structures of teachers; (d) Despite subtle differences, the basic teacher 
profile remained constant: the five needs motivating teachers to participate in professional growth and development, in descending order of strength, were Self-Actualization Needs, Social Needs, Basic Needs, Status Needs, and Security Needs. 


\section{ACKNOWLEDGEMENTS}

I would like to acknowledge the following individuals without whose support and encouragement this study might not have come to fruition:

First and foremost, my love and gratitude go to my husband, Rocky Barilla. His patience, caring and gentle nudging helped me to reach a goal that often seemed elusive and distant.

To Ken Kempner, Chair of my Committee, I give special thanks for providing guidance, moral support and friendship throughout the length of the study.

I am also indebted to JoAnn Kink-Mertens, a friend and colleague who helped conceptualize the study and refine the framework for the research, with the assistance of the Washington Education Association.

Finally, to my children, friends and colleagues who encouraged me along the way, I owe a debt of gratitude. 


\section{TABLE OF CONTENTS}

PAGE
ACKNOWLEDGEMENTS ii
LIST OF TABLES vi
LIST OF FIGURES
.x

\section{CHAPTER}

1 INTRODUCTION TO THE STUDY $\ldots \ldots \ldots \ldots \ldots \ldots \ldots \ldots \ldots$

Identification of the Research Problem ...............2

Research Hypothesis and Major Study Questions .5

Definitions of Terminology Used in the Study .7

Need for the Study $\ldots \ldots \ldots \ldots \ldots \ldots \ldots \ldots \ldots \ldots \ldots, 12$

Methods and Procedures $\ldots \ldots \ldots \ldots \ldots \ldots \ldots \ldots \ldots$

Limitations of the Study $\ldots \ldots \ldots \ldots \ldots \ldots \ldots \ldots . \ldots 28$

II REVIEW OF THE LITERATURE $\ldots \ldots \ldots \ldots \ldots \ldots \ldots \ldots . \ldots 33$

Role of School Administrator in Promoting Professional Growth of Teachers ................ 35

Research on Staff Development ................... 53

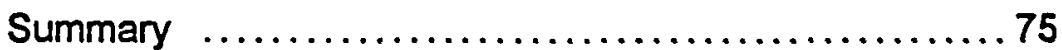


III METHODOLOGY AND PROCEDURES $\ldots \ldots \ldots \ldots \ldots \ldots \ldots$

Development of the Instruments $\ldots \ldots \ldots \ldots \ldots \ldots \ldots . \ldots 8$

Scoring of the Instruments $\ldots \ldots \ldots \ldots \ldots \ldots \ldots . \ldots 94$

Pilot Testing of the Instruments $\ldots \ldots \ldots \ldots \ldots \ldots . \ldots 96$

Validation of the Instruments $\ldots \ldots \ldots \ldots \ldots \ldots \ldots . . .97$

Administration of the Research Instruments .............................. 110

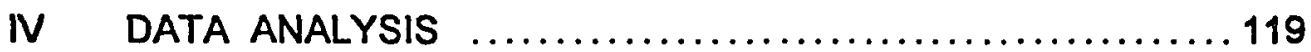

Target Population $\ldots \ldots \ldots \ldots \ldots \ldots \ldots \ldots \ldots \ldots \ldots \ldots \ldots$

Composite Picture of Total

Respondents ............................ 129

Impact of Variables on Incentive

Structures .............................. 132

Summary of Procedures $\ldots \ldots \ldots \ldots \ldots \ldots \ldots \ldots \ldots \ldots 186$

V SUMMARY, ANALYSIS, AND RECOMMENDATIONS ........ 189

Summary and Analysis of Motivators for

Participating in Staff Development ............. 194

Summary of Findings from the Study $\ldots \ldots \ldots \ldots \ldots \ldots 217$

Implications of the Study ....................... 223

Recommendations for Further Research $\ldots \ldots \ldots \ldots \ldots 228$

Final Recommendations and Concluding

Remarks 


\section{APPENDICES}

A Staff Development and Work Motivation Profile ............ 250

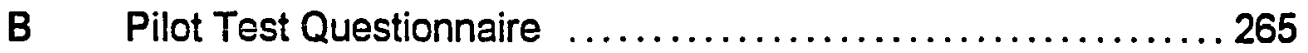

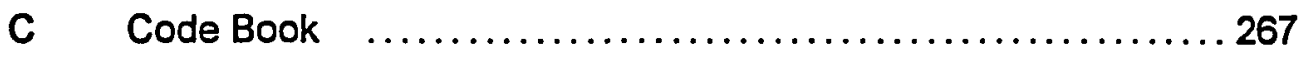




\section{LIST OF TABLES}

TABLE

PAGE

Hall-Williams Work Motivation Inventory:

Established Norms 99

II

Comparison of Means: Sample 1 and

Established Norms

III

Comparison of Means: Hall-Williams Established

Norms and Work Motivation Profile

IV

Comparison of Means: Work Motivation Profile and Staff Development Motivation Profile

V

Comparison of Reliability Scores: Work Motivation

Profile and Staff Development Motivation Profile

VI

All Teachers in the State of Washington by Gender and Number of Years of Teaching Experience

(Prior to September 1985)

VII Proportionate Number of Teachers Needed in Each

Years of Teaching Experience Category

for Sample Size of 2,000

VIII Summary Disposition of Mailed Inventories

IX

Years of Full Time Public School Experience of

Study Respondents

X Gender Breakout of Study Respondents 122

XI

Major Work Assignment of Study Respondents 122

XII

Highest Degree Received by Study Respondents 123

XIII

Salary Schedule Mobility of Study Respondents 123 
XIV Percentage of Household Income Derived from

School District Salary

XV Grade Level Assignment of Study Respondents

XVI Pupil Enrollment in the District

XVII Years of Full Time Public School Experience:

Eight Year Categories 126

XVIII Gender by Full Time Public School Experience 128

XIX Variables Predicting Variance in Basic Needs 134

XX Variables Predicting Variance in Security Needs 135

$\mathbf{X X I}$

Variables Predicting Variance in Social Needs 136

XXII Variables Predicting Variance in Status Needs 137

XXIII Variables Predicting Variance in Self-Actualization Needs 138

XXIV Gender by Major Work Assignment 139

XXV Gender by Highest Degree Received 139

XXVI Gender by Salary Schedule Mobility 140

XXVII Gender by Percentage of Household Income Derived from School District Salary 140

XXVIII Gender by Grade Level Assignment $\ldots . . \ldots \ldots \ldots \ldots \ldots . . . .141$

XXIX Gender by Pupil Enrollment in District ............... 141

XXX T-Tests for Independent Samples of Gender by Needs ... 143

XXXI Analysis of Variance: Gender by Full Time Public School Experience on. Basic Needs 146

XXXII Analysis of Variance: Gender by Full Time Public School Experience on Security Needs 
XXXIII Analysis of Variance: Gender by Full Time Public, School Experience on Social Needs ............... 148

XXXIV Analysis of Variance: Gender by Full Time Public School Experience on Status Needs 150

XXXV Analysis of Variance: Gender by Full Time Public School Experience on Self-Actualization Needs

XXXVI Major Work Assignment of Study Respondents:

Regular Teachers and Others

XXXVII Analysis of Variance: Gender by Major Work Assignment on Basic Needs

XXXVIII Analysis of Variance: Gender by Major Work Assignment on Security Needs

XXXIX Analysis of Variance: Gender by Major Work Assignment on Social Needs 160

XL Analysis of Variance: Gender by Major Work Assignment on Status Needs

XLI Analysis of Variance: Gender by Major Work Assignment on Self-Actualization Needs 162

XLII Number of Study Respondents by Pupil Enrollment in the District 166

XLIII Analysis of Variance: Gender by Pupil Enrollment in the District on Basic Needs

XLIV Analysis of Variance: Gender by Pupil Enrollment in the District on Security Needs 169

XLV Analysis of Variance: Gender by Pupil Enrollment in the District on Social Needs

XLVI Analysis of Variance: Gender by Pupil Enrollment in the District on Status Needs 
XLVII Analysis of Variance: Gender by Pupil Enrolliment in the District on Self-Actualization Needs

XLVIII Percentage of Household Income Derived from School District Salary

XLIX Analysis of Variance: Gender by Percentage of Household Income Derived from School District Salary on Basic Needs

L

Analysis of Variance: Gender by Percentage of Household Income Derived from School District Salary on Security Needs 182

LI Analysis of Variance: Gender by Percentage of Household Income Derived from School District Salary on Social Needs 183

LII Analysis of Variance: Gender by Percentage of Household Income Derived from School District Salary on Status Needs 184

LIII Analysis of Variance: Gender by Percentage of Household Income Derived from School District Salary on Self-Actualization Needs 


\section{LIST OF FIGURES}

FIGURE

PAGE

1. Comparison of Sergiovanni's (1987) Clockworks I and

Clockworks II Models with McGregor's (1960)

Theories $\mathrm{X}$ and $\mathrm{Y}$ 46

2. Sergiovanni's (1980) Ideal Decision-Making Situation ........50

3. Maslow's (1954) Theory of Hierarchical Needs (adapted). ......64

4. Comparison of Maslow (1954) and Herzberg (1974)

Constructs.

5. Sample Needs Profile $\ldots \ldots \ldots \ldots \ldots \ldots \ldots \ldots \ldots \ldots \ldots \ldots . \ldots 5$

6. Validation Procedure $\ldots \ldots \ldots \ldots \ldots \ldots \ldots \ldots \ldots \ldots \ldots . . .68$

7. Hall-Williams Work Motivation Inventory Norms (1967) ....... 100

8. Hall-Williams Work Motivation Inventory (Established

Norms, 1967) ano Small Sample of Teachers ........... 102

9. Hall-Williams Work Motivation Inventory (Established

Norms, 1967) and Work Motivation Profile .............. 104

10. Staff Development Motivation Profile (Large Sample) and

Work Motivation Profile ............................ 108

11. Disposition of Mailed Survey Inventories $(2,000$

Surveys Mailed) ................................ 125

12. Staff Development Motivation Profile (Large Sample) ........ 130

13. Total Sample Means by Gender ...................... 144 
14. Means by Gender for 0 to 8 Years of Teaching

Experience (Newcomers)

15. Means by Gender for 9 to 16 Years of Teaching

Experience (Established Teachers)

16. Means by Gender for 17 to 24 Years of Teaching

Experience (Veteran Teachers)

17. Means by Gender far 25 or More Years of Teaching

Experience (Career Teachers)

18. Means by Gender for "Regular" and "Other" Teacher

Work Assignments 164

19. Means by Total Population and Major Work Assignment 165

20. Means by Gender for Pupil Enrollment in the District

(Total Population) 175

21. Means by Pupil Enrollment in the District 175

22. Means by Gender for Small School District Pupil

Enrollment 176

23. Means by Gender and Pupil Enrollment in the District for Security Needs 176

24. Means by Pupil Enrollment in the District for Social Needs

25. Means by Percentage of Household Income Derived

School District Salary for Security Needs 186

26. Staff Development Motivation Profile (Large Sample) 197

27. Total Sample Means by Gender 200

28. Total Sample Means and Total Sample Means by Gender 201

29. Means by Years of Teaching Experience for

Basic Needs 203 
30. Means by Years of Teaching Experience and Gender for Basic Needs

31. Means by Years of Teaching Experience for

Social Needs

32. Means by Major Work Assignment for

Basic Needs

33. Means by Major Work Assignment for

Security Needs 209

34. Means by Major Work Assignment for Status Needs 210

35. Means by Gender for Basic Needs 211

36. Means by Size of School District for Basic Needs 212

37. Means by Size of School District for

Security Needs 212

38. Means by Gender and Size of School

District for Security Needs

39. Means by Size of School District for Social Needs

40. Means by Percentage of Household Income

Derived from School District Salary for Security Needs 


\section{CHAPTER I}

\section{INTRODUCTION TO THE STUDY}

The education reform movement of the 1980s stirred whirlwinds of activity among educational researchers, educational policy makers, state governmental agencies, arid the general public (Darling-Hammond \& Berry, 1988; Rosenholtz, 1984). The publication, in 1983, of the National Commission on Excellence in Education Report, A Nation at Risk, initiated renewed scrutiny of the effectiveness of public education in the United States. This report cited several indicators of poor performance by the public schools: high functional illiteracy rates, low mastery of higher-order intellectual skills, declining test scores, and the decreasing competitiveness of students in the United States compared with students in other countries (National Commission on Excellence in Education [NCEE], 1983).

A Nation at Risk (NCEE) and the series of reports published in the 1980 s by the Carnegie Forum on Education and the Economy (1986), the Education Commission of the States (1983), The Holmes Group (1986), and others have received credit for stimulating the educational community to actively pursue the improvement and reform of educational policies and practices (Darling-Hammond \& Berry, 1988). According to Darling-Hammond and Berry 
(1988), "these reports reaffirm the importance of competent teachers for improving American education, and the necessity of such improvements for America's future economic welfare" (p. 5). Darling-Hammond and Berry further conclude that the reform prescriptions suggested by the reports of the 1980 s emphasized that "lasting improvements will occur only if decisions about education are both decentralized and professionalized. That is, they must reflect teachers' and principals' best professional judgments on behalf of students..." ( p. 5).

\section{IDENTIFICATION OF THE RESEARCH PROBLEM}

Although the precise role of the school administrator in insuring optimal educational outcomes for students continues to be debated, administrators (particularly principals) are still held responsible for the academic performance and achievement scores of students (Dwyer, Barnett, \& Lee, 1987). According to Sweeney (1982), "the direct responsibility for improving instruction is in the hands of school principals" (p. 347).

Researchers report that successful administrators can be key agents in the development of successful schools (Brookover, Gigliotti, Henderson, \& Schneider, 1973; Wynne, 1981). Sergiovanni (1982) went further and proposed that the leadership that the principal exhibits can be "the" key factor in determining the effectiveness of a school. He additionally stated that two 
specific prerequisites of quality leadership include the leadership ability (management skills) and the decision-making skills (including an adequate information base) necessary to develop and operate an effective school.

The renewed recognition by educational leaders, that if schools are to improve the skills of the individual classroom teacher must receive attention (Darling-Hammond \& Berry, 1988), points to the importance of effective administrative leadership skills in planning professional growth and development for teachers. In her 1981 study of staff development in urban, desegregated settings, Little found that principals in successful schools play a key role in establishing and maintaining a climate conducive to professional growth. Clearly, the professional growth and development of teachers is a key factor in determining the success of educational reform.

Since "staff development offers one of the most promising roads to the improvement of instruction" (Sparks, 1983. p. 65), knowing more about the factors that motivate teachers to participate in professional growth and development can be extremely important to administrators. According to Fenstermacher and Berliner (1984), "research that examines teachers' reasons for participating in staff development is a critical need" (p. 69). Administrators need to know whether participation is based on concerns about professional improvement, financial incentives, compliance with policy mandates or a combination of these reasons. A better understanding of the various motivators 
for teachers would allow policy makers to devise more effective strategies for increasing teacher attendance and commitment to staff development activities (Fenstermacher \& Berliner, 1984).

The major focus for investigation in this study was the identification of factors that motivate teachers to participate in staff development activities. Individual teachers may be motivated in their work setting by a broad spectrum of reasons or motivators. These motivators can be placed on a multiple-level framework that might range from intrinsic motivators, described by Lawler and Porter (1967) as internally given rewards, to extrinsic factors which are externally controlled.

There is some evidence to suggest that intrinsic rewards provide the most powerful incentives for teachers (Lortie, 1975). This research evidence is not reflected, however, in the popular belief structures about teachers. Additionally, some researchers believe that there is insufficient information about the incentive systems that motivate teachers, particularly in the arena of professional or staff development (Fenstermacher \& Berliner, 1984).

Given the dearth of conclusive information about the incentives that motivate teachers in a variety of areas, it seemed appropriate to add to the body of knowledge in this field by seeking answers from teachers themselves. In a related study on motivation, Jaycox and Tallman (1967) observed that "the best way to find out what makes a teacher feel good about his [sic] job is to ask him 
[sic]" (p.4). Adding to the body of knowledge about the motivators and incentives that teachers consider important could help facilitate the current reform movement and aid in shaping policy decisions about inservice education for teachers.

\section{RESEARCH HYPOTHESIS AND MAJOR STUDY QUESTIONS}

\section{Research Hypothesis}

Although teachers may be motivated to participate in professional growth and development activities for different reasons, it will be possible to identify common factors that form a distinguishable incentive profile for them.

\section{Major Questions}

Within the primary focus of this study, i.e., the identification of factors that motivate teachers to participate in staff development activities, three major questions were asked:

1. What are the needs, incentives or motivators that influence teachers to further their professional growth and development?

2. What are the "relative strengths" of the various needs, incentives, or motivators influencing teachers' participation in professional growth or staff development activities? 
3. How do the incentive structures of teachers vary based on a set of variables that includes gender, years of teaching experience, size of school district, teaching assignment, highest degree held, potential for movement on the salary schedule, grade level assignment, and proportion of income attributable to school district salary?

Answers to question one were formulated in the process of conducting a literature review of staff development, motivation theory generally, and teacher motivation theory specifically, and while developing the research instruments used in this study. Questions two and three were answered by analyzing the results of administering the research instruments to study respondents.

The study instruments (Work Motivation Profile and Staff Development Motivation Profile) utilized the technique of paired comparisons. Respondents were asked to weight two statements which had been related to levels of Maslow's (1954) and Herzberg's (Herzberg, Mausner, \& Snyderman, 1959) five-tiered motivation constructs. The questionnaire statements were categorized in the following manner: Basic Needs were related to time and money concerns; Security Needs were related to job security and work evaluation; Social Needs were related to collegiality and social interaction; Status Needs were related to personal recognition and tangible rewards; Self-Actualization Needs were related to personal satisfaction and self-fulfillment (Herzberg, Mausner \& Snyderman, 1959; Maslow, 1954). 
The scoring system used to analyze the responses of study participants produced group profiles that depicted the relative strength of each of the five "need" categories: Basic; Security; Social; Status; and Self-Actualization. The highs and lows of the teacher profiles indicated their satisfied and unsatisfied sources of motivation. A composite profile of all the need areas portrayed the group's motivational construct (need system) for participating in professional growth and development activities.

\section{DEFINITIONS OF TERMINOLOGY USED}

IN THE STUDY

\section{Need Systems}

Maslow (1954) has written that human behavior can be explained in terms of the needs experienced by the individual. When a specific need is active, it can serve as the impetus for action and as a shaper of the activities in which the individual engages. Need systems serve as a source of motivation.

\section{Motivation}

Motivation occurs as a result of an encounter between the individual's needs and the environment. It is not governed only by the context of the environment, nor does it result solely from the individual's interests, abilities, and personal traits. Motivation results from both. Motivation is dynamic and continuously changing as circumstances within the environment change (Gellerman, 1968). 
Incentive/ Motivator

According to Maslow (1968), a motivator or incentive is a need stimulated in response to a desire, a feeling of yearning, a wish, or a sense of lacking.

\section{Basic Needs}

According to Maslow (1954), human needs are organized on a series of levels. At the lowest level are the basic, physiological needs-the needs for food, drink, shelter-the things that money can buy (Miller, 1966.) On the job, basic needs become a concern for things such as pleasant working conditions, more leisure time and increased salary (Hall \& Williams, 1967).

\section{Security Needs}

Security needs are those motivators which lead humans to seek freedom from physical danger and fear (Maslow, 1954). Translated into the world of work, security needs deal with job security, working conditions or company policy (Frase, Hetzel, \& Grant, 1982).

\section{Social Needs}

Social needs revolve around a desire to associate and interact with others (Maslow, 1954). The desire for belonging, for meaningful interpersonal relationships, and for feeling accepted and appreciated by others are reflective of social needs. In a work setting, this level of need hierarchy is concerned with 
"group membership, affiliation, acceptance and the feeling that one belongs to an organizational family" (Hall \& Williams, 1967, p. 2).

\section{Status Needs}

Status (esteem) needs involve the desire for achieving self respect, power, or special status within a group (Maslow, 1954). In the workplace, individuals search for opportunities to display competence and are concerned with the potential for job advancement, recognition based on merit, freedom in conducting job assignments and involvement in planning activities (Hall \& Williams, 1967).

\section{Self-Actualization Needs}

Self-Actualization implies a self-challenge for achieving one's greatest potential, for being all that one can be (Maslow, 1954). In the work setting, "self-actualizing behaviors focus on the intrinsic merits of the work itself and require autonomy, a willingness and opportunity for risk taking, and freedom to experiment" (Hall \& Williams, 1967, p.2).

\section{Paired Comparisons}

The method of paired comparisons presents objects in pairs to one or more persons. The basic experimental unit is the comparison of two items or questions. The individual is asked to select between the two items although the choice will not necessarily represent a preference. A preference may be 
recorded on a point scale which allows for the weighting of one item over another. The method of paired comparisons is used primarily in cases where the items to be compared can only be judged subjectively (David, 1988).

\section{Intrinsic Rewards}

According to Lawler and Porter (1967), intrinsic rewards are those that relate to "self-actualization" as identified by Maslow (1954) or Herzberg (Herzberg, Wiener, Mathapo, \& Wiesen, 1974). Herzberg et al. (1959) defined intrinsic rewards as motivators related to job content and influencing job satisfaction. Lortie (1975, p. 101) defined intrinsic rewards as "psychic rewards", related primarily to job satisfaction. Intrinsic rewards are further associated with the need "to feel competent and self-determining" (Deci, 1976, p. 65). Lawler and Porter (1967, p. 24) stated that intrinsic rewards are internally given or "internally mediated" and can have a direct effect on successful performance.

\section{Extrinsic Rewards}

According to Herzberg (1959), extrinsic rewards are those that satisfy Maslow's lower order needs (i.e. basic, security, belonging) and are factors that influence job dissatisfaction. Lortie (1975) described extrinsic rewards as those that can lead to job tension, confusion of role, and discontent. Lortie further explained that extrinsic rewards "exist independently of the individual who occupies the role [and have an] objective quality" (pp. 101-102). Lawler and 
Porter (1967) defined extrinsic rewards as those which are "organizationally controlled [such as] pay, promotion, status, and security" (pp. 23-24).

Professional Development/Staff Development/Inservice Education

Throughout this study, the terms professional development, staff development and inservice education are used interchangeably. "Staff development is defined as those processes that improve the job-related knowledge, skills, or attitudes of school employees" (Sparks \& Loucks-Horsley, 1990, p. 234). Another definition of staff development is "any activity that is intended partly or primarily to prepare paid staff members for improved performance in present or future roles in the school district" (Little et al., 1987, p. 1). "Professional growth and development" aims to provide teachers ample and varied opportunities for growth within the education profession (Loucks-Horsley et al., 1987). "Inservice education" has been defined as the "formal and informal provisions for the improvement of educators as people, educated persons, and professionals as well as in terms of the competence to carry out their assigned roles" ( Yarger, Howey, \& Joyce, 1980, p. 6). 


\section{NEED FOR THE STUDY}

In her paper entitled "Political Myths About Reforming the Teaching Profession", Rosenholtz (1984) suggests that the major problems in education have been inadequately analyzed and that "educational reform would be much more likely to succeed if it were informed by knowledge of the research on teaching and analysis of the policy implications of that research" (p. 5).

Research on the topic of teaching inevitably leads to research regarding teachers - their characteristics, their motivations, and their skill levels. Administrators need greater insights into and knowledge about the individuals who make up the present day teaching force. According to Rosenholtz (1984), policy makers who are attempting to reform the teaching profession without paying heed to recent research data, are in danger of failure. Educational reform should be based on information derived from research and not based primarily on popular assumptions.

Swirling in the flurries of reform activity are a multitude of questions about classroom teachers: Why are some teachers more effective than others? What are the characteristics of successful teachers? What will induce teachers to improve? What will encourage teachers to stay in teaching? What will motivate teachers to pursue educational excellence? What do teachers want from their professional lives? What will motivate teachers to pursue self improvement? What will attract more and better teachers into the teaching profession? These 
questions, and others, abound as various segments of the educational community search for ways to improve an educational system that has been encountering unprecedented criticism.

Due in part to a dearth of firm answers in the research, and partially due to a failure to consult the available research, assumptions have evolved that form the basis for a series of myths and stereotypes about teachers (Rosenholtz, 1984). Some of the "myths" have come to be commonly accepted as "truths" and are being utilized for long range planning or as the foundation for program development by school administrators and other policy makers. According to Rosenholtz (1984), one of the most misleading stereotypes is one that a significant segment of the public has come to believe: that teachers can be motivated to improve their performance primarily through the use of monetary-based incentives. That this assumption drives policy decisions is evidenced by the myriad of merit pay plans, career ladders and differential pay programs proposed in state-based school reform efforts designed by politicians, not educators (Johnson, 1986; Rosenholtz, 1984).

The belief that teachers are primarily motivated by extrinsic rewards, such as monetary incentives, however, is generally contradicted by research (Moore \& Hyde, 1981; Lortie, 1975). In a national study conducted by McLaughlin and Marsh (1978), money was found to be a disincentive for change in teachers. According to Johnson (1986), "efforts to motivate veteran teachers with pay and 
promotions may prove to be misdirected and counterproductive" (p. 59). Teachers, rather, have been found to value the intrinsic, psychic rewards that come from watching their students progress and succeed (Lortie, 1975). Teachers are also motivated by their own success in helping students grow and develop intellectually (Bredeson, Fruth, \& Kasten, 1983; Heath, 1981; Lortie, 1975).

Despite the research evidence, myths about teacher motivation continue to abound. Policy level decisions are made and programs are planned based upon these stereotypes. One common example exists within the area of professional development or inservice education. Widely used methods that school districts have devised to entice teachers to attend inservice classes include payment in the form of stipends, the potential for advancement on the salary schedule, and partially or completely subsidized college credit (Little et al., 1987). These incentives are heavily premised on monetary rewards. While such practices may attempt to address the reality that teacher salaries remain low and that teachers need as much financial assistance as possible, the question arises as to whether they address the real reasons teachers participate in staff development activities. When asked directly, teachers typically respond that what they are seeking from inservice education is information or knowledge that is relevant to their jobs. Consequently, the reason they attend such training is to acquire skills that will be of immediate practical applicability to their 
teaching situations (Hall \& Loucks, 1978). Research seems to imply that teachers are motivated to change their instructional techniques primarily when they believe that the attempt will improve their effectiveness with students (Rosenholtz, 1984).

There has been an evident lack of consensus within the research community and among policy makers about what teachers consider to be incentives in their work setting. What is the relationship between myth and research evidence? Is it possible that neither myth nor research has told the entire story? This study was developed with the belief that incentives should perhaps be examined in clusters and on relative scales with high and low points. Such an examination might point out motivational differences in different individuals or groups. This approach might prove more useful than simply listing incentives as single, unrelated factors and treating them as valid for everyone. Barnard (1938) suggested that people are motivated by different incentives or combinations of incentives at different times. Perhaps the same individual can be motivated by two or more incentives, to differing degrees, at the same time. It may be important to examine the influence of different incentives at a particular point in time or in relationship to the stage of development of a teacher's career. Rather than searching for lists of single incentives that might serve as motivators, perhaps combinations of incentives should be sought that together might prove more powerful through their synergy. For example, a profile 
depicting the relative strength of existing needs might provide a clearer picture of competing or complementary motivators within an individual or a group.

Another premise guiding this study was the belief that researchers and policy makers should identify those incentives that will motivate teachers to improve their professional skills. "Research stresses that the best teachers stay in teaching because of intrinsic rewards, although they may be forced to leave because of poor salaries or working conditions" (Johnson, 1986, p. 73). Johnson (1986) also stated the following about inducing teachers to improve their performance in the classroom:

[it will] "likely require more than improved pay, status, or working conditions.... Research suggests that it may require the orchestration of organizational incentives that encourage teachers to think about their work in new ways and commit themselves to new standards and goals...although little is known about such incentives...." (p. 74)

It was intended that information generated from this study would provide new information about incentives important to teachers and would inform the decision-making process in the following areas:

Planning for Improved Staff Development. By identifying and tapping the incentive structures that motivate teachers to participate in staff development activities, more successful professional growth programs can be developed.

Differentiated Planning for the Incentive Needs of Teachers. If differences are found in the incentive structures of teachers who have been 
teaching for varying numbers of years, this information can be used to design incentives appropriate for different segments of the teaching population. Such an approach would be preferable to assuming that incentives are the same for all teachers. For example, various incentive structures may have to be developed for a staff of thirty teachers that differ based on years of teaching experience (e.g., 1-5 years, 5-10 years, etc.).

Policy and Decision Making. School administrators, school boards of education, state departments of education, and legislators are currently making policy decisions based on incomplete or erroneous information about teacher incentive systems. It is important to the education reform movement to consider information that is derived directly from teachers themselves, rather than from generalized myths.

Planning by Professional Education Associations. Professional education associations are in a position to promote leacher incentive needs through collective bargaining strategies. As more creative approaches are sought in the formulation and negotiation of teacher contracts, information about what teachers value can be extremely important. Professional education associations are as prone to operating on faulty information as are other policy making groups.

Adding to the General Knowledge Base About Teacher Incentives. In this continually changing society, it is important to constantly update the information 
base about teacher needs and wants in order to ensure the most informed decision-making possible.

\section{METHODS AND PROCEDURES}

\section{Development of the instrument}

A review of the literature did not surface any research instruments that specifically measured factors motivating teachers to participate in staff development. Most of the Instruments that were available focused on work motivation factors. Among the most commonly used work motivation inventories is one developed by Hall and Williams (1967), which is currently utilized primarily within the business community.

The Hall-Williams Work-Motivation Inventory (Hall \& Williams, 1967) was selected as a model from which to develop a staff development motivation profile for this study for two major reasons: a) The Hall-Williams Inventory (1967) draws heavily on a combination of the Maslow (1954) need hierarchy and Herzberg's (1959) work-motivation constructs; and b) The Hall-Williams Inventory utilizes the technique of paired comparisons. This forced-choice structure requires the respondent to make decisions that will more objectively define his or her motivational preferences than an open-ended questionnaire might accomplish. 
Tine scoring system of the Hall-Williams Inventory was designed to produce an individual or group profile that depicts the relative strength of competing needs (Hall \& Williams, 1967). Maslow (1954) suggested that all five needs (basic, security, social, status, self-actualization) operate simultaneously within adults in this culture, and often compete against each other. Rather than focusing on a list of strongest single needs, this inventory creates a synergistic picture or profile of competing needs within an individual or within a group. The highs and lows depicted on this profile indicate the satisfied and unsatisfied sources of motivation and combine to portray an individual's or a group's orientation toward work.

A needs profile of this type can yield several pieces of information about an individual or a group. The highest scoring needs, which are potentially the greatest sources of motivation, can be identified. Additionally, the relative strength of the five needs areas can be examined to give a more complete picture of motivators which can affect behavior.

Based on the Hall-Williams instrument and drawing upon its strengths, a 30 item Staff Development Motivation Profile (SDMP) was specifically designed for use in this study (Hall \& Williams, 1967). Additionally, a 40 item Work Motivation Profile was developed primarily for use in the validation process of the Staff Development Motivation Profile. (A discussion of the Work Motivation Profile is found in the section of this chapter entitled "Validation of the 
Instruments".) The Staff Development Motivation Profile utilizes three basic statement stems regarding motivation:

1. I believe the real rewards of participating in staff development activities are ...

2. In deciding whether or not to participate in staff development activities, I would be most concerned to the extent to which ...

3. I would be most motivated to participate in staff development activities if ...

(See Appendix A for a copy of the Staff Development and Work Motivation Profiles.)

For each of the 30 items contained in the Staff Development Motivation Profile, respondents were asked to distribute five points between two completion statements that had been matched with levels of Maslow's (1954) and Herzberg's (1959) constructs. This process of measuring preferences is known as paired comparisons. The method of paired comparisons is used primarily in cases where the objects to be compared can only be judged subjectively. Paired comparisons are widely used by psychometricians, especially in values testing (David, 1988).

The completion statements were matched with Maslow's (1954) and Herzberg's (1959) constructs in the following manner ("read = sign as "correspond to"): 


$\begin{array}{lll}\text { Basic Needs } & =* & \text { Time and Money Concerns } \\ \text { Security Needs } & = & \text { Job Security/ Work Evaluation } \\ \text { Social Needs } & = & \text { Collegiality/ Social Interaction } \\ \text { Status Needs } & = & \text { Personal Recognition/ Rewards } \\ \text { Self-Actualization } & = & \text { Personal Satisfaction/Growth }\end{array}$

Prior to finalizing the new instruments, initial drafts of the Staff Development Motivation Profile and Work Motivation Profile were piloted with two groups of teachers totaling approximately 120 . These teachers were asked to complete the inventories and answer a series of questions ranging from how intelligible the instruments were, to how simple its format was to follow. In an effort to avoid a misunderstanding of the content of each individual statement in the final instruments, the teachers were also requested to suggest corrections or improvements on the clarity of each statement. A copy of the questions asked about the inventories is found in Appendix B.

Based on the responses of these groups of teachers, modifications and revisions were incorporated into the instruments. Feedback from this pilot group was also utilized to plan and design the final format of both instruments. For example, comments about the length and repetitiveness of the instruments led to the development of an introduction to the inventories, in the form of a cover letter to the respondents, which was intended to address the issue of length of the instruments. Instructions developed for the profile instruments themselves 
addressed several issues including that of the perceived repetitiveness of the questionnaires.

\section{Validation of the Instruments}

Once the profile questions had been revised and modified, a series of validation steps were initiated. The first validation step consisted of administering the Hall-Williams Work Motivation Inventory to a small sample population of randomly selected teachers (69 of the 125 teachers in this sample responded). The inventory results were compared with norms existing for the Hall-Williams Work Motivation Inventory that were based on thousands of individuals who had previously been administered the WMI (Hall \& Williams, 1967). Since the Hall-Williams Work Motivation Inventory was used as the basis for the two new instruments developed for this study, it was important to determine the extent to which the Hall-Williams Work Motivation Inventory was applicable to teachers, and how teachers respond to questions of work motivation compared with employees within the business-oriented populations surveyed by Hall and Williams.

The second step in the validation process was to compare the established norms for the Hall-Williams Work Motivation Inventory with the results of the newly created Work Motivation Profile (WMP) (Hall \& Williams, 1967). (The WMP was administered in conjunction with the Staff Development Motivation Profile [SDMP] to a large sample of 2,000 teachers.) If the results of the two 
instruments were found to be sufficiently similar, the new Work Motivation Profile could prove to be a valid measure of work motivation when compared with the Hall-Williams instrument.

The third step in the validation process was to compare the results from the Work Motivation Profile with those from the Staff Development Motivation Profile. Since both instruments had been fashioned to specifically address the education workplace, it was expected that the profile results would be sufficiently similar to validate the results, yet different enough to point out subtle differences between work motivation and staff development motivation. (See Chapter III for Profile results and graphs.)

The final step in the validation procedure was to analyze both the Work Motivation and the Staff Development Motivation Profiles for instrument reliability. Reliability measures the consistency or stability of an instrument and is a necessary ingredient for validity. This step was intended to determine how well the items in the questionnaires measured the various need categories (Basic, Security, Social, Status, and Self-Actualization).

\section{Identification of the Population for the Study}

The analysis unit examined in this research study consisted of all teachers, kindergarten through twelfth grade, in the state of Washington during the time period 1986-1987. The total population of teachers in Washington state in 1986-1987 numbered approximately 39,500. The original intent in conducting 
the study was to draw a stratified random sample from the total population of teachers. Unfortunately, problems were encountered in finding a complete listing of all teachers that included their addresses, gender, and years of teaching experience. The two primary sources contacted for teacher names and addresses were the Washington State Office of the Superintendent of Public Instruction and the Washington Education Association. The Washington Education Association's membership list was chosen as the source for participants for this study because it was more current and yielded more information about each individual teacher. This list was provided by the National Education Association. The Washington Education Association (WEA) is an affiliate of the National Education Association (NEA).

Two systematic samples were drawn utilizing the Washington Education Association's membership list and its computerized system for drawing random samples. A small sample of 125 teachers was drawn for use in the validation procedure. The larger sample of 2,000 was used for the main study. The Staff Development Motivation Profile and the Work Motivation Profile were mailed to the two thousand teachers selected for the random sample. Of the 2,000 main study surveys mailed to the teachers, $770(38.5 \%)$ were usable for the study. Another $84(4.2 \%)$ were returned with problems and were not utilized for the study. An additional $86(4.3 \%)$ were returned blank or had incorrect addresses, and were also not utilized for the study. 
Survey results from the main study sample of Washington state teachers yielded a composite needs profile depicting the greatest and least sources of motivation for participating in staff development activities. Further analysis by gender and by a number of other variables produced more specific information about various segments of the teaching population.

\section{Data Collection Methodology}

Study respondents were sent copies of the finalized instruments, along with a cover letter emphasizing the importance of the inventory and urging them to respond. Preliminary instructions included in the cover letter gave respondents an indication of the time necessary to complete the Inventory, the major focus of the study, and some possible uses for the results of the research.

In order to increase the response rate and to make it easier for respondents to return the completed survey, a one-page tear-off answer sheet was designed as part of the questionnaire. The one-sided answer sheet contained spaces for responses to all inventory questions plus nine demographics items. The reverse side of the answer sheet had instructions for folding the completed questionnaire into a self-addressed postage paid mailer, commonly referred to as a self-mailer (see Appendix A).

Approximately 30 days after the initial mailing, the first follow-up questionnaire was sent to persons who had not responded to the original questionnaire. The first two main study mailings yielded 464 usable returns 
( $49.4 \%$ of the total returns). On the sixtieth and ninetieth days, second and third follow-up mailings were sent. The second follow-up yielded 182 valid returns while the third follow-up drew 124 valid questionnaires.

A total of 939 inventories were returned although only 770 of these inventories proved usable.

\section{Statistical Procedures}

While some thought was given to utilizing interviews or case studies to determine teachers' attitudes toward participating in staff development activities, the obvious limitation of these methods in terms of the numbers of possible subjects discouraged their use. Since one of the purposes of the study was to find out what incentives motivate teachers, it seemed appropriate to seek answers by asking teachers themselves - and in sufficient numbers to be able to generalize to a broader population.

Another consideration in selecting the research procedures for this study was the fact that teachers' belief structures and attitudes were to be examined in the study. According to McCall (1982), the most common method for attitude testing in teachers is the sampling method. Also of importance was the opportunity provided by the Washington Education Association to conduct a state-wide survey and potentially utilize the entire population of teachers in the state of Washington as a survey sample. Results from the study would be 
generalizable to the total teacher population of Washington state, and perhaps beyond that to teachers in general.

Development of the instruments to be used in the survey included a review of the literature to identify existing instruments that might render information about the motivators that influence teachers to participate in furthering their professional development. Since an existing instrument was not found, new instruments, based on some preexisting models from the business community, were developed.

Data collected from the study respondents were organized and analyzed utilizing a variety of statistical procedures. Mean scores were calculated from the study instruments representing the relative strength of each Need Category. Profile graphs were developed from these scores to illustrate the differences in Need Categories for each group of teachers analyzed and between groups of teachers analyzed. Multiple regressions were conducted to determine the percentage of variance predictable in dependent variables (Need Categories) by the independent variables (Gender, Work Assignment, Size of School District, etc.). Cross-tabulations by gender for all the other demographic variables were generated to help isolate specific sub-groups of teachers for additional study. T-tests were used to compare the mean scores of males and females to check for significant differences in response patterns by gender. Finally, a series of two-way ANOVAs were conducted utilizing Need Categories as the dependent 
variables and treating gender plus one additional demographic question as the independent variables. This was done in order to discover potentially significant interactions between different sets of demographic variables.

Elaboration on the findings from the statistical procedures described above is found in Chapter IV.

\section{LIMITATIONS OF THE STUDY}

This study sought to identify factors that motivate teachers to participate in furthering their professional growth and development. In the process of pursuing this goal, a series of limitations to the study became obvious: (a) The nature of the topic could create the impression that the study is focusing on already known information; (b) The teaching population of the state of Washington may not be representative of teachers throughout the nation, therefore, the results of the study might not be applicable to a broader teacher population; (c) The use of averages or aggregate scores for describing a group of individuals or for generalizing to a larger population may be questionable; (d) New policy developments "requiring" teachers to participate in professional development as a condition of credential renewal may render the study results moot; (e) The premise upon which the instruments used in this study were based (the motivation theories of Maslow [1954]) has been criticized for its culturally-bound descriptions of human motivation, therefore calling into question 
its applicability to a culturally diverse teaching population. These possible limitations should be give careful consideration when reviewing the study results. Elaboration on each of the five potential limitations follows in the succeeding paragraphs.

The perception that the topic of this study (teacher motivation) is "old news" and that nothing new is being uncovered may stem from the fact that research has been conducted, information is available, and educators know and understand what the research suggests will motivate teachers. in this case, however, knowing and acting upon that knowledge seem to be two different matters. Motivation research conducted in recent years has provided information for administrators to utilize in designing staff development activities. For example, considerable research evidence suggests that intrinsic rewards are more effective motivators than external rewards such as money (Deci, 1976; Hackman \& Oldham, 1980; Herzberg, 1966; Sergiovanni, 1967; Spuck, 1974). There is also evidence to indicate that the use of external rewards can lower internal motivation (Calder \& Staw, 1975; Deci, 1976; Daniel \& Esser, 1980). The information produced by this study might therefore be overlooked or ignored due to an assumption that nothing new is being studied.

Limitations two and three listed above raise questions about the ability to generalize the study findings to a broader population of teachers. The teaching population of the state of Washington may not be represeritative of teachers 
throughout the nation. A careful examination of the demographics of the state of Washington might be in order. In 1986, Washington was a more rural than urban setting, with a teacher population of approximately 39,500 . The student population was approximately $16 \%$ ethnic minority, while the teacher population was about $5 \%$ ethnic minority (Washington State Office of Superintendent of Public Instruction, 1985). Therefore, the results of the study may have limited geographic validity. Further study with other populations of teachers could answer this question.

The related issue of generalizing from aggregates of the average scores of groups of individuals presents a potential problem. The instrument developed for this study was primarily designed to identify the factors that motivate an individual to pursue professional growth activities. The averaging of individual scores per force will have a leveling effect on the resulting information. When dealing with human needs, this may be problematic. The results of this study, however, were conclusive enough to suggest that in this case, the aggregate scores were strongly representative of the individuals in all segments of the study population.

A fourth limitation may be the timeliness, consequently the usefulness, of the information produced by this research study. Some policy issues may have already been decided in such a way as to prevent the study results from even being considered. Many state credentialing bodies have recently created 
requirements that force teachers to participate in professional development activities in order to maintain their teaching credentials - thereby eliminating the need for concern by school administrators about motivating teachers to pursue staff development activities. As of 1988 , only 16 states issued lifetime teaching credentials. Thirty-two states required that teachers renew their teaching certificates on a continuing basis, generally by earning a stipulated number of college credits or their inservice equivalent every five or six years (Darling-Hammond \& Berry, 1988). Under these circumstances of "required" professional development, the question of motivation may become moot.

One final possible limitation addresses the premise upon which the instruments used in this study were based - primarily the motivation theories of Maslow (1954). Maslow's theories have been called into question for their culturally-bound descriptions of human motivation. According to Hofstede (1980), Maslow's hierarchy "is not the description of a universal human motivation process - it is the description of a value system, the value system of the U. S. middle class to which the author belonged" (p. 42). The notions of ego status and self-actualization are grounded in the cultural ideals of self-reliance, individuality, and self-satisfaction. Is it appropriate to measure all individuals against these cultural yardsticks? Does this hierarchy accurately describe the motivation constructs of men and women, minority and majority individuals, and of individuals across class lines? These are questions that should be 
considered carefully before accepting this study's results as representative of all teachers.

In order to understand the relative nature of culture more clearly, the following definition proposed by Hofstede (1980) seems helpful:

I define culture as the collective programming of the people in an environment. Culture is not a characteristic of individuals; it encompasses a number of people who were conditioned by the same education and life experience. (p. 43)

Should it be assumed that all classroom teachers have been conditioned by the same education and life experiences? This is a question that perhaps remains to be explored, but is deemed to be outside the scope of this research study. There was no effort made to control for cultural or class differences in this study. In 1985 in Washington state, approximately $5 \%$ of the teacher population were members of an ethnic minority group (Washington State Superintendent of Public Instruction, 1985.) Gender, however, was specifically chosen as one of the variables for analysis.

Additional concepts of motivation theory are thoroughly discussed in Chapter II, specifically in relationship to teacher motivation and staff development. These areas of literature are reviewed in depth as they relate to the role of the school administrator in promoting the professional growth of teachers. 


\section{CHAPTER ॥}

\section{REVIEW OF THE LITERATURE}

This chapter contains a review of the literature relevant to this study and has been organized into two major sections plus a summary section. The areas of literature highlighted herein provide a foundation for the focus and findings of this study. The types of literature examined included but were not limited to books, journal articles, research studies, government documents, dissertations, and bibliographies.

The first area of literature reviewed discusses the role of the school administrator in promoting the successful professional growth and development of teachers. The research cited indicates that the building principal plays a significant role in motivating teachers to strive for professional excellence. Sub-categories within this area of review include definitions of administrative leadership, the importance of skillful leadership, and the central role that decision-making plays within the educational setting. These concepts are examined within the context of the current education reform movement.

The second major area of literature reviewed for this study was the research on staff development. Since "staff development offers one of the most promising roads to the improvement of instruction" (Sparks, 1983, p. 65), it is of 
utmost importance to know more about professional development and the factors that can motivate teachers to participate in further professional growth experiences. It is also vital to consider some of the major variables that positively affect the success of professional development programs.

As a sub-section of the staff development literature, a review of concepts dealing with motivation theory was conducted. In order for school administrators to develop better systems for managing human potential, they need greater insights into and knowledge about the individuals that make up their work force. This is critically important information to feed into the decision-making process. A review of the literature on motivation can provide a better understanding of the human motivations and incentives which operate within the school setting.

A review of the literature relating specifically to teacher motivation comprises the second sub-section of staff development. The classroom teacher has been a major focal point of scrutiny for the currently ongoing education reform movement. The belief that in order for education to improve in the global sense, instruction in each classroom must be improved is rapidly becoming axiomatic within the education reform movement. According to Darling-Hammond and Berry (1988), there is renewed recognition by educational leaders that if schools are to improve, the skills of the individual classroom teacher must receive attention. Identifying the incentives that will motivate teachers to improve their practice therefore becomes of critical importance. 
Research question \#1, "What are the needs, incentives or motivators that influence teachers to further their own professional growth and development?", was answered in the course of writing these sections of the literature review. A summary of the literature is provided at the end of the chapter.

\section{ROLE OF SCHOOL ADMINISTRATOR IN PROMOTING PROFESSIONAL GROWTH OF TEACHERS}

During the 1980s, education became (and has remained) one of the dominant issues on state policy agendas (Darling-Hammond \& Berry, 1988). The fundamental message of the reports issued in response to A Nation at Risk (NCEE, 1983) has been that the system of public education in the United States is in need of reform.

Although the series of reports published throughout the 1980 s by the Carnegie Forum on Education and the Economy (1986), the Education Commission of the States (1983), The Holmes Group (1986) and others, differ in the types of reform that they recommend, they agree on the "importance of competent teachers for improving American education, and the necessity of such improvements for America's future economic welfare" (Darling-Hammond \& Berry, 1988, p. 5). Darling-Hammond and Berry further concluded that the reform prescriptions suggested by the reports of 1980 s emphasized that "lasting improvements will occur only if decisions about education are both decentralized 
and professionalized. That is, they must reflect teachers' and principals' best professional judgments on behalf of students...." (p. 5).

Within the reform context, the debate continues over the precise role that a school administrator should play in order to insure optimal educational outcomes for students (Dwyer, Barnett \& Lee, 1987). Administrators (particularly principals) are still held responsible for the academic performance and achievement scores of students (Dwyer, Barnett, \& Lee, 1987). Throughout the 1980s, it was not uncommon to find statements such as, "The direct responsibility for improving instruction is in the hands of school principals" (Sweeny, 1982, p. 347), in books and articles describing the role of the principal in creating effective schools. Other researchers have remarked similarly about the importance of administrative leadership in educational reform and school improvement. Lipham (1981) concluded that an essential ingredient for educational change and improvement is the appropriate leadership behavior of the school administrator. Brookover et al. (1973) and Wynne (1981) concurred that successful administrators can be key agents in the development of successful schools. According to Sergiovanni (1982), the leadership that the principal exhibits can be "the" key factor in determining the effectiveness of a school.

Sergiovanni (1982) additionally stated that two specific prerequisites to quality leadership include the management skills and the information skills 
necessary to develop and operate an effective school. Efforts to enhance the administrative potential of school principals has caused researchers to reexamine the accumulated information about the tasks that administrators conduct (Dwyer, 1985; Metz, 1978). Training academies and assessment centers throughout the country have transformed the existing knowledge base about administrative leadership into management models that delineate and describe the tasks that administrators must perform and the competencies they must possess. According to Dwyer (1985), traditional administrative task areas and processes such as planning, organizing, coordinating, supervising, and evaluating are being redefined to respond to the demands of the education reform-oriented society.

One typical example of the newly developed management systems is the Snyder and Anderson (1986) Model. This management system is based on a four-cluster structure that includes organizational planning, staff development, program development, and school assessment as key elements of administrative leadership. Incorporated within the system are the 10 management competencies listed below (Snyder \& Giella, 1987):

Organizational Planning

1. Schoolwide Goal Setting

2. Work Group Performance

3. Individual Staff Performance

Developing Staff

4. Staff Development

5. Clinical Supervision

6. Work Group Development 
7. Quality Control

Developing Program

8. Instructional Program

9. Resource Development

Assessing School Productivity

10. Assessing Achievement (p. 39)

Notably in this management system, developing staff has a greater number of competencies than any of the other three clusters. In fact, staff development has been described as an important leadership function for administrators by a number of researchers, among them Duke (1982); Squires, Huitt, and Segars (1981); and Dwyer, Barnett, and Lee (1987).

Importance of Effective Leadership

Skills in Staff Development

Effective leadership skills in staff development play an important role in administrative functioning because of their potential for creating a direct positive effect upon the school setting (Griffin, 1983). As a result of the series of education reform reports released in the 1980 s including the Carnegie Forum on Education and the Economy (1986), the Education Commission of the States (1983), and The Holmes Group (1986) of education deans, there has been a renewed recognition by educational leaders that if schools are to improve, the skills of the individual classroom teacher must receive attention (Darling-Hammond \& Berry, 1988). These reports emphasize the importance of competent teachers in the quest for improving American education. Clearly, the 
professional growth and development of each individual teacher should be a key factor in plans for educational reform.

Variables that affect staff development outcomes in positive ways have been the focus of several studies conducted over the span of several years. Major factors affecting the success of professional development programs have been found to include the level of administrative support given to program efforts, the type of leadership role played by the building administrator in instructional issues, and the existing school climate and interactions among the staff (Sparks, 1983).

In the Rand study of educational innovations, hundreds of federally funded programs were analyzed with an interest in discovering the relationship between organizational context and the success of staff development efforts (Berman \& McLaughlin, 1978). These researchers concluded that administrative support at all levels was a major factor in determining the success of the programs.

Another study, conducted by Stallings and MohIman (1981), determined that in schools where the principal was supportive of teachers' improvement plans, teachers exhibited the most growth. In their 1981 study, Lieberman and Miller focused on the role of the principal as instructional leader in bringing about improvements in teaching. It is clear that the building principal can play a 
substantial role in motivating teachers to pursue their own professional development.

Little's (1981) study of staff development in urban, desegregated settings also found that principals in successful schools play a key role in establishing and maintaining a climate conducive to professional growth. In situations where the prevailing climate encouraged collegial interactions (collegiality) and the pursuit of "continuous improvement," staff development was found to have a greater influence on the success of the school.

"Collegiality" refers to a situation in which teachers work together as colleagues or team members. Collegiality is in place when teachers participate together in shared discussions, work projects or other activities that include planning, designing and experimenting with new ideas. Teachers have been found to participate more readily in staff development activities when the school climate fosters sharing knowledge and experiences among staff members or promotes teamwork and professional discussions (Little, 1981).

A norm of "continuous improvement" implies the belief that even the experienced teacher must continue to strive for improvements in knowledge and practice. In a context of "continuous improvement," the attitudes of teachers toward staff development are focused on learning and experimenting in order to develop more effective and efficient methods for teaching siudents. Little (1981) concluded that staff development appears to have the greatest influence on 
total school success and the greatest results with students in schools where there is a norm of continuous improvement.

Results of Little's (1981) study seem to indicate that in addition to the intrinsic motivators described by Lortie (1975) and others, there are environmental factors that can create an atmosphere conducive to continuous learning and professional growth. Furthermore, the principal of the school is in a key position to establish and maintain the important norms of continuous improvement and excellence. A more recent case study focusing on the teacher's perspective of effective and ineffective principals supports the importance of the principal in setting a tone or establishing an atmosphere conducive to excellence. Blase (1987) found that teachers identified effective principals as those who contributed to the development of a sense of cohesion within the school setting. In such school settings, cooperation, opportunities for shared decision-making and freedom to experiment with new ideas were the norm.

Other key elements that determine the ability of the school administrator to direct the activities that will result in improved instruction by teachers include leadership ability and decision-making skills (Sergiovanni, 1982). Discussions of the evasive concept of leadership and of the importance of the decision-making process within the educational setting follow in the next two sections. 


\section{Concepts of Educational Leadership}

Welte's (1978) description of administrative behaviors included the following list of activities: "planning, organizing staffing, directing, and controlling" (p. 630). Welte defined management as the "mental and physical effort to coordinate diverse activities to achieve desired results" (p. 630). However, Welte differentiated between management and leadership by suggesting that the latter includes the skills, abilities and personal characteristics necessary to influence people to take a predetermined action.

An emphasis on influencing others can be noted in other definitions of leadership. Fiedler, Chemers, and Mahar (1976) suggested that leadership includes the ability to counsel and thus influence subordinates, to inspire loyalty in them, and to instill within them a sense of job satisfaction. Similarly, Terry (1960) defined leadership as the act of influencing others to work toward common goals.

Perhaps the classic definition that captures the essence of leadership has been proposed by Thomson (1980). He stated it simply by saying that leadership is "getting the job done through people" (p. 2). The underlying implication of this definition is that effective leadership has a dual task: goal accomplishment (getting the job done), and influencing others (through people).

The concept of influencing others lends itself to a discussion of extrinsic vs. intrinsic motivation. In order to influence others, a leader needs to have a 
clear understanding of both the intrinsic and extrinsic motivations of the employee. The leader can thereby shape his or her own behavior in the act of influencing. The challenge may be to achieve as close a match as possible between extrinsic motivators (influence) and the intrinsic drives of the employee.

Despite an abundance of definitions provided in the literature, the concept of leadership remains so evasive that the entire 1987 ASCD Yearbook was titled and devoted to the topic: "Leadership: Examining the Elusive" (Sheive \& Schoenheit). The titles of some of the articles in this publication exemplify the diversity of thought and the multitude of perspectives about the elusive concept of leadership: Leadership: A Change Agent's View; Leadership A Woman's View; How Leaders' Minds Work; Vision and Work Life of Educational Leaders; The Conscience of Leadership. It is clear that the questions outnumber the answers with regard to the precise nature of educational leadership.

In his article, "The Culture of Schools", Deal (1987) suggested that the core task of leadership may be reenergizing the existing structure rather than reforming or restructuring the educational system. Deal pointed out that despite efforts to reform the schools, efforts which have been ongoing for at least two decades, the resilient nature of the educational system seems to bounce back to the same basic shape. Sarason (1971) echoed this sentiment when he stated that the more effort is exerted, the less change seems to be evidenced in schools and classrooms. 
If this is true, then leaders perhaps should be spending more time attending to renewal activities, attending to human needs - at least being aware of human needs. According to Champlin (1987), the frenzy of reform often becomes characterized by nonsupportive behavior that can border on hostility. Instead, stated Champlin, it is the responsibility of leaders to create supportive, enabling environments. Schools, he suggested, have "ignored the accumulated knowledge about organizational behavior, individual needs and the management of change" (p. 60).

Champlin (1987) believed that part of his success as a district superintendent, in "renewing" a school district and creating "excellence", hinged on redefining the role of the teacher. Champlin worked to break the stereotypic role of the classroom teacher as an individual with little decision-making authority. He envisioned classroom teachers as professionals, capable of identifying educational problems and developing viable alternative solutions. "I wanted to give teachers a strong sense of importance by making it possible for them to exercise professional judgment and to make important decisions that enhanced student learning" ( p. 57).

New studies of leaders and leadership in highly successful enterprises (within both the public and private sectors) provide insights about a definition of leadership that can be applied to educational administration (Deal \& Kennedy, 1982; Dwyer, Filby, \& Rowan, 1984; Lightfoot, 1983; Peters \& Waterman, 1982). 
According to Sergiovanni (1987), "these studies reveal that highly successful leaders view how their schools operate and what is important to teachers at work differently from ordinary leaders" (p. 117). Assumptions they make about teachers as people are also different.

In an earlier publication, Sergiovanni (1982) stated that the key factor in determining the effectiveness of a school is the leadership that the principal exhibits. Sergiovanni described "principles" and "prerequisites" as two major ingredients in his definition of quality leadership. Prerequisites of quality leadership include the management and information skills necessary to develop and operate an effective school. Principles are those things the leader stands for, what the leader believes about schooling, and about the place of education in society.

From this information, Sergiovanni (1987) has developed his concept of "mindscapes" (world views or paradigms) to describe the differences in leader views and their effects on practice. "A mindscape is composed of a person's mental image, view, theory, and set of beliefs that orient that person to problems, help to sort out the important from the unimportant, and provide a rationale for guiding actions and decisions" (p. 117).

An example of two "mindscapes" that typically characterize educational leaders is described in Sergiovanni's (1987) Clockworks I and Clockworks II models. Note in Figure 1 that the Clockworks 1 model is reminiscent of 
McGregor's (1960) Theory $X$ style of management orientation, while the Clockworks II model more nearly resembles the Theory $Y$ management model. Leaders with a Clockworks I mentality see teachers as workers for whom teaching is "just a job," and who are incapable of self direction. By contrast, leaders with a Clockworks II frame of reference see teachers as professionals, exercising their professional judgment and participating actively in accomplishing shared goals.

\begin{tabular}{|c|c|}
\hline Clockworks I Mindscape & Theory $X$ \\
\hline Teaching is a job. & Worker is not intelligent. \\
\hline Teacher as a worker. & Worker lacks ambition, direction. \\
\hline Leader links parts of the system. & $\begin{array}{l}\text { Worker is indifferent to needs of } \\
\text { organization. }\end{array}$ \\
\hline Clockworks II Mindscape & Theory $Y$ \\
\hline $\begin{array}{l}\text { Teaching is a vocation engaged } \\
\text { in by professionals. }\end{array}$ & $\begin{array}{l}\text { Worker has capacity for personal } \\
\text { growth and development. }\end{array}$ \\
\hline $\begin{array}{l}\text { Teacher as a professional } \\
\text { exercising judgment. }\end{array}$ & $\begin{array}{l}\text { Worker has capacity to assume } \\
\text { responsibility. }\end{array}$ \\
\hline $\begin{array}{l}\text { Leader bonds people together by } \\
\text { developing a shared commitment } \\
\text { and a common culture. }\end{array}$ & $\begin{array}{l}\text { Worker has desire to fulfill higher } \\
\text { order of Maslow needs (i.e. } \\
\text { belongingness, self-actualization) }\end{array}$ \\
\hline
\end{tabular}

Figure 1. Comparison of Sergiovanni's (1987) Clockworks I and Clockworks II models with McGregor's (1960) Theories X and Y.

The concept of leader as developer of a shared commitment for the accomplishment of common goals is a constant theme in the reform literature of the eighties (Sergiovanni, 1987). Yet as early as 1960, Terry defined leadership in terms of the ability to influence people to work willingly for group goals. In 
order to fulfill this definition of leadership, a leader should know what will motivate teachers to accomplish the goals of school improvement.

If a major goal of the education reform movement is to create excellent schools, effective schools, then improvement of teaching skills is a direct corollary. What can a principal do to inspire teachers to improve? According to Sergiovanni (1980), in order to be effective, a leader must achieve a balance between information based on scientific data and information based on established belief structures. Sizer (1984) suggested that administrators should challenge those belief structures (educational myths and assumptions) that no longer serve education well. Champlin (1987) believed that leaders must be keenly aware of and knowledgeable about the human needs of classroom teachers, based on "hard data."

In order for school administrators to develop better systems for managing human potential, they need greater insights into (more information about) the individuals that make up their work force. Administrators require information from which to make informed decisions (Sergiovanni, 1980). The importance of information-based decision-making is the focus of the next section.

\section{Administrative Decision-Making}

In recent years, students of organizational behavior have come to view decision-making and the decision-making process as central to the study of education administration (Hanson, 1979). According to Griffiths (1959), "All 
other functions of administration can best be interpreted in terms of the decision-making process" (pp. 74-75). The decision-making process, in turn, is comprised of all judgments that affect a course of action, and the importance of decision-rnaking ultimately depends upon the action that results from the judgments made.

Sergiovanni (1980) viewed administration as "an art which uses science in seeking its ends" (p. 2), and described the decision-making process as a balance between the use of information derived from scientific methods (theoretical analyses, quantitative data) and reliance on normative theory (beliefs, assumptions, and ideals related to an issue). Normative theory contains the models and "assumptions about how humans behave and of what they are capable" (p. 2). According to Sergiovanni (1980),

One test of leadership in an applied field is the ability of the leader to sort through both the perspectives of science [the descriptive] and values [the normative] in a fashion which provides some balance and which permits reasonable action. (p.2)

Until the recent information explosion generated by the effective schools research, the educational decision-making process had perhaps relied too heavily on intuition-based normative views and too lightly on firmer scientific data. One reason for this phenomenon has perhaps been the dearth of research information available prior to the 1980's. The rather recent accumulation of a 
research base appears to provide a clearer and more detailed picture of how effective schools operate organizationally (Sparks, 1983).

Normative views, however, are ingrained and are difficult to overcome. While educators believe that goals and logic govern their actions, most often they do not. According to Deal (1987), "Beneath the facade [of logic] lurks another world, a primordial place of myths, fairy tales, ceremonies, heroes and demons..." (p. 4). This often describes the elusive world that is known as the "culture of the school," hence, the "culture of education."

Sarason (1971) described a similar concept when he wrote about "behavioral regularities" and belief structures in education including "ideas, practices, values, and expectations that are 'givens' not requiring thought or deliberation" (pp. 227-228). Regularities are habits and assumptions with which one lives and which one fails to question because of their familiarity. Sizer (1984) urged leaders to challenge the regularities - to systematically question some of the educational myths, assumptions, and structures that no longer serve education well.

The link between effective leadership and decision-making is clear. In order to make decisions about the type of influence (i.e. style of leadership; motivating behaviors) appropriate to a given situation, a leader needs to draw a balance between information gathered through scientific methods (surveys, questionnaires) and normative beliefs about how teachers behave and of what 
they are capable (Sergiovanni, 1980). Hanson (1979) believed that decision-making is central to the process of leadership. All other administrative functions are secondary to the decision-making process and can be described in relationship to it (Griffiths, 1959). Since decision-making is seen to hold such an important role in educational administration, it follows that the information that serves as a basis for making decisions should be the best available.

Sergiovanni (1980) described the ideal decision-making situation as one which draws both from information derived from an accumulated knowledge base and that drawn from intuition or accepted value structures. He believed that "successful leaders" make an effort to achieve a balance between the two sets of sometimes dichotomous "knowledge" described in Figure 2. Within the context of the education reform movement, successful leaders are indispensable since they can be "key" agents in the creation of successful schools (Brookover et al., 1973; Wynne, 1981).

\begin{tabular}{|c|c|}
\hline \multicolumn{2}{|c|}{ Draw From Both Sources Of Information } \\
\hline Accumulated Knowledge & Accepted Values \\
\hline Information from scientific methods & Normative Theory (beliefs) \\
\hline $\begin{array}{l}\text { Constantly new and changing } \\
\text { information or knowledge }\end{array}$ & Ingrained knowledge \\
\hline Information that breaks with tradition & $\begin{array}{l}\text { Information that follows the regular } \\
\text { path }\end{array}$ \\
\hline
\end{tabular}

Fiqure 2. Sergiovanni's (1980) ideal decision-making situation. 
Importance of Decision-Making to

School Reform

Since so much of the "information" administrators receive can be contradictory in nature, the tasks of sorting through the information, reaching balance points and making decisions based on the results have become critical to the leadership process. The turmoil of the education reform movements of the 1980 's has provided a special challenge for decision-making. Several patterns of thought have emerged that suggest new ideas about school improvement that break with the earlier theories of educational improvement (Rosenholtz, 1984). The first wave of educational reform focused attention on issues such as state-mandated testing of students and teachers, the adoption of statewide curriculum standards, and improving management techniques (Darling-Hammond \& Berry, 1988; Darling-Hammond \& Sclan, 1992).

The second reform wave called for the decentralization and sharing of decision-making authority, emphasized the important role for teachers in achieving successful school reform, urged the professionalization of teaching, and scrutinized the process of teacher preparation (Darling-Hammond \& Berry, 1988). Several reform proposals, such as those outlined by the Carnegie Forum on Education and the Economy (1986) and The Holmes Group (1986), recognized that teacher competence is a critical component of educational quality. These reform proposals focused attention on strategies for enhancing teacher knowledge and skills (professional preparation), teacher evaluation, and 
the support and involvement of teachers in the decision-making process as necessary features of effective schooling and teaching (Darling-Hammond \& Sclan, 1992).

Earlier reform efforts concentrated more on the need for developing "teacher proof" curricula and school management techniques than on investing in teacher knowledge (Darling-Hammond \& Sclan, 1992). Each set of reform strategies is based on a different theory of educational improvement:

One theory, which may be called bureaucratic in orientation, assumes specialized knowledge for teaching is unnecessary because techniques, iools, and methods can be prescribed from above; they need not be crafted by teachers themselves. The other theory, which may be called professional in orientation, assumes that pedagogical preparation is essential, because teachers must be capable of making complex educational decisions on behalf of diverse students (Darling-Hammond \& Berry, 1988, p. xi).

The more recent reform strategies emphasize the importance of asking teachers about their needs and of involving them in the decision-making process. An extensive body of research supports the notion that considering the desires, opinions, and needs of professional staff, as well as encouraging their participation in decision-making, facilitates the implementation of school reform efforts (Purkey \& Smith, 1984). In schools, as in industry, participative decision-making leads to increased job satisfaction (Duke, Showers, \& Imber, 1980; Howes \& McCarthy, 1982; Lipham, 1981; O'Toole, 1981). 
Knowledge gathered from the effective schools literature is engendering the development of better systems of managing human resources. In the past, one of the greatest wastes in the workplace has been in the area of human potential. The major reason for this waste has been management's failure to understand and appreciate the human motivations and incentives that operate in the work setting (Bowles, 1966).

Two truisms about needs and motivation systems are that: (a) everyone has needs; but (b) no one has quite the same needs and motivation systems as anyone else (Gellerman, 1968). According to Herzberg (1968), "the psychology of motivation is tremendously complex and what has been unraveled with any degree of assurance is indeed small" (p. 53). Motivation is a broad, important, and dynamic topic. The following sections on staff development, motivation theory and teacher motivation will provide an overview of the human motivations and incentives that operate within the school setting.

\section{RESEARCH ON STAFF DEVELOPMENT}

Sparks and Loucks-Horsley (1990) offered the following definition of staff development: "those processes that improve the job-related knowledge, skills or attitudes of school employees" (p. 234). Fenstermacher and Berliner (1984) used slightly different language in their definition of staff development: "The provision of activities designed to advance the knowledge, skills, and 
understanding of teachers in ways that lead to changes in their thinking and classroom behavior" (p. 4). In a study conducted for the state of California by Little et al. (1987), the definition of staff development is framed in terms of the outcomes that it is intended to produce:

Presumably, staff development affects students' current learning and future opportunities by contributing to teachers'

- up-to-date knowledge of curriculum content

- range of teaching methods

- ability to diagnose student learning and evaluate student progress

- comriitment to and enthusiasm for teaching

- ability to evaluate the strengths and weaknesses of their own teaching.

Similarly, staff development may affect students' learning by contributing to administrators'

- ability to plan and organize staff development consistent with schoolwide goals and problems

- ability to organize adequate support for the daily work of teaching

- ability to evaluate teaching (pp. 1-2)

According to Sparks and Loucks-Horsley (1990), research in the area of staff development has a fairly recent history. During the 1970s, a mounting preoccupation with the effectiveness of inservice education led to the proliferation of studies to investigate the attitudes of teachers about staff development (Ainsworth, 1976; Brim \& Tollet, 1974; Joyce \& Peck, 1977). The studies generated information about the widespread dissatisfaction of teachers with then current inservice practices. The studies also found, however, general 
agreement about the critical nature of inservice to school improvement programs and practices (Wood \& Kleine, 1987).

Studies conducted in the late 1970 s and early 1980 s focused not so much on teacher attitudes about inservice but on the actual practices or types of staff development models available to them (Berman \& McLaughlin, 1978; Kells, 1981; Yarger, Howey, \& Joyce, 1980; ). Such studies yielded lists of the characteristics of effective teaching practices that formed an integral part of the effective schooling research base. "The effective schooling research base identifies schooling practices and characteristics associated with measurable improvements in student achievement and excellence in student behavior" (Blum, 1982, p. 1).

During the 1980s, staff development stepped further into the limelight. Much attention was given to the topic of professional growth and development in the form of conferences, books, articles and research reports. Policy makers at the state and local levels identified staff development as a key ingredient of school improvement efforts (Darling-Hammond \& Berry, 1988). Based on the effective schools research, school districts created ambitious staff development projects aimed at improving student learning (Sparks \& Loucks-Horsley, 1990).

In an extremely thorough article, "Models of Staff Development," Sparks and Loucks-Horsley (1990) identified five effective models of Staff Development currently in use by school administrators. A brief description of each of the 
models, its supporting theory, and the organizational context necessary to support its success follows.

Individually guided staff development: Teachers plan and pursue those activities they believe will promote their own learning. This model assumes that teachers are capable of self-direction, that adults learn most effectively when they select and execute their own learning activities, and that teachers are most motivated when they select their own learning goals.

Principals can assist teachers in setting goals, based on the motivation and ability of the teacher. Principals can also facilitate teachers' efforts to pursue individual professional growth activities by helping to identify classes, financial resources, and release time.

Observation/Assessment model: Teachers are provided with objective feedback regarding their classroom instruction. Such feedback can be used for selecting learning goals. Underlying assumptions of this model include a belief that both reflection and analysis are necessary for professional growth, that an individual teacher's personal reflection can be enhanced by outside observations, and that "nothing succeeds like success" - that is, when teachers experience positive results from their efforts to improve, they are inspired to continue their efforts.

Orie of the most successful administrative practices with regard to improving student learning appears to be the training of teachers in effective 
instructional practices followed by observations and coaching in the classroom.

Development/mprovement process: This model of staff development involves teachers in developing curriculum, designing programs, or participating in school-improvement programs aimed at solving general or specific school problems. The development/improvement model assumes that teachers learn most effectively in a problem solving mode, that teachers themselves are the best judges of what is required to improve their performance, and that involvement in a school improvement or curriculum development process provides an opportunity for teachers to acquire knowledge and build new skills.

The probability for the success of this model is enhanced by the commitment demonstrated by district and building administrators to the process. Such commitment is evidenced by sharing decision-making authority with the teachers involved, providing adequate resources both in time and money, and providing leadership that gives vision and guidance to the project.

Training: The training model is perhaps the most common staff development practice and involves providing individual or group instruction for the purpose of enhancing the knowledge or skill levels of teachers. One assumption upon which this model is based is the belief that there are behaviors and techniques that have been identified by the effective schools research of the 1970's and 1980's that are worthy of application in the classroom. Another 
assumption is that teachers can change their behavior and can learn additional effective classroom techniques.

The success of training depends on the quality of the stated objectives and of the training provided. The administrator's responsibilities include motivating teachers to participate in training, identifying objectives that are important to teachers, and to assuring that the quality of the training is the best it can be.

Inquiry: Inquiry involves teachers in identifying an area of instructional interest, collecting data on the topic, and changing their instructional practices based on the results of their research. This model is based on the assumptions that teachers (a) are capable of critiquing and developing valid questions about their instructional practices, (b) are inclined to seek answers to pressing problems about their improvement, and (c) will learn best from a process that is self-driven.

The inquiry model is most successful when teachers and administrators work together to identify problems, learn from one another's perspectives, gather information together, and address school problems collaboratively (Sparks \& Loucks-Horsley, 1990).

Despite the attention given to the exploration of the topic of staff development, much remains to be learned about the motivators, procedures and outcomes involved in the professional development process (Fenstermacher \& 
Berliner, 1984; Sparks \& Loucks-Horsley, 1990). General consensus among researchers, however, points to the belief in its importance for the process of school improvement (Wood \& Kleine, 1987).

Since "staff development offers one of the most promising roads to the improvement of instruction" (Sparks, 1983, p. 65), knowing more about the factors that motivate teachers to pursue further professional growth and development experiences can be extremely important to administrators. According to Fenstermacher and Berliner (1984), "research that examines teachers' reasons for participating in staff development is a critical need" (p. 69). Administrators need to know whether participation is "based on concern for professional improvement, compliance with administrative mandates, financial incentives, or some combination of these and other reasons" (Fenstermacher \& Berliner, p. 69). It would also be useful to determine whether teachers are motivated to participate in staff development for differing reasons at different stages of their careers. According to Levine (1988), individuals have different personal and professional needs at different stages of their development.

A better understanding of the various motivators for teachers would allow policy makers to devise more effective strategies for encouraging teacher participation in and commitment to needed staff development activities (Fenstermacher \& Berliner, 1984). Loucks-Horsley et al. (1987) stated that "the quality of a staff development program is determined by the quality of the 
decisions that drive it. And quality decisions mean informed decision-makers" (p. 28).

Commenting on educational change, Goodlad (1983) observed that American public education, during the past twenty-five years, has not succeeded in developing the necessary school reform. Notable among the reasons cited by Goodlad is our past failure to utilize the information we have accumulated about change, the change process, "and the principles of human motivation."

Since most efforts to implement school improvement involve the training or retraining of teachers in new concepts, methodologies and curriculum, careful attention to the critical area of motivation is warranted. Hall and Loucks (1978) suggested that staff development can be best facilitated by the use of a teacher-centered model that considers the motivations of teachers. The Concerns Based Adoption Model (CBAM) reinforces the importance of considering and utilizing teachers' perceived needs and concerns about their professional growth as a basis for developing inservice training. According to the CBAM, a typical starting point for teachers about to participate in staff development is to ask themselves, "What's in it for me?" This question is reflective of the lower level motivations and concerns on the Maslow hierarchy.

The CBAM model progresses along a Maslow-style hierarchy as it measures the changes in the types of concerns that teachers have as they learn new behaviors and classroom practices. As teachers become more secure 
about newly learned techniques, their focus of attention moves from being self-centered (What's in it for me?) to being student centered (How can this process be improved to be even more effective for teaching students?) (Hall \& Loucks, 1978).

The necessity of focusing attention on the individual classroom teacher in the education reform process has been reinforced by a three-year study conducted by The Network, Inc. and described by Shalaway (1981). In this study of dissemination efforts supporting school improvement, The Network found that change occurs primarily in the classroom, rather than at the building or district level. The study concluded that the ultimate source of change and the results of that change can be attributed to the individual teacher. The individual teacher creates the classroom environment, designs instruction around a curriculum, and teaches students (Shalaway, 1981). For these reasons, it is important to unlock some of the secrets of motivation that will encourage teachers to participate in and be committed to the content of staff development training.

Sparks (1983, p. 65) described staff development as a "nested process" consisting of goals and content at the core, surrounded by a second layer that consists of the training process. Both are surrounded by an outer contextual layer. The contextual layer includes the leadership climate created by the building administrator. Each portion of the nested process is important to the 
successful implementation of professional development programs for educators. The inner portions of the nest (process, goals, content), however, will not be accessed if the leadership context does not encourage, support or motivate the individual to participate in the entire staff development process.

The importance of staff development to the educational reform process has been thoroughly discussed, as has the critical role that administrative leadership plays in promoting the professional growth and development of teachers. Central to both issues, is an expanded general knowledge of human motivation theory and a more specialized understanding of the research on teacher motivation. These topics are covered in the sections that follow.

\section{Motivation Theory}

In 1954, Maslow proposed a theory of human motivation based on a hierarchy of needs that act as the driving forces to action. In a later publication, Toward a Psychology of Being, Maslow (1968) refined his theory of growth motivation, which he suggested as an alternative to another earlier theory that proposed that the primary motivator in a living organism is the extinction of annoying or negative needs. Pre-Maslow theories implied that the result of extinguishing a negative need was "cessation of tension, an equilibrium, a homeostasis, a quiescence, a state of rest, a lack of pain" (1968, p. 29).

Buhler (1951) differentiated between homeostasis and the state of rest theory. The state of rest theory, she explained, implies that zero tension is 
desirable and that removal of tension is the motivator. Homeostasis, on the other hand, was described as arriving at a balance point or optimal state of being. In order to arrive at homeostasis, it might be necessary to either increase or decrease tension.

To the idea of homeostasis, Maslow (1968) responded that it, too, remained lacking as an adequate explanation for motivation. His growth motivation theory proposed that the missing piece in human drives is a "dynamic principle which ties together and interrelates all these separate motivational episodes" and propels human beings toward a state of "self actualization" (p. 30). Maslow discussed his growth motivation theory in the following paragraph:

...when we examine people who are predominantly growth-motivated, the coming-to rest conception of motivation becomes completely useless. In such people, gratification breeds increased rather than decreased motivation, heightened rather than lessened excitement. The appetites become intensified and heightened. They grow upon themselves and instead of wanting less and less, such a person wants more and more of, for instance, education. The person, rather than coming to rest, becomes more active. The appetite for growth is whetted rather than allayed by gratification. Growth is, "in itself," a rewarding and exciting process. (p. 30)

Maslow's (1954) construct (Figure 3) established a hierarchy of needs beginning with basic physiological needs such as food and shelter, progressing in sequence to the need for safety and security, to the need for social belonging and affiliation, to the need for recognition and achievement or self esteem, and finally to the need for self-actualization through competence or self expression. 


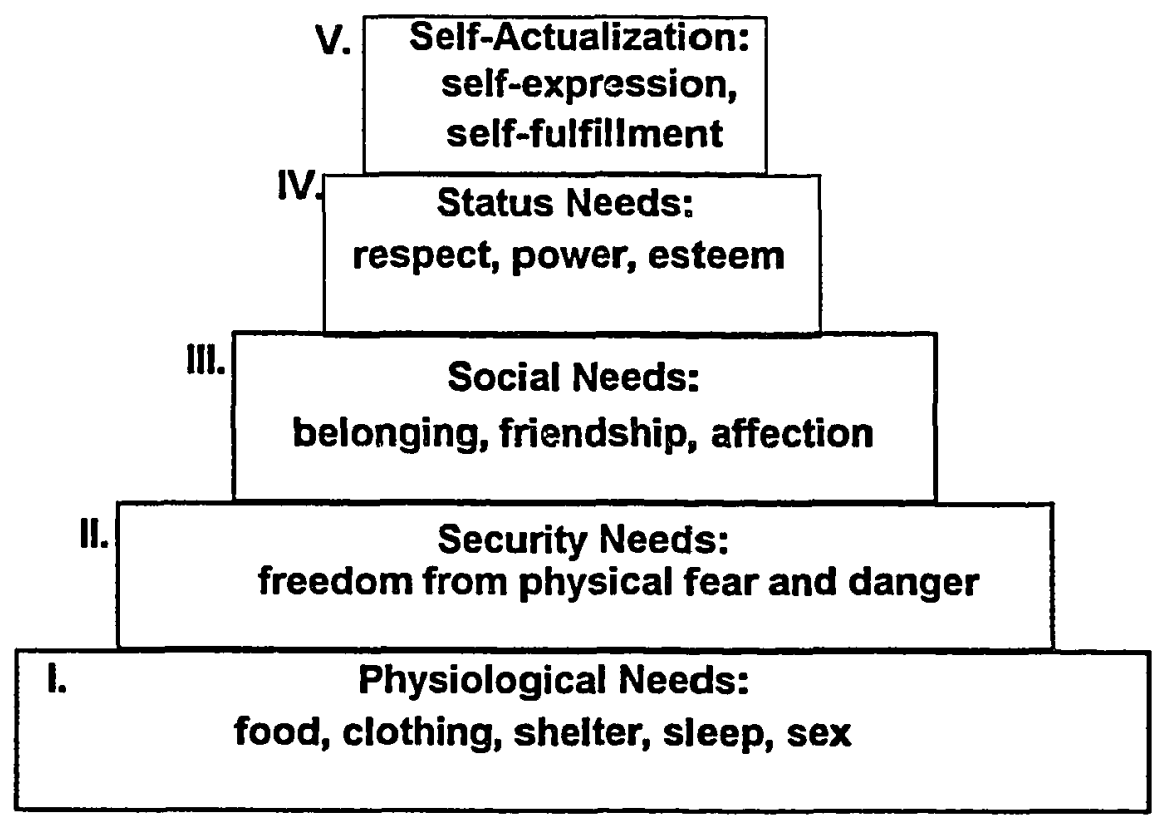

Figure 3. Maslow's (1954) theory of hierarchical needs (adapted).

As the highest point on the scale, self-actualization is described as the "ongoing actualization of potentials, capacities and talents...as a fuller knowledge of, and acceptance of, the person's own intrinsic nature, as an increasing trend toward unity...." (Maslow, 1968, p. 25). Due to its adaptability to various situations, Maslow's theory has often been used as a framework for identifying and structuring needs or motives specifically related to the work place (Hersey \& Blanchard, 1977; Kaiser, 1982).

A second motivation construct utilized in this study was proposed by Herzberg, Wiener, Mathapo and Wiesen (1974). These authors described a two-tiered continuum of needs and feelings. The dual structure that Herzberg et 
al. created focuses on growth needs and pain avoidance needs. Growth needs operate along an emptiness-fulfillment continuum and serve as motivators. Pain avoidance needs operate along a pain--relief from pain continuum and serve as maintainers, or hygienes.

According to the Herzberg et al. (1974) construct, the first three levels of Maslow's (1954) hierarchy correspond to pain avoidance needs, levels IV and V correspond to growth needs. In addition, Herzberg et al. have translated Maslow's psychological descriptions into job-oriented terminology. A side by side comparison of the Maslow and Herzberg constructs is shown in Figure 4.

Herzberg's (Herzberg, 1966; Herzberg et al., 1959) earlier research on job attitudes and motivation provided the basis for his motivation-hygiene theory. Herzberg proposed that two different sets of factors account for "satisfaction" (motivation) and "dissatisfaction avoidance" (hygiene). According to his theory, those factors that can serve as motivators are inherent in the work itself (i.e. achievement, recognition, intrinsic interest in the work, growth, advancement). Hygiene factors that account for job dissatisfaction avoidance are external to the work content and include matters such as supervision, company policy, working conditions, salary, working relationships, status and security. While meeting hygiene needs can help avoid job dissatisfaction in the individual, increasing the "dosage" given of these factors will not necessarily result in satisfaction or motivation. 


\begin{tabular}{|c|c|c|c|}
\hline & MASLOW & HERZBERG & \multirow[b]{2}{*}{ GROWTH } \\
\hline LEVEL V & Self-Actualization & $\begin{array}{l}\text { Responsibility } \\
\text { Growth Possibility } \\
\text { Work Itself }\end{array}$ & \\
\hline LEVEL IV & Status Needs & $\begin{array}{l}\text { Recognition } \\
\text { Achievement }\end{array}$ & NEEDS \\
\hline LEVEL III & Social Needs & $\begin{array}{l}\text { Working } \\
\text { Relationships }\end{array}$ & PAIN \\
\hline LEVEL ॥ & Security Needs & \begin{tabular}{|l} 
Fringe Benefits \\
Working Conditions \\
Job Security
\end{tabular} & AVOIDANCE \\
\hline LEVEL I & Basic Needs & Salary & NEEDS \\
\hline
\end{tabular}

Figure 4. Comparison of Maslow (1954) and Herzberg (1974) constructs. Adapted from Kaiser (1981, p .3).

Both Maslow's theory of a hierarchy of needs (1954) and Herzberg's (1974) two-tiered system are commonly referenced in the literature on job satisfaction. By logical extension, these motivation constructs should be applicable to an exploration of the various motives for wanting to improve professionally. Frase, Hetzel, and Grant (1982) point out that Herzberg's theory...

focuses on the person in terms of how job conditions affect basic needs. In contrast, Maslow's theory focuses on the human needs of the psychological person at work and anywhere else. The most crucial similarity between the two theories is that Herzberg's job motivators correlate with Maslow's higher order needs; for example, work-related factors such as job achievement, work itself, 
recognition and opportunity for advancement are motivators that correlate directly with self-actualization and self-esteem. (p. 70)

The lower levels of both theories reflect extrinsic needs while the upper levels describe higher order intrinsic needs. Based on his research, Herzberg (1968) concluded that "motivator factors were the primary cause of satisfaction and hygiene factors the primary cause of unhappiness on the job" (p. 56).

Herzberg's (Herzberg et al., 1959) research has been applied to education by Sergiovanni (1967), Wickstrom (1971), and Schmidt (1976) with results that deviated only slightly from the original theory. While the motivation-hygiene theory has been criticized by some researchers, others have considered it valid and useful (Frase, Hetzel, \& Grant,1982; Lawler, 1986; Minor, 1980; Sergiovanni \& Carver, 1980). Frase et al. (1982) have gone so far as to state that Herzberg's "motivation-hygiene theory is the most valid source of information to work from" (p. 68) in determining what factors will motivate teachers to pursue instructional excellence. The motivation-hygiene theory also "gains credibility from the fact that the two distinct groups of factors associated with hygiene needs and motivation correlate very closely with Abraham Maslow's hierarchy of needs" (Frase et al., 1968, p. 68).

Research conducted with teachers seems to support Herzberg's theories that intrinsic rewards are more powerful motivators than extrinsic rewards. Lortie (1975) and Kottcamp, Provenzo and Cohn (1986) found that teachers consistently rated intrinsic rewards, such as knowing that they have caused 
students to learn, as more powerful motivators than extrinsic rewards such as money and fringe benefits.

\section{Research on Teacher Motivation}

In 1975, Lortie conducted a thorough sociological study of teachers and teaching as a profession and discovered patterns in the motivational systems guiding teacher behaviors. While Lortie's study examined a broad range of issues dealing with becoming and remaining a teacher, he gave particular attention to the career and work rewards of teaching and their congruence with the perceptions and preferences of teachers for various types of rewards (Bredeson et al., 1983). Lortie (1975) concluded that teachers are motivated primarily by internal (psychic) rewards.

Lortie (1975) categorized rewards related to teaching into three distinct types: extrinsic, ancillary and psychic. Salary and fringe benefits are examples of extrinsic rewards and are connected to a position rather than to the person in that position. In teaching, extrinsic rewards are as predictable as the typical twenty step salary schedule with little differentiation from individual to individual. According to Murnane and Cohen (1987), "more than 99 percent of public school teachers in the United States work in districts that employ uniform salary scales. All teachers with the same credentials and experience receive the same salary..." (pp. 350-351). 
Ancillary rewards are those incentives that have more effect on individuals contemplating entry into the teaching profession than they do on individuals already in the profession (Lortie, 1975). Examples of ancillary rewards in teaching might be the hours and working conditions - including winter, spring and summer vacations. Once again, ancillary rewards tend to be fairly stable over time and available to all teachers without differentiation (Bredeson et al., 1983).

Psychic rewards are internally derived. Lortie (1975) suggested that psychic rewards are the most powerful motivational forces that attract and retain successful teachers in the classroom. Included on the list of internal satisfactions are: working with students, observing students learn and succeed, belief in the value of helping others, and being able to grow personally and professionally (Bishop, 1977; Glenn \& McLean, 1981; Lortie, 1975). In a related study on teacher morale, Heath (1981) confirmed the importance of psychic rewards to teachers.

On both the Maslow (1954) and Herzberg (1974) hierarchies, the concept of professional growth and development fits into the category of the higher level, growth-producing needs. Professional growth and development is clearly described by Maslow's definition of self-actualization as the "ongoing actualization of potentials, capacities and talents..." (Maslow, 1968, p. 25). 
The question of motivating individuals to learn or change closely involves issues of adult learning theory (Elmore \& McLaughlin, 1988). Adults are seldom interested in learning content for its own sake. As learners, adults are motivated to learn in response to immediate questions, problems or other real-life situations (Knowles, 1978). External factors are not generally effective for motivating learning; the motivation to learn and develop improved skills must come from within. In a comprehensive review of adult learning, Brundage (1980) concludes:

\begin{abstract}
What seems most clear is that the tendencies which are labeled 'motives' arise from within the learner. They are not something added on by an external agent. The behavior of an external agent must be viewed as contributing either to feedback or to reinforcement and by this route indirectly to further motivation. (p. 48)
\end{abstract}

Similarly, Knowles (1978) suggested that adults have a perspective of immediacy which helps motivate them to learn. Their needs and interests (internal incentives) guide them to seek learning experiences that will satisfy their questions or problems. Andragogy, as an emerging theory for adult learning, is based on Knowles' (1970) observations of the characteristics of the adult learner. He purported that as individuals mature, they move from dependence on others in the learning situation to self directed behavior and autonomy. Motivation for learning becomes increasingly intrinsic as the individual develops. Learning readiness in adults is affected by their need to 
fulfill their perceived social or career roles. Additionally, adults have a desire to apply newly gained knowledge quickly. They are anxious to utilize new information or skills for the resolution of their immediate problems.

Teachers' motivation to participate in new learning situations (professional development activities) is closely related to their sources of satisfaction as teachers and to their belief about the potential benefits of such training for their students (Elmore \& McLaughlin, 1988). According to Lortie (1969, 1975) and McPherson (1972), one of the primary sources of teacher satisfaction and reward revolves around their desire to positively impact student achievement. Teachers are constantly concerned about their efficacy with students (Jackson, 1968; Lortie, 1975). Consequently, in order to be motivated to learn, teachers must believe that further training for them will positively affect their ability to teach students (Lortie, 1975; McLaughlin \& Marsh, 1978).

Extrinsic factors, such as money, have been found to be weak motivators for teachers to change their behaviors (Lortie, 1975). The subordinate nature of extrinsic rewards was exemplified in a study on incentives in large urban school districts (Bruno \& Dosch, 1981). Teachers refused to accept bonuses offered to retain them in high turnover schools. In another study, conducted by Moore and Hyde (1981), researchers found that extra pay was not an effective incentive to motivate teachers to participate in professional development. Instead, teachers participated if the benefits to their students were made sufficiently clear. 
McLaughlin and Marsh (1978) even found that money could have a negative effect on change in teachers.

In spite of the research findings, present day staff development practices tend to follow a different path. According to Johnson (1986), the performance incentives stemming from the recent reform movement are "based on a conventional notion of motivation, drawn from expectancy theory" (p. 56). Expectancy theory, first proposed by Vroom (1964), suggested that individuals' actions can be predicted based on their anticipation of achieving favorable rewards or of avoiding unfavorable penalties. More recent theories, as has been discussed, have moved beyond expectancy theory to consider the role of intrinsic incentives in shaping the behavior of teachers. A current policy debate that has been generated by reform efforts raises two questions: (a) "whether intrinsic and extrinsic rewards play distinct or compatible roles in motivation", and (b) "whether all rewards can function as incentives" (Johnson, 1986, p. 56).

To these questions, Johnson (1986) responds:

Although there is some dispute among industrial psychologists, it is generally agreed that people can be motivated by extrinsic rewards, such as pay and promotion, as well as by intrinsic rewards, such as pride in work. Underlying many of the current incentives policies is the assumption that people can be motivated primarily by extrinsic rewards, a belief that some educators dispute. It is clear that money does matter to teachers and that they respond to opportunities for greater earnings. However, there is disagreement about whether extrinsic rewards are effective incentives for all types of work. Based on their review of the literature, Bacharach et al. [1984] concluded that extrinsic rewards such as money will improve the performance of "uninteresting or 
otherwise unattractive tasks", but that intrinsic motivation is sufficient for problem-solving tasks. (p. 57)

Of major concern to school administrators is the question of how to reward teachers for excellent teaching performance as well as how to motivate teachers to continue to improve their practice. Concepts such as merit pay have been created in response to the need for reward systems. However, the premise upon which merit pay plans are based is faulty-that money serves as an effective motivator. Thus, most merit pay programs have ended in failure (Frase et al., 1982). Lortie (1975) concured that in devising reward systems for teachers, it is important to design systems that utilize the higher order, internal motivators since the lower order, extrinsic factors have proven unsuccessful for motivating teachers.

Little et al. (1987) pointed out that

despite the relative absence of extrinsic incentives or rewards for improving professional performance, the vast majority of teachers desire more, not less, staff development opportunities. They list 'access to new ideas' as their number one motivation for attending conferences or workshops. (p. 6)

From their comprehensive study of staff development in California, Little et al. (1987) also yielded eight major conclusions. Number three in their findings was that "California teachers and administrators demonstrate a firm commitment to improving their own knowledge and practice" ( pp. 5-6). Examples of this commitment are evidenced below: 
- For every dollar spent by districts and schools directly on formal staff development activities, individual teachers personally contribute 60 cents in volunteer time, with no present or future financial compensation.

- Among teachers, consistent supporters of staff development activities outnumber consistent critics six to one. The consistent supporters are more likely to be employed in schools that make professional development an accepted part of daily work, schools in which teachers and administrators together play a major role in deciding, planning, arranging, or leading staff development. (p. 6)

Johnson (1986) pointed out that it would be a mistake, however, to discount extrinsic rewards entirely as being appropriate incentives. "To say that teachers are motivated primarily by intrinsic rewards does not necessarily mean that they are motivated solely by them. Money does matter, particularly to teachers whose pay falls short of personal needs" (Johnson, 1986, p. 59).

Some administrators have concluded that teachers can be motivated by providing them recompense other than money for their efforts. A variety of rewards such as attendance at conferences, instructional materials, equipment purchases and personal recognition have been used successfully with classroom teachers (Frase et al., 1982).

In order to identify specific motivators that influence teachers to improve their practice, it may be necessary to differentiate between incentives that attract teachers to the profession and those that tend to retain them in teaching (Johnson, 1986). "Better pay and higher status might draw those with an interest in teaching to the profession, but probably are not sufficient to retain or sustain outstanding staff members" (Johnson, 1986, p. 73). Research studies 
indicate that the best teachers are inclined to remain in the field for intrinsic rewards (Lortie, 1975), "although they may be forced to leave because of poor salaries or working conditions" (Johnson, 1986, p. 73). Johnson also stated that inducing teachers to improve their performance in the classroom will probably

require more than improved status, pay or working conditions. Research suggests that it may require the orchestration of organizational incentives that encourage teachers to think about their work in new ways and commit themselves to new standards and goals...little is yet known about such incentives... (p. 74)

\section{SUMMARY}

According to Elmore and McLaughlin (1988), American education has had a series of "recurring cycles of reform" (p. v). Reform, they believe, has not typically had a substantial effect on teaching and learning. Educational reform can operate at three distinct levels: "policy, administrative and practice" (p. 5). Policy involves decision-making about the purposes of education, the roles of institutions and individuals, the fiscal parameters, and the operational structures that deliver instruction. Legislatures and boards of education make policy when they set teacher certification standards, create new systems for financing education and define the basic educational program that will be offered by schools. Local boards create policy when they set teacher-pupil ratios and class size, develop operating budgets, hire administrative personnel, or propose new building developments. 
Administration has the task of transforming policy into reality. Administrators must operate and maintain the educational system in a manner that sets the conditions for effectiveness. They cannot, however, control practice (the actions of the teacher in the classroom). Educational practice involves the instructional decisions necessary to teach content, manage a classroom, diagnose and treat individual learning problems and evaluate student performance. Educational practice is the domain of the classroom teacher and is defined by the interactions between the teacher and the student (Elmore \& McLaughlin, 1988).

For administrators who must set the conditions for excellent teaching and successful learning, reform necessitates understanding and managing the "incentives, constraints, practical problems and institutional realities of classroom teachers. What teachers do and the institutional context within which they do it sets primary conditions for the limits and possibilities of reform" (Elmore \& McLaughlin, 1988, p. 38).

In light of the critically important nature of the reform movement, this study proposes to add to the body of knowledge about the critical area of staff development, specifically the identification of factors that motivate teachers to participate in inservice activities. Armed with more complete information about the incentive needs of their staffs, administrators can be in a better position to 
make informed decisions in planning the staff development portions of their school reform efforts.

The key role that administrative leadership plays in educational reform and school improvement has been well established and documented by research studies (Brookover et al., 1973; Lipham, 1981; Sergiovanni, 1982; Sweeney, 1982; Wynne, 1981). According to Sergiovanni (1982), the leadership that the principal exhibits can be the major factor in determining the effectiveness of a school. Prerequisites to quality leadership include the management skills and the information base necessary to develop and operate an effective school (Sergiovanni, 1982). Administrator training academies and assessment centers throughout the country have been redefining traditional administrative task areas and processes to respond to the demands of a reform-oriented society (Dwyer, 1985).

Notable among the leadership functions described as important by many researchers is the area of staff development (Duke, 1982; Dwyer, Barnett, \& Lee, 1987; Squires, Huitt, \& Segars, 1981). Effective leadership skills in influencing the professional growth and development of teachers directly address the renewed recognition by educational leaders that if schools are to improve, the skills of the individual classroom teacher must receive attention (Darling-Hammond \& Berry, 1988). Most reform efforts have targeted teachers as the object of change. The rationale for this is simple: education can be 
defined as teachers teaching in classrooms. If the intent of reform is to influence what is taught and the way it is taught, then the attitudes, skills and behaviors of teachers must be affected (Elmore \& McLaughlin, 1988). By guiding the staff development programs and offerings available to teachers, administrators can help to shape the reform agenda in their schools or districts.

Efforts have been made by researchers over a span of several years to identify the specific variables that affect staff development outcomes in positive ways (Sparks, 1983). Sparks cited the following major factors that affect the successful outcome of professional development programs:

- Level of administrative support given to program efforts (Berman \& McLaughlin, 1978)

- Type of leadership role played by the building administrator in instructional issues (Lieberman \& Miller, 1981)

- Existing school climate and interactions among staff (Little, 1981)

- Workplace "norms" of collegiality and continuous improvement (Little, 1981)

- Opportunities for shared decision-making (Blase, 1987)

- Leadership ability and decision-making skills (Sergiovanni, 1982) 
The last two variables, leadership ability and decision-making skills lead to a discussion of the evasive concept of leadership and the importance of the decision-making process.

The classic definition of leadership was proposed by Thomson (1980) when he stated simply that leadership is "getting the job done through people" (p. 2). Welte's (1978) differentiation between management and leadership also emphasized that leadership includes the skills, abilities and personal characteristics necessary to influence people to take a predetermined action. In 1960, Terry defined leadership as the act of influencing others to work toward common goals. In order to influence others, a leader needs to have a clear understanding of the human needs and motivations of the employee. Champlin (1987) believed that "schools have ignored the accumulated knowledge about organizational behavior, individual needs and the management of change" ( $p$. $60)$.

In order for school administrators to develop better systems for managing human potential, they need greater insights into (more information about) the individuals that make up their work force. Administrators require information from which to make informed decisions (Sergiovanni, 1980). According to Griffiths (1959), "All other functions of administration can best be interpreted in terms of the decision-making process" (pp. 74-75). Sergiovanni (1980) viewed administration as "an art which uses science in seeking its ends" (p. 2), and 
describes the decision-making process as a balance between the use of information derived from scientific methods (theoretical analysis, quantitative data) and reliance on normative theory (beliefs, assumptions, and ideals related to an issue).

Prior to the recent information explosion generated by the effective schools research, the educational decision-making process had perhaps relied too heavily on intuition-based normative views and too lightly on firmer scientific data. The lack of a solid research base about effective schooling practices had tipped the scales in favor of long-held beliefs and assumptions. Sizer (1987) and other researchers, however, have urged educational practitioners to challenge the regularities-to systematically question some of the educational myths, assumptions, and structures that no longer serve education well.

Since decision-making is an essential element of the educational administration process (Griffiths, 1959; Sergiovanni, 1980), it follows that the information that serves as a basis for making decisions should be the best available. An extensive body of research supports the notion that considering the desires, opinions, and needs of teachers facilitates the implementation of school reform efforts (Purkey \& Smith, 1984). Knowledge gathered from the effective schools literature is engendering the development of better systems of managing human resources. According to Bowles (1966), one of the greatest wastes in the workplace occurs in the area of human potential, and the reason 
for this is the lack of information available to management about the human motivations and incentives that operate in the work setting.

One of the areas identified as important to administrative functioning is effective leadership skills in staff development (Sparks, 1983). Since "staff development offers one of the most promising roads to the improvement of instruction" (Sparks, 1983, p. 65), knowing more about the factors that motivate teachers to pursue further professional growth and development experiences can be extremely important to administrators. According to Fenstermacher and Berliner (1984), "research that examines teachers' reasons for participating in staff development is a critical need" (p. 69) A better understanding of the various motivators for teachers would allow policy makers to devise more effective strategies for encouraging teacher participation in and commitment to needed staff development activities (Fenstermacher \& Berliner, 1984).

The importance of staff development to the educational reform process has been established (Anderson, Evertson, \& Brophy, 1979; Sparks \& Loucks-Horsley, 1990; Wood \& Kleine, 1987; ), as has the critical role that administrative leadership plays in promoting the professional growth and development of teachers (Berman \& McLaughlin, 1978; Lieberman \& Miller, 1981; Sparks, 1983; Stallings \& Mohlman, 1981; ). Further, the necessity of focusing attention on the individual classroom teacher has been reinforced by a three-year study conducted by Shalaway (1981). Shalaway found that major 
instructional change occurs in the classroom, not at the system level. The study concluded that the ultimate source of change and the results of that change can be attributed to the individual teacher. For these reasons, close attention has been given in the literature review to an expanded discussion of human motivation theory and to a more specialized scrutiny of the research on teacher motivation.

In 1954, Maslow proposed a theory of human motivation based on a hierarchy of needs that act as the driving forces to action. Due to its adaptability to various situations, Maslow's theory has often been used as a framework for identifying and patterning needs or motives specifically related to the work place (Hersey \& Blanchard, 1977; Kaiser, 1982). A second motivation construct that lends itself to this study was proposed by Herzberg, Wiener, Mathapo, and Wiesen (1974). The dual structure that Herzberg et al. created focuses on growth needs and pain avoidance needs. The first three levels of the Maslow hierarchy correspond to Herzberg's pain avoidance needs, levels IV and V from Maslow correspond to Herzberg's growth needs. Additionally, Herzberg et al. translated Maslow's psychological descriptions of the hierarchy into job-oriented terminology.

Both Maslow's (1954) theory of a hierarchy of needs and Herzberg's (1974) two-tiered system are commonly referenced in the literature on job satisfaction. Herzberg's research has been applied to education by Sergiovanni 
(1967), Wickstrom (1971), and Schmidt (1976) with results that deviated only slightly from the original theory. Research conducted with teachers seems to support Herzberg's theories that intrinsic rewards are more powerful motivators than extrinsic rewards. Lortie (1975) and Kottcamp et al. (1986) found that teachers consistently rated intrinsic rewards, such as knowing that they have caused students to learn, as more powerful motivators than extrinsic rewards such as money and fringe benefits.

On both the Maslow (1954) and Herzberg (1974) hierarchies, the concept of professional growth and development fits into the category of the higher level, growth-producing needs. Professional growth and development is clearly described by Maslow's definition of self-actualization as the "ongoing actualization of potentials, capacities and talents..." (Maslow, 1968, p. 25).

Teachers' motivation to participate in new learning situations (professional development activities) is closely related to their sources of satisfaction as teachers and with their belief about the potential benefits of such training for their students (Elmore \& McLaughlin, 1988). According to Lortie (1969, 1975) and McPherson (1972), one of the primary sources of teacher satisfaction and reward revolves around their desire to positively impact student achievement. Teachers are constantly concerned about their efficacy with students (Jackson, 1968; Lortie, 1975). Consequently, teachers believe that in order to be effective, training for them must positively affect their students. 
Rosenholtz (1984) argued that "the ability to attract, train and keep good teachers depends heavily on base salary, the organizational conditions of work and the professional development opportunities, in addition to the type of incentive system offered by the school" (p. 5).

According to Johnson (1986), motivating teachers to improve their performance in the classroom will probably

require more than improved status, pay or working conditions. Research suggests that it may require the orchestration of organizational incentives that encourage teachers to think about their work in new ways and commit themselves to new standards and goals... little is yet known about such incentives. ( $p .74$ )

This study proposes to add to the body of knowledge about the motivators and incentives that teachers consider important. Such knowledige can help facilitate the current reform movement and assist in shaping policy decisions about inservice education for teachers.

A thorough review of the methodology used to conduct this study follows in Chapter III. 


\section{CHAPTER III}

\section{METHODOLOGY AND PROCEDURES}

The purposes of this chapter are to describe the methodology used in this study and to document the development, field-testing, validation and administration of the instruments utilized in the research. In deciding upon the methodology to be employed in this study, consideration was given to the various ways in which to answer the major questions posed, regarding the factors that motivate teachers to participate in professional growth and development activities.

While some thought was given to utilizing interviews or case studies, the obvious limitations of these methods in terms of the numbers of possible subjects discouraged their use. Since one of the purposes of this study was to corroborate or refute the myths about teachers and the incentives that motivate them, it seemed appropriate to seek answers by asking teachers themselves and in sufficient numbers to be able to generalize to a broader population.

Another consideration in selecting the methodology was the fact that teachers' belief structures and attitudes were to be examined in the study. According to McCall (1982), the most common method for attitude testing in teachers is the sampling technique. McCall further pointed out that 
Modern sampling techniques make possible many studies that could not be done on a comprehensive or census basis. Moreover, sample studies often make data available more quickly, more economically, and sometimes more accurately than do comprehensive studies. (p. 3)

Also of importance in selecting the methodology for this study was the opportunity to conduct a state-wide survey and to sample nearly an entire state population of teachers that was provided by the Washington Education Association. Results from the study would be generalizable to the entire teacher population in Washington State and perhaps beyond. Once the decision to conduct a survey was made, attention turned to developing survey instruments, drawing the samples and utilizing effective and efficient sampling techniques.

Development of the instruments to be used in the survey included a review of the literature to identify existing instruments that might provide the information sought regarding the motivations that influence teachers to participate in staff development activities. Since an existing instrument that specifically measures the motivations of teachers for participating in staff development activities was not found, two new instruments, based on some preexisting models, were developed.

The new instruments, entitled "Staff Development Motivation Profile" (SDMP) and "Work Motivation Profile" (WMP), were field tested and validated in a multiple-step process. Initial drafts of the instruments were administered to two different groups of teachers (approximately 120 individuals). These 
teachers responded to a series of questions about the format, the wording, and the clarity of each item used in the questionnaires. The instruments were modified and revised based on the responses of the two groups of teachers.

As part of the validation procedures, the Hall-Williams Work Motivation Inventory (Hall \& Williams, 1967) (the instrument used as a model for the creation of the two new questionnaires), and the newly created Profiles were administered to different systematic random samples of teachers. Comparisons of the responses made by teachers to all three instruments were made to test the extent to which: (a) the Hall-Williams Inventory would be applicable to teachers; (b) teachers responded to work motivation questions like employees in other work settings; (c) the newly created instruments were valid measures of work motivation and staff development motivation; (d) the motivation factors that affect teachers in the workplace carried over to influence their participation in staff development activities; (e) the newly created instruments possessed internal reliability.

The Work Motivation Profile was developed as an intermediary step to facilitate the administration of the Staff Development Motivation Profile and to use as a link in the validation process of the latter instrument. The rationale for its development and use was that, as a first step in creating a valid test for staff development motivation, it would be appropriate to craft a work motivation instrument for teachers using a model currently in use in another professional 
community. The newly developed work motivation profile served as a model from which to create the staff development motivation measure.

The finalized instruments (Staff Development Motivation Profile and Work Motivation Profile) were administered to a systematic random sample of 2,000 teachers from the state of Washington. The process of identifying the study population had already been completed, and once the instruments had been mailed out to respondents, follow-up activities to achieve a favorable response rate were undertaken. The end result was a usable response rate of $\mathbf{7 7 0}$ profiles out of 2,000 or $38.5 \%$.

\section{DEVELOPMENT OF THE INSTRUMENTS}

This study primarily required the development of a research instrument to measure the motivation factors that lead teachers to participate in staff development activities. Even though two instruments were developed for the purpose of conducting this study, a work motivation profile designed specifically for teachers and a staff development motivation profile, the major focus of this study was directed at issues surrounding staff development. Therefore, major emphasis in the analysis section of Chapter IV was placed on the data emanating from the staff development instrument.

As reported in Chapter II, the most commonly available motivation inventories focus on the work place and work related situations. A review of the 
literature did not surface any research instruments that specifically measure motivation factors related to classroom teachers' participation in staff development activities.

A work motivation inventory developed by Hall and Williams (1967), however, provided a model from which to develop a staff development motivation profile. The Hall-Williams Work-Motivation Inventory was selected for two reasons:

1. This instrument is based heavily on a combination of the Maslow (1954) need hierarchy and Herzberg's (1959; 1974) work motivation constructs. Both of these models have been commonly utilized in educational studies conducted by such researchers as Sergiovanni (1967), Wickstrom (1971), and Schmidt (1976). As Frase et al. (1982) pointed out, Herzberg's theory 'focuses on the person in terms of how job conditions affect basic needs" (p. 70). Maslow's theory complements this idea by focusing on the psychological needs of the individual in daily life in general.

2. The format of this instrument utilizes the technique of paired comparisons. This "forced choice" structure requires a respondent to make decisions that will more objectively define his or her motivation preferences than an open-ended questionnaire might accomplish. In this inventory, each of the Maslow "need" categories (basic, security, social, status, and self-actualization) is paired with every other Maslow "need" a number of times, and respondents 
are forced to distribute five points between the two. For example, if an item contains responses indicating need types $A$ [basic] and $E$ [self-actualization], the teacher is instructed to assign a value of " 5 " to the $A$ alternative if $A$ is totally characteristic of the teacher's feelings and " 0 " to $E$, if $E$ is totally uncharacteristic of the teachers' feelings. If the alternatives are each partially characteristic of the teacher, a value less than " 5 " but greater than " 0 " is to be assigned to each, with the stipulation that the sum of the two must total "5". Each of the five "need" systems is therefore measured relative to the remaining four. The strongest "needs" thus emerge when pitted against those of lesser concern to the respondents.

Prior experience of this researcher in administering the Hall-Williams Work-Motivation Inventory to teachers, however, suggested that the business-oriented language of the instrument is difficult for teachers to transiate into their daily experience. In order to create a more relevant and valid survey situation for teachers, two new motivation instruments geared specifically to educational system employees were developed. The newly created instruments were designed specifically to answer questions about the educational work setting (Work Motivation Profile) and the reasons for participating in professional development activities (Staff Development Motivation Profile). The major purpose for developing the instruments was to yield information critical to the 
focus of this study: to identify and measure the factors that motivate teachers to participate in professional growth and development activities.

Paired comparisons was maintained as the instrument format, and the five level Maslow/Herzberg "needs" system (Kaiser, 1982) continued to form the basis for the resultant need profiles. The 40 item Work Motivation Profile was developed and used primarily as part of the validation procedures utilized in the study.

The 30 item Staff Development Motivation Profile was designed utilizing three basic statement stems regarding motivation:

1. I believe the real rewards of participating in staff development activities are...

2. In deciding whether or not to participate in staff development activities, I would be most concerned to the extent which...

3. I would be most motivated to participate in staff development activities if....

Completion statements that correspond to each level of Maslow's (1954) and Herzberg's et al. (1974) five-tiered constructs were then developed. The completion statements were developed and categorized in the following manner, utilizing Maslow and Herzberg et al. constructs and terminology:

$\begin{array}{ll}\text { Basic Needs } & =* \text { Time and Money Concerns } \\ \text { Security Needs } & =\text { Job Security/ Work Evaluation }\end{array}$


Social Needs $\quad=\quad$ Collegiality/ Social Interaction

Status Needs = Personal Recognition/Rewards

Self Actualization = Personal Satisfaction/Growth

" (the = sign should be read as "corresponds to")

See Appendix A for a copy of the finalized instruments.

The completion statements for the Basic Needs portion of the Staff Development Motivation Profile included the following incentives:

- Receiving extra pay or release time;

- Potential for advancement on salary schedule;

- Not requiring more work or cutting into time for personal pleasure.

Security incentives were described in the following ways:

- $\quad$ Ensuring job security;

- Looking good on evaluations thereby helping to ensure job security;

- Feeling more secure about the job and more able to cope with changes in the field.

Incentives responding to the Social Needs of teachers were described in this fashion:

- Opportunities to build positive relationships with colleagues, to socialize, and to share good times; 
- Interacting with colleagues, exchanging ideas, and sharing experiences;

- Colleagues participating and working together as a team.

The instrument used the following language to describe Status Needs incentives:

- Receiving personal recognition and tangible rewards;

- Receiving additional expertise or help in obtaining an advanced degree in order to gain personal recognition;

- Having an opportunity to demonstrate competence and be recognized by others as being one of the better educators in the group.

Self-actualization incentives were described in the following manner on the survey instrument:

- The personal satisfaction of learning new skills that are relevant to the job;

- Engaging in staff development that is stimulating and challenging;

- Being able to learn, grow professionally, and become more knowledgeable. 


\section{SCORING OF THE INSTRUMENTS}

The scoring system utilized in the Hall-Williams Inventory (Hall \& Williams, 1967) was used as a model for that of the two newly created instruments (Work Motivation Profile and Staff Development Motivation Profile). This scoring system yields an individual or group profile showing the relative strength of each of the five "need" categories (basic, security, social, status, self-actualization). The highs and lows of this profile indicate the satisfied and unsatisfied sources of motivation and combine to portray an individual's or group's orientation toward either work or participation in staff development activities. According to Maslow (1954), all five "need" categories can exist simultaneously within each adult, and often compete against each other for dominance. This suggests that in order to thoroughly understand the factors that can motivate individuals, it might be important to see a profile of all the "needs" and compare their relative hold on the individual. (See Figure 5 for a sample needs profile.)

The points on the graph depicted in Figure 5 represent hypothetical scores for the five "need" areas previously described and are like those generated by the survey instruments developed for use in this study. Figure 5 is a hypothetical visual representation of the relative scale, produced by the Staff Development Motivation Profile, that measures each need category against the 
remaining four. The needs that emerge most strongly (Basic Needs and Status Needs) can be said to have "won out" when pitted against other need systems of lesser concern to the teacher. The peaks and valleys combine to yield a picture of the teacher's total incentive orientation toward participating in staff development activities.

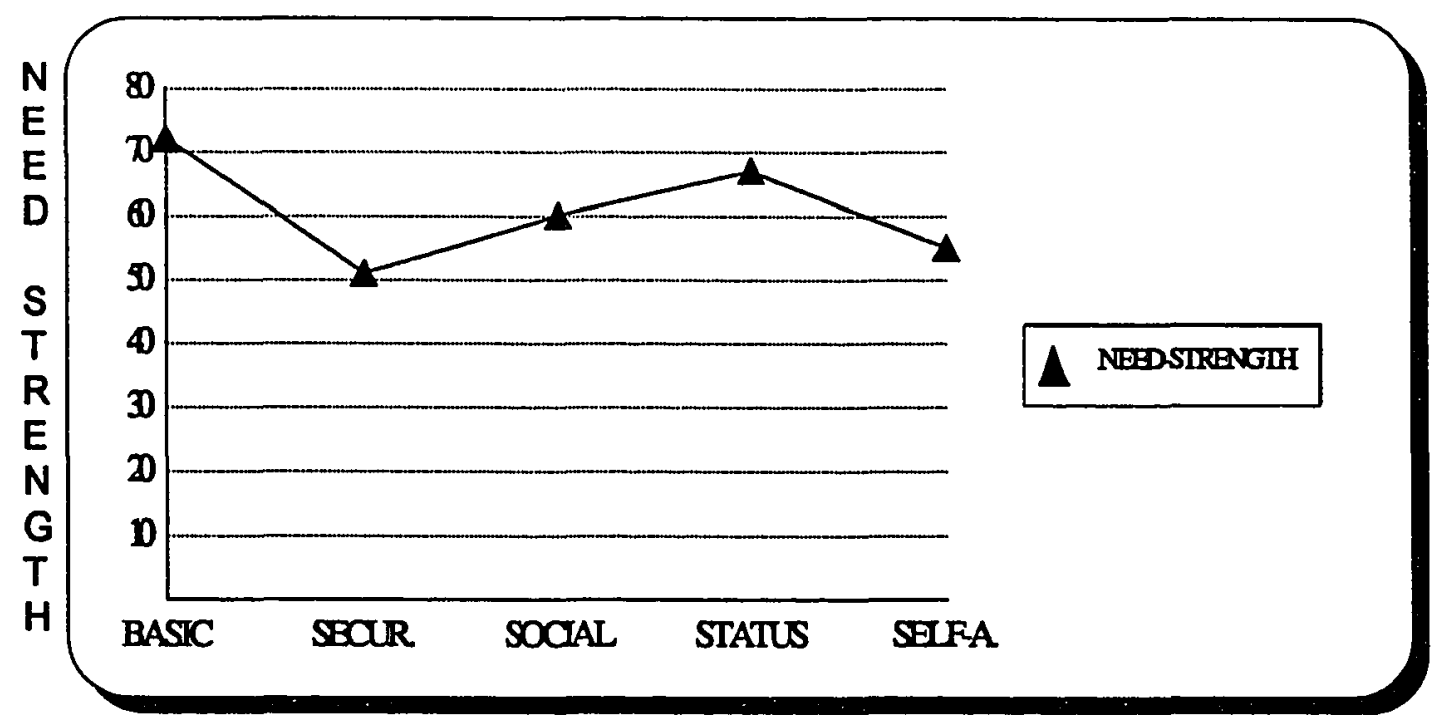

Figure 5. Sample needs profile.

A needs profile of this type can yield a greater amount of information about an individual or a group than can be determined from a fixed piece of information or a single score. On this profile, it is possible to identify the greatest sources of motivation which are also the highest scoring needs. (This hypothetical individual or group would be most motivated by his of her basic and status needs.) Conversely, the lowest sources of motivation are the lowest 
scoring needs (in this case, security and self-actualization). In addition, it is possible to examine the relative strength of the five need areas in order to draw a more complete picture of the motivators that can affect behavior.

\section{PILOT TESTING OF THE INSTRUMENTS}

Prior to finalizing the new instruments, a pilot phase was conducted. During the instrument development phase, a draft of both the Work Motivation Profile and the Staff Development Motivation Profile was administered to two groups of teachers totaling approximately 120 individuals. The teachers were asked to answer a series of questions about the instrument:

1. Were the instructions clear and sufficient?

2. Did you have any difficulty understanding the questions?

3. Were any of the questions particularly confusing? Which one(s)?

4. What was your overall reaction to the survey instrument?

5. Do you have any questions about the survey?

The teachers were also asked to suggest corrections or improvements for the instrument. See Appendix B for a copy of the pilot questionnaire.

Modifications and revisions were incorporated into the final instrument based on the responses of the pilot study teachers. Commentary from this group of validators was also utilized to plan and design the final length as well as the cover letter for the Motivation Profiles. For example, teacher 
commentary regarding the length and repetitiveness of the instrument led not only to cutting the length of the instrument but also to including the portion of the cover letter which suggests to respondents that they allow some quiet, uninterrupted time to devote to filling out the questionnaire. The profile instructions also addressed the issue of the perceived repetitiveness of the instrument. Note that the cover letter was incorporated into the body of the survey instrument booklet.

\section{VALIDATION OF THE INSTRUMENTS}

After the profile questions had been revised and refined to respond to pilot study concerns, a series of validation steps were conducted. Figure 6 provides a schematic depicting the four-step validation procedure outlined below.

\section{Step One}

The first step of the validation procedure consisted of administering the Hall-Williams Work Motivation Inventory (WMI) (Hall \& Williams, 1967) to a small sample of teachers (Sample 1) and analyzing the results. This sample consisted of a population of 125 teachers from which 69 valid responses were obtained. This portion of the validation process was therefore based on a usable return rate of $55 \%$. This rate was regarded as adequate for a validation 
analysis. (A more detailed discussion of the administration of the research instruments is contained in the next section of this chapter).

\begin{tabular}{|ll|}
\hline \multicolumn{1}{|c|}{ VALIDATION } & \multicolumn{1}{c|}{ PROCEDURE } \\
\hline Step 1: Compare A to B & Determine: \\
& 1) Extent to which WMI is \\
& applicable to teachers. \\
& 2) Whether teachers respond to \\
& work motivation similarly to \\
& non-teachers. \\
& Determine: \\
Step 2: Compare A to C & 1) Whether WMP is a valid \\
& measure of work motivation. \\
& Determine: \\
Step 3: Compare C to D & 1) Whether instruments produce \\
& similar results \\
Step 4: Compare alphas of & Determine: \\
C and D & 1) Instrument Reliability for both \\
& instruments \\
\hline
\end{tabular}

A: Hall-Williams Work Motivation Inventory (WMI) norm (1967)

B: Results, Hall-Williams (WMI) administered to Sample 1

C: Results, Work Motivation Profile (WMP) administered to Sample 2

D: Results, Staff Development Motivation Profile (SDMP) administered to Sample 2

Figure 6. Validation procedure.

Since norms exist (See Table I and Figure 7) for the Hall-Williams Work Motivation Inventory (WMI), based on thousands of individuals who have taken the WMI, it was possible to compare the results from this small random sample to the norms established by the Hall-Williams studies (see Table II and Figure 8) 
(Hall \& Williams, 1967). This validation step was intended to determine: a) the extent to which the Hall-Williams Work Motivation Inventory was generally applicable to teachers despite problems of language specific to a business setting; and b) whether teachers respond to questions of work motivation in much the same way as employees within the business-oriented populations surveyed by Hall and Williams.

\section{TABLE I}

HALL-WILLIAMS WORK MOTIVATION INVENTORY: ESTABLISHED NORMS

NEEDS Mean Scores Mean Scores

Basic Security Social

Status

Self-Act. (Est. Norms) Average Range

\begin{tabular}{|r|r|}
\hline 48 & $38-58$ \\
\hline 46 & $36-56$ \\
\hline 54 & $44-64$ \\
\hline 74 & $64-84$ \\
\hline 80 & $70-90$ \\
\hline$N=30,000$ & teachers \\
\hline
\end{tabular}

The Hall-Williams Work Motivation Inventory provides summary scores which include means and average-range scores for each of the five "need" categories (Hall \& Williams, 1967). The average ranges have been established by a cumulative process that has aggregated the scores of the individuals who have been administered this instrumeni over the years. According to Hall and Williams, deviations of 10 points or more outside this band of average scores- 
either above or below-are necessary before a significant difference in the scores can be said to exist.

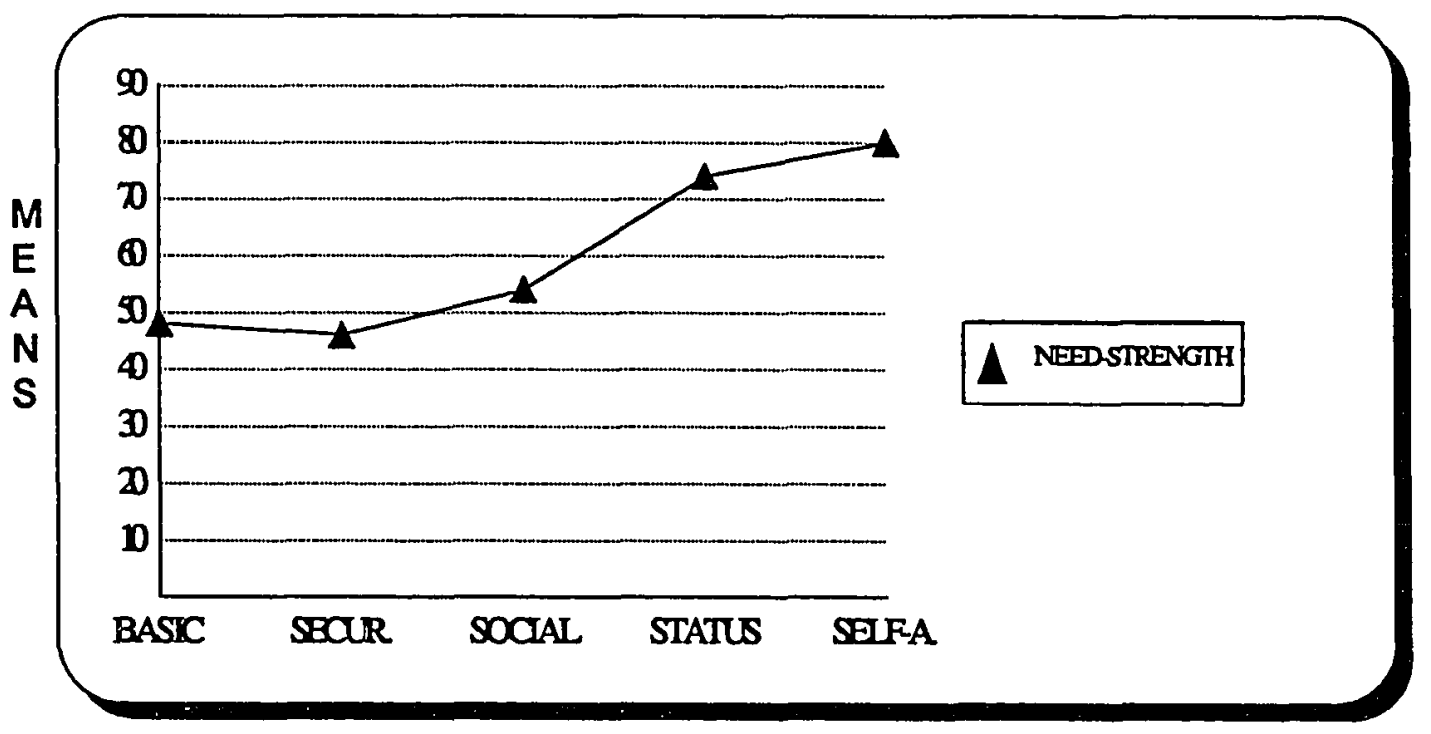

Figure 7. Hall-Williams Work Motivation Inventory norms (1967).

Both Table II and Figure 8 indicate a high correlation between the Sample 1 teacher norms and the reporied norms of the Hall-Williams summary scores (Hall \& Williams, 1967). The Sample 1 scores were all well within the band of plus or minus 10 points from the stated average range of scores of the Hall-Williams instrument. Figure 8 clearly shows paraliel peaks and valleys for each of the need categories on both instruments, indicating a similar relative standing among the need categories and producing very similar "profiles." The most notable difference, however, is that teachers scored somewhat higher in 
basic, security and social needs than the established norms, and slightly lower in status and self-actualization needs.

TABLE ॥

COMPARISON OF MEANS: SAMPLE 1 AND ESTABLISHED NORMS

\begin{tabular}{|c|c|c|c|}
\hline \multirow[b]{2}{*}{ NEEDS } & \multicolumn{2}{|c|}{ COMPARISON OF MEANS } & \multirow[b]{2}{*}{$\begin{array}{l}\text { Hall-Williams } \\
\text { Work Mot Inv } \\
\text { Average } \\
\text { Range }\end{array}$} \\
\hline & $\begin{array}{c}\text { Hall-Williams } \\
\text { Work Mot Inv } \\
\text { (Sample 1) } \\
\mathrm{N}=69 \text { Teachers }\end{array}$ & $\begin{array}{l}\text { Hall-Williams } \\
\text { Work Mot Inv } \\
\text { (Est Norms) } \\
\mathrm{N}=30,000 \\
\text { Non-teachers }\end{array}$ & \\
\hline Basic & 54.0 & 48 & $38-58$ \\
\hline Security & 53.5 & 46 & $36-56$ \\
\hline Social & 59.2 & 54 & $444-64$ \\
\hline Status & 63.7 & 74 & $64-84$ \\
\hline Self-Act. & 69.6 & 80 & $70-90$ \\
\hline
\end{tabular}

Two conclusions drawn from these data are that (a) the Hall-Williams Inventory can be applicable to teachers, and that (b) teachers respond to questions of work motivation in much the same way as the employees within the business community previously surveyed by Hall and Williams (1967). 


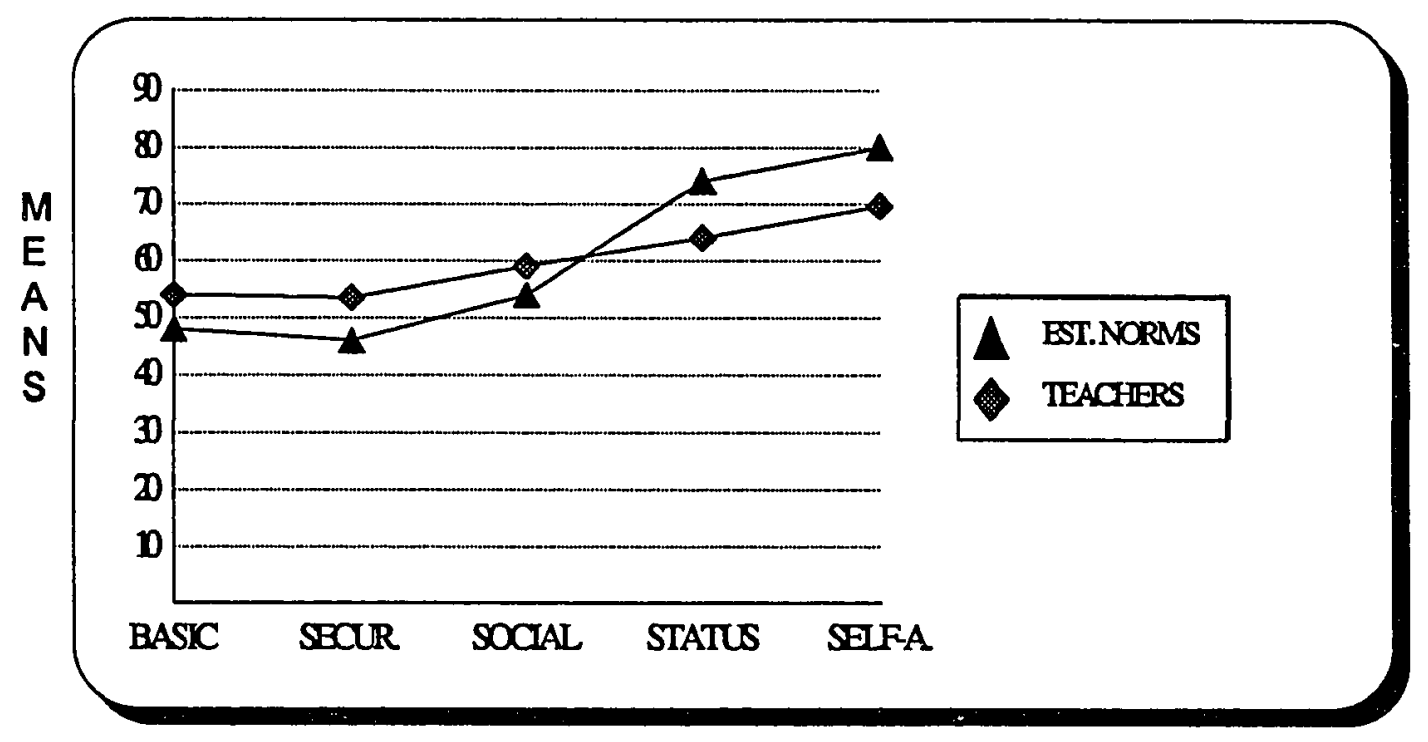

Fiqure 8. Hall-Williams Work Motivation Inventory (established norms, 1967) and small sample of teachers.

\section{Step Two}

A second step in the validation process involved the use of the new created Work Motivation Profile. The focus for this study was specifically the motivation factors influencing teachers. The creation of an instrument similar in format to the Hall-Williams Work Motivation Inventory (Hall \& Williams, 1967), but different in terminology, was deemed necessary in order to more appropriately address the concerns of teachers. The newly developed Work Motivation and Staff Development Motivation Profiles were intended to assess teachers within the school setting with regard to work motivation generally and with regard to professional growth and development specifically. 
The development and use of the Work Motivation Profile was seen as an intermediary step to facilitate the administration of the Staff Development Motivation Profile and to use as a link in the validation process of the latter instrument. The rationale for its development and use was that as a first step in creating a valid test for staff development motivation, it would be appropriate to develop a work motivation measure for teachers. The newly developed work motivation instrument would then serve as a model from which to create a staff development motivation profile.

This step in the validation process, therefore, was a comparison of the norms established by the Hall-Williams Work Motivation Inventory (Hall \& Williams, 1967) with the results produced by the Work Motivation Profile. The Work Motivation Profile was administered in conjunction with the Staff Development Motivation Profile to a large sample (Sample 2) of 2,000 teachers. The intent of this validation step was to test whether the new instrument (WMP) measured the same kinds of job related motivations as the normed Hall-Williams instrument (WMI). It was hypothesized that if the results of these two instruments were found to be sufficiently similar, the new Work Motivation Profile would be a valid measure of work motivation as compared to the Hall-Williams instrument. Table III and Figure 9 display a comparison of the means from both instruments, numerically and graphically. 
TABLE III

COMPARISON OF MEANS: HALL-WILLIAMS ESTABLISHED NORMS AND WORK MOTIVATION PROFILE

\begin{tabular}{|c|c|c|c|}
\hline \multirow[b]{2}{*}{ NEEDS } & COMPARISON & OF MEANS & \multirow[b]{2}{*}{$\begin{array}{l}\text { Hall-Williams } \\
\text { Work Mot Inv } \\
\text { Average } \\
\text { Range }\end{array}$} \\
\hline & $\begin{array}{c}\text { Work Motivation } \\
\text { Profile } \\
\text { (Sample 2) } \\
N=770\end{array}$ & $\begin{array}{l}\text { Hall-Williams } \\
\text { Work Mot Inv } \\
\text { (Est Norms) } \\
N=30,000 \\
\text { Non-Teachers }\end{array}$ & \\
\hline Basic & 61.3 & 48 & $38-58$ \\
\hline Security & 56.4 & 46 & $36-56$ \\
\hline Social & 55.4 & 54 & $44-64$ \\
\hline Status & 60.3 & 74 & $64-84$ \\
\hline Self-Act. & 66.6 & 80 & $70-90$ \\
\hline
\end{tabular}

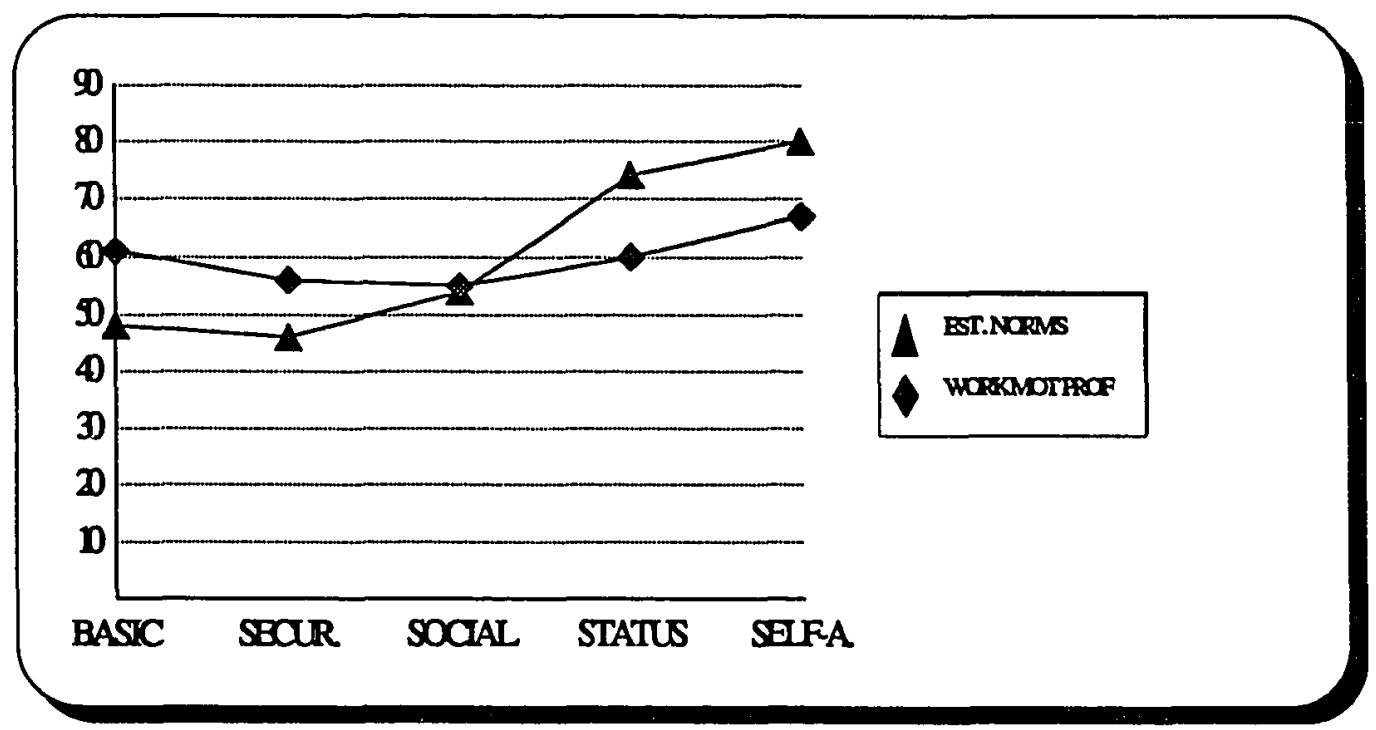

Figure 9. Hall-Williams Work Motivation Inventory (established norms, 1967) and Work Motivation Profile. 
In calculating the mean scores for the Work Motivation Profile, a weighting procedure was utilized. This weighting adjustment was necessary in order to graph the results of both instruments on the same profile, since the Hall-Williams Inventory contains 60 questions, and 300 possible points, while the Work Motivation Profile has 40 questions and only 200 possible points. Each mean score for the Work Motivation Profile was therefore multiplied by a weighted factor of 1.5 .

The graph in Figure 9 shows that the profiles created by the Work Motivation Profile and the Hall-Williams Work Motivation Inventory (Hall \& Williams, 1967) follow the same basic contours, with slight differences potentially attributable to the terminology of the Work Motivation Profile more adequately addressing the school workplace. The security, social, and status needs scores on the Work Motivation Profile are well within the plus or minus 10 point band of average scores established by the Hall-Williams Inventory. Only the basic and self-actualization needs scores fall slightly outside the average band. This might indicate that teachers feel more strongly about both their basic needs and self-actualization needs compared with the general population of workers in other organizations. According to the Hall-Williams scoring mechanism, however, in order to be significantly different, scores must be plus or minus ten points outside the average band of scores. Based on these data, 
the new Work Motivation Profile appears to be a valid measure when compared to the Hall-Williams Motivation Inventory.

A further comparison of the Sample 1 and Sample 2 teacher scores and profiles (Tables II and III, Figures 8 and 9) indicates distinct similarities of results. Teachers responded in similar ways to both the Hall-Williams Work Motivation Inventory (Hall \& Williams, 1967) and to the newly created Work Motivation Profile.

\section{Step Three}

Once having established the validity of the Work Motivation Profile, a subsequent step in the validation process was to compare the means from the Staff Development Motivation Profile (SDMP) with the results of the Work Motivation Profile (WMP) (both from large sample data). The assumption was made that since both instruments had been fashioned to specifically address the education workplace, the profile results would be sufficiently similar to validate the results, yet different enough to point out subtle differences between work motivation and staff development motivation.

In calculating the mean scores for the Staff Development Motivation Profile, a weighting procedure was also utilized. This weighting process was necessary in order to plot the means on the same graph, since the Staff Development Motivation Profile contains 30 questions for a possible 150 points and the Work Motivation Profile contains 40 items with a possible 200 points. 
Each mean score on the Staff Development Motivation Profile was multiplied by a weighted factor of 2 prior to plotting the scores, just as the Work Motivation Profile had earlier been multiplied by a weighted factor of 1.5. Table IV and Figure 10 display the means of the two instruments as administered to the large sample of teachers.

TABLE IV

COMPARISON OF MEANS: WORK MOTIVATION PROFILE AND STAFF DEVELOPMENT MOTIVATION PROFILE

\begin{tabular}{|c|c|c|}
\hline \multirow[b]{2}{*}{ NEEDS } & \multicolumn{2}{|c|}{ COMPARISON OF MEANS } \\
\hline & $\begin{array}{c}\text { Work Motivation } \\
\text { Profile } \\
\text { (Sample 2) } \\
\text { N=770 }\end{array}$ & $\begin{array}{c}\text { Staff Develop. } \\
\text { Mot. Profile } \\
\text { (Sample 2) } \\
N=770\end{array}$ \\
\hline Basic & 61.3 & 55.4 \\
\hline Security & 56.4 & 51.7 \\
\hline Social & 55.4 & 63.3 \\
\hline Status & 60.3 & 54.3 \\
\hline Self-Act. & 66.6 & 75.4 \\
\hline
\end{tabular}

The means for both instruments are close enough to each other to indicate that they are measuring similar things (Note that in every instance except Social Needs, the means are closer between these two instruments than between the Hall-Williams Work Motivation Inventory (Hall \& Williams, 1967) and the Work Motivation Profile. Compare Tables III and IV.) Also noteworthy, 
however, are the subtle differences that appear in the comparisons. Basic, Security, and Status scores on the Staff Development Motivation Profile drop, while the Social and Self-Actualization scores rise in comparison with the Work Motivation Profile.

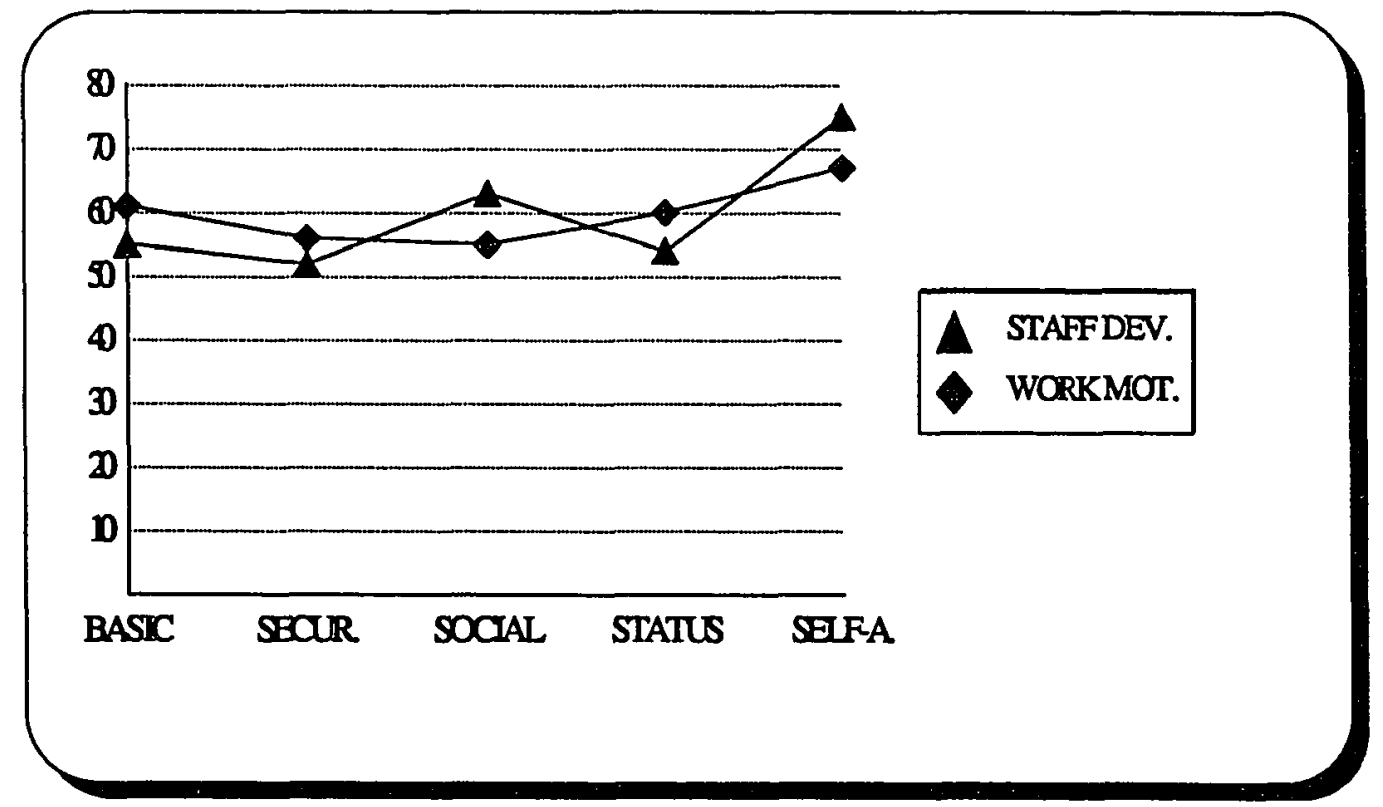

Figure 10. Staff Development Motivation Profile (large sample) and Work Motivation Profile.

\section{Step 4}

The final step in the validation procedure involved analyzing both the Staff Development Motivation Profile and the Work Motivation Profile for instrument reliability. Reliability is the consistency or stability of an instrument and a necessary ingredient of validity. The Cronbach alpha was used to 
measure how well the items on a subscale (need categories) measure a construct. For all the need categories, the procedure divided the scale in half and calculated a sum for each half, then correlated the two halves with each other. This calculation is made for all possible split halves, and takes the mean of all those correlation coefficients. The alphas for all the need categories of the Staff Development Motivation Profile (large sample) and the Work Motivation Profile were calculated and the reliability coefficients were analyzed (see Table V).

TABLE V

COMPARISON OF RELIABILITY SCORES: WORK MOTIVATION PROFILE AND STAFF DEVELOPMENT MOTIVATION PROFILE

\begin{tabular}{|c|c|c|}
\hline \multirow[b]{2}{*}{ NEEDS } & \multicolumn{2}{|c|}{$\begin{array}{l}\text { COMPARISON OF RELIABILITY } \\
\text { (ALPHAS) }\end{array}$} \\
\hline & $\begin{array}{c}\text { Work Motivation } \\
\text { Profile } \\
N=770\end{array}$ & $\begin{array}{l}\text { Staff Dev. Mot. } \\
\text { Profile } \\
N=770\end{array}$ \\
\hline Basic & 0.64 & 0.85 \\
\hline Security & 0.7 & 0.67 \\
\hline Social & 0.78 & 0.79 \\
\hline Status & 0.66 & 0.57 \\
\hline Self-Act. & 0.81 & 0.76 \\
\hline
\end{tabular}


An alpha of .60 and above is generally considered acceptable for research purposes. In this case, all alpha reliabilities were above the .60 minimum, except status needs on the Staff Development Motivation Profile. However, the fact that the status needs category on both the Work Motivation and Staff Development Motivation Profiles have lower reliability coefficients is an indication that less credence should perhaps be given to these scores in the data analysis than to the other needs categories.

\section{ADMINISTRATION OF THE RESEARCH INSTRUMENTS}

The population used in this study was comprised of all teachers, kindergarten through twelfth grade in the state of Washington. Realizing that the most effective procedure for controlling for the primary variables is through the use of a stratified random sample, the original intent of the study was to draw a stratified random sample of the approximately 40,000 teachers in the state. However, problems were encountered in obtaining a comprehensive directory of teachers that included gender, years of teaching experience and addresses. Contact with the Washington State Department of Education yielded a listing of all teachers by name only-addresses were not available. The secondary source tapped for an accessible and complete listing of teachers was the membership roster of the Washington Education Association (WEA), available on a data base through the National Education Association. 
The membership roster of the Washington Education Association provided both names and addresses of teachers and was determined to be more current than the Department of Education information. One minor drawback in using the WEA information was that only about $95 \%$ of the teachers in Washington state were WEA members (or agency fee payers) at the time of the study. Both Association members and agency fee payers were selected for representation in the sample. (Agency fee payers are individuals who work in a school represented by a union in collective bargaining and therefore pay dues, but who do not choose to be union members.) In order to begin with the most complete population from which to sample, some consideration was given to attempting a match between the Department of Education data and the NEA data tapes. Such a match was deemed impractical since the Department of Education utilizes teaching certificate number as the primary identifier while the NEA membership data uses social security numbers. An unacceptable number of non-matches were likely by running the tapes against each other.

Ultimately, the Washington Education Association membership roster was chosen as the source of the population to be sampled. The $95 \%$ population of teacher members in the state was deemed large enough to be representative of the entire state. Consequently, a systematic sample was drawn utilizing the National Education Association membership list and computerized system. According to McCall (1982), "obtaining pure random samples from large 
populations, particularly in sample survey work, is frequently most difficult. Systematic sampling is considered in many situations as a reasonable alternative" (p. 7).

Another consideration was sample size. In determining the optimal sample size, the following questions were asked (McCall, 1982):

1. Is the sample adequate for the desired accuracy and confidence levels?

2. What are the attributes and/or variables to be measured or observed?

3. What are the subgroups to be considered in the research?

4. What are the summary measures to be utilized?

Particular attention was given, for instance, to the examination of subgroups of teachers according to their number of years of teaching experience. Other major variables and attributes of special interest to the study were: (a) gender; (b) work assignment; (c) highest degree earned; (d) potential for movement on salary schedule; (e) proportion of household income attributable to individual's school district salary; (f) grade level assignment; ( $g$ ) size of school district.

Washington State Office of Superintendent of Public Instruction (OSPI) records (1985) indicated a total of 39,344 teachers in the state, prior to September of that year. The total number of teachers were broken out by gender and number of years of teaching experience and are displayed in Table 
VI. Although the OSPI records contained information about years of experience, the Washington Education Association data tapes did not. Consequently, another drawback in using the WEA membership lists was an inability to conduct a random sample stratified for years of teaching experience. In an effort to yield sufficiently large subsamples in the years of teaching experience category, a sample size of 2,000 was selected. According to the Simple Random Sample Tables for Specific Permissible Errors Expressed as Absolute Proportions, when the True Proportion in the Population is 0.50 (McCall, 1982), this figure $(2,000)$ falls within the $95 \%$ confidence level with a $.02-.03$ permissible error.

\section{TABLE VI}

\section{ALL TEACHERS IN THE STATE OF WASHINGTON BY GENDER AND NUMBER OF YEARS OF TEACHING EXPERIENCE (PRIOR TO SEPTEMBER 1985)}

GENDER

\begin{tabular}{|c|c|c|c|c|}
\hline & Female & Male & $\%$ Female & \%Male \\
\hline Under 5 & 4,533 & 1,802 & 11.5 & 4.6 \\
\hline 5 to $<10$ & 5,695 & 2,579 & 4.5 & 6.6 \\
\hline 10 to $<15$ & 5,637 & 3,453 & 14.3 & 8.8 \\
\hline 15 to $<20$ & 4,269 & 3,146 & 10.9 & 8.0 \\
\hline 20 to $<25$ & 2,207 & 2,488 & 5.6 & 6.3 \\
\hline 25 plus & 1,364 & 2,171 & 3.5 & 5.5 \\
\hline TTOTAL & 23,705 & 15,639 & 60.3 & 39.7 \\
\hline
\end{tabular}


Next, an estimated sample size was calculated for each experience group based on a total sample size of 2,000 . For example, the $11.5 \%$ figure in Table VI for females teaching under 5 years was used to calculate the proportionate number of females (230) in a total sample size of 2,000 . These results are displayed in Table VII.

\section{TABLE VII}

PROPORTIONATE NUMBER OF TEACHERS NEEDED IN EACH YEARS OF TEACHING EXPERIENCE CATEGORY

FOR SAMPLE SIZE OF 2,000

\begin{tabular}{|c|c|c|}
\hline \multicolumn{3}{|c|}{ GENDER } \\
\hline & Female & Male \\
\hline Under 5 & 230 & 92 \\
\hline 5 to $<10$ & 289 & 131 \\
\hline 10 to $<15$ & 286 & 176 \\
\hline 15 to $<20$ & 218 & 160 \\
\hline 20 to $<25$ & 112 & 126 \\
\hline 25 plus & 70 & 110 \\
\hline
\end{tabular}

Another consideration in settling upon the sample size was the potential non-response rate. Two major problems are created by non-response of a segment of the sample: (a) possible effects on the sample size, and (b) effects of non-response on the nature of the findings (McCall, 1982). In this instance, a response rate of $60 \%$ was the target figure after four mailings: the initial mailing plus three follow-ups. A $60 \%$ return rate would provide 1,200 responses. 
Twelve hundred returns would still fall within the $95 \%$ confidence level with a .03 permissible error (McCall, 1982).

A closer scrutiny of the subgroup sample sizes in Table VII revealed that many of the subgroup sample sizes might not be large enough for statistical calculations of a high confidence level. These estimated calculations suggested another decision point in determining sample size. One possibility was to increase the sample size, another was to collapse the experience categories into eight-year rather than five-year intervals, for analysis after the survey instruments were returned. Since cost considerations mitigated against increasing the sample size, sample size was maintained at 2,000 . Sample data was collapsed into eight-year teaching experience categories for analysis.

Two thousand kindergarten through twelfth grade teachers were selected to receive the Staff Development Motivation Profile and Work Motivation Profiles by mail. Between seven and eight thousand surveys were printed in order to allow for follow-up mailings. The follow-up mailings were intended to increase the return rate. An additional tactic for encouraging the completion and return of the survey instrument was to include a cover letter emphasizing the importance of the instrument and urging response. Instructions included in the cover letter gave respondents an indication of the time needed to complete the Profile, stated the major focus of the study, and suggested some possible uses for the research results. 
One further strategy for increasing response rate was the use of a one-page, tear-off answer sheet designed as part of the Profile. The one-sided answer sheet contained spaces for responses to all the profile questions plus the eight demographics items. The reverse side of the answer sheet contained instructions for folding the completed survey into a self-addressed postage paid mailer commonly called a self-mailer ( see Appendix A).

From the original mailing, 292 surveys were returned within one month. The first follow-up mailing was conducted at the end of the first month and yielded another 172 usable returns. Thirty days later, a second follow-up mailing was sent. An additional 193 valid surveys were returned. The third and final follow-up mailing was sent three months after the original questionnaire was administered and yielded another 134 usable returns. Of the 793 surveys thought to be properly completed, 23 were found faulty. Therefore, the total valid surveys numbered 770. A summary of the disposition of the two thousand inventories mailed is found in Table VIII.

A smaller systematic sample of 125 teachers was drawn and utilized for purposes of validating both new instruments. This sample is referred to as Sample 1 in prior sections. Sample 1 received the Hall-Williams Work Motivation Inventory and the new Staff Development Motivation Profile. A process similar to that used for the large sample was followed for distribution, administration, follow-up and collection of the small sample. Sixty-nine valid 
responses were obtained from this smaller sample. Thirteen responses were rejected for failure to follow directions or for incomplete data. Forty-three teachers did not return the instruments. The data analysis of the validation steps involving the small sample was based on a usable return rate of $55 \%$. This rate was regarded as adequate for a validation analysis.

TABLE VIII

SUMMARY DISPOSITION OF MAILED INVENTORIES

\begin{tabular}{|l|r|}
\multicolumn{1}{l}{ DISPOSITION OF SURVEYS } & \multicolumn{1}{c}{ NUMBER } \\
\hline Sample Size & 2,000 \\
\hline Non-responses & 1,061 \\
\hline Returned Questionnaires & 939 \\
\hline Valid Returns & 770 \\
\hline Returns with Problems & 84 \\
\hline Blank Returns & 49 \\
\hline Postal Returns (wrong addresses) & 36 \\
\hline Valid Return Rate & $39 \%$ \\
\hline
\end{tabular}

Survey results from the Staff Development Motivation Profile, administered to the large systematic sample of Washington state teachers, yielded a series of composite need profiles depicting the greatest and least sources of motivation for participation in professional development activities. Deeper analysis utilizing a set of variables including, among others, gender, number of years of teaching experience, and size of school district produced 
more specific information about various segments of the teaching population. These variables and attributes are examined thoroughly in Chapter IV. 


\section{CHAPTER IV}

\section{DATA ANALYSIS}

This chapter contains more specific information about the target population used in the study, the instruments used in the study and the data generated by the process used to validate the instruments. In addition, a thorough analysis of data generated by the study is presented (see Appendix C for complete code book information). The orientation toward "professional growth and development" of study respondents is closely examined for differences based on variables, including years of teaching experience, size of school district, and percentage of household income attributable to individual salary, and on attributes such as major work assignment and gender. Other variables, such as grade level assignment, potential for mobility on the salary schedule, and highest degree earned, are used for ancillary or supportive data analysis.

\section{TARGET POPULATION}

As the data gathered in this study are reviewed and analyzed, it is important to examine the target population used in this study. In order to completely understand the results of the data analysis, the reader must have a 
thorough understanding of the individuals whe responded to the instruments used for data gathering purposes. It is also important to consider the population of teachers who did not respond to the study questionnaire. Since there was a sizable non-response rate, the study results may reflect the characteristics of the respondents compared to the non-respondents. While questions about the motivational profile of the non-respondents arose, no effort was made in this study to address those concerns.

The analysis unit considered for this research was comprised of all teachers, kindergarten through twelfth grade, in the state of Washington during the school year 1986-1987. In order to probe more closely into the analysis unit, the following set of variables were examined in the study: a) years of certificated public school teaching experience, b) proportion of household income attributable to individual salary, (c) grade level assignment, and d) size of school district. Additionally, the attributes considered in the data analysis were: a) gender; b) highest earned degree (level of academic training), c) major work assignment, d) potential for mobility on salary schedule. Tables IX through XVI summarize the set of characteristics of the analysis unit examined in this study.

A total of 939 kindergarten through twelfth grade teachers from Washington state, out of a potential 2,000 originally surveyed, responded to the study instruments. The number of non-responses was 1,061. Of the 939 
surveys returned, 770 were valid, 49 were returned blank, 36 were undeliverable due to incorrect addresses, and 84 were incomplete or had other problems rendering them invalid. The data analysis, therefore, was based on a valid response rate of $39 \%$ (see Figure 11).

TABLE IX

YEARS OF FULL-TIME PUBLIC SCHOOL EXPERIENCE OF STUDY RESPONDENTS

\begin{tabular}{|c|c|c|c|c|c|}
\hline $\begin{array}{l}\text { YEARS OF } \\
\text { TEACHING }\end{array}$ & FREQUENCY & $\%$ & $\begin{array}{l}\text { YEARS OF } \\
\text { TEACHING }\end{array}$ & |FREQUENCY & $\%$ \\
\hline 0 & 6 & 0.8 & 20 & 36 & 4.7 \\
\hline 1 & 16 & 2.1 & 21 & 24 & 3.1 \\
\hline 2 & 18 & 2.3 & 22 & 14 & 1.8 \\
\hline 3 & 23 & 3.1 & 23 & 15 & 1.9 \\
\hline 4 & 21 & 2.7 & 24 & 21 & 2.7 \\
\hline 5 & 25 & 3.2 & 25 & 22 & 2.9 \\
\hline 6 & 24 & 3.1 & 26 & 9 & $\overline{1.2}$ \\
\hline 7 & 31 & 4.1 & 27 & 16 & 2.1 \\
\hline 8 & 27 & 3.5 & 28 & 13 & 1.7 \\
\hline 9 & 26 & 3.4 & 29 & 4 & 0.5 \\
\hline 10 & 39 & 5.1 & 30 & 13 & 1.7 \\
\hline 11 & 23 & 3.1 & 31 & 3 & $\overline{0.4}$ \\
\hline 12 & 36 & 4.7 & 32 & 6 & 0.8 \\
\hline 13 & 34 & 4.4 & 33 & 5 & $\overline{0.6}$ \\
\hline 14 & 42 & 5.5 & 34 & 3 & 0.4 \\
\hline 15 & 40 & 5.2 & 36 & 1 & 0.1 \\
\hline 16 & 35 & 4.5 & 37 & 1 & 0.1 \\
\hline 17 & 34 & 4.4 & 39 & 2 & 0.3 \\
\hline 18 & 29 & 3.8 & 41 & 1 & 0.1 \\
\hline \multirow[t]{2}{*}{19} & 30 & & NR & 2 & 0.3 \\
\hline & & & Total & 770 & $100 \%$ \\
\hline $\begin{array}{l}\text { Mean } 1 \\
\text { Varlance } 7 \\
\text { Std }\end{array}$ & $\begin{array}{l}14.895 \\
9.241 \\
8.902\end{array}$ & $\begin{array}{c}.321 \\
1.824\end{array}$ & & & \\
\hline
\end{tabular}


TABLE $X$

GENDER BREAKOUT OF STUDY

RESPONDENTS

\begin{tabular}{|l|r|r|}
\hline GENDER & Frequency & Percentage \\
\hline Female & 494 & 64.2 \\
\hline Male & 275 & 35.7 \\
\hline Missing Cases & 1 & 0.1 \\
\hline TOTAL & 770 & 100 \\
\hline
\end{tabular}

TABLE XI

MAJOR WORK ASSIGNMENT OF STUDY RESPONDENTS

\begin{tabular}{|l|r|r|}
\hline MAJOR WORK ASSIGNMENT & Frequency & Percentage \\
\hline Regular Classroom Teacher & 531 & 69.0 \\
\hline Teaching Specialist & 99 & 12.9 \\
\hline Special Education Teacher & 62 & 8.1 \\
\hline Certificated Support & 61 & 7.9 \\
\hline Other & 14 & 1.8 \\
\hline Missing Cases & 3 & 0.4 \\
\hline TOTAL & 770 & $100 \%$ \\
\hline
\end{tabular}


TABLE XII

HIGHEST DEGREE RECEIVED BY STUDY RESPONDENTS

\begin{tabular}{|l|r|r|}
\hline HIGHEST DEGREE & Frequency & Percentage \\
\hline Vocational Degree & 10 & 1.3 \\
\hline Bachelors Degree & 417 & 54.2 \\
\hline Masters Degree & 319 & 41.4 \\
\hline Doctorate Degree & 14 & 1.8 \\
\hline Other & 8 & 1.0 \\
\hline Missing Cases & 2 & 0.3 \\
\hline TOTAL & 770 & $100 \%$ \\
\hline
\end{tabular}

TABLE XIII

SALARY SCHEDULE MOBILITY OF STUDY RESPONDENTS

\begin{tabular}{|l|r|r|}
\hline SALARY SCHEDULE & Frequency & Percentage \\
\hline Yes-More Experience & 311 & 40.4 \\
\hline Yes-Only Educational & 184 & 23.9 \\
\hline Yes-Only Experience & 53 & 6.9 \\
\hline No-Can Not Move & 213 & 27.7 \\
\hline Do Not Know/Not Sure & 7 & 0.9 \\
\hline Missing Cases & 2 & 0.3 \\
\hline TOTAL & 770 & $100 \%$ \\
\hline
\end{tabular}


TABLE XIV

PERCENTAGE OF HOUSEHOLD INCOME DERIVED FROM SCHOOL DISTRICT SALARY

\begin{tabular}{|l|r|r|}
\hline $\begin{array}{l}\text { PERCENTAGE OF } \\
\text { HOUSEHOLD } \\
\text { INCOME }\end{array}$ & Frequency & Percentage \\
\hline 100 & 202 & 26.2 \\
\hline $75-99$ & 133 & 17.3 \\
\hline $50-74$ & 255 & 33.1 \\
\hline $25-49$ & 157 & 20.4 \\
\hline Less Than 25 & 20 & 2.6 \\
\hline Missing Cases & 3 & 0.4 \\
\hline TOTAL & 770 & $100 \%$ \\
\hline
\end{tabular}

TABLE XV

GRADE LEVEL ASSIGNMENT OF STUDY RESPONDENTS

\begin{tabular}{|l|r|r|}
\hline GRADE LEVEL & Frequency & Percentage \\
\hline Elementary/Primary & 355 & 46.1 \\
\hline Middle/Junior High & 162 & 21.1 \\
\hline High School & 209 & 27.1 \\
\hline Combination of Level & 38 & 4.9 \\
\hline Not Applicable & 3 & 0.4 \\
\hline Missing Cases & 3 & 0.4 \\
\hline TOTAL & 770 & $100 \%$ \\
\hline
\end{tabular}


TABLE XVI

PUPIL ENROLLMENT IN THE DISTRICT

\begin{tabular}{|l|r|r|}
\hline PUPILS & Frequency & Percentage \\
\hline Small - 2000 or less & 141 & 18.3 \\
\hline Medium - 2001 to & 317 & 41.2 \\
\hline Large - 10,000 or & 271 & 35.2 \\
\hline Do Not Know/Not & 31 & 4.0 \\
\hline Missing Cases & 10 & 1.3 \\
\hline Valid Cases & 760 & 98.7 \\
\hline TOTAL & 770 & $100 \%$ \\
\hline
\end{tabular}

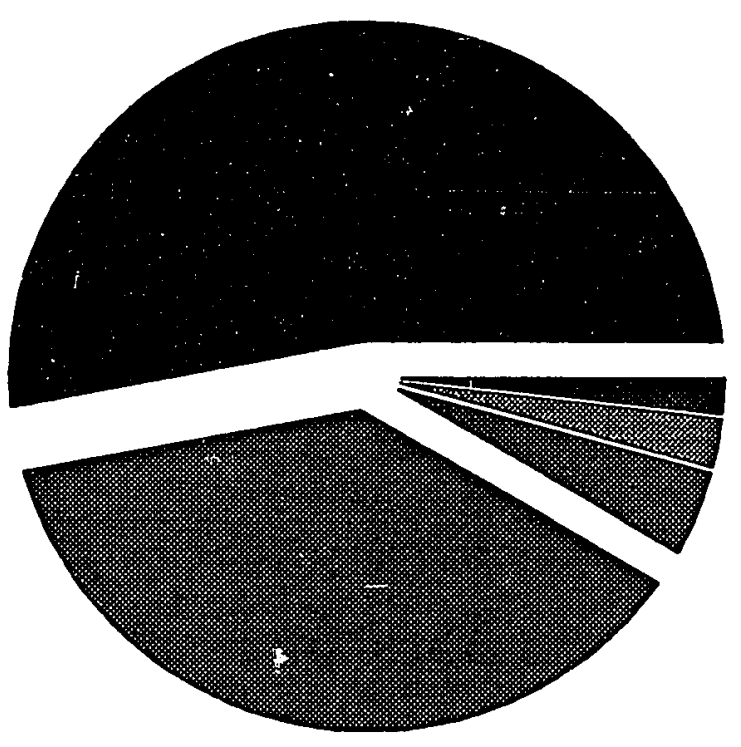

Non-responses 106

Valid Returms 770

Retumsw/Prob. 84

Blank Retums 49

Postal Returms 36

Figure 11. Disposition of mailed survey inventories $(2,000$ surveys mailed). 
Of the demographic variables, years of full-time public school experience was used to divide the sample into four categories for further analysis (see Table XVII). Teachers with zero to eight years of teaching experience were grouped together to represent one segment of the teaching population which was described as relative "newcomers" to the profession for purposes of this study. One hundred ninety-one or $24.8 \%$ of the total respondents fell into this category. Those individuals with 9 to 16 years of teaching experience numbered 275 and represented $35.7 \%$ of the total valid response sample. This group has been described as "established professionals." Responding teachers with 17 to 24 years of full-time public school experience, called "veteran teachers," comprised $26.4 \%$ (203) of the total population. Respondents with 25 or more years of teaching experience numbered 99 and represented $12.9 \%$ of the total. These individuals have been deemed "career teachers."

TABLE XVII

YEARS OF FULL TIME PUBLIC SCHOOL EXPERIENCE: EIGHT YEAR CATEGORIES

\begin{tabular}{|l|r|c|}
\hline YEARS OF & Frequency & Percentage \\
\hline TEACHING & 191 & 24.8 \\
\hline 0 through 8 & 275 & 35.7 \\
\hline 9 through 16 & 203 & 26.4 \\
\hline 17 through 24 & 99 & 12.9 \\
\hline 25 or more & 2 & .3 \\
\hline No response & 770 & $100 \%$ \\
\hline TOTAL Valid Cases & & \\
\hline
\end{tabular}


These four categories are useful units of analysis for further scrutiny of the data generated by the study. Additionally, these subsample sizes allowed a greater confidence level than a breakdown into smaller subsample sizes would have provided. According to McCall (1982), "the more combining [of subgroups] that can be done without disturbing the essential needs of the study, the more savings will accrue in terms of sample size requirements" (p. 207).

The population being sampled, Washington state teachers, was comprised of approximately $60 \%$ females and $40 \%$ males at the time this study was conducted (see Table VI, Chapter III). Table XVIII indicates that the sample generated by this study was $64.1 \%$ female and $35.9 \%$ male. The subgroupings discussed above with the added dimension of gender are displayed in Table XVIII.

Other noteworthy characteristics of the study respondents included the following facts:

- Nearly $70 \%$ had regular classroom teaching assignments

- $\quad 54 \%$ had bachelor's degrees

- $\quad 41 \%$ had master's degrees

- Approximately $2 \%$ had doctorate degrees

- $64 \%$ still qualified for incremental movement on the salary schedule based on experience and education

- $43 \%$ attributed $75 \%$ or more of their total household 
income to their school district salary

- $46 \%$ were elementary school teachers

- $\quad 21 \%$ taught middle or junior high school

- $\quad 27 \%$ were high school teachers

- $18 \%$ taught in "small" school districts of 2,000 or

fewer students

- $\quad 41 \%$ taught in "medium-sized" school districts with between 2,000 and 10,000 students

- $\quad 35 \%$ taught in "large" school districts of more than 10,000 students.

TABLE XVIII

GENDER BY FULL-TIME PUBLIC

SCHOOL EXPERIENCE

\begin{tabular}{|l|r|r|r|r|r|c|}
\hline \multicolumn{6}{|c|}{ TEACHING (YRS) } \\
\hline GENDER & \multicolumn{1}{|c|}{$0-8$} & $9-16$ & $17-24$ & $25+$ & $\begin{array}{l}\text { Row } \\
\text { Total }\end{array}$ & $\%$ \\
\hline Female & 140 & 193 & 117 & 42 & 492 & 64.1 \\
\hline Male & 50 & 82 & 86 & 57 & 275 & 35.9 \\
\hline Column Total & 190 & 275 & 203 & 99 & 767 & $100 \%$ \\
\hline Percentage & 24.8 & 35.9 & 26.5 & 12.9 & $100 \%$ & \\
\hline
\end{tabular}




\section{COMPOSITE PICTURE OF TOTAL RESPONDENTS}

One major focus of this study was the measurement of the relative strength of various needs, incentives or motivators in influencing teachers to participate in staff development activities. As previously explained, the analysis unit considered for the research was comprised of all teachers, kindergarten through twelfth grade in the state of Washington during the time period, 1986-1987. The responses of this group, as a whole, to the Staff Development Motivation Profile are depicted in Figure 12. The scores used to create this profile consisted of the mean scores generated by the Staff Development Motivation Profile as shown in Table IV, Chapter III (Basic $=55.4$; Security $=$ 51.7; Social $=63.3 ;$ Status $=54.3 ;$ Self-Actualization $=75.4$ ). In order to plot these scores on a graph which can be compared to the model instrument (Hall-Williams Work Motivation Inventory [Hall \& Williams, 1967]), the scores were multiplied by a weighted factor of 2 , since the model instrument consisted of 60 questions, and the Staff Development Motivation Profile consisted of 30 questions.

Figure 12 is a visual representation of the relative scale, produced by the Staff Development Motivation Profile, that measures each need category against the remaining four. The needs that emerge most strongly can be said to have "won out" when pitted against other need systems of lesser concern to the teacher. The peaks and valleys (the satisfied and unsatisfied sources of 
motivation) combine to yield a picture of the teachers' total incentive orientation toward participating in staff development activities. The highest points reflect those need systems that are least satisfied and that are of most concern to the individual.

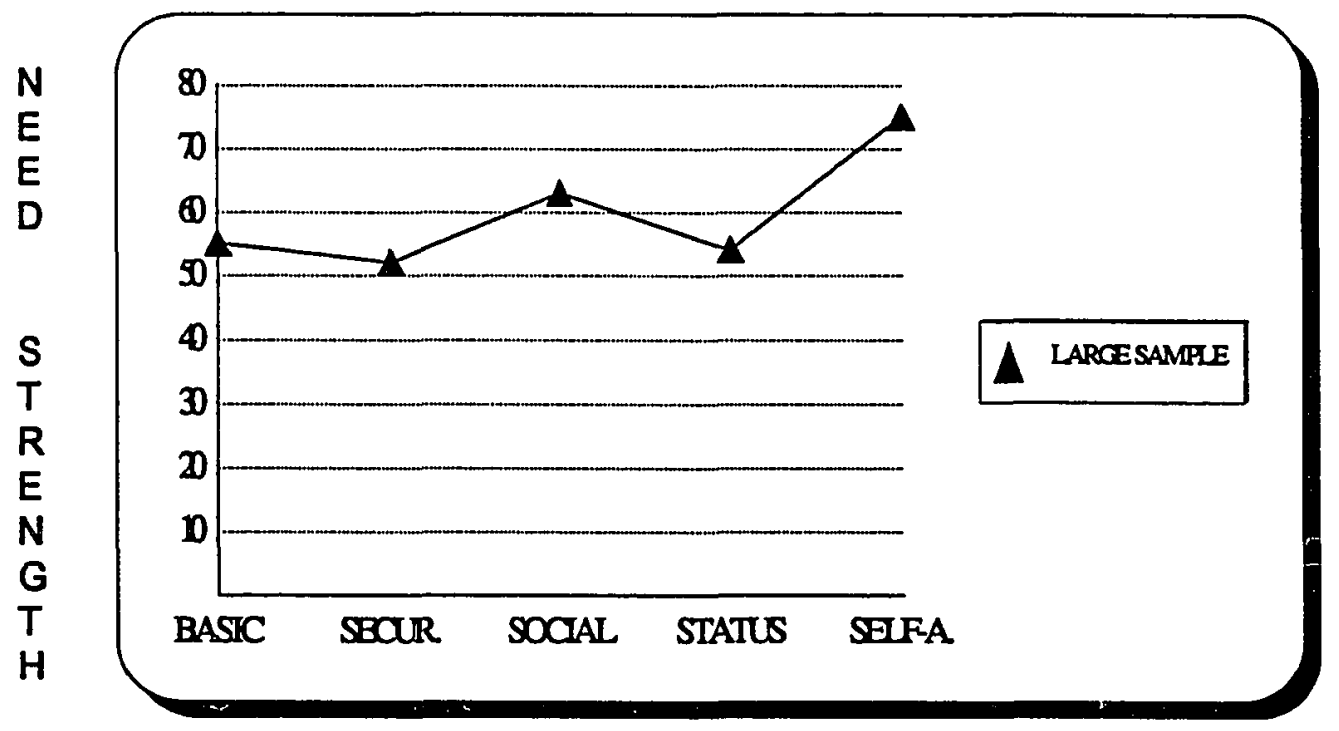

Figure 12. Staff Development Motivation Profile (large sample).

In the profile depicted in Figure 12, which represents a composite of all the teachers responding to the survey instrument, it is obvious that the highest peaks and potentially the greatest sources of motivation are the Self-Actualization and Social needs. This suggests that the major reasons that teachers in this survey had as their impetus for participating in staff development activities were their own personal Self-Actualization needs and their Social 
needs. While both the Social Needs and Self-Actualization Needs are high, note that the Self-Actualization score is by far the highest. This finding indicates that the teachers in this sample were prompted to continue their professional development primarily for the intrinsic motivation of self-actualization. The importance of intrinsic motivators for teachers is supported by research previously conducted by Lortie (1969, 1975), McPherson (1972), Jackson (1968) and others. Additionally, research conducted by George (1986) and Lambert (1989) emphasizes that one of the major attractions of staff development, as reported by teachers, has been the opportunity to socialize and interact with other teachers.

The lower Basic and Status scores would lead one to conclude that teachers in this study sought neither additional pay nor increased status primarily when considering whether or not to pursue professional development activities. The relatively low Security score implies that this group of teachers did not feel that the continuance of their positions depended on their further participation in staff development. Before making absolute statements, however, it is important to keep in mind that the Staff Development Motivation Profile yields a series of relative scores that must be considered in relationship to each other rather than in comparison to any absolute numbers. 


\section{IMPACT OF VARIABLES ON INCENTIVE STRUCTURES}

Another major question asked in this study was how the incentive structures of teachers differ based on the following variables:

- gender

- number of years of teaching experience

- major work assignment

- highest degree earned

- potential for mobility on district salary schedule

- proportion of household income attributable to salary

- grade level assignment

- size of school district (pupil enrollment)

In a study to determine which organizational incentives help retain teachers within the profession, Bredeson et al. (1983) hypothesized that teachers would respond differently to various organizational incentives based on gender and years of teaching experience.

In order to identify the demographic variables having the most impact on the incentive structures of the teachers, a series of multiple regressions were conducted to isolate the variables that might best predict variance within the need categories. The need categories were treated as dependent variables, while the independent variables consisted of the demographic questions. Years 
of teaching experience was treated as a ratio variable and the other demographic data as class variables.

The multiple regressions were conducted in order to determine the percentage of variance predictable in the dependent variable by each independent variable uniquely and separately from the other independent variables. In this analysis, the focus was on the ability of any one independent variable to predict variance above and beyond all the other independent variables in the equation. The results of this analysis are depicted for each need category in Tables XIX through XXIII.

Table XIX, representing the category of Basic Needs, indicates that both Work Assignment and Size of School District (Pupil Enrollment) predicted unique and independent variance in basic needs at the $\underline{p}=.05$, or lesser, level of significance. In order to calculate the percentage of variance in basic needs predicted by these two variables, the type III sum of squares was divided by the corrected total sum of squares. Thus, Work Assignment predicted $1 \%$ of the variance (Type III SS $845.4733 /$ Corr. SS $58958.33=1.4$ ), pupil enrollment predicted $2.6 \%$ of the variance (1529.43/58959.33). None of the other variables predicted variance in basic needs at the .05 level of significance.

For the category of Security Needs (Table $X X$ ), there was no variable that predicted a significant amount of variance. The two areas approximating 
significance, however, were Pupil Enrollment (Size of School District) and Proportion of Family Income Attributable to Salary.

TABLE XIX

VARIABLES PREDICTING VARIANCE IN

BASIC NEEDS

\begin{tabular}{|r|r|r|r|r|r|}
\hline SOURCE & \multicolumn{1}{|c|}{ DF } & SUM & MEAN & F & PR>F \\
\hline Model & 25 & $3,486.3$ & 139.45 & 1.83 & 0.01 \\
\hline Error & 727 & & 76.3 & & \\
\hline Corr. Total & 752 & $58,959.3$ & & & \\
\hline & & & & & \\
\hline & & & & & \\
\hline SOURCE & DF & TYPE III & MEAN & F VALUE & PR>E \\
\hline Years & 1 & 60.96 & 60.96 & 0.80 & 0.37 \\
\hline Gender & 1 & 240.06 & 240.06 & 3.15 & 0.08 \\
\hline Work & 4 & 845.47 & 211.37 & 2.77 & 0.03 \\
\hline Degree & 4 & 123.42 & 30.86 & 0.40 & 0.81 \\
\hline Salary & 4 & 664.23 & 166.06 & 2.18 & 0.07 \\
\hline & 4 & 114.31 & 28.58 & 0.37 & 0.83 \\
\hline & 4 & 66.28 & 16.57 & 0.22 & 0.93 \\
\hline & 3 & $1,529.43$ & 509.81 & 6.68 & 0 \\
\hline
\end{tabular}

An examination of the Social Needs category (Table XXI) indicates that only Pupil Enrollment (Size of School District) predicted unique and independent variance at the $\mathrm{Q}=.05$ level of significance. The percentage of variance predicted by Pupil Enrollment was $1.7 \%$ (Type III SS/Corr SS).

Within the Status Needs category (Table XXII), the only variable that predicted variance at the .05 , or lesser, level of significance was Work 
Assignment. The percentage of variance predicted by this variable was $1.8 \%$ (491.16/27242.63).

TABLE XX

VARIABLES PREDICTING VARIANCE IN SECURITY NEEDS

\begin{tabular}{|c|c|c|c|c|c|}
\hline SOURCE & DF & $\begin{array}{c}\text { SUM } \\
\text { SQUARES }\end{array}$ & $\begin{array}{c}\text { MEAN } \\
\text { SQUARE }\end{array}$ & FVALUE & $P R>E$ \\
\hline Model & 25 & $1,235.75$ & 49.43 & 1.32 & 0.14 \\
\hline Error & 727 & $27,176.00$ & 37.38 & & \\
\hline Corr. Total & 752 & $28,412.00$ & & & \\
\hline & R-SQUARE & c.V. & ROOT MSE & $\begin{array}{c}\text { SAFETY } \\
\text { Mean }\end{array}$ & \\
\hline & 0.04 & 23.67 & 6.11 & 25.83 & \\
\hline SOURCE & DF & TYPE III SS & $\begin{array}{l}\text { MEAN } \\
\text { SQUARE }\end{array}$ & E VALUE & $P R>E$ \\
\hline Years & $\overline{1}$ & 0.50 & 0.50 & 0.01 & 0.91 \\
\hline Gender & $\overline{1}$ & 13.20 & 13.20 & 0.35 & 0.55 \\
\hline Work & $\overline{4}$ & 151.56 & 37.89 & 1.01 & 0.40 \\
\hline Degree & 4 & 170.05 & 42.51 & 1.14 & 0.34 \\
\hline Salary & $\overline{4}$ & 39.71 & 9.93 & 0.27 & 0.90 \\
\hline Income & 4 & 314.3 & 78.58 & 2.10 & 0.08 \\
\hline Grade & 4 & 65.57 & 16.39 & 0.44 & 0.78 \\
\hline Pupils & 3 & 271.78 & 90.59 & 2.42 & 0.06 \\
\hline
\end{tabular}

Finally, in the category of Self Actualization, Table XXIII indicates that once again only Size of School District (Pupil Enrollment) predicted a significant amount of variance. The percentage of variance predicted by Pupil Enrollment in this instance was $1.1 \%$ (Type III SS/ Corr SS).

Overall, the percentages of variance predicted by the independent variables (demographic data) are very small. This might indicate that none of 
the demographic questions asked in the study were key to understanding the differences among groups of teachers in their responses to the questionnaire. It could also indicate that teachers, regardless of gender, years of teaching experience, and the other variables identified, have the same feelings about the factors that motivate them to participate in staff development activities.

TABLE XXI

VARIABLES PREDICTING VARIANCE IN SOCIAL NEEDS

\begin{tabular}{|c|c|c|c|c|c|}
\hline SOURCE & DF & $\begin{array}{c}\text { SUM } \\
\text { SQUARES }\end{array}$ & $\begin{array}{l}\text { MEAN } \\
\text { SQUARE }\end{array}$ & F VALUE & $P R>E$ \\
\hline Model & 25 & $2,250.11$ & 90 & 1.67 & 0.02 \\
\hline Error & 727 & $39,104,00$ & 53.79 & & \\
\hline Corr. Total & 752 & $41,353.66$ & & & \\
\hline & R-SQUARE & C.V. & ROOT MSE & $\begin{array}{c}\text { SOCIAL } \\
\text { Mean }\end{array}$ & \\
\hline & 0.05 & 23.14 & 7.33 & 31.69 & \\
\hline SOURCE & DF & TYPE III SS & $\begin{array}{l}\text { MEAN } \\
\text { SQUARE }\end{array}$ & F VALUE & PR>F \\
\hline Years & 1 & 76.09 & 76.09 & 1.41 & 0.23 \\
\hline Gender & 1 & 65.67 & 65.67 & 1.22 & 0.27 \\
\hline Work & 4 & 170.18 & 42.55 & 0.79 & $\overline{0.53}$ \\
\hline Degree & 4 & 449.10 & 112.27 & 2.09 & 0.08 \\
\hline Salary & 4 & 295.20 & 73.80 & 1.37 & 0.24 \\
\hline Income & 4 & 276.61 & 69.15 & 1.29 & 0.27 \\
\hline Grade & 4 & 127.35 & 31.84 & 0.59 & 0.67 \\
\hline Pupils & 3 & 698.85 & 232.95 & 4.33 & 0.00 \\
\hline
\end{tabular}

There was, however, a slight pattern to the variables that surfaced as making a slight difference. In the five instances where significant variance was accounted for, Major Work Assignment appeared three times and Pupil 
Enrollment (size of school district) appeared twice. These variables were the only significant predictors of variance.

TABLE XXII

VARIABLES PREDICTING VARIANCE IN STATUS NEEDS

\begin{tabular}{|r|r|r|r|r|r|}
\hline SOURCE & DF & $\begin{array}{r}\text { SUM } \\
\text { SQUARES }\end{array}$ & $\begin{array}{c}\text { MEAN } \\
\text { SQUARE }\end{array}$ & F VALUE & PR>E \\
\hline Model & 25 & $1,479.26$ & 59.17 & 1.67 & 0.02 \\
\hline Error & 727 & $25,763.00$ & 35.44 & & \\
\hline Corr. Total & 752 & $27,242.64$ & & & \\
\hline & R-SQUARE & C.V. & ROOT MSE & $\begin{array}{c}\text { STATUS } \\
\text { Mean }\end{array}$ & \\
\hline SOURCE & DF & 21.93 & 5.95 & 27.15 & \\
\hline Years & 1 & TYPE III SS & MEAN & F VALUE & \multicolumn{1}{|c|}{ PR>E } \\
\hline Gender & 1 & 4.76 & 4.76 & 0.13 & 0.71 \\
\hline Work & 4 & 491.16 & 122.79 & 3.46 & 0.01 \\
\hline Degree & 4 & 73.53 & 18.38 & 0.52 & 0.72 \\
\hline Salary & 4 & 191.91 & 47.98 & 1.35 & 0.25 \\
\hline Income & 4 & 289.83 & 72.46 & 2.04 & 0.09 \\
\hline Grade & 4 & 142.22 & 35.56 & 1.00 & 0.41 \\
\hline Pupils & 3 & 40.77 & 13.59 & 0.38 & 0.76 \\
\hline
\end{tabular}

In order to further isolate specific sub-groups of teachers for additional study, cross-tabulations by gender were run for all the remaining demographic variables. See Tables XXIV through XXIX. 
TABLE XXIII

VARIABLES PREDICTING VARIANCE IN SELF-ACTUALIZATION NEEDS

\begin{tabular}{|r|r|r|r|r|r|}
\hline SOURCE & DF & $\begin{array}{c}\text { SUM } \\
\text { SQUARES }\end{array}$ & $\begin{array}{c}\text { MEAN } \\
\text { SQUARE }\end{array}$ & \multicolumn{1}{l|}{ E VALUE } & \multicolumn{1}{l|}{ PR>E } \\
\hline Model & 25 & $1,048.21$ & 41.93 & 1.09 & 0.35 \\
\hline Error & 727 & $28,054.00$ & 38.59 & & \\
\hline Corr. Total & 752 & $29,102.00$ & & & \\
\hline & R-SQUARE & C.V. & ROOT MSE & $\begin{array}{c}\text { ACTUAL } \\
\text { Mean }\end{array}$ & \\
\hline & 0.04 & 16.49 & 6.21 & 37.67 & \\
\hline SOURCE & DF & TYPE III SS & SQUARE & F VALUE & PR>E \\
\hline Years & 1 & 3.90 & 3.90 & 0.10 & 0.75 \\
\hline Gender & 1 & 24.74 & 24.74 & 0.64 & 0.42 \\
\hline Work & 4 & 84.47 & 21.12 & 0.55 & 0.70 \\
\hline Degree & 4 & 103.26 & 25.82 & 0.67 & 0.61 \\
\hline Salary & 4 & 288.29 & 72.07 & 1.87 & 0.11 \\
\hline Income & 4 & 96.68 & 24.17 & 0.63 & 0.64 \\
\hline Grade & 4 & 11.78 & 2.94 & 0.08 & 0.99 \\
\hline Pupils & 3 & 317.78 & 105.93 & 2.75 & 0.04 \\
\hline
\end{tabular}

The information gathered through these procedures was utilized to guide the further study of subcategories of respondents and the profiles produced by their mean scores. The following variables were selected for more in-depth scrutiny: Gender, Years of Teaching Experience, Major Work Assignment, Pupil Enrollment (Size of School District), and Proportion of Household Income Attributable to School District Salary. 
TABLE XXIV

GENDER BY MAJOR WORK ASSIGNMENT

\begin{tabular}{|l|r|r|r|r|r|r|r|}
\hline GENDER & $\begin{array}{c}\text { Reg. } \\
\text { Class }\end{array}$ & $\begin{array}{l}\text { Teach } \\
\text { Spec. }\end{array}$ & $\begin{array}{c}\text { Spec. } \\
\text { Ed. }\end{array}$ & $\begin{array}{c}\text { Cert. } \\
\text { Supp. }\end{array}$ & Other & $\begin{array}{l}\text { ROW } \\
\text { Total }\end{array}$ & $\%$ \\
\hline Female & 340 & 63 & 42 & 40 & 7 & 492 & 64.1 \\
\hline Male & 191 & 36 & 20 & 21 & 7 & 275 & 35.9 \\
\hline COL.Total & 531 & 99 & 62 & 61 & 14 & 767 & $100 \%$ \\
\hline$\%$ & 69.2 & 12.9 & 8.1 & 8.0 & 1.8 & $100 \%$ & \\
\hline
\end{tabular}

TABLE XXV

GENDER BY HIGHEST DEGREE RECEIVED

\begin{tabular}{|l|r|r|r|r|r|r|c|}
\hline GENDER & $\begin{array}{l}\text { Voc. } \\
\text { Deg. }\end{array}$ & $\begin{array}{l}\text { Bach. } \\
\text { Deg. }\end{array}$ & $\begin{array}{l}\text { Mast. } \\
\text { Deg. }\end{array}$ & $\begin{array}{l}\text { Doct. } \\
\text { Deg. }\end{array}$ & Other & $\begin{array}{l}\text { ROW } \\
\text { Total }\end{array}$ & $\%$ \\
\hline Female & 10 & 303 & 169 & 6 & 6 & 494 & 64.3 \\
\hline Male & 0 & 114 & 150 & 8 & 2 & 274 & 35.7 \\
\hline COL.Total & 10 & 417 & 319 & 14 & 8 & 768 & $100 \%$ \\
\hline$\%$ & 1.3 & 54.3 & 41.5 & 1.8 & 1.0 & $100 \%$ & \\
\hline
\end{tabular}


TABLE XXVI

GENDER BY SALARY SCHEDULE MOBILITY

\begin{tabular}{|l|r|r|r|r|r|r|r|}
\hline GENDER & $\begin{array}{l}\text { Yes- } \\
\text { Educ. } \\
\text { \& Exp. }\end{array}$ & $\begin{array}{l}\text { Yes- } \\
\text { Educ. } \\
\text { Only }\end{array}$ & $\begin{array}{l}\text { Yes- } \\
\text { Exp. } \\
\text { Only }\end{array}$ & $\begin{array}{l}\text { No- } \\
\text { Can't } \\
\text { Move }\end{array}$ & $\begin{array}{l}\text { Don't } \\
\text { Know }\end{array}$ & $\begin{array}{l}\text { Row } \\
\text { Total }\end{array}$ & \multicolumn{1}{c|}{$\%$} \\
\hline Female & 229 & 110 & 41 & 109 & 4 & 493 & 64.2 \\
\hline Male & 82 & 74 & 12 & 104 & 3 & 275 & 35.8 \\
\hline COL.Total & 311 & 184 & 53 & 213 & 7 & 768 & $100 \%$ \\
\hline Percent & 40.5 & 24.0 & 6.9 & 27.7 & .9 & $100 \%$ & \\
\hline
\end{tabular}

TABLE XXVII

GENDER BY PERCENTAGE OF HOUSEHOLD INCOME DERIVED FROM SCHOOL DISTRICT SALARY

\begin{tabular}{|l|r|r|r|r|r|r|c|}
\hline GENDER & $100 \%$ & $75-99 \%$ & $50-74 \%$ & $25-49 \%$ & $0-24 \%$ & $\begin{array}{r}\text { ROW } \\
\text { Total }\end{array}$ & $\%$ \\
\hline Female & 121 & 54 & 157 & 142 & 18 & 492 & 64.1 \\
\hline Male & 81 & 79 & 98 & 15 & 2 & 275 & 35.9 \\
\hline COL.Total & 202 & 133 & 255 & 157 & 20 & 767 & $100 \%$ \\
\hline$\%$ & 26.3 & 17.3 & 33.2 & 20.5 & 2.6 & $100 \%$ & \\
\hline
\end{tabular}


TABLE XXVIII

GENDER BY GRADE LEVEL ASSIGNMENT

\begin{tabular}{|l|r|r|r|r|r|r|l|}
\hline GENDER & $\begin{array}{r}\text { Elem/ } \\
\text { Primary }\end{array}$ & $\begin{array}{c}\text { Middlel } \\
\text { Junior }\end{array}$ & $\begin{array}{r}\text { High } \\
\text { School }\end{array}$ & Comb. & $\begin{array}{c}\text { Not } \\
\text { Appl. }\end{array}$ & $\begin{array}{l}\text { ROW } \\
\text { Total }\end{array}$ & $\%$ \\
\hline Female & 279 & 90 & 95 & 26 & 2 & 492 & 64.1 \\
\hline Male & 76 & 72 & 114 & 12 & 1 & 275 & 35.9 \\
\hline COL.Total & 355 & 162 & 209 & 38 & 3 & 767 & $100 \%$ \\
\hline$\%$ & 46.3 & 21.1 & 27.2 & 5.0 & .4 & $100 \%$ & \\
\hline
\end{tabular}

TABLE XXIX

GENDER BY PUPIL ENROLLMENT IN DISTRICT

\begin{tabular}{|l|r|r|r|r|r|c|}
\hline & $\begin{array}{l}\text { Small } \\
\leq 2000\end{array}$ & $\begin{array}{l}\text { Medium } \\
>2000 \\
\leq 10000\end{array}$ & $\begin{array}{l}\text { Large } \\
>10000\end{array}$ & $\begin{array}{l}\text { Don't } \\
\text { Know }\end{array}$ & $\begin{array}{l}\text { ROW } \\
\text { Total }\end{array}$ & \multicolumn{1}{c|}{$\%$} \\
\hline Female & 94 & 200 & 168 & 24 & 486 & 63.9 \\
\hline Male & 47 & 117 & 103 & 7 & 274 & 36.1 \\
\hline COL.Total & 141 & 317 & 271 & 31 & 760 & $100 \%$ \\
\hline$\%$ & 18.6 & 41.7 & 35.7 & 4.1 & $100 \%$ & \\
\hline
\end{tabular}




\section{Gender Differences}

When all males and females were compared on the five need categories utilizing $t$ tests, none of the results reached the .05 level of significance (see Table $X X X)$. A review of the $E$ values for each of the need categories indicated that there were not large differences between the variances of males and females. Since there were not significant differences in the separate variances, the pooled variance estimates were selected for examination. A further review of the pooled variance data in Table $X X X$ also failed to yield significance at the .05 or lesser level.

Figure 13 illustrates the profiles of all male and female teachers in the sample created by plotting their mean scores (multiplied by a weight factor of 2 in order to remain consistent with graphing techniques used earlier in the study). Note that the profiles are nearly identical to one another, and virtually the same as the composite profile shown in Figure 12. There were no significant gender differences from the previously reported composite results that indicated that the greatest sources of motivation were the self-actualization and social needs. Both male and female teachers have self-actualization as the highest need and both groups were prompted to continue their professional development primarily for the intrinsic motivation of self-actualization. Although it is not statistically significant, note that the Basic Need mean of males (56.9) was higher than that 
of females (54.4), while females have a slightly higher Social Need score (64) than males (62.2).

TABLE XXX

T-TESTS FOR INDEPENDENT SAMPLES OF GENDER BY NEEDS

\begin{tabular}{|c|c|c|c|c|c|c|c|c|c|c|}
\hline NEEDS & BASIC & & SECUR. & & SOCIAL & & STATUS & & SELF-AC. & \\
\hline GENDER & Female & Male & Female & Male & Female & Male & Femalo & Male & Female & Malo \\
\hline Number & 494 & 275 & 494 & 275 & 494 & 275 & 494 & 275 & 494 & 275 \\
\hline Mean & 27.22 & 28.45 & 25.97 & 25.62 & 32.00 & 31.09 & 27.04 & 27.32 & 37.77 & 37.53 \\
\hline Sid Dev & 8.94 & 8.68 & 6.17 & 6.05 & 7.48 & 7.20 & 6.01 & 5.95 & 6.16 & 6.45 \\
\hline Std ErT & 0.40 & 0.52 & 0.28 & 0.37 & 0.38 & 0.43 & 0.27 & 0.36 & 0.28 & 0.39 \\
\hline F Value & 1.06 & 1.06 & 1.04 & 1.04 & 1.08 & 1.08 & 1.02 & 1.02 & 1.10 & 1.10 \\
\hline 2-tali P & 0.59 & 0.59 & 0.72 & 0.72 & 0.48 & 0.48 & 0.86 & 0.86 & 0.38 & 0.38 \\
\hline $\begin{array}{l}\text { Pool Var } \\
\text { T Value }\end{array}$ & -1.84 & -1.84 & 0.77 & 0.77 & 1.64 & 1.64 & -0.63 & -0.63 & 0.51 & 0.51 \\
\hline DF & 767 & 767 & 767 & 767 & 767 & 767 & 767 & 767 & 767 & 767 \\
\hline 2-tail P & 0.07 & 0.07 & 0.44 & 0.44 & 0.10 & 0.10 & 0.53 & 0.53 & 0.61 & 0.61 \\
\hline $\begin{array}{l}\text { Sep Var } \\
\text { T Value }\end{array}$ & -1.85 & -1.05 & 0.77 & 0.77 & 1.66 & 1.66 & -0.63 & -0.63 & 0.50 & 0.50 \\
\hline DF & 580.63 & 580.63 & 575.84 & 575.85 & 584.87 & 584.87 & 571.06 & 571.05 & 544.64 & 544.64 \\
\hline 2 -tall P & 0.06 & 0.50 & 0.44 & 0.44 & 0.10 & 0.10 & 0.53 & 0.53 & 0.62 & 0.62 \\
\hline
\end{tabular}




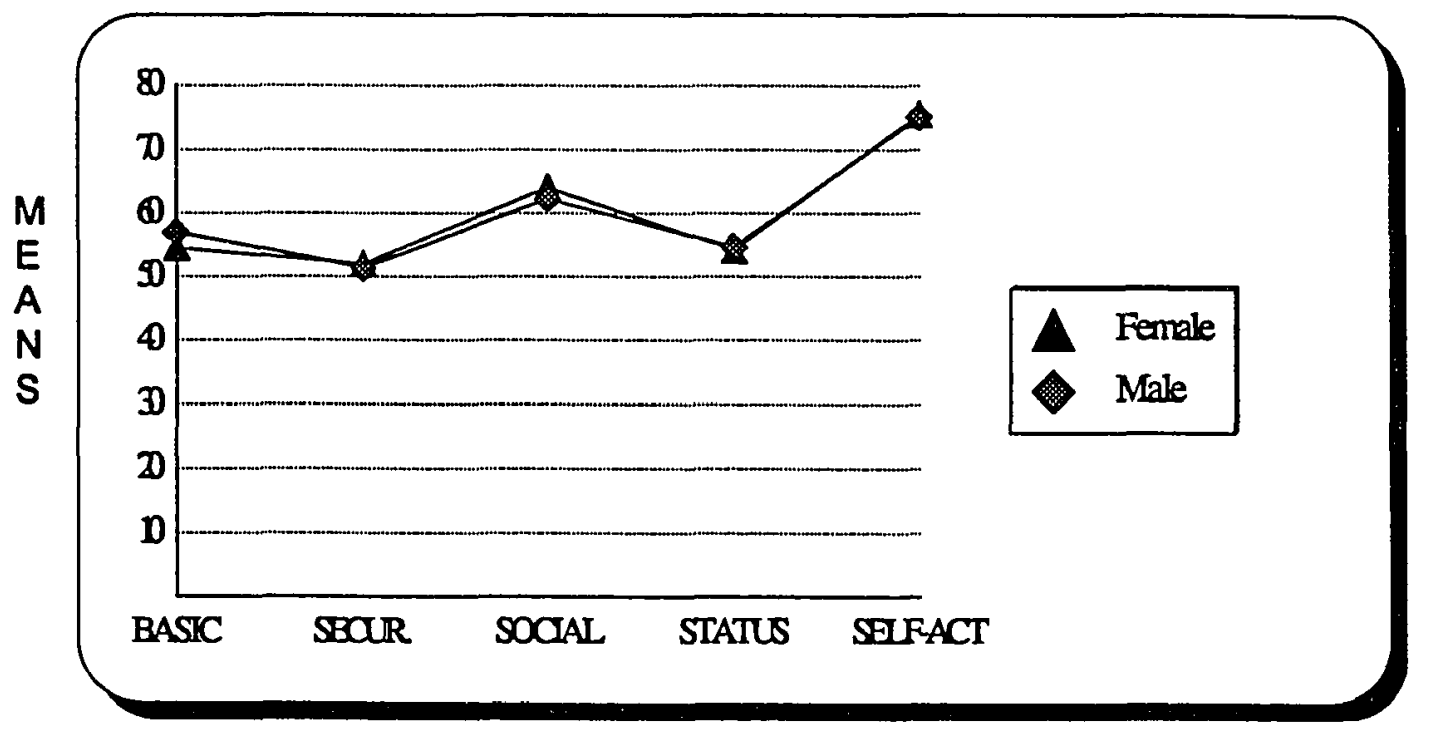

Figure 13. Total sample means by gender

\section{Gender by Years of Teaching Experience}

Since gender alone did not reveal significant differences in the needs category responses of sample participants, a further scrutiny of the data was made utilizing gender and the remaining variables previously selected for review (Years of Teaching Experience; Major Work Assignment; Pupil Enrollment; Proportion of Income Attributable to School District Salary). The first analysis conducted was of Gender by Years of Teaching Experience. Although the preliminary data analysis did not indicate that years of teaching experience yielded statistically significant differences, the possibility that adding gender as a second variable would make a difference was considered. In order to ascertain this possibility, a two way ANOVA was calculated for Gender by Years of Teaching Experience on All Need categories. 
As noted in Tables $X X X \mid$ through $X X X V$, years of full-time public school teaching experience were divided into four eight-year categories to facilitate analysis. Teachers with zero to eight years of teaching experience were grouped together to represent one segment of the teaching population. This group was described as "newcomers" to the profession. Those teachers with 9 to 16 years of teaching experience were described as "established professionals." The third group of teachers with 17 to 24 years of teaching experience was referred to as "veteran teachers." Teachers with 25 or more years of experience were considered "career teachers."

Results of the two-way ANOVAs showed only two significant main effects, Years on Basic Needs, $\mathrm{p}=.013$ and Years on Social Needs, $\mathrm{p}=.02$, and one significant interaction effect of Gender by Years on Basic Needs, $\mathrm{Q}=.027$ (see Tables $X X X \mid$ and $X X X \mid I I)$. Table $X X X \mid$ shows that the means for the four categories of experience (total population) differed very slightly from each other on Basic Needs (0-8 yrs. $=26.13,9-16$ yrs. $=28.63,17-24$ yrs. $=28.17,25+$ yrs . $=26.82)$. Groups two (9-16 years) and three (17-24 years), however, had somewhat higher mean scores in Basic Needs (28.63 and 28.17 respectively) than groups one (0-8 years) and four (25+ years). This indicates that the Basic Needs of the categories designated "established" and "veteran" teachers would more greatly influence their participation in Staff Development activities than the Basic Needs of the "newcomer" or "career" teachers. The effect size is weak, 
TABLE XXXI

ANALYSIS OF VARIANCE: GENDER BY FULL TIME PUBLIC SCHOOL EXFERIENCE ON BASIC NEEDS

\begin{tabular}{lr} 
TOTAL POPULATION & $27.65(767)$ \\
\hline Female & $27.21(492)$ \\
Male & $28.45(275)$ \\
YEARS OF EXPERIENCE & \\
\hline $0-8$ & $26.13(190)$ \\
$9-16$ & $28.63(275)$ \\
$17-24$ & $28.17(203)$ \\
$25+$ & $26.82(99)$
\end{tabular}

MEANS BY GENDER AND YEARS OF EXPERIENCE

\begin{tabular}{|l|r|r|r|r|}
\hline GENDER & $0-8$ yrs. & $9-16$ yrs. & $17-24$ yrs. & $25+$ yrs. \\
\hline Female & $25.70(140)$ & $28.85(193)$ & $26.40(117)$ & $26.95(42)$ \\
\hline Male & $27.32(50)$ & $28.11(82)$ & $30.57(86)$ & $26.72(57)$ \\
\hline
\end{tabular}

ANOVA - GENDER BY YEARS OF EXPERIENCE

\begin{tabular}{|l|r|r|r|r|r|}
\hline $\begin{array}{l}\text { SOURCE OF } \\
\text { VARIATION }\end{array}$ & SUm of Squares & DF & Mean Square & E & Slg of E \\
\hline Main Effects & 1.110 .38 & 4 & 277.6 & 3.61 & 0.01 \\
\hline GENDER & 282.8 & 1 & 282.8 & 3.67 & 0.06 \\
\hline YEARS & 840.05 & 3 & 280.02 & 3.64 & 0.01 \\
\hline 2-Way Interaction & 707.82 & 3 & 235.940 & 3.07 & 0.03 \\
\hline Explained & 1818.200 & 7 & 259.74 & 3.38 & 0 \\
\hline Residual & $58,415.55$ & 759 & 76.96 & & \\
\hline Total & 60.233 .75 & 766 & 78.63 & & \\
\hline
\end{tabular}


TABLE XXXII

ANALYSIS OF VARIANCE: GENDER BY FULL TIME PUBIC SCHOOL EXPERIENCE ON SECURITY NEEDS

\begin{tabular}{lr} 
TOTAL POPULATION & $25.85(767)$ \\
\hline Female & $25.98(492)$ \\
Male & $25.62(275)$ \\
YEARS OF EXPERIENCE & \\
\hline $0-8$ & $25.67(190)$ \\
$9-16$ & $15.96(275)$ \\
$17-24$ & $26.09(203)$ \\
$25+$ & $25.41(99)$
\end{tabular}

MEANS BY GENDER AND YEARS OF EXPERIENCE

\begin{tabular}{|l|c|c|c|c|}
\hline GENDER & $0-8$ yrs. & $9-16$ yrs. & $17-24$ yrs. & $25+$ yrs. \\
\hline Female & $25.69(140)$ & $26.37(193)$ & $25.95(117)$ & $25.29(42)$ \\
\hline Male & $25.62(50)$ & $24.99(82)$ & $26.29(86)$ & $25.51(57)$ \\
\hline
\end{tabular}

\section{ANOVA - GENDER BY EXPERIENCE}

\begin{tabular}{|l|r|r|r|r|r|}
\hline $\begin{array}{l}\text { SOURCE OF } \\
\text { VARIATION }\end{array}$ & Sum of Squares & DF & Mean Square & E & \multicolumn{1}{|c|}{ Slg ofE } \\
\hline Main Effects & 61.71 & 4 & 15.43 & 0.41 & 0.8 \\
\hline GENDER & 21.27 & 1 & 21.27 & 0.56 & 0.45 \\
\hline YEARS & 38.13 & 3 & 12.71 & 0.34 & 0.8 \\
\hline 2-Way Interaction & 96.33 & 3 & 32.11 & 0.85 & 0.47 \\
\hline Explained & 158.03 & 7 & 22.58 & 0.6 & 0.76 \\
\hline Residual & $28,624.32$ & 759 & 37.71 & & \\
\hline Total & $28,782.35$ & 766 & 37.58 & & \\
\hline
\end{tabular}


TABLE XXXIII

ANALYSIS OF VARIANCE: GENDER BY FULL TIME PUBLIC SCHOOL EXPERIENCE ON SOCIAL NEEDS

\begin{tabular}{lr} 
TOTAL POPULATION & $31.68(767)$ \\
\hline Female & $32.01(492)$ \\
Male & $31.09(275)$ \\
YEARS OF EXPERIENCE & \\
\hline $0-8$ & $33.01(190)$ \\
$9-16$ & $30.85(275)$ \\
$17-24$ & $31.43(203)$ \\
$25+$ & $31.93(99)$
\end{tabular}

MEANS BY GENDER AND YEARS OF EXPERIENCE

\begin{tabular}{|l|c|r|r|r|}
\hline GENDER & $0-8$ yrs. & $9-16$ yrs. & $17-24$ yrs. & $25+$ yrs. \\
\hline Female & $33.48(140)$ & $30.88(193)$ & $32.24(117)$ & $31.67(42)$ \\
\hline Male & $31.70(50)$ & $30.78(82)$ & $30.34(86)$ & $32.12(57)$ \\
\hline
\end{tabular}

ANOVA - GENDER BY EXPERIENCE

\begin{tabular}{|l|r|r|r|r|r|}
\hline $\begin{array}{l}\text { SOURCE OF } \\
\text { VARIATION }\end{array}$ & Sum of Squares & DF & Mean Square & E & \multicolumn{1}{|c|}{ Sig of E } \\
\hline Main Effects & 685.94 & 4 & 171.49 & 3.170 & 0.01 \\
\hline GENDER & 142.06 & 1 & 142.06 & 2.63 & 0.11 \\
\hline YEARS & 535.69 & 3 & 178.56 & 3.3 & 0.020 \\
\hline 2-Way Interaction & 159.43 & 3 & 53.14 & 0.98 & 0.400 \\
\hline Explained & 845.36 & 7 & 120.77 & 2.23 & 0.030 \\
\hline Residual & $41,057.74$ & 759 & 54.1 & & \\
\hline Total & $41,903.1$ & 766 & 54.7 & & \\
\hline
\end{tabular}


however, being crudely estimated by the sum of squares over the total sum of squares $(840.052 / 60233.75=.0139)$ Therefore, only a little over $1 \%$ of the variance in Basic Needs is predictable due to Years of Teaching Experience. Throughout these data, statistically significant effects with very small differences have been present. This might be due to the large number of subjects in the study. The chances of finding statistically significant relationships between any two variables that are measured are greatly enhanced when the numbers are as large as found in this study.

This same phenomenon is seen again in the two-way interaction between Gender and Years of Experience on Basic Needs (Table XXXI) which indicates a statistical significance of $\underline{p}=.027$. Note that Group 1 (0-8 Years) showed a slightly higher score for males (27.32 versus 25.70$)$, and Group 3 (17-24 Years) showed an even greater difference (males $=30.57$, females $=26.40$ ). The Basic Needs of beginning male teachers and of veteran male teachers appeared to be greater motivators for participation in Staff Development activities than was true for females. Although the differences were more pronounced in this two-way interaction, the effect size is still very weak $(707.821 / 60233.75=.011)$. Only $1 \%$ of the differences can be predicted on the basis of the interaction of Gender and Years of Teaching Experience.

No significant main effects or interactions were noted for Gender by Years on Security Needs, Status Needs or Self-Actualization Needs. In Table XXXIII, 
TABLE XXXIV

ANALYSIS OF VARIANCE: GENDER BY FULL TIME PUBLIC SCHOOL EXPERIENCE ON STATUS NEEDS

\begin{tabular}{lr} 
TOTAL POPULATION & $27.13(767)$ \\
\hline Female & $17.03(492)$ \\
Male & $27.32(275)$ \\
YEARS OF EXPERIENCE & \\
\hline $0-8$ & $27.18(190)$ \\
$9-16$ & $27.27(275)$ \\
$17-24$ & $26.52(203)$ \\
$25+$ & $27.93(99)$
\end{tabular}

MEANS BY GENDER AND YEARS OF EXPERIENCE

\begin{tabular}{|l|c|r|r|r|}
\hline GENDER & \multicolumn{1}{|c|}{$0-8$ yrs. } & $9-16$ yrs. & $17-24$ yrs. & \multicolumn{1}{|c|}{$25+$ yrs. } \\
\hline Female & $27.01(140)$ & $26.96(193)$ & $26.78(117)$ & $28.10(42)$ \\
\hline Male & $27.66(50)$ & $27.99(82)$ & $26.16(86)$ & $27.81(57)$ \\
\hline
\end{tabular}

\section{ANOVA - GENDER BY EXPERIENCE}

\begin{tabular}{|l|r|r|r|r|r|}
\hline $\begin{array}{l}\text { SOURCE OF } \\
\text { VARIATION }\end{array}$ & Sum of Squares & DF & Mean Square & \multicolumn{1}{|c|}{ E } & \multicolumn{1}{|c|}{ Sig of E } \\
\hline Main Effects & 157.52 & 4 & 39.38 & 1.1 & 0.36 \\
\hline GENDER & 12.19 & 1 & 12.19 & 0.340 & 0.560 \\
\hline YEARS & 142.74 & 3 & 47.58 & 1.33 & 0.27 \\
\hline 2-Way Interaction & 84.28 & 3 & 28.09 & 0.78 & 0.5 \\
\hline Explained & 241.8 & 7 & 34.54 & 0.96 & 0.46 \\
\hline Residual & $27,483.37$ & 759 & 35.89 & & \\
\hline Total & $27,483.17$ & 766 & 35.88 & & \\
\hline
\end{tabular}


TABLE XXXV

ANALYSIS OF VARIANCE: GENDER BY FULL TIME PUBLIC SCHOOL EXPERIENCE ON SELF-ACTUALIZATION NEEDS

\begin{tabular}{lr} 
TOTAL POPULATION & $37.68(767)$ \\
\hline Female & $37.77(492)$ \\
Male & $37.53(275)$ \\
YEARS OF EXPERIENCE & \\
\hline $0-8$ & $38.01(190)$ \\
$9-16$ & $37.29(275)$ \\
$17-24$ & $37.79(99)$
\end{tabular}

MEANS BY GENDER AND YEARS OF EXPERIENCE

\begin{tabular}{|l|c|r|r|r|}
\hline GENDER & $0-8$ yrs. & $9-16$ yrs. & $17-24$ yrs. & \multicolumn{1}{|c|}{$25+$ yrs. } \\
\hline Female & $38.12(140)$ & $36.93(193)$ & $38.63(117)$ & $38.0(42)$ \\
\hline Male & $37.70(50)$ & $38.13(82)$ & $36.64(86)$ & $37.84(57)$ \\
\hline
\end{tabular}

\section{ANOVA - GENDER BY EXPERIENCE}

\begin{tabular}{|l|r|r|r|r|r|}
\hline $\begin{array}{l}\text { SOURCE OF } \\
\text { VARIATION }\end{array}$ & Sum of Squares & DF & Mean Square & E & \multicolumn{1}{|c|}{ Sig of E } \\
\hline Main Effects & 84.230 & 4 & 21.06 & 0.54 & 0.71 \\
\hline GENDER & 14.27 & 1 & 14.27 & 0.36 & 0.55 \\
\hline YEARS & 74.16 & 3 & 24.72 & 0.63 & 0.6 \\
\hline 2-Way Interaction & 272.83 & 3 & 90.94 & 2.32 & 0.07 \\
\hline Explained & 357.06 & 7 & 51.01 & 1.3 & 0.25 \\
\hline Residual & $29,713.69$ & 759 & 39.15 & & \\
\hline Total & $30,070.74$ & 766 & 39.26 & & \\
\hline
\end{tabular}


however, Gender by Years on Social Needs, a slight main effect of Years ( $\underline{Q}=$ .02) was once again seen. The effect size was also very weak, 535.692/41903.1 $=.0127$. The beginning teachers (0-8 years of experience) scored slightly higher in the Social Needs category than the rest of the groups. No significant difference in the Social Needs was indicated in the two-way interaction between Gender and Years of Teaching Experience.

Figures 14 through 17 display the profile results of the analysis by Gender and Years of Teaching Experience in the four categories 0-8 years, 9-16 years, $17-24$ years, $25+$ years. Note that the profiles are nearly identical for the four groups and closely resemble the composite picture of the total respondents discussed previously. Both male and female teachers regardless of the number of years they have been teaching are likely to be motivated to participate in staff development activities by the social interaction and self-actualization rewards provided by the experience. Only slight differences were found that might indicate that "established teachers" (9-16 years of experience) and "veteran teachers" (17-24 years of experience) have slightly higher Basic Needs than "newcomers" (0-8 years) or "career teachers" (25+ years). It is interesting to note that $62 \%$ of all the teachers in the study fell into the 17 to 24 years of experience range.

In examining gender differences in addition to experience, it was noted that beginning male teachers (0-8 years) and "veteran teachers" (17-24 years) 


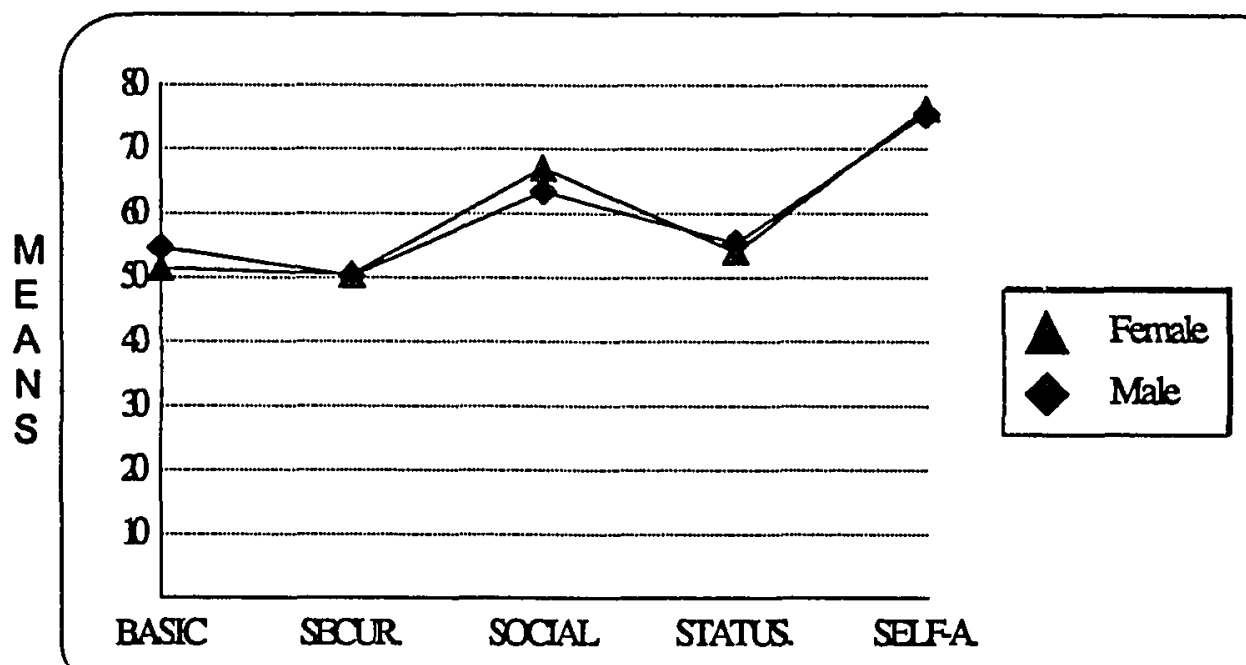

Fiqure 14. Means by gender for 0 to 8 years of teaching experience (newcomers).

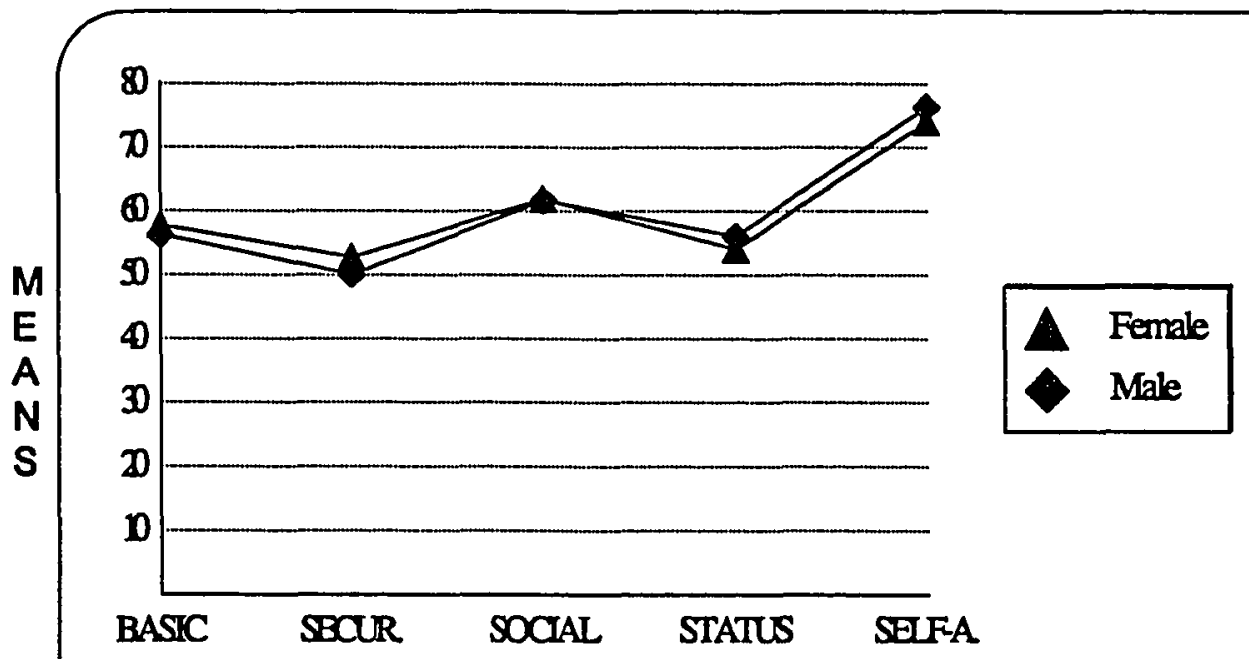

Figure 15. Means by gender for 9 to 16 years of teaching experience (established teachers). 


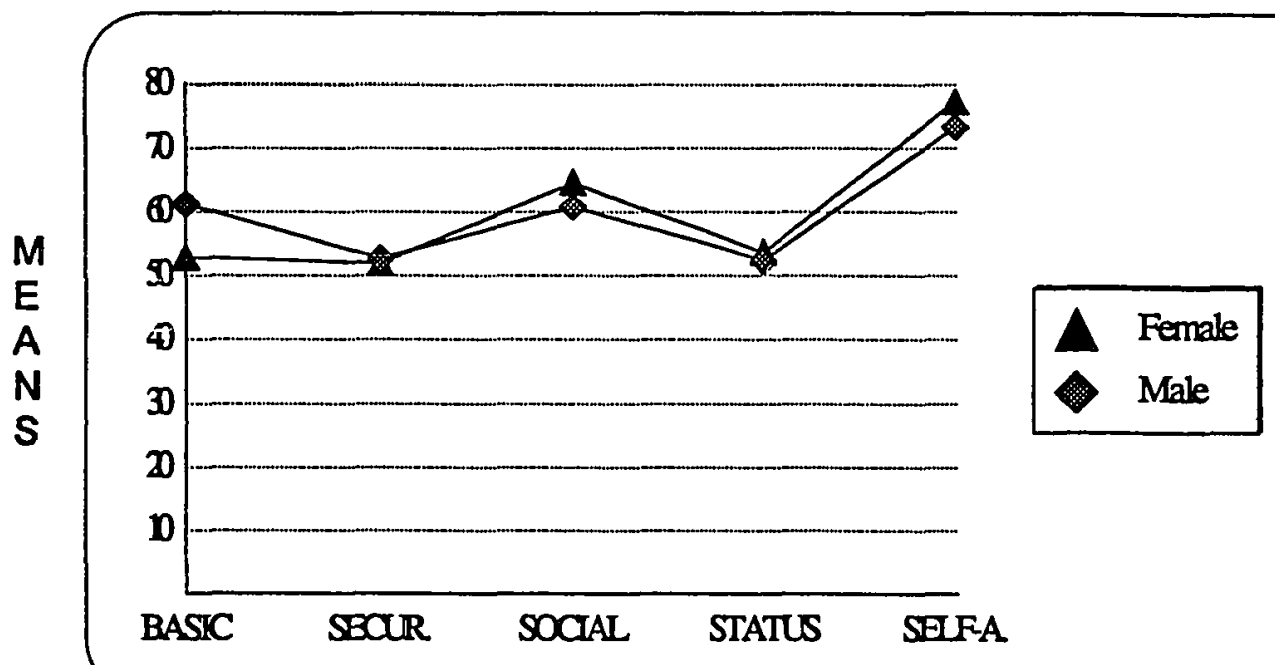

Figure 16 . Means by gender for 17 to 24 years of teaching experience (veteran teachers).

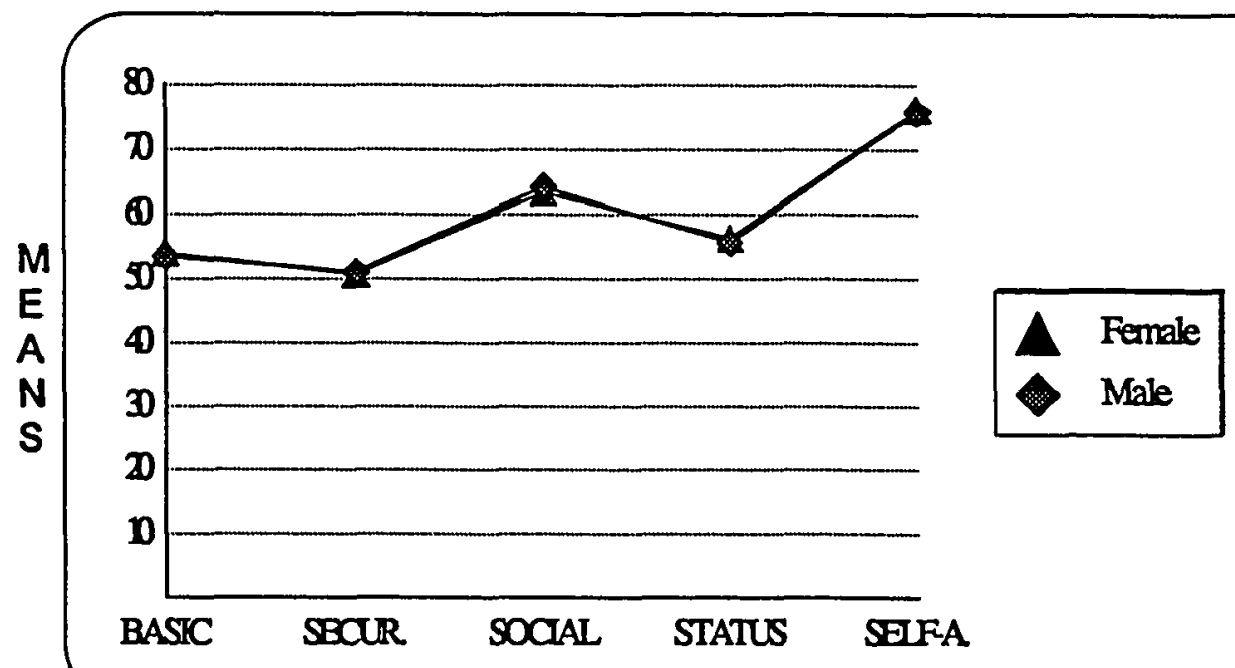

Figure 17. Means by gender for 25 or more years of teaching experience (career teachers). 
scored higher in Basic Needs than their counterpart female teachers. Perhaps male teachers are most concerned about compensation issues when they begin teaching, and again mid-way into their careers.

Finally, the data indicate that beginning teachers as a whole ( $0-8$ years) scored slightly higher in Social Needs. Perhaps beginning teachers have a lesser ability to cope with the isolation of the classroom and have an even higher social need than the rest of the teaching population. The analysis for Gender and Years of Teaching Experience yielded four profiles, basically the same as the one previously described for the total teaching population of this study. The strongest categories of need influencing teachers to pursue professional development activities continued to be the Self-Actualization and Social needs.

\section{Gender by Work Assignment}

In the preliminary data analysis resulting from the multiple regressions described earlier, major work assignment was isolated as a variable which was a predictor of variance among the need categories. For this reason, work assignment was selected for more in-depth study. Five choices of response for work assignment were given on the questionnaire: (a) regular classroom teacher; (b) teaching specialist (i.e. music, art, reading, librarian); (c) special education teacher (resource, Chapter $I$, etc.); (d) certificated support personnel (counselor nurse, audiologist, etc.); e) other. Since nearly $70 \%$ of all the respondents fell into the first category of regular classroom teacher, all others 
were grouped into a second category for purposes of analysis. Table XXXVI (Major Work Assignment) displays this breakout.

TABLE XXXVI

MAJOR WORK ASSIGNMENT OF STUDY RESPONDENTS:

REGULAR TEACHERS AND OTHERS

\begin{tabular}{|l|r|r|}
\hline MAJOR WORK & FREQUENCY & PERCENTAGE \\
\hline Regular Teachers & 531 & 69 \\
\hline Others & 236 & 30.6 \\
\hline Missing Cases & 3 & 0.4 \\
\hline TOTAL & 770 & $100 \%$ \\
\hline
\end{tabular}

As was done with the demographic variable of Years of Teaching Experience in the previous section, the two categories of Work Assignment were further analyzed by Gender for all the Need Categories. A two-way ANOVA of Gender by Work Assignment for All Need Categories was calculated to search for significant interactions (see Tables XXXVII-XLI). Results of the ANOVA showed a weak main effect of Work Assignment on Basic Needs and Safety Needs. A stronger main effect of Work Assignment on Status Needs was noted. No significant two-way interactions of Gender and Work Assignment on any iveed Categories were found. 
TABLE XXXVII

ANALYSIS OF VARIANCE: GENDER BY MAJOR WORK ASSIGNMENT ON BASIC NEEDS

TOTAL POPULATION

Female

Male

WORK ASSIGNMENT

Regular

Other
$27.66(767)$

27.22(492)

$28.45(275)$

$28.17(531)$

$26.51(236)$

MEANS BY GENDER AND WORK ASSIGNMENT

\begin{tabular}{|l|l|l|}
\hline GENDER & \multicolumn{1}{l|}{ Regular } & \multicolumn{1}{l|}{ Other } \\
\hline Female & $27.61(340)$ & $26.35(152)$ \\
\hline Male & $29.17(191)$ & $26.81(84)$ \\
\hline
\end{tabular}

ANOVA - GENDER BY WORK ASSIGNMENT

\begin{tabular}{|l|r|r|r|r|r|}
\hline $\begin{array}{l}\text { SOURCE OF } \\
\text { VARIATION }\end{array}$ & Sum of Squares & DF & Mean Square & E & Sig of E \\
\hline Main Effects & 712.18 & 2 & 356.09 & 4.46 & 0.01 \\
\hline GENDER & 261.66 & 1 & 261.66 & 3.36 & 0.07 \\
\hline WORK & 448.03 & 1 & 448.03 & 5.75 & 0.02 \\
\hline 2-Way Interaction & 44.73 & 1 & 44.73 & 0.57 & 0.45 \\
\hline Explained & 756.9 & 3 & 252.3 & 3.24 & 0.02 \\
\hline Residual & $59,466.64$ & 763 & 77.94 & & \\
\hline Total & $60,223.54$ & 766 & 78.62 & & \\
\hline
\end{tabular}


As shown on Table $X X X V I I$, a significant effect of $\mathrm{p}=.017$ was shown by Work Assignment on Basic Needs. The effect size $(448.027 / 60223.541=.007)$ was weak, however, and indicated that less than $1 \%$ of the variance in Basic Needs is predictable by Work Assignment. A comparison of the mean scores for the two categories of Work Assignment indicated that Regular Classroom Teachers had a higher Basic Need score than the "Other" category (28.17 versus 26.51). Regular Classroom Teachers responded to the questionnaire in such a way as to indicate that they would be more influenced by Basic Need considerations than "Other" teachers when deciding whether to participate in Staff Development activities.

An examination of the effects of Gender and Work Assignment on Security Needs (Table XXXVIII), showed a significant main effect of Work Assignment $(p=.047)$. The effect size was weak, however $(147.804 / 28708.537$ $=.005)$. The mean scores for the two categories of Work Assignment showed that "Other" teachers had a higher Security Need score than Regular Classroom teachers (26.5 versus 25.55). The "Other" category of teachers, which included positions such as music or art teachers, librarians, counselors, and nurses, were more likely to be motivated by concerns of Security (keeping their jobs) than Regular Teachers when considering their further professional development.

No significant main effects or interactions were noted for Gender by Work Assignment on Social Needs or Self-Actualization Needs. A strong main effect 
TABLE XXXVIII

ANALYSIS OF VARIANCE: GENDER BY MAJOR WORK ASSIGNMENT ON SECURITY NEEDS

\begin{tabular}{ll} 
TOTAL POPULATION & $25.84(767)$ \\
\hline Female & $25.97(492)$ \\
Male & $25.62(275)$ \\
WORK ASSIGNMENT & \\
\hline Regular & $25.55(531)$ \\
Other & $26.50(236)$
\end{tabular}

MEANS BY GENDER AND WORK ASSIGNMENT

\begin{tabular}{|l|l|l|}
\hline GENDER & \multicolumn{1}{|l|}{ Regular } & \multicolumn{1}{l|}{ Other } \\
\hline Female & $25.60(340)$ & $26.80(152)$ \\
\hline Male & $25.46(191)$ & $25.98(84)$ \\
\hline
\end{tabular}

ANOVA - GENDER BY WORK ASSIGNMENT

\begin{tabular}{|l|r|r|r|r|r|}
\hline $\begin{array}{l}\text { SOURCE OF } \\
\text { VARIATION }\end{array}$ & Sum of Squares & DF & Mean Square & E & Sig of E \\
\hline Main Effects & 169.830 & 2 & 84.92 & 2.27 & 0.1 \\
\hline GENDER & 21.61 & 1 & 21.61 & 0.58 & 0.45 \\
\hline WORK & 147.8 & 1 & 147.8 & 3.95 & 0.05 \\
\hline 2-Way Interaction & 17.23 & 1 & 17.23 & 0.46 & 0.5 \\
\hline Explained & 187.06 & 3 & 62.35 & 1.67 & 0.17 \\
\hline Residual & $28,521.48$ & 763 & 37.38 & & \\
\hline Total & $28,708.54$ & 766 & 37.48 & & \\
\hline
\end{tabular}


TABLE XXXIX

ANALYSIS OF VARIANCE: GENDER BY MAJOR WORK ASSIGNMENT ON SOCIAL NEEDS

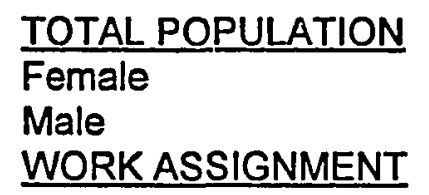

Regular

Other
$31.67(767)$

$31.99(492)$

$31.09(275)$

$31.84(531)$

$31.28(236)$

\section{MEANS BY GENDER AND WORK ASSIGNMENT}

\begin{tabular}{|l|r|r|}
\hline GENDER & \multicolumn{1}{l|}{ Regular } & \multicolumn{1}{l|}{ Other } \\
\hline Female & $32.36(340)$ & $31.17(152)$ \\
\hline Male & $30.92(191)$ & $31.48(84)$ \\
\hline
\end{tabular}

\section{ANOVA - GENDER BY WORK ASSIGNMENT}

\begin{tabular}{|l|r|r|r|r|r|}
\hline $\begin{array}{l}\text { SOURCE OF } \\
\text { VARIATION }\end{array}$ & Sum of Squares & \multicolumn{1}{|c|}{ DF } & Mean Square & \multicolumn{1}{|c|}{ E } & \multicolumn{1}{|c|}{ Sig of E } \\
\hline Main Effects & 197.26 & 2 & 98.63 & 1.81 & 0.17 \\
\hline GENDER & 145.63 & 1 & 145.63 & 2.67 & 0.1 \\
\hline WORK & 52.26 & 1 & 52.26 & 0.96 & 0.33 \\
\hline 2-Way Interaction & 114.96 & 1 & 114.96 & 2.11 & 0.15 \\
\hline Explained & 312.22 & 3 & 104.07 & 1.91 & 0.13 \\
\hline Residual & $41,649.67$ & 763 & 54.59 & & \\
\hline Total & $41,961.89$ & 766 & 54.78 & & \\
\hline
\end{tabular}


TABLE XL

ANALYSIS OF VARIANCE: GENDER BY MAJOR WORK ASSIGNMENT ON STATUS NEEDS

\begin{tabular}{ll} 
TOTAL POPULATION & $27.14(767)$ \\
\hline Female & $27.04(492)$ \\
Male & $27.32(275)$ \\
WORK ASSIGNMENT & \\
\hline Regular & $26.57(531)$ \\
Other & $28.14(236)$
\end{tabular}

MEANS BY GENDER AND WORK ASSIGNMENT

\begin{tabular}{|l|r|l|}
\hline GENDER & \multicolumn{1}{l|}{ Regular } & \multicolumn{1}{l|}{ Other } \\
\hline Female & $26.54(340)$ & $28.14(152)$ \\
\hline Male & $26.63(191)$ & $28.88(84)$ \\
\hline
\end{tabular}

\section{ANOVA - GENDER BY WORK ASSIGNMENT}

\begin{tabular}{|l|r|r|r|r|r|}
\hline $\begin{array}{l}\text { SOURCE OF } \\
\text { VARIATION }\end{array}$ & Sum of Squares & \multicolumn{1}{|c|}{ DF } & Mean Square & \multicolumn{1}{c|}{ E } & \multicolumn{1}{c|}{ Sig of $E$} \\
\hline Main Effects & 563.41 & 2 & 281.7 & 7.99 & .000 \\
\hline GENDER & 14.82 & 1 & 14.82 & 0.420 & 0.52 \\
\hline WORK & 549.24 & 1 & 549.24 & 15.58 & .000 \\
\hline 2-Way Interaction & 15.55 & 1 & 15.55 & 0.44 & 0.51 \\
\hline Explained & 578.96 & 3 & 192.99 & 5.47 & 0 \\
\hline Residual & $26,904.39$ & 763 & 35.26 & & \\
\hline Total & $27,483.35$ & 766 & 35.88 & & \\
\hline
\end{tabular}


TABLE XLI

ANALYSIS OF VARIANCE: GENDER BY MAJOR WORK ASSIGNMENT ON SELF-ACTUALIZATION NEEDS

\begin{tabular}{ll} 
TOTAL POPULATION & $37.69(767)$ \\
\hline Female & $37.77(492)$ \\
Male & $37.53(275)$ \\
WORK ASSIGNMENT & \\
\hline Regular & $37.86(531)$ \\
Other & $37.30(236)$
\end{tabular}

MEANS BY GENDER AND WORK ASSIGNMENT

\begin{tabular}{|l|c|c|}
\hline GENDER & \multicolumn{1}{|c|}{ Regular } & \multicolumn{1}{l|}{ Other } \\
\hline Female & $37.88(340)$ & $37.54(152)$ \\
\hline Male & $37.82(191)$ & $36.86(84)$ \\
\hline
\end{tabular}

ANOVA - GENDER BY WORK ASSIGNMENT

\begin{tabular}{|l|r|r|r|r|r|}
\hline $\begin{array}{l}\text { SOURCE OF } \\
\text { VARIATION }\end{array}$ & Sum of Squares & DF & Mean Square & E & \multicolumn{1}{|c|}{ Sig of E } \\
\hline Main Effects & 62.58 & 2 & 31.29 & 0.81 & 0.45 \\
\hline GENDER & 10.94 & 1 & 10.94 & 0.28 & 0.6 \\
\hline WORK & 51.8 & 1 & 51.8 & 1.34 & 0.25 \\
\hline 2-Way Interaction & 14.65 & 1 & 14.65 & 0.38 & 0.54 \\
\hline Explained & 77.22 & 3 & 25.74 & 0.67 & 0.57 \\
\hline Residual & $29,548.05$ & 763 & 38.73 & & \\
\hline Total & $29,625.28$ & 766 & 38.68 & & \\
\hline
\end{tabular}


of Work Assignment on Status Needs, however, was seen in Table XL ( $\mathfrak{Q}=$ .000 ). The effect size was $549.236 / 27483.351=.019$. The "Other" category of teachers had higher Status Need scores than the regular classroom teachers (28.41 versus 26.57 ). One possible explanation for this may be that teaching "specialists" who comprised the "Other" category often have to obtain advanced degrees or specialized credentials and have a higher Status Need in mind as they decide whether or not to participate in Staff Development Activities.

As previously stated, no significant two-way interactions of Gender by Work Assignment for any of the need categories were found (see Figure 18). Additionally, Figure 19 shows the profile results of the analysis by Total Population and Major Work Assignment for the two categories of work assignment, "regular" teacher and "other" teacher. This profile follows the same general contours with the same peaks and valleys that have come to identify the prototypical teacher in this study. Statistically significant differences occur, however, in three areas:

1. In Figure 19, Regular Classroom Teachers had a higher Basic Need score than the "Other" category. Typically, regular classroom teachers are not placed as high on the salary schedule as teaching specialists because specialists often require advanced degrees or special credentials. This may account for the higher Basic Need score of the regular teachers. 
2. Also in Figure 19, note that the "Other" category teachers had a higher Security Need score than Regular Classroom Teachers. "Other" category teachers may be more likely to fear for job security when school districts are faced with budget cuts.

3. Figure 19 also points out that the "Other" category teachers had a higher Status mean than the Regular Classroom Teachers. These are only minimal differences, however, and the Social and Self-Actualization needs still dominated the profiles of the teachers regardless of teaching assignment.

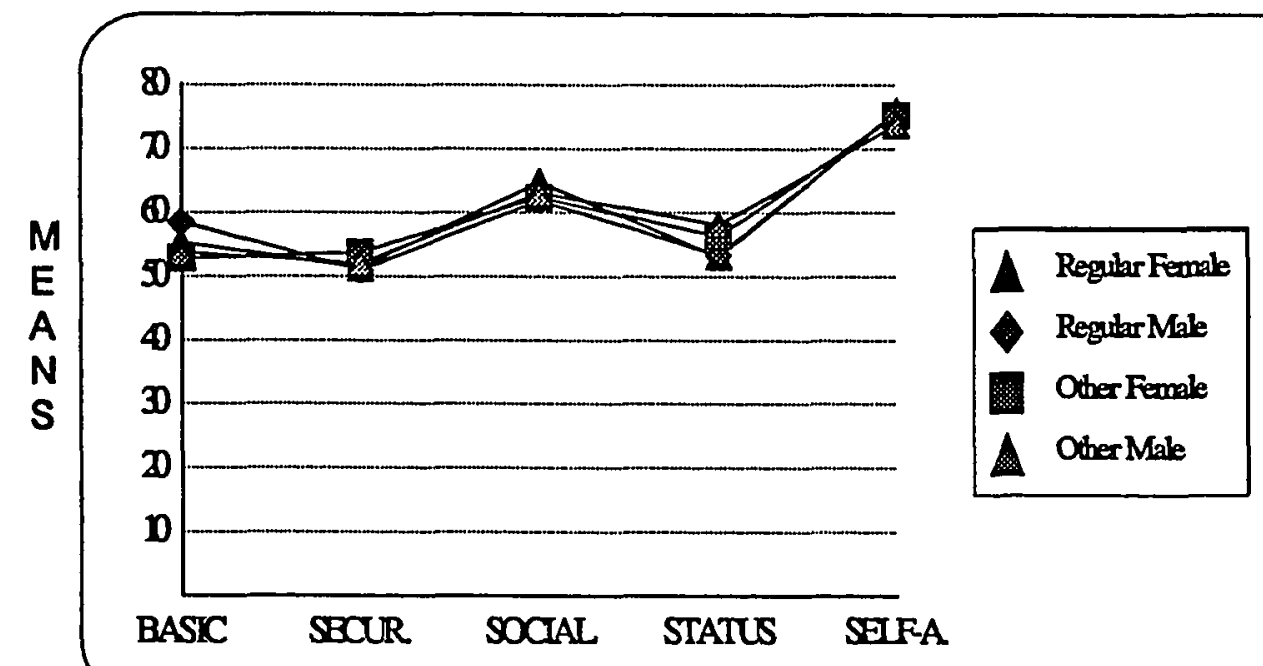

Figure 18. Means by gender for "regular" and "other" teacher work assignments. 


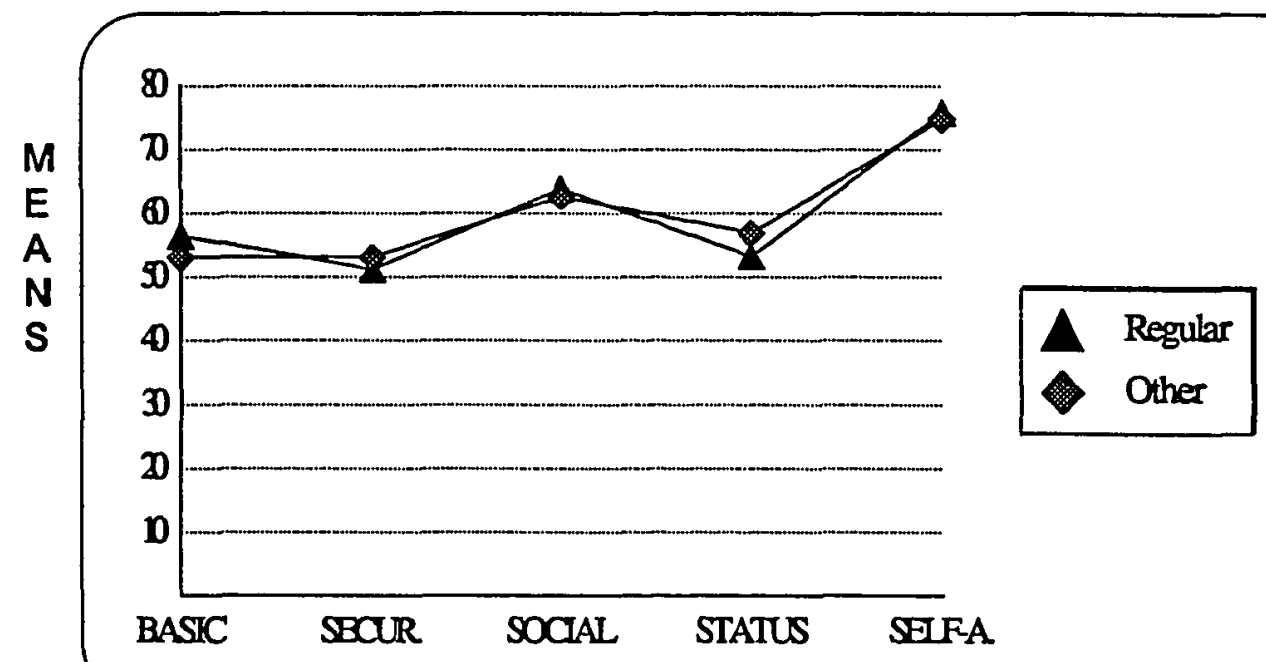

Figure 19. Means by total population and major work assignment.

\section{Gender by Pupil Enrollment in District}

A second variable that was isolated as one which predicted variance among the need categories was Pupil Enrollment in the District. The preliminary data analysis resulting from the multiple regressions described earlier provided these data. (See section entitled Impact of Variables on Incentive Structures.) On the study questionnaire, respondents were asked to indicate the approximate pupil enrollment in the district in which they worked. Four response choices were provided: a) Small-2,000 or fewer pupils, b) Medium-2,001 to 9,999 pupils, c) Large-10,000 or more pupils, and d) Don't know/Not sure (see Table XLII for the results of the demographic breakout). Nearly $19 \%$ of the study participants taught in Small school districts, about $41 \%$ were from Medium-sized 
districts, and slightly over 35\% taught in Large districts with over 10,000 students.

TABLE XLII

NUMBER OF STUDY RESPONDENTS BY PUPIL ENROLLMENT IN THE DISTRICT

\begin{tabular}{|l|r|r|}
\hline PUPIL ENROLLMENT & FREQUENCY & PERCENTAGE \\
\hline Small-2,000 or less & 141 & $18.3 \%$ \\
\hline Medium-2,001 to 9999 & 317 & $41.2 \%$ \\
\hline Large-10,000 or more & 271 & $35.2 \%$ \\
\hline Do Not Know & 31 & $4.0 \%$ \\
\hline Missing Cases & 10 & $1.3 \%$ \\
\hline TOTAL & 770 & $100 \%$ \\
\hline
\end{tabular}

In order to analyze for gender differences, a two-way ANOVA of Gender by Pupil Enrollment for all Need Categories was conducted (Tables XLIII-XLVII). The population responding "do not know - not sure" were omitted from this portion of analysis. For this reason, the total population in this two-way ANOVA consists of 729 respondents rather than the higher total populations seen in all other ANOVA analyses. Weak main effects were noted for Gender and Pupil Enrollment separately on Basic Needs. A weak main effect of Pupil Enrollment and a weak interaction effect of Gender by Pupil Enrollment were noted on Security Needs. A weak main effect of Pupil Enrollment was noted on Social 
TABLE XLIII

ANALYSIS OF VARIANCE: GENDER BY PUPIL ENROLLMENT IN THE DISTRICT ON BASIC NEEDS

\begin{tabular}{ll} 
TOTAL POPULATION & $27.43(729)$ \\
\cline { 1 - 2 } Female & $26.88(462)$ \\
Male & $28.37(267)$ \\
PUPIL ENROLLMENT & \\
\hline Small $(\leq 2000)$ & $25.70(141)$ \\
Medium $(<9999)$ & $27.49(317)$ \\
Large $(>10,000)$ & $28.25(271)$
\end{tabular}

MEANS BY GENDER AND PUPIL ENROLLMENT

\begin{tabular}{|l|l|l|l|}
\hline GENDER & \multicolumn{1}{|c|}{ Small } & \multicolumn{1}{l|}{ Medium } & \multicolumn{1}{l|}{ Large } \\
\hline Female & $25.54(94)$ & $26.45(200)$ & $28.14(168)$ \\
\hline Male & $26.02(47)$ & $29.26(117)$ & $28.43(103)$ \\
\hline
\end{tabular}

ANOVA - GENDER BY PUPIL ENROLLMENT

\begin{tabular}{|l|r|r|r|r|r|}
\hline $\begin{array}{l}\text { SOURCE OF } \\
\text { VARIATION }\end{array}$ & Sum of Squares & DF & Mean Square & E & \multicolumn{1}{|c|}{ Sig of E } \\
\hline Main Effects & 945.36 & 3 & 315.12 & 4.12 & 0.01 \\
\hline GENDER & 340.67 & 1 & 340.67 & 4.45 & 0.04 \\
\hline PUPILS & 572.75 & 2 & 286.38 & 3.74 & 0.02 \\
\hline 2-Way Interaction & 250.980 & 2 & 125.490 & 1.640 & 0.2 \\
\hline Explained & $1,196.34$ & 5 & 239.27 & 3.13 & 0.01 \\
\hline Residual & $55,329.99$ & 723 & 76.53 & & \\
\hline Total & $56,526.32$ & 728 & 77.65 & & \\
\hline
\end{tabular}


Needs. Main effects and interactions for the other two dependent variables (Status and Self-Actualization) were not significant.

Table XLIII shows that both Gender $(\underline{p}=.035)$ and Pupil Enrollment $(\mathrm{g}=$ .024) independently indicated statistically significant differences on the Basic Needs scores. Both, however, were weak effects. For Gender, the effect size was $340.672 / 56526.324=.006$, for Pupil Enrollment it was $572.752 / 56526.324=.01$. Note that the mean score for males on Basic Needs became significantly higher than for females when the total population figure dropped from 770 to 729 (by omitting the individuals who responded that they did not know or were unsure of the size of their district). This difference was mentioned in the section on Gender Differences, but it was not statistically significant when calculated for the entire study population of 770 .

Differences in Pupil Enrollment affected the mean scores for Basic Needs in an interesting fashion. A progressively higher Basic Needs mean score was noted as the size of the school district increased from small $(2,000$ or fewer pupils) to large (10,000 or more students). This finding implies that teachers in larger school districts might be more likely to consider Basic Needs concerns in their decisions to pursue additional professional development activities. Although not statistically significant, the Basic Need mean score for males in Medium-sized Districts was higher than that of any other group described in 
TABLE XLIV

ANALYSIS OF VARIANCE: GENDER BY PUPIL ENROLLMENT IN THE DISTRICT ON SECURITY NEEDS

\begin{tabular}{ll} 
TOTAL POPULATION & $25.74(729)$ \\
\hline Female & $25.85(462)$ \\
Male & $25.56(267)$ \\
PUPIL ENROLLMENT & \\
\hline Small $(<2000)$ & $26.82(141)$ \\
Medium $(<9999)$ & $25.19(317)$ \\
Large $(>10,000)$ & $25.84(271)$
\end{tabular}

MEANS BY GENDER AND PUPIL ENROLLMENT

\begin{tabular}{|l|l|l|l|}
\hline GENDER & \multicolumn{1}{|l|}{ Small } & \multicolumn{1}{l|}{ Medium } & \multicolumn{1}{l|}{ Large } \\
\hline Female & $26.11(94)$ & $25.30(200)$ & $26.38(168)$ \\
\hline Male & $28.23(47)$ & $25.00(117)$ & $24.97(103)$ \\
\hline
\end{tabular}

ANOVA - GENDER BY PUPIL ENROLLMENT

\begin{tabular}{|l|r|r|r|r|r|}
\hline $\begin{array}{l}\text { SOURCE OF } \\
\text { VARIATION }\end{array}$ & Sum of Squares & \multicolumn{1}{|c|}{ DF } & Mean Square & E & Slg of E \\
\hline Main Effects & 275 & 3 & 91.67 & 2.42 & 0.07 \\
\hline GENDER & 11.86 & 1 & 11.86 & 0.31 & 0.58 \\
\hline PUPILS & 260.3 & 2 & 130.15 & 3.44 & 0.03 \\
\hline 2.Way Interaction & 262.300 & 2 & 131.150 & 3.47 & 0.03 \\
\hline Explained & 537.3 & 5 & 107.460 & 2.840 & 0.02 \\
\hline Residual & $27,359.24$ & 723 & 37.84 & & \\
\hline Total & $27,896.54$ & 728 & 38.32 & & \\
\hline
\end{tabular}


Table XLIII. There were no significant interactions of Gender and Pupil Enrollment for Basic Needs.

Table XLIV displays the analysis of variance for Security Needs by Gender and Pupil Enrollment. Both a weak main effect of Pupil Enrollment ( $\mathrm{g}=$ .033; effect size is $260.298 / 27896.543=.009$ ) and a weak interaction effect of Gender and Pupil Enrollment ( $\mathrm{g}=.032$; effect size is $262.3 / 27896.543=.009$ ) were present. The size of school district had a different effect on Security Needs than it did on Basic Needs. Teachers in Small Districts had a higher Security Need mean score (26.82) than teachers in Medium (25.19) or Large Districts (25.84). Teachers in Medium-sized Districts had the lowest mean score. Perhaps teachers in small districts have greater concerns about job security concerns than those in larger districts because of a more limited number of teaching positions.

Results of the two-way interaction analysis of Gender by Pupil Enrollment, also displayed in Table XLIV, yielded some interesting effects on Security Needs. Males in Small Districts had a higher Security Need score (28.23) than females (26.11). The Security means for males and females in the Medium-sized Districts were nearly the same (25.30 and 25.00$)$. Females in the Large Districts, however, had a higher Security mean (26.38) than the males (24.97). 
The last significant effect found through an analysis of Gender by Pupil Enrollment for the five Need variables was a weak main effect of Pupil Enrollment on Social Needs $(\underline{p}=.024$; size of effect is $404.825 / 39870.9=.01)$. As shown in Table XLV, as the size of the district becomes larger, the Social Need score becomes smaller. That is, teachers in the Smaller Districts had a higher Social Need score than teachers in the Larger Districts. Teachers in Smaller Districts, then, would be more likely to consider their social needs in deciding whether or not to participate in staff development activities.

No significant effects were found by Gender and Pupil Enrollment for either Status Needs or Self-Actualization Needs (see Tables XLVI and XLVII).

Profiles for selected analyses by Gender and Pupil Enroliment are shown in Figures 20 through 24 . Note particularly the statistically significant differences in five areas: a) as shown in Figure 20, Males had a higher mean on Basic Needs than females; b) Figure 21 indicates that teachers in Larger Districts $(10,000$ or more students) scored higher in Basic Needs than teachers in either Small (2,000 or fewer students) or Medium-sized Districts (2001-9999 students); c) as noted in Figure 22, teachers in Small Districts had a higher mean score on Security Needs than either of the other two groups; d) Figure 23 shows that males in Small Districts had a higher mean score on Security Needs than females in Small Districts, and a higher Security mean than males or females in any other size school district; e) as shown in Figure 24, 
TABLE XLV

ANALYSIS OF VARIANCE: GENDER BY PUPIL ENROLLMENT IN THE DISTRICT ON SOCIAL NEEDS

\begin{tabular}{|c|c|}
\hline TOTAL POPULATION & $31.84(729)$ \\
\hline Female & $32.21(462)$ \\
\hline $\begin{array}{l}\text { Male } \\
\text { PUPIL ENROLLMENT }\end{array}$ & $31.20(267)$ \\
\hline Smali $(\leq 2000)$ & $33.09(141)$ \\
\hline Medium ( $\leq 9999)$ & $32.01(317)$ \\
\hline Large $(\geq \overline{10000)}$ & $30.99(271)$ \\
\hline
\end{tabular}

MEANS BY GENDER AND PUPIL ENROLLMENT

\begin{tabular}{|l|r|r|l|}
\hline GENDER & \multicolumn{1}{|c|}{ Small } & \multicolumn{1}{l|}{ Medium } & \multicolumn{1}{l|}{ Large } \\
\hline Female & $34.01(94)$ & $32.46(200)$ & $30.90(168)$ \\
\hline Male & $31.23(47)$ & $31.23(117)$ & $31.15(103)$ \\
\hline
\end{tabular}

\section{ANOVA - GENDER BY PUPIL ENROLLMENT}

\begin{tabular}{|l|r|r|r|r|r|}
\hline $\begin{array}{l}\text { SOURCE OF } \\
\text { VARIATION }\end{array}$ & Sum of Squares & \multicolumn{1}{|c|}{ DF } & Mean Square & E & \multicolumn{1}{|c|}{ Slg of E } \\
\hline Main Effects & 577.19 & 3 & 192.4 & 3.56 & 0.01 \\
\hline GENDER & 155.25 & 1 & 155.25 & 2.87 & 0.09 \\
\hline PUPILS & 404.83 & 2 & 202.41 & 3.74 & 0.02 \\
\hline 2-Way Interaction & 201.75 & 2 & 100.87 & 1.87 & 0.16 \\
\hline Explained & 778.940 & 5 & 155.79 & 2.88 & 0.01 \\
\hline Residual & 39.091 .96 & 723 & 54.07 & & \\
\hline Total & 39870.900 & 728 & 54.77 & & \\
\hline
\end{tabular}


TABLE XLVI

ANALYSIS OF VARIANCE: GENDER BY PUPIL ENROLLMENT IN THE DISTRICT ON STATUS NEEDS

\begin{tabular}{|c|c|}
\hline POPULATIC & $27.16(729)$ \\
\hline Female & $27.08(462)$ \\
\hline $\begin{array}{l}\text { Male } \\
\text { PUPIL }\end{array}$ & $27.31(267)$ \\
\hline$<0$ & $27.37(14$ \\
\hline Medium ( $\leq 9999)$ & $27.00(317)$ \\
\hline Large $(\geq 10000)$ & 7.25 \\
\hline
\end{tabular}

MEANS BY GENDER AND PUPIL ENROLLMENT

\begin{tabular}{|l|r|r|l|}
\hline GENDER & \multicolumn{1}{|c|}{ Small } & \multicolumn{1}{l|}{ Medium } & \multicolumn{1}{l|}{ Large } \\
\hline Female & $27.11(94)$ & $27.23(200)$ & $26.90(168)$ \\
\hline Male & $27.89(47)$ & $26.62(117)$ & $27.82(103)$ \\
\hline
\end{tabular}

ANOVA - GENDER BY PUPIL ENROLLMENT

\begin{tabular}{|l|r|r|r|r|r|}
\hline $\begin{array}{l}\text { SOURCE OF } \\
\text { VARIATION }\end{array}$ & Sum of Squares & DF & Mean Square & E & \multicolumn{1}{|c|}{ Sig of E } \\
\hline Main Effects & 24.92 & 3 & 8.31 & 0.230 & 0.88 \\
\hline GENDER & 8.92 & 1 & 8.92 & 0.25 & 0.62 \\
\hline PUPILS & 16.36 & 2 & 8.18 & 0.23 & 0.8 \\
\hline 2-Way Interaction & 90.83 & 2 & 45.41 & 1.26 & 0.20 \\
\hline Explained & 115.740 & 5 & 23.15 & 0.64 & 0.67 \\
\hline Residual & $26,094.507$ & 723 & 36.09 & & \\
\hline Total & $26,210.25$ & 728 & 36 & & \\
\hline
\end{tabular}


TABLE XLVII

ANALYSIS OF VARIANCE: GENDER BY PUPIL ENROLLMENT IN THE DISTRICT ON SELF-ACTUALIZATION NEEDS

\begin{tabular}{|c|c|}
\hline \multirow{3}{*}{$\begin{array}{l}\text { TOTAL POPULATION } \\
\text { Female } \\
\text { Male } \\
\text { PUPIL ENROLLMENT }\end{array}$} & (29) \\
\hline & \\
\hline & \\
\hline & 37. \\
\hline$n(\leq 9999)$ & 7.02 \\
\hline
\end{tabular}

MEANS BY GENDER AND PUPIL ENROLLMENT

\begin{tabular}{|l|r|r|l|}
\hline GENDER & \multicolumn{1}{|c|}{ Small } & \multicolumn{1}{l|}{ Medium } & \multicolumn{1}{l|}{ Large } \\
\hline Female & $37.23(94)$ & $38.56(200)$ & $37.68(168)$ \\
\hline Male & $36.62(47)$ & $37.89(117)$ & $37.64(103)$ \\
\hline
\end{tabular}

ANOVA - GENDER BY PUPIL ENROLLMENT

\begin{tabular}{|l|r|r|r|r|r|}
\hline $\begin{array}{l}\text { SOURCE OF } \\
\text { VARIATION }\end{array}$ & Sum of Squares & DF & Mean Square & E & \multicolumn{1}{|c|}{ Sig of E } \\
\hline Main Effects & 203.13 & 3 & 67.71 & 1.77 & 0.15 \\
\hline GENDER & 30.7 & 1 & 30.7 & 0.8 & 0.370 \\
\hline PUPILS & 175.41 & 2 & 87.71 & 2.3 & 0.1 \\
\hline 2-Way Interaction & 15.09 & 2 & 7.55 & 0.2 & 0.82 \\
\hline Explained & 218.22 & 5 & 43.64 & 1.14 & 0.34 \\
\hline Residual & $27,608.66$ & 723 & 38.19 & & \\
\hline Total & $27,826.88$ & 728 & 38.22 & & \\
\hline
\end{tabular}




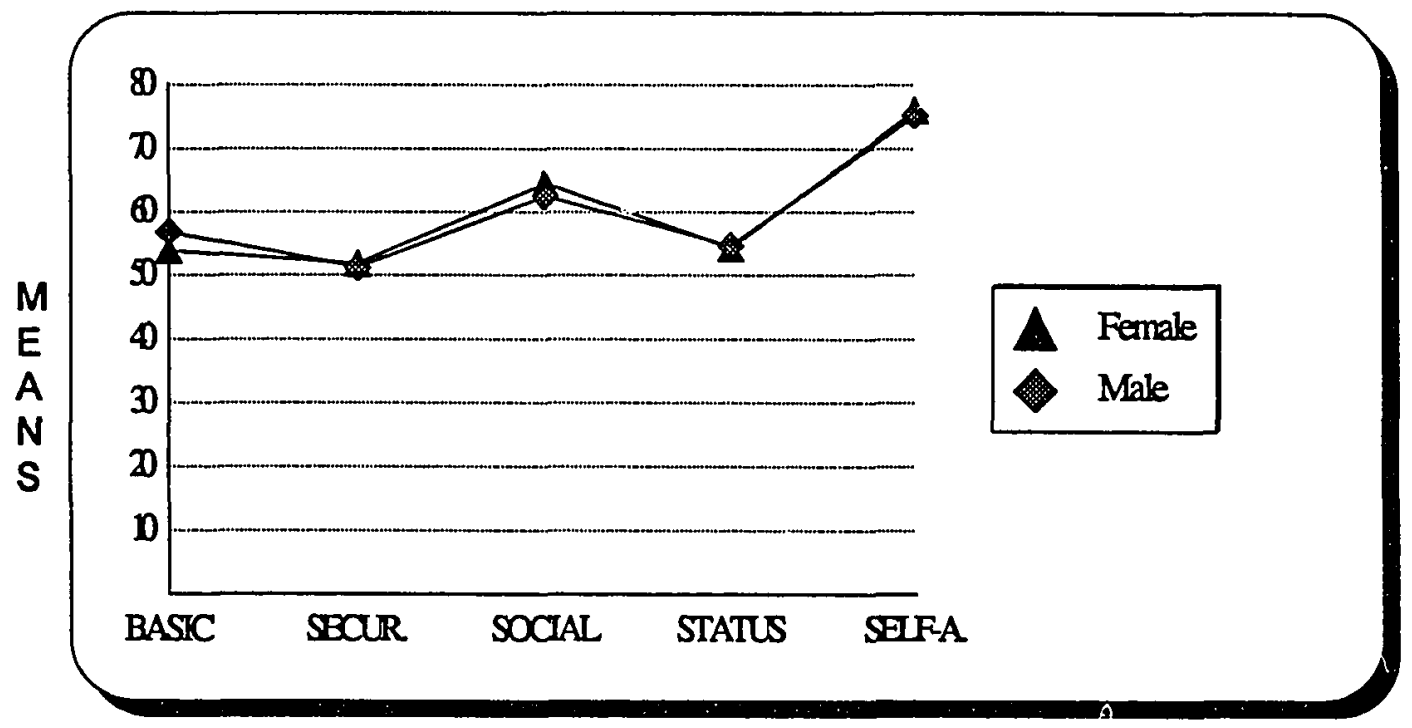

Figure 20. Means by gender for pupil enrollment in the district (total population).

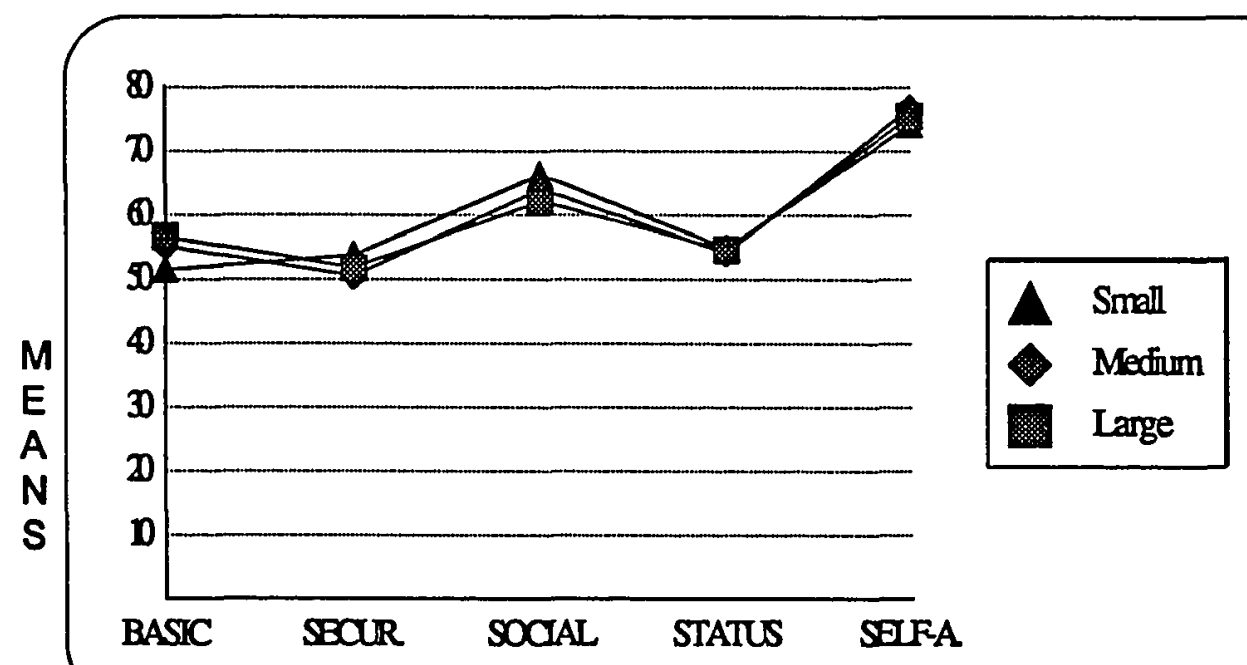

Figure 21. Means by pupil enrollment in the district. 


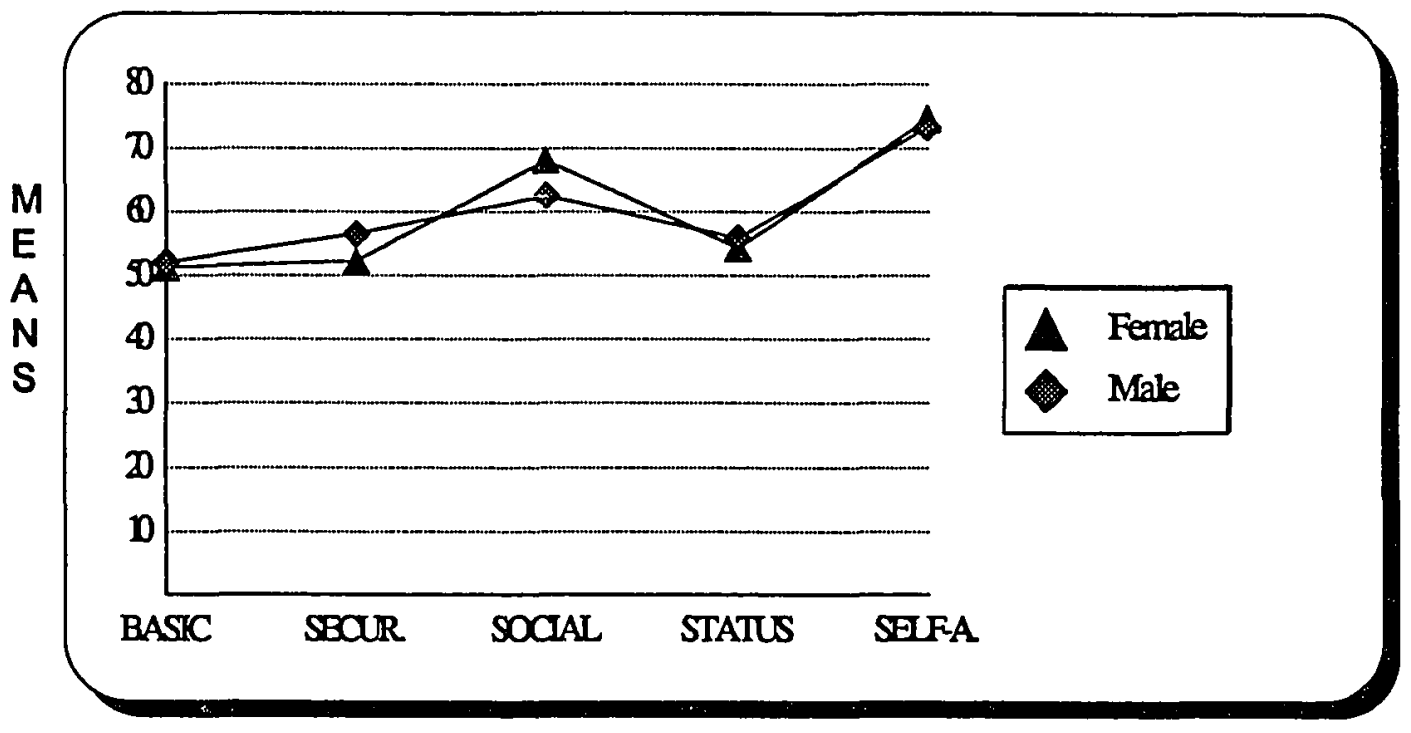

Fiqure 22. Means by gender for small school district pupil enrollment.

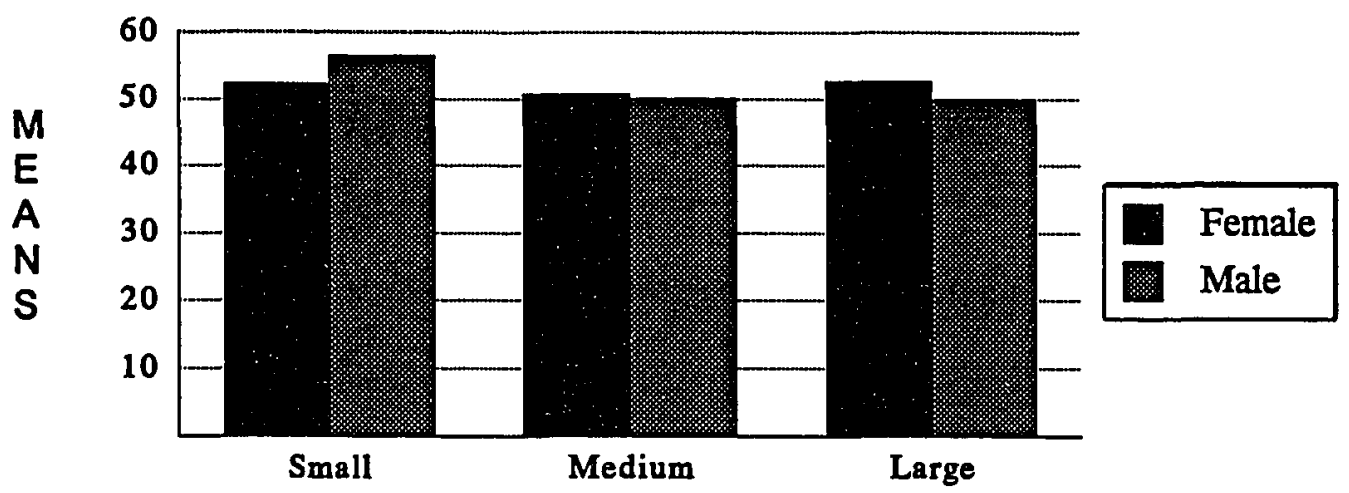

Figure 23. Means by gender and pupil enrollment in the district for security needs. 


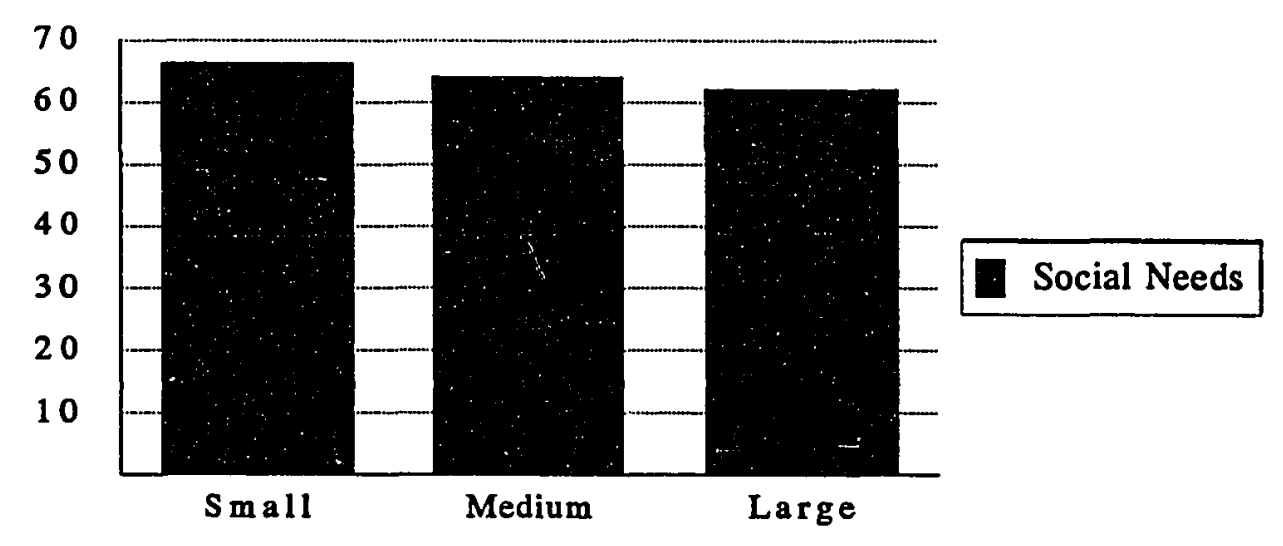

Figure 24. Means by pupil enrollment in the district for social needs.

there was an inverse relationship between the size of school district and the mean score on Social Needs (teachers from small districts had higher Security Need scores than teachers from large districts). Despite the subtle differences found by conducting ANOVAs on the relationship of Gender and Pupil Enrollment to the five Need variables, the basic shape of the profiles remained constant and Social and Self-Actualization Needs remained the highest motivators.

Gender by Percent of Income Attributable to School District Salary

The final variable selected for closer study was the Percentage of Household Income Attributable to School District Salary. Although this variable did not surface in earlier analyses as a significant predictor of variance among the Need Categories, the potential for two-way interactions between Gender and 
Percentage of Household Income needed to be explored. In selecting this demographic variable for inclusion in the study, it was conjectured that teachers who were sole family supporters would respond differently to Basic or Security Need questions than others. When this did not materialize in the data analysis, the possibility that adding Gender as a second variable would make a difference was considered. The Demographic Section of the survey instrument used in this study asked teachers to respond to the question: "What proportion of your household's total income is attributable to your school district salary?" Five choices of response were provided: 100\%; $75-99 \% ; 50-74 \% ; 25-49 \%$; and less than $25 \%$. Twenty-six percent of all respondents reported deriving $100 \%$ of their household income from their school district salary. Another $17 \%$ of the teachers derived between 75 and $99 \%$ of their household income from their school district salary. Therefore, nearly one-half $(43.5 \%)$ of the entire population sampled derived at least three fourths of their entire household income from their school salary. These teachers were the sole or primary supporters of their families and, with gender as a second variable consideration, might be expected to express more concern about basic and security needs than the other groups. Only $23 \%$ of the teachers sampled derived less than half of their income from their school salaries (see Table XLVIII). 
TABLE XLVIII

PERCENTAGE OF HOUSEHOLD INCOME DERIVED FROM SCHOOL DISTRICT SALARY

\begin{tabular}{|l|r|r|}
\hline $\begin{array}{l}\text { PERCENTAGE OF } \\
\text { INCOME DERIVED }\end{array}$ & FREQUENCY & PERCENTAGE \\
\hline $100 \%$ & 202 & 26.2 \\
\hline $75-99 \%$ & 133 & 17.3 \\
\hline $50-74 \%$ & 255 & 33.1 \\
\hline $25-49 \%$ & 157 & 20.4 \\
\hline Less Than 25\% & 20 & 2.6 \\
\hline Missing Cases & 3 & 0.4 \\
\hline TOTAL & 770 & $100 \%$ \\
\hline
\end{tabular}

A two-way ANOVA, using Gender and Percentage of Household Income Attributable to School District Salary as independent variables and the five Need Categories as dependent variables, was conducted in order to analyze possible interactions more closely (see Tables XLIX - LIII). There was a nearly significant $(\underline{q}=.067)$ main effect of Gender by Basic Needs. The only significant main effect or interaction in the analysis was the main effect of Percentage of Household Income on Security Needs. There were no significant Gender differences by Percentage of Household Income for any of the Need categories.

Although not statistically significant, Table XLIX indicates a p of .067 for the main effect of Gender on Basic Needs. Males as a whole had a higher Basic 
Need score than females. It was interesting to note that males deriving $100 \%$ of their household income from their school salary had a higher basic need score than females in the same circumstance. Additionally, males with $25-49 \%$ of their household income attributable to their school district salary had a higher Basic Need score than any other group in either gender category.

As shown in Table L, while Percentage of Household Income had a significant effect on Security Needs $(\underline{p}=.029)$, the effect size was very weak (Sum of Squares $404.29 /$ total Sum of Squares $28709.51=.014$.) Figure 25 points out that contrary to expectations, teachers receiving less than $25 \%$ of their household income from their school district salary had by far the highest Security Need score of all the groups. Teachers who derived $100 \%$ of their salary from teaching had the second highest Security Need score. Those teachers receiving from $25 \%$ to $99 \%$ of their income from teaching had somewhat lower Security Need scores.

Once again, no direct correlation between income concerns and the Needs or incentives structures was forthcoming from these data. Even though there were some slight variations in means by Percentage of Household Income, the same basic pattern that had been established by the total population of teachers continued to be dominant. 
TABLE XLIX

\begin{abstract}
ANALYSIS OF VARIANCE: GENDER BY PERCENTAGE OF HOUSEHOLD INCOME DERIVED FROM SCHOOL

DISTRICT SALARY ON BASIC NEEDS
\end{abstract}

\begin{tabular}{ll} 
TOTAL POPULATION & $27.67(767)$ \\
\hline Female & $27.23(492)$ \\
Male & $28.45(275)$
\end{tabular}

PEREENT OF HOUSEHOLD INCOME FROM SCHOOL DISTRICT

\begin{tabular}{ll}
\hline $100 \%$ & $27.72(202)$ \\
$75-99 \%$ & $27.46(133)$ \\
$50-74 \%$ & $27.60(255)$ \\
$25-49 \%$ & $26.70(157)$ \\
$<25 \%$ & $28.05(20)$
\end{tabular}

MEANS BY GENDER AND PERCENTAGE OF HOUSEHOLD INCOME

\begin{tabular}{|l|c|c|c|c|c|}
\hline GENDER & $100 \%$ & $75-99 \%$ & $50-74 \%$ & $25-49 \%$ & $<25 \%$ \\
\hline Female & $27.34(121)$ & $26.94(54)$ & $27.34(157)$ & $27.18(142)$ & $26.83(18)$ \\
\hline Male & $29.11(81)$ & $28.23(79)$ & $27.66(98)$ & $31.53(15)$ & $25.50(2)$ \\
\hline
\end{tabular}

\title{
ANOVA - GENDER BY PERCENTAGE OF HOUSEHOLD INCOME
}

\begin{tabular}{|l|r|r|r|r|r|}
\hline $\begin{array}{l}\text { SOURCE OF } \\
\text { VARIATION }\end{array}$ & Sum of Squares & DF & Mean Square & E & \multicolumn{1}{|c|}{ Slg of E } \\
\hline Main Efrects & 324.6 & 5 & 64.920 & 0.83 & 0.53 \\
\hline GENDER & 264.76 & 1 & 264.76 & 3.37 & 0.07 \\
\hline INCOME & 63.95 & 4 & 15.99 & 0.2 & 0.94 \\
\hline 2-Way Interaction & 206.82 & 4 & 51.7 & 0.66 & 0.62 \\
\hline Explained & 531.41 & 9 & 59.05 & 0.75 & 0.66 \\
\hline Resldual & $59,458.81$ & 757 & 78.55 & & \\
\hline Total & $59,990.22$ & 766 & 78.32 & & \\
\hline
\end{tabular}


TABLE L

ANALYSIS OF VARIANCE: GENDER BY PERCENTAGE OF HOUSEHOLD INCOME DERIVED FROM SCHOOL DISTRICT SALARY ON SECURITY NEEDS

\begin{tabular}{lr} 
TOTAL POPULATION & $25.86(767)$ \\
Female & $25.99(492)$ \\
Male & $25.62(275)$ \\
PERCENT OF HOUSEHOLD INCOME \\
\hline FROM SCHOOL DISTRICT \\
\hline $100 \%$ & $26.53(202)$ \\
$75-99 \%$ & $26.26(133)$ \\
$50-74 \%$ & $25.47(255)$ \\
$25-49 \%$ & $25.01(157)$ \\
$<25 \%$ & $28.00(20)$
\end{tabular}

MEANS BY GENDER AND PERCENTAGE OF HOUSEHOLD INCOME

\begin{tabular}{|l|c|c|c|c|c|}
\hline GENDER & $100 \%$ & $75-99 \%$ & $50-74 \%$ & $25-49 \%$ & $<25 \%$ \\
\hline Female & $26.72(121)$ & $26.70(54)$ & $25.61(157)$ & $25.24(142)$ & $28.22(18)$ \\
\hline Male & $26.26(81)$ & $25.95(79)$ & $25.24(98)$ & $22.80(15)$ & $26.00(2)$ \\
\hline
\end{tabular}

ANOVA - GENDER BY PERCENTAGE OF HOUSEHOLD INCOME

\begin{tabular}{|l|r|r|r|r|r|}
\hline $\begin{array}{l}\text { SOURCE OF } \\
\text { VARIATION }\end{array}$ & Sum of Squares & DF & Mean Square & E & Sig of F \\
\hline Main Effects & 428.92 & 5 & 85.79 & 2.3 & 0.04 \\
\hline GENDER & 71.5 & 1 & 71.5 & 1.92 & 0.17 \\
\hline INCOME & 404.290 & 4 & 101.07 & 2.71 & 0.03 \\
\hline 2-Way Interaction & 54.74 & 4 & 13.68 & 0.37 & 0.83 \\
\hline Explained & 433.66 & 9 & 53.740 & 1.44 & 0.17 \\
\hline Residual & $28,225.85$ & 757 & 37.29 & & \\
\hline Total & 28709.510 & 766 & 37.480 & & \\
\hline
\end{tabular}


TABLE LI

ANALYSIS OF VARIANCE: GENDER BY PERCENTAGE OF HOUSEHOLD INCOME DERIVED FROM SCHOOL

DISTRICT SALARY ON SOCIAL NEEDS

\begin{tabular}{lr} 
TOTAL POPULATION & $\begin{array}{r}31.65(767) \\
31.97(492) \\
\text { Female }\end{array}$ \\
Male & $31.09(275)$ \\
PERCENT OF HOUSEHOLD INCOME \\
\hline FROM SCHOOL DISTRICT \\
\hline $100 \%$ & $31.34(202)$ \\
$75-99 \%$ & $30.42(133)$ \\
$50-74 \%$ & $32.48(255)$ \\
$25-49 \%$ & $31.90(157)$ \\
$<25 \%$ & $30.45(20)$
\end{tabular}

MEANS BY GENDER AND PERCENTAGE OF HOUSEHOLD INCOME

\begin{tabular}{|l|c|c|c|c|c|}
\hline GENDER & $100 \%$ & $75-99 \%$ & $50-74 \%$ & $25-49 \%$ & $<25 \%$ \\
\hline Female & $31.71(121)$ & $30.67(54)$ & $32.64(157)$ & $32.08(142)$ & $30.89(18)$ \\
\hline Male & $30.79(81)$ & $30.25(79)$ & $32.23(98)$ & $30.20(15)$ & $26.50(2)$ \\
\hline
\end{tabular}

ANOVA - GENDER BY PERCENTAGE OF HOUSEHOLD INCOME

\begin{tabular}{|l|r|r|r|r|r|}
\hline $\begin{array}{l}\text { SOURCE OF } \\
\text { VARIATION }\end{array}$ & Sum of Squares & DF & Mean Square & \multicolumn{1}{|c|}{ E } & \multicolumn{1}{|c|}{ Slg of E } \\
\hline Main Effects & 520.67 & 5 & 104.13 & 1.910 & 0.090 \\
\hline GENDER & 85.46 & 1 & 85.46 & 1.57 & 0.21 \\
\hline INCOME & 384 & 4 & 96 & 1.76 & 0.14 \\
\hline 2-Way Interaction & 53.4 & 4 & 13.35 & 0.25 & 0.91 \\
\hline Explained & 574.08 & 9 & 63.79 & 1.170 & 0.31 \\
\hline Residual & $41,265.98$ & 757 & 54.51 & & \\
\hline Total & $41,840.06$ & 766 & 54.62 & & \\
\hline
\end{tabular}


TABLE LII

ANALYSIS OF VARIANCE: GENDER BY PERCENTAGE OF HOUSEHOLD INCOME DERIVED FROM SCHOOL DISTRICT SALARY ON STATUS NEEDS

\begin{tabular}{lr} 
TOTAL POPULATION & $27.14(767)$ \\
\hline Female & $27.05(492)$ \\
Male & $27.32(275)$ \\
PERCENT OF HOUSEHOLD INCOME \\
\hline FROM SCHOOL DISTRICT \\
\hline $100 \%$ & $26.91(202)$ \\
$75-99 \%$ & $27.95(133)$ \\
$50-74 \%$ & $26.55(255)$ \\
$25-49 \%$ & $27.54(157)$ \\
$<25 \%$ & $28.75(20)$
\end{tabular}

MEANS BY GENDER AND PERCENTAGE OF HOUSEHOLD INCOME

\begin{tabular}{|l|c|c|c|c|c|}
\hline GENDER & $100 \%$ & $75-99 \%$ & $50-74 \%$ & $25-49 \%$ & $<25 \%$ \\
\hline Female & $26.50(121)$ & $28.80(54)$ & $26.13(157)$ & $27.67(142)$ & $28.56(18)$ \\
\hline Male & $27.52(81)$ & $27.37(79)$ & $27.21(98)$ & $26.27(15)$ & $30.50(2)$ \\
\hline
\end{tabular}

ANOVA - GENDER BY PERCENTAGE OF HOUSEHOLD INCOME

\begin{tabular}{|l|r|r|r|r|r|}
\hline $\begin{array}{l}\text { SOURCE OF } \\
\text { VARIATION }\end{array}$ & Sum of Squares & \multicolumn{1}{|c|}{ DF } & Mean Square & \multicolumn{1}{c|}{ E } & \multicolumn{1}{|c|}{ Sig of E } \\
\hline Main Effects & 282.14 & 5 & 56.43 & 1.58 & 0.16 \\
\hline GENDER & 18.27 & 1 & 18.27 & 0.51 & 0.47 \\
\hline INCOME & 268.96 & 4 & 67.24 & 1.89 & 0.11 \\
\hline 2-Way Interaction & 201.94 & 4 & 50.49 & 1.42 & 0.23 \\
\hline Explained & 484.08 & 9 & 53.79 & 1.510 & 0.140 \\
\hline Residual & $26,964.86$ & 757 & 35.62 & & \\
\hline Total & 27.448 .94 & 766 & 35.83 & & \\
\hline
\end{tabular}


TABLE LIII

ANALYSIS OF VARIANCE: GENDER BY PERCENTAGE OF HOUSEHOLD INCOME DERIVED FROM SCHOOL DISTRICT SALARY

ON SELF-ACTUALIZATION NEEDS

\begin{tabular}{lc} 
TOTAL POPULATION & $37.68(767)$ \\
Female & $37.76(492)$ \\
Male & $37.53(275)$ \\
PERCENT OF HOUSEHOLD INCOME \\
\hline FROM SCHOOL DISTRICT \\
\hline $100 \%$ & $37.26(202)$ \\
$75-99 \%$ & $37.67(133)$ \\
$50-74 \%$ & $38.04(255)$ \\
$25-49 \%$ & $37.96(157)$ \\
$<25 \%$ & $36.10(20)$
\end{tabular}

MEANS BY GENDER AND PERCENTAGE OF HOUSEHOLD INCOME

\begin{tabular}{|l|c|c|c|c|c|}
\hline GENDER & $100 \%$ & $75-99 \%$ & $50-74 \%$ & $25-49 \%$ & $<25 \%$ \\
\hline Female & $37.73(121)$ & $36.89(54)$ & $38.29(157)$ & $37.83(142)$ & $35.50(18)$ \\
\hline Male & $36.32(81)$ & $38.20(79)$ & $37.64(98)$ & $39.20(15)$ & $41.50(2)$ \\
\hline
\end{tabular}

ANOVA - GENDER BY PERCENTAGE OF HOUSEHOLD INCOME

\begin{tabular}{|l|r|r|r|r|r|}
\hline $\begin{array}{l}\text { SOURCE OF } \\
\text { VARIATION }\end{array}$ & Sum of Squares & DF & Mean Square & \multicolumn{1}{|c|}{ E } & \multicolumn{1}{c|}{ Sig of E } \\
\hline Main Effects & 157.320 & 5 & 31.46 & 0.8 & 0.55 \\
\hline GENDER & 8.09 & 1 & 8.09 & 0.21 & 0.650 \\
\hline INCOME & 147.59 & 4 & 36.9 & 0.940 & 0.440 \\
\hline 2-Way Interaction & 258.45 & 4 & 64.61 & 1.65 & 0.16 \\
\hline Explained & 415.77 & 9 & 46.2 & 1.18 & 0.31 \\
\hline Residual & $29,723.69$ & 757 & 39.27 & & \\
\hline Total & $30,139.46$ & 766 & 39.35 & & \\
\hline
\end{tabular}




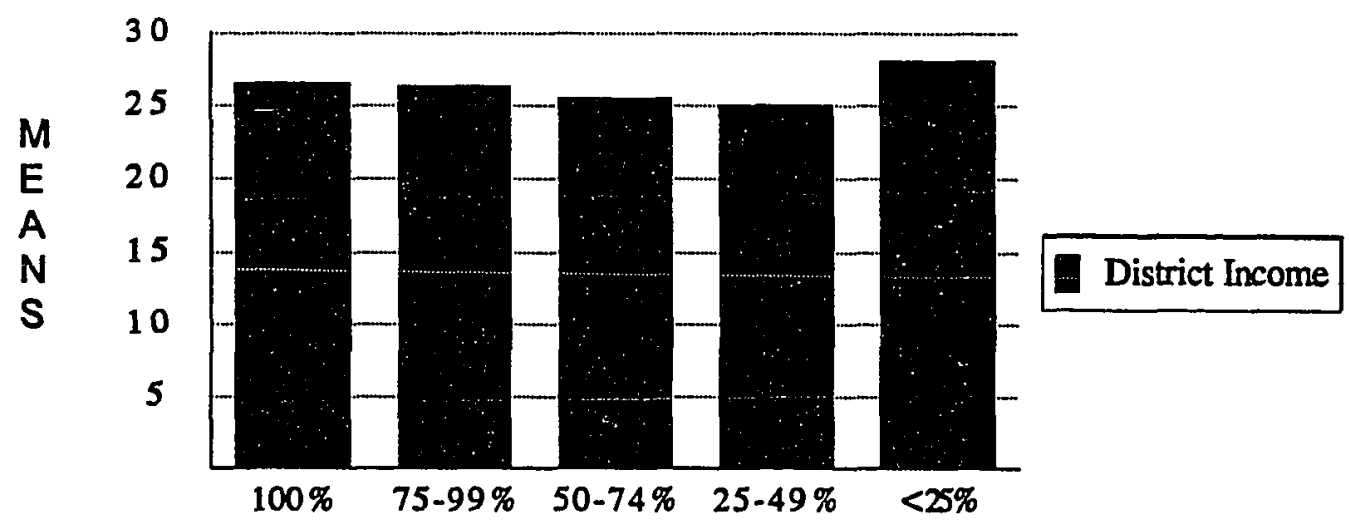

Figure 25. Means by percentage of household income derived from school district salary for security needs.

\section{SUMMARY OF PROCEDURES}

The preceding sections have described the research procedures and data analyses conducted to: 1 ) identify the needs, incentives or motivators that influence teachers to further their professional growth and development; 2) examine the relative strength of the need systems governing their actions; and 3) search for ways in which these incentive structures vary based on a series of demographic variables and attributes.

Development of the instruments to be used in the study included a review of the literature to identify existing instruments that might yield information about the motivators that influence teachers to participate in furthering their professional development. Since an existing instrument was not found, a staff 
development motivation instrument was developed. The Staff Development Motivation Profile was administered to the study population of 2000 teachers, kindergarten through twelfth grades, in the state of Washington.

Data collected from the study respondents were organized and analyzed utilizing a variety of statistical procedures. Mean scores were calculated from the study instruments representing the relative strength of each Need Category. Profile graphs were developed from these scores to illustrate the differences in Need Categories for each group of teachers analyzed and between groups of teachers analyzed. Multiple regressions were conducted to determine the percentage of variance predictable in dependent variables (Need Categories) by the independent variables (Gender, Work Assignment, Size of School District, etc.). Cross-tabulations by gender for all the other demographic variables were generated to help isolate specific sub-groups of teachers for additional study. T-tests were used to compare the mean scores of males and females to check for significant differences in response patterns by gender. Finally, a series of two-way ANOVAs were conducted utilizing Need Categories as the dependent variables and treating gender plus one additional demographic question as the independent variables. This was done in order to discover potentially significant interactions between different sets of demographic variables.

The most significant finding from the study was that despite the series of subtle differences in means produced by manipulating the data, none of the 
variables or attributes had any effect on the basic shape and contour of the composite profile created from plotting the scores of the total group of study respondents. Self-Actualization and Social Needs were the dominant motivators, while Basic, Status and Security Needs were low motivators.

Elaboration and conclusions drawn from this and other findings derived from the preceding statistical procedures are found ir: Chapter V. 


\section{CHAPTER V}

\section{SUMMARY, ANALYSIS, AND RECOMMENDATIONS}

\section{SUMMARY OF THE RESEARCH DESIGN}

This summary highlights the research focus of the study, the research questions pursued in the study, and the research procedures utilized in their deliberation. Additionally, a series of recommendations based on the findings of the study are provided.

\section{The Research Focus}

The major focus for investigation in this study was the identification of factors that motivate teachers to participate in professional development activities. Motivating factors were measured by a specially developed instrument (Staff Development Motivation Profile) based on the five-level Maslow (1954) Need Hierarchy and the Herzberg (Herzberg et al., 1959) Work-Motivation construct. This thirty item forced-choice instrument utilized three basic statement stems regarding motivation to participate in staff development activities. Eight demographic questions were added to provide depth to the study by including a series of variables potentially influential to motivation. 
The study also sought to identify variables that might contribute to the factors motivating teachers to participate in staff development activities. Those variables included: a) years of certificated public school teaching experience, b) proportion of household income attributable to individual salary, c) size of school district of present assignment, d) gender, e) major work assignment, f) percent of income attributable to school district salary, g) highest degree held; and $h$ ) degree of mobility on district salary schedule. The analysis unit utilized as the study population was comprised of all teachers, kindergarten through twelfth grade, in the state of Washington during the 1986-1987 school year.

\section{Research Hypothesis and Questions}

The underlying research hypothesis used as the foundation for this study was the belief that although teachers are motivated to participate in professional growth and development activities for different reasons, it would be possible to identify common factors that form a distinguishable incentive profile for them.

Within the primary focus of the study, i.e., the identification of factors that motivate teachers to participate in staff development activities, three major questions were presented:

1. What are the needs, incentives or motivators that influence teachers to further their professional growth and development?

2. What is the relative importance of various incentives or motivators for teachers in the area of professional/staff development? 
3. How do the incentive structures of teachers vary based on a set of variables that includes gender, years of teaching experience, size of school district, teaching assignment, highest degree held, potential for mobility on salary schedule, grade level assignment, and proportion of income attributable to school district salary?

Question one was answered in the process of conducting the literature review on staff development and while developing the research instruments used in the study. Responses to questions two and three emanated from the administration and analysis of the research instruments.

The major survey instrument developed for this study, the Staff Development Motivation Profile, asked respondents to distribute five points between two statements that were matched with levels of Maslow's (1954) and Herzberg's (Herzberg et al., 1959) constructs. The statements were categorized in the following manner:

$\begin{array}{lll}\text { Basic Needs } & =* & \text { Time and Money Concerns } \\ \text { Security Needs } & = & \text { Job Security/ Work Evaluation } \\ \text { Social Needs } & = & \text { Collegiality/ Social Interaction } \\ \text { Status Needs } & = & \text { Personal Recognition/ Rewards } \\ \text { Self-Actualization } & = & \text { Personal Satisfaction/Growth } \\ \text { *(the = sign should be read as "corresponds to") }\end{array}$


The scoring system utilized in the Staff Development Motivation Profile produces an individual or group profile that shows the relative strength of each of the five "need" categories. The highs and lows of this profile indicate the satisfied and unsatisfied sources of motivation and, combined, portray an individual's or group's incentive structures for participating in professional development activities.

\section{Research Procedures}

While some thought was given to utilizing interviews or case studies to determine teacher's attitudes toward participating in staff development activities, the obvious limitations of these methods in terms of the numbers of possible subjects discouraged their use. Since one of the purposes of the study was to find out what incentives motivate them, it seemed appropriate to seek answers by asking teachers themselves-and in sufficient numbers to be able to generalize to the broader population of teachers within the United States.

Another consideration in selecting the research procedures for this study was the fact that teachers' belief structures and attitudes were to be examined in the study. According to McCall (1982), the most common method for attitude testing in teachers is the sampling method. Also of importance was the opportunity provided by the Washington Education Association to conduct a state-wide survey by drawing a sample from nearly the entire population of teachers in the state of Washington. 
Development of the instruments to be used in the survey included a review of the literature to identify existing instruments that might provide information about the motivators that influence teachers to participate in staff development activities. Since an existing instrument was not found, new instruments, based on some preexisting models from the business sector, were developed.

Data collected from the study respondents were organized and analyzed utilizing a variety of statistical procedures. Profile graphs of mean scores were developed to illustrate the differences among Need Categories for one group and between groups. Multiple regressions were conducted to determine the percentage of variance predictable in dependent variables (Need Categories) by the independent variables (Gender, Work Assignment, Size of School District, etc.). Cross-tabulations by gender for all the other demographic variables were generated to help isolate specific sub-groups of teachers for additional study. T-tests were used to compare the mean scores of males and females to check for significant differences in response patterns by gender. Finally, a series of two-way ANOVAs were conducted, utilizing Need Categories as the dependent variables and demographic data as independent variables, to discover potentially significant interactions between different sets of variables. 


\section{SUMMARY AND ANALYSIS OF MOTIVATORS FOR PARTICIPATING IN STAFF DEVELOPMENT}

\section{Composite Picture of Total Respondents}

Question Number One. What are the needs, incentives or motivators that influence teachers to further their own professional growth and development?

The existing literature on staff development, motivation theory, and more specifically, teacher motivation theory provided the foundation for defining the needs, incentives and motivators that influence teachers to participate in professional growth and development activities. A five-tiered structure based on Maslow's (1954) Hierarchy of Needs and Herzberg's (Herzberg et al., 1959) Motivation construct was developed to categorize the types of incentives most commonly considered by classroom teachers. The resulting categories of motivators were described in the following manner:

Basic Needs:

- Receiving extra pay or release time

- Potential for advancing on salary schedule

- Not requiring more work or cutting into time for personal pleasures

Security Needs:

- Ensuring job security 
- Looking good on evaluations thereby helping to ensure job security

- Feeling more secure about the job and more able to cope with changes in the field

Social Needs:

- Opportunities to build positive relationships with colleagues, to socialize, and to share good times - Interacting with colleagues, exchanging ideas, and sharing experiences

- Colleagues participating and working together as a team Status Needs:

- Receiving personal recognition and tangible rewards

- Providing additional expertise or assistance in obtaining an advanced degree that would provide personal recognition - Providing an opportunity to demonstrate competence and be recognized by others as being one of the better educators in the group

Self-Actualization Needs:

- The personal satisfaction of learning new skills that are relevant to the job 
- Engaging in staff development that is stimulating and challenging

- Being able to learn, grow professionally, and become more knowledgeable.

Relative Strength of Needs, Incentives, Motivators

Question Number Two. What is the relative strength of various needs, incentives or motivators in influencing teachers' participation in professional/staff development activities?

The means for each Need Category (Basic, Security, Social, Status, Self-Actualization) as measured by the Staff Development Motivation Profile, were calculated for the total group of 770 teachers. When the means were visually represented on a graph, the resulting profile presented a clear picture of the relative strength of each Need Category as measured against the other four Need Categories. The peaks and valleys represented the satisfied and unsatisfied sources of motivation, and the profile produced a picture of the teachers' orientation toward participating in staff development activities. The highest points identified those need systems that were least satisfied, were of most concern, and were potentially the strongest motivators for the teachers.

The profile that represents a composite of all the teachers responding to the Staff Development instrument indicates that the greatest sources of 
motivation were the and Self-Actualization and Social Needs (see Figure 26). This would suggest that teachers responding to the survey considered personal self-actualization needs and social needs (interacting and sharing with other teachers) to be their major impetus for participating in staff development activities.

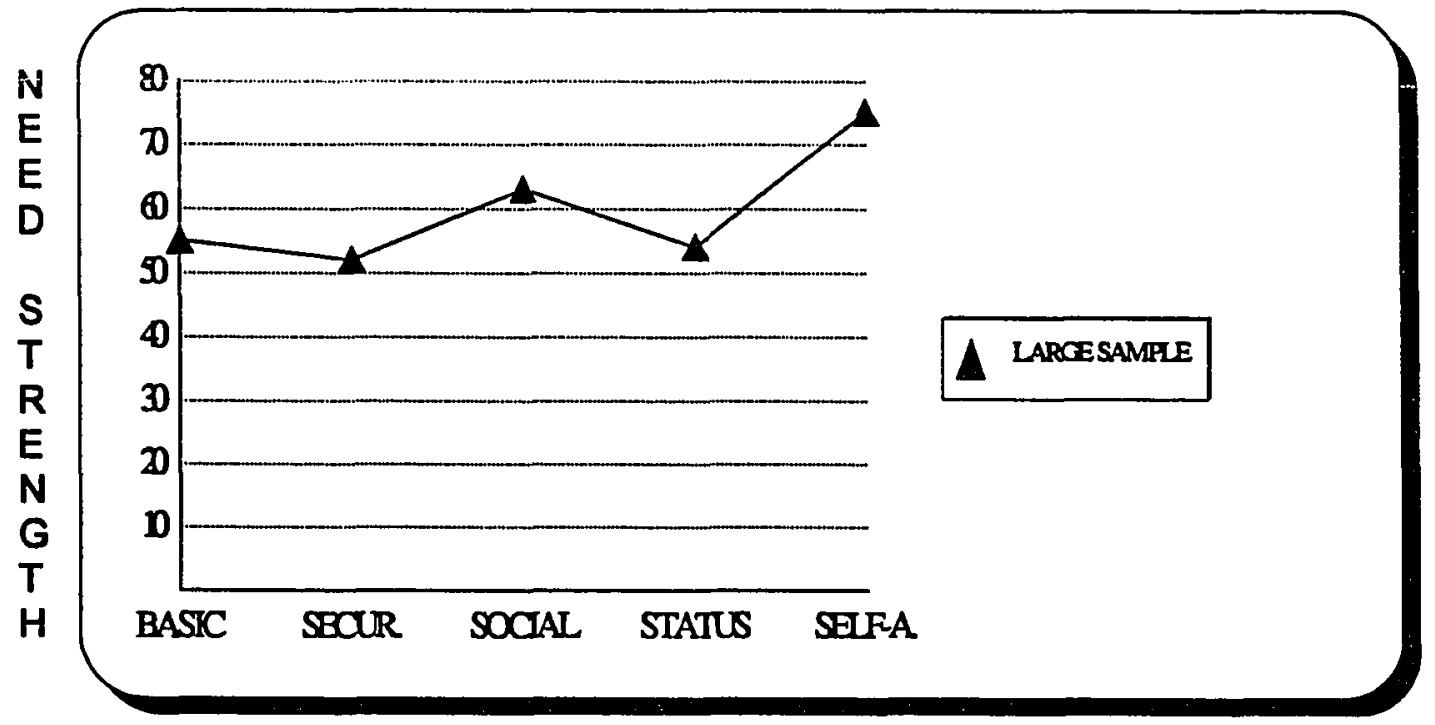

Figure 26. Staff Development Motivation Profile (large sample).

Although both the Social Needs and the Self-Actualization Needs were high, the Self-Actualization score was by far the highest. This finding revealed that the primary need that prompted teachers in this sample to continue their professional development was the intrinsic motivation of self-actualization.

Social Needs was the second highest scoring Need Category. The composite profile clearly showed Social Needs as a prominent though secondary 
peak on the graph. Perhaps the notion that teachers feel isolated in their classrooms should be given more study. Elmore and McLaughlin (1988) point out that "the professional existence of a classroom teacher is necessarily isolated [with] only episodic interaction with other adults..." (p. 5).

The third Need Category in order of prominence on the profile was Basic Needs. This relatively lower score on Basic Needs would lead one to conclude that teachers in this study were not driven to participate in staff development primarily for purposes of additional pay.

The fourth Need Category in order of prominence on the graph and strength of mean score was Status. This lower Status Need score might indicate that teachers were also not primarily concerned with seeking higher status when considering whether or not to pursue professional development activities.

The Need Category with the lowest mean score was Security. The relatively low Security Need indicates that this group of teachers did not feel that the continuance of their positions depended on their further participation in staff development.

Before making decisive statements based on the preceding information, it is important to keep in mind that the Staff Development Motivation Profile was designed to yield a series of relative scores that must be considered in 
relationship to one another, rather than as absolute measures or in comparison with any predetermined absolute scores.

\section{Impact of Variables on Incentive Structures}

Question Three. The third major question asked in this study was how the incentive structures of teachers vary based on the following variables:

- gender

- number of years of teaching experience

- work assignment

- highest degree earned

- mobility on district salary schedule

- proportion of household income attributable to district salary

- grade level assignment

- $\quad$ size of school district (pupil enrollment)

Gender differences were explored through the use of $t$ tests comparing the mean scores of males and females for the five need categories. A series of multiple regressions isolated the variables that might predict significant variance within the Need Categories. The information gained through these procedures was utilized to guide the further study of subcategories of respondents and the profiles produced by their mean scores. The following variables were selected for more in-depth scrutiny: Gender, Gender by Years of Teaching Experience, 
Gender by Percentage of Income Attributable to School District Salary, Gender by Work Assignment, and Gender by Size of School District (Pupil Enrollment).

Gender. When males and females were compared on the five Need Categories, the results showed no significant differences. The profiles for both groups were nearly identical (see Figure 27). A comparison of the composite profile and the male and female profiles indicates that self-actualization and social needs are the greatest sources of motivation in all cases (see Figure 28). Although not statistically significant, the basic need score of males was higher than that of females, while females had a higher Social Need score.

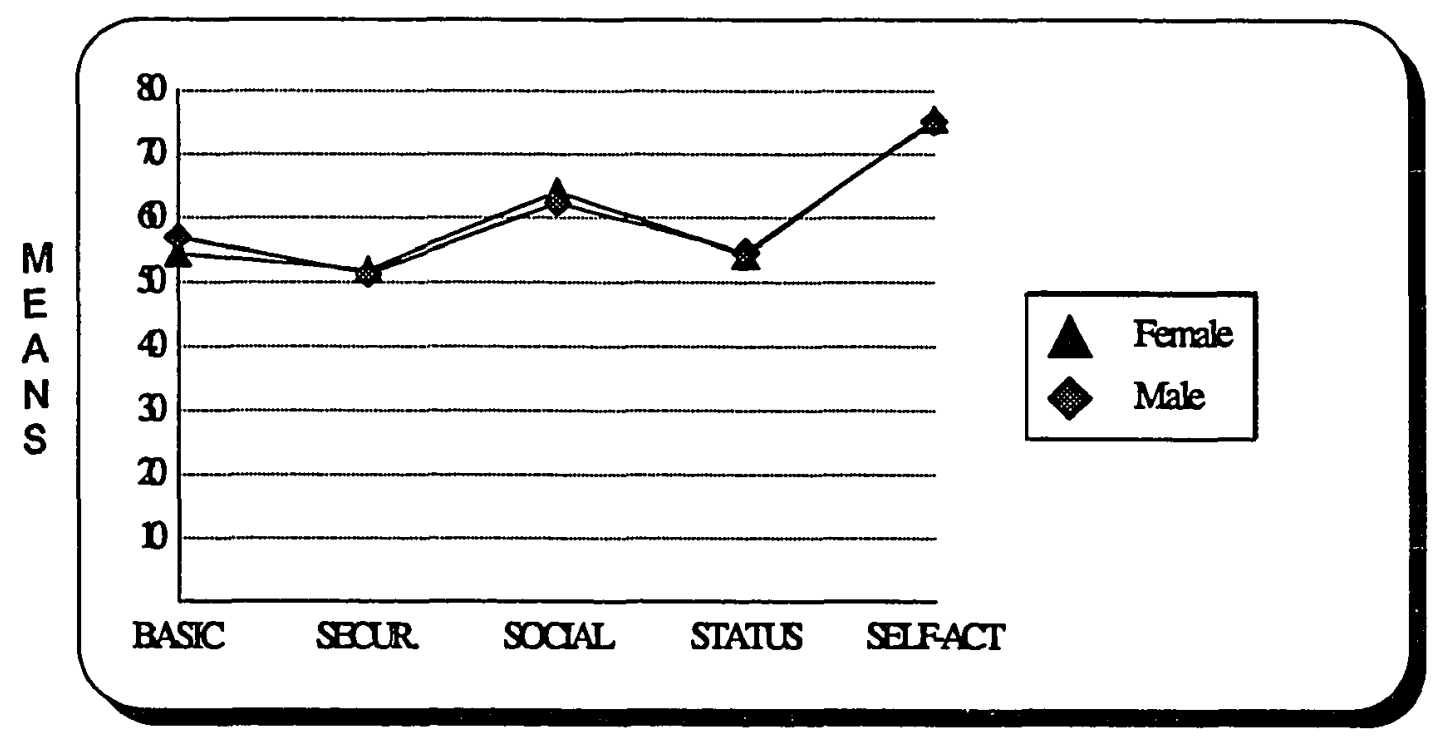

Figure 27. Total sample means by gender. 
Both male and female teachers scored self-actualization as the highest need, indicating that both groups were prompted to continue their professional development primarily for the intrinsic motivation of self-actualization. Self-Actualization needs were described in this study as : (a) the personal satisfaction of learning new skills that are relevant to the job; (b) engaging in staff development that is stimulating and challenging; and (c) being able to learn, grow professionally, and become more knowledgeable.

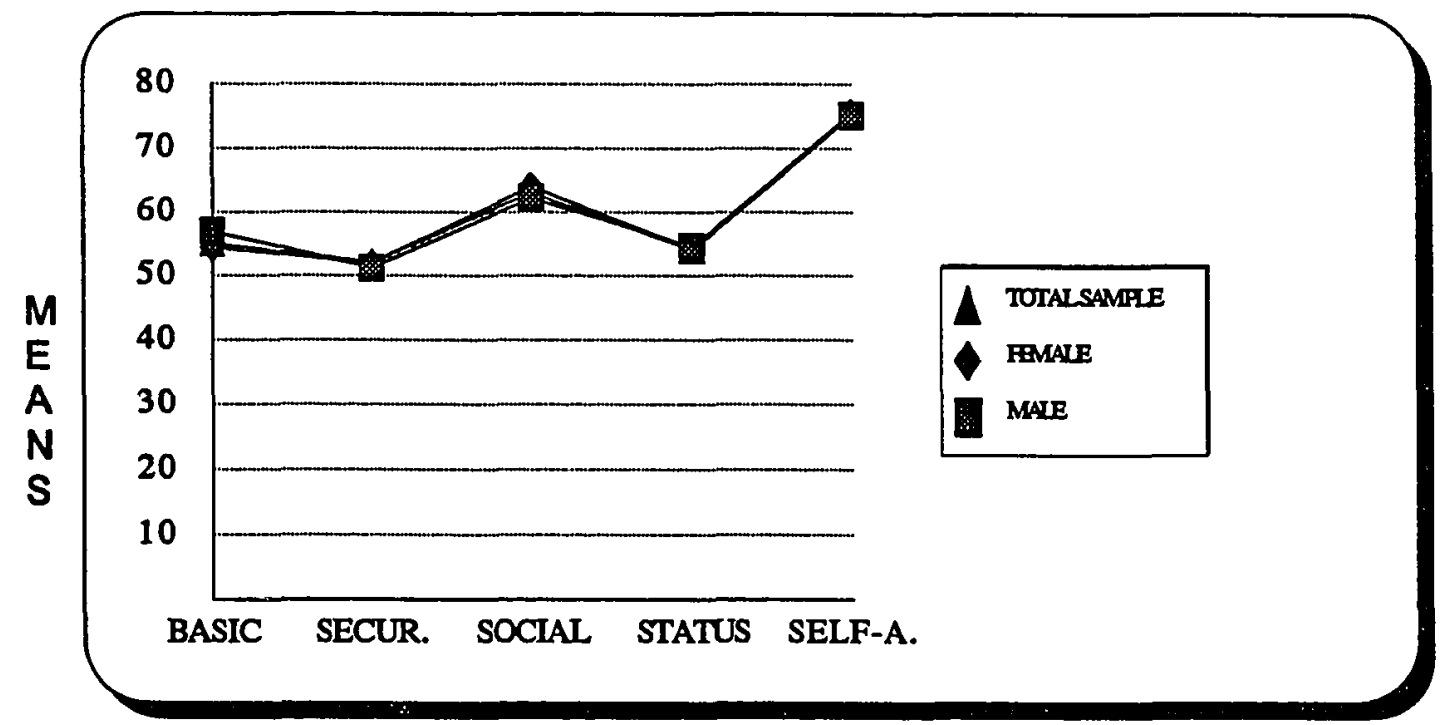

Figure 28. Total sample means and total sample means by gender.

These findings are supported by research cited earlier. Lortie (1975) suggested that intrinsic motivators are the most powerful forces that affect teachers. Among the list of intrinsic motivators cited by researchers are: 
working with students, observing students learn and succeed; belief in the value of helping others, and being able to grow personally and professionally (Bishop, 1977; Glenn \& McLean, 1981; Lortie, 1975).

Gender by Years of Teaching Experience. Since gender alone did not effect significant differences in the Needs Category responses of study respondents, a further investigation of the data was made utilizing gender in conjunction with the demographic questions asked on the survey instrument. Although the preliminary data analysis had not indicated that Years of Teaching Experience yielded statistically significant results, the possibility that adding gender as an additional variable would make a difference was considered. A two-way ANOVA of Teaching Experience by Gender for all Needs Categories was calculated.

Years of full-time public school teaching experience were divided into four categories with eight years in each group. Teachers with zero to eight years of experience were grouped together to represent one segment of the teaching population. This group was described as "newcomers" to the profession. Those teachers with 9 to 16 years of teaching experience were described as "established professionals". Teachers with 17 to 24 years of experience were referred to as "veteran teachers." Teachers with 24 or more years of experience were considered "career teachers". 
Results of the two-way ANOVA showed differences in the categories of Years of Experience on Basic Needs, Years of Experience by Gender on Basic Needs, and Years of Experience on Social Needs. "Established professionals" (9-16 yrs.) and "veteran teachers" (17-24 yrs.) showed a slightly higher Basic Need mean score than the "newcomers" (0-8 yrs.) or the "career teachers" (25+ yrs.), see Figure 29. The categories of "established" and "veteran" teachers accounted for $62 \%$ of all the teachers participating in this study. "Established" and "veteran teachers" were more motivated to participate in Staff Development activities by Basic Needs than were the other two groups of teachers.

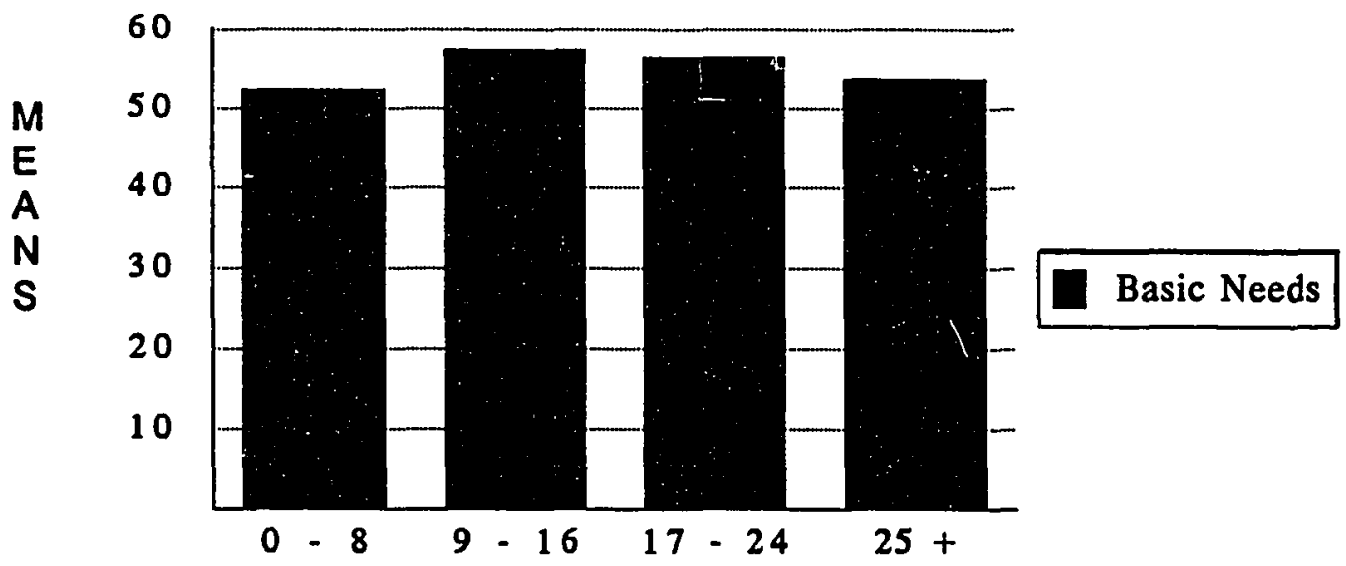

Figure 29. Means by years of teaching experience for basic needs.

The fact that teachers with 9 to 24 years of experience displayed elevated basic need concerns directly addresses the problems of teacher retention in the profession. According to Engleking (1987), low salaries and small salary 
increments are discouraging individuals from remaining in teaching. He points out that "annual raises in teaching salaries have not kept pace with the economy" (p. 2).

A two-way interaction effect between Years of Experience and Gender was also found on Basic Needs (see Figure 30). "Newcomer" males showed a slightly higher score than females on Basic Needs. "Veteran" males had an even higher mean score on Basic Needs than females. The Basic Needs of beginning male teachers and of veteran male teachers appeared to be greater motivators for participation in Staff Development activities than they were for females of the same years of teaching experience. Perhaps male teachers are most concerned about compensation issues when they begin teaching, and again midway into their careers.

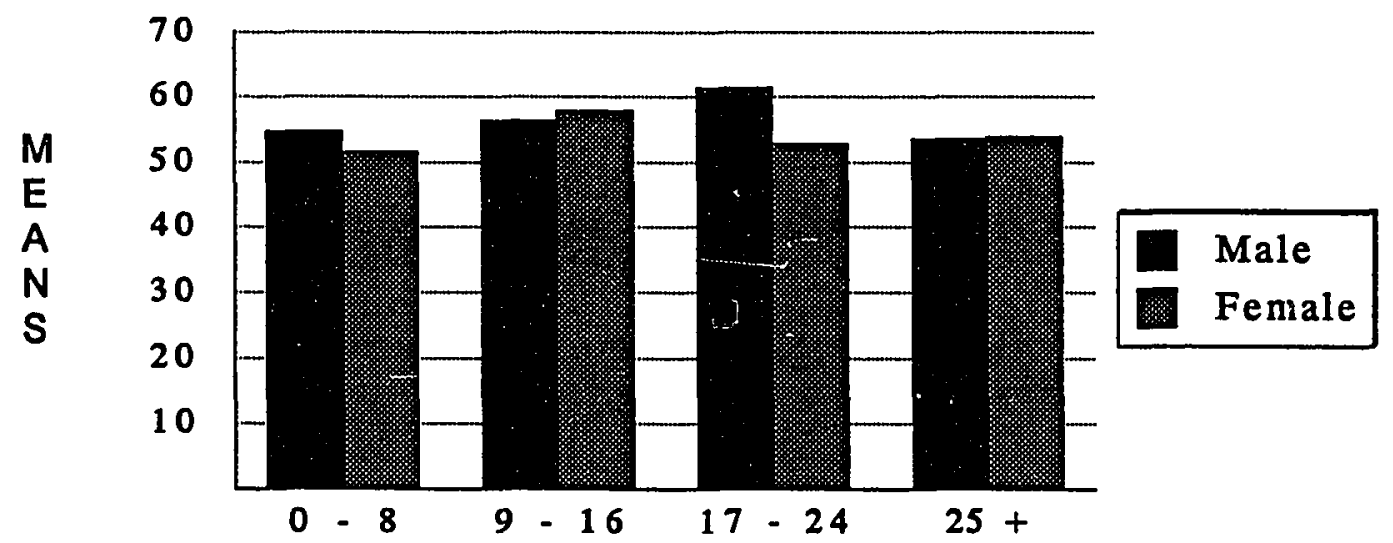

Figure 30. Means by years of teaching experience and gender for basic needs. 
The inadequate compensation of teachers is a continuous theme in the education literature. In his book, High School, Boyer (1983) discussed the difficulty of living on a teacher's salary. He reported that nationally, nearly $30 \%$ of teachers moonlight at a second job, while others hold a third job. Another $36 \%$ of teachers take summer jobs to supplement their teaching income.

No significant main effects were found for years of experience or gender on Security Needs, Ego/Status Needs, or Self-Actualization Needs. Social Needs, however, were affected by years of teaching experience. "Newcomer" teachers (0-8 yrs.) scored slightly higher in the Social Needs category than the rest of the groups (see Figure 31). Perhaps beginning teachers have a lesser ability to cope with the isolation of the classroom and have an even higher social need than the rest of the teaching population.

The topic of the isolated and isolating nature of the classroom has been discussed by numerous researchers. Rosenholtz (1984) comments that "teachers spend much of their time cut off from colleagues, neither seeing nor hearing others teach" (p. 5). According to Lortie (1975), many teachers have no contact with other adults during the workday. Little (1981), in her study of staff development in urban, desegregated settings, emphasized the importance of teachers working together and operating as colleagues or team members in order for successful staff development to take place. Little also found that 
teachers are more likely to participate in staff development activities in situations that encourage the sharing of knowledge and experiences.

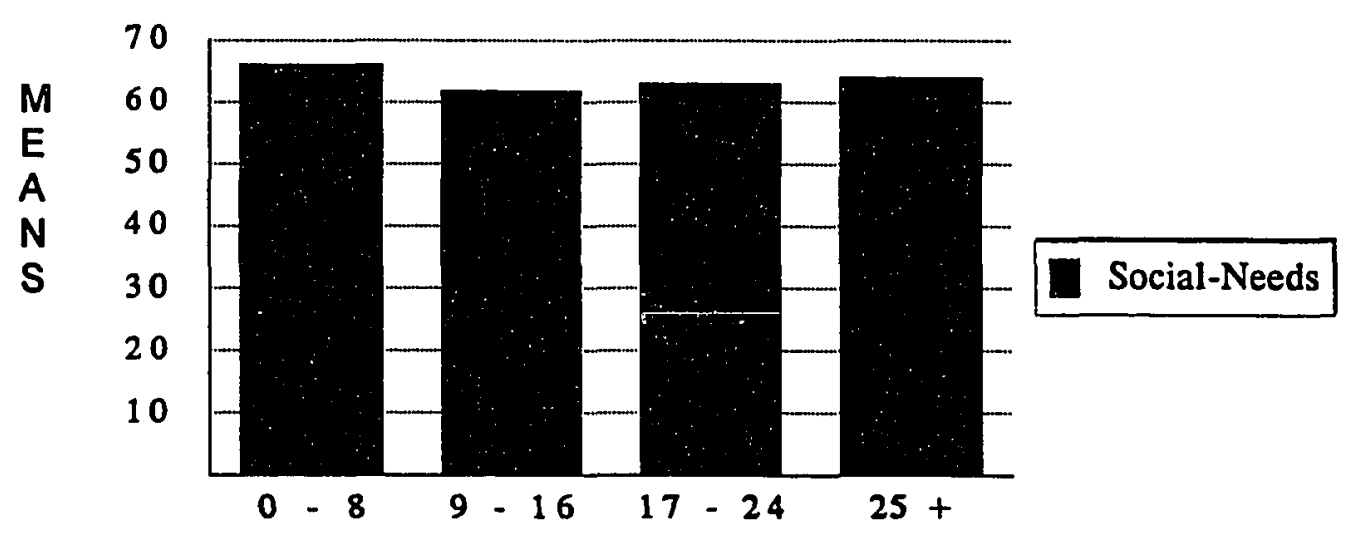

Figure 31. Means by years of teaching experience for social needs.

Gender by Major Work Assignment. Another demographic question used in this study asked the respondents' major work assignment. Five response choices were given: a regular classroom teacher, b) teaching specialist (music, art, reading, librarian), c) special education teacher (resource, Chapter I, etc.), d) certificated support personnel (counselor, nurse, audiologist, etc.), e) other. Sixty-nine percent of all respondents fell into the category of classroom teacher, and the remaining thirty-one percent were a combination of all other categories. For purposes of analysis, therefore, respondents were grouped into two categories-"classroom teacher" and "other."

The two categories of Work Assignment were examined by Gender for all the Need Categories. Results of a two-way ANOVA showed significant 
effects of Work Assignment on Basic Needs, on Security Needs and on Status Needs. No two-way interaction effects of Gender and Work Assignment on any of the Need Categories was found.

The Basic Need Category was affected by differences in Work Assignment. A comparison of the means for the two categories of Work Assignment indicated that Regular Classroom Teachers had a higher Basic Need score than the "Other" category (see Figure 32). Regular Classroom teachers responded to the questionnaire in such a way as to indicate that they would be more influenced by Basic Need considerations than other teachers when deciding to participate in Staff Development. In most school districts, teaching specialists earn higher salaries because they possess advanced degrees or specialized credentials, and this may account for the differences in concern for additional pay. In 1991, the average yearly national salary differential for teachers with a master's degree or higher, compared with teachers with a bachelor's degree or less, was $\$ 8,569$ (NEA, 1992).

Work Assignment also had a significant effect on Security Needs. The means for the two categories of Work Assignment indicate that "Other" teachers had a higher Security Need score than Regular Classroom Teachers (see Figure 33). This may be due to the fact that positions such as art or music teachers, librarians, counselors and nurses are more likely to be cut when school districts are faced with budget cuts. For teachers in these positions, job security could 
be a compelling factor to encourage them to participate in inservice training. Job security as a real concern is given credence by a review of the demographic characteristics of teachers nationally in 1986 and 1991 . In this study, $69 \%$ of the subjects reported being "regular classroom teachers." Thirty-one percent were in the "other" category: teaching specialists, special education, or certificated support personnel. The same year that this survey was conducted, NEA (National Education Association, 1989) reported from their national survey of teachers that $73 \%$ of all respondents were "regular classroom teachers," and $27 \%$ fell into the "other" category. By 1991, in a follow-up survey also conducted by NEA, the "other" category of respondents had shrunk by $7.5 \%$ to $19.5 \%$. As financial resources are shrinking, many of the "other" categories of teaching positions are being reduced.

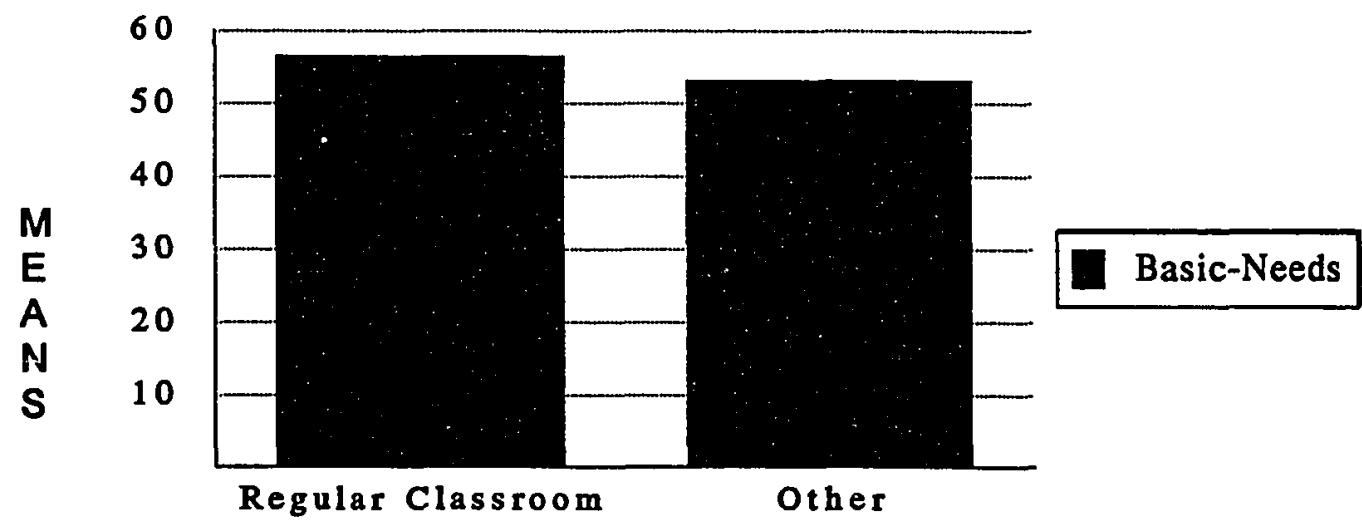

Figure 32. Means by major work assignment for basic needs. 


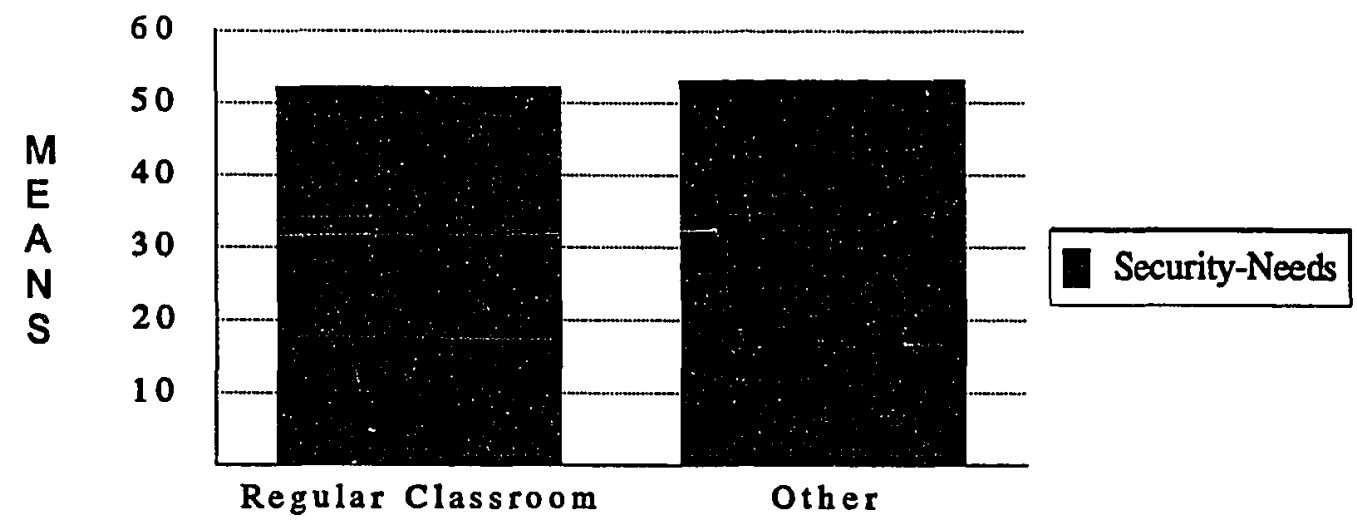

Figure 33 . Means by major work assignment for security needs.

Moreover, Status Needs were similarly affected by Work Assignment. "Other" category teachers had higher Status Need scores than the regular classroom teachers (see Figure 34). This might be explained by the fact that teaching "specialists" often have obtained advanced degrees or specialized credentials and consequently may have higher Status Needs in mind as they decide whether or not to participate in Professional Development.

Gender by Pupil Enrollment in District (Size of School District). Multiple regressions conducted early in the data analysis process identified "Pupil Enrollment in the District" as a variable which would predict variance within the Need Categories. The study questionnaire asked respondents to indicate the approximate pupil enrollment in their districts. Four response choices were provided: a) Small-2,000 or fewer pupils, b) Medium-from 2,001 to 9,999 pupils, c) Large-10,000 or more pupils, and d) Don't know/not sure. 
Approximately $19 \%$ of the study participants taught in "Small" school districts, about $41 \%$ were from "Medium-sized" districts, and slightly over $35 \%$ taught in "Large" districts.

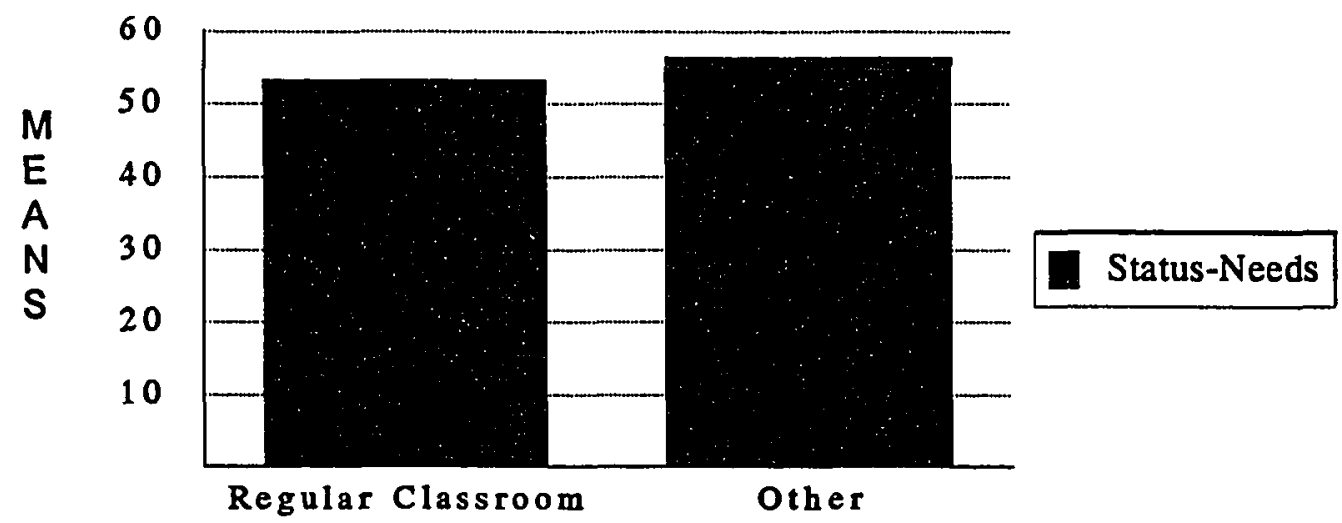

Figure 34 . Means by major work assignment for status needs.

A two-way ANOVA of Gender by Size of School District revealed effects of both Gender and Pupil Enrollment separately on Basic Needs. Differences in Security Needs were attributable to differences in Pupil Enrollment and the interaction of Gender and Pupil Enrollment. Another effect was noted in Social Needs attributable to differences in Size of School District.

Both Gender and Pupil Enrollment, independently, effected significant differences on Basic Needs scores. The Basic Needs mean for the total group of males was higher than that of females (see Figure 35). This difference did not become statistically significant until the total number of respondents considered 
in the analysis dropped from 770 to 729 by virtue of omitting those individuals who responded "don't know/not sure" on the demographics portion of the survey.

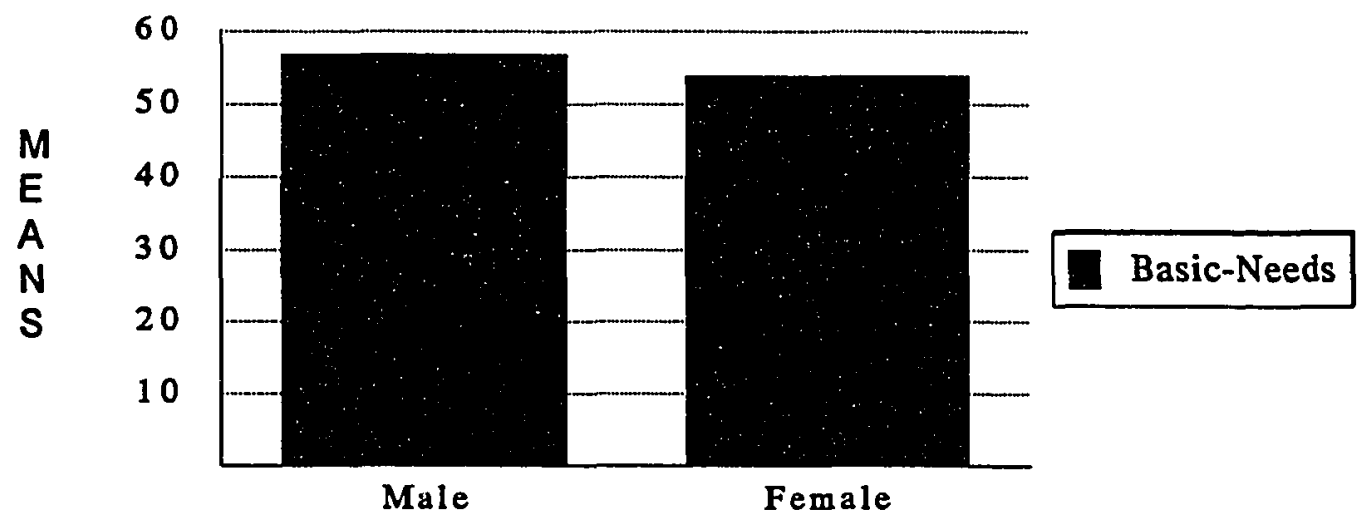

Figure 35. Means by gender for basic needs.

Differences in Pupil Enrollment alone also generated significant differences in the means for Basic Needs. As the size of the school district increased, the Basic Need mean scores also increased (see Figure 36). Teachers in "Large" districts (10,000 or more students) scored higher in Basic Needs than teachers in either "Medium" or "Small" districts. This finding suggests that the teachers from larger school districts were more likely to consider Basic Needs concerns in their decisions to pursue additional professional development.

Security Need scores were affected by Pupil Enrollment and by the interaction of Gender and Pupil Enrollment. The size of the school district had a different effect on Security Needs than it did on Basic Needs (see Figure 37). 
Teachers in "Small" districts had a higher Security Need mean than teachers in "Medium" or "Large" districts. Teachers in "Medium-sized" districts had the lowest mean scores. Perhaps teachers in small districts have greater job security concerns than those in larger districts because of the more limited number of teaching positions.

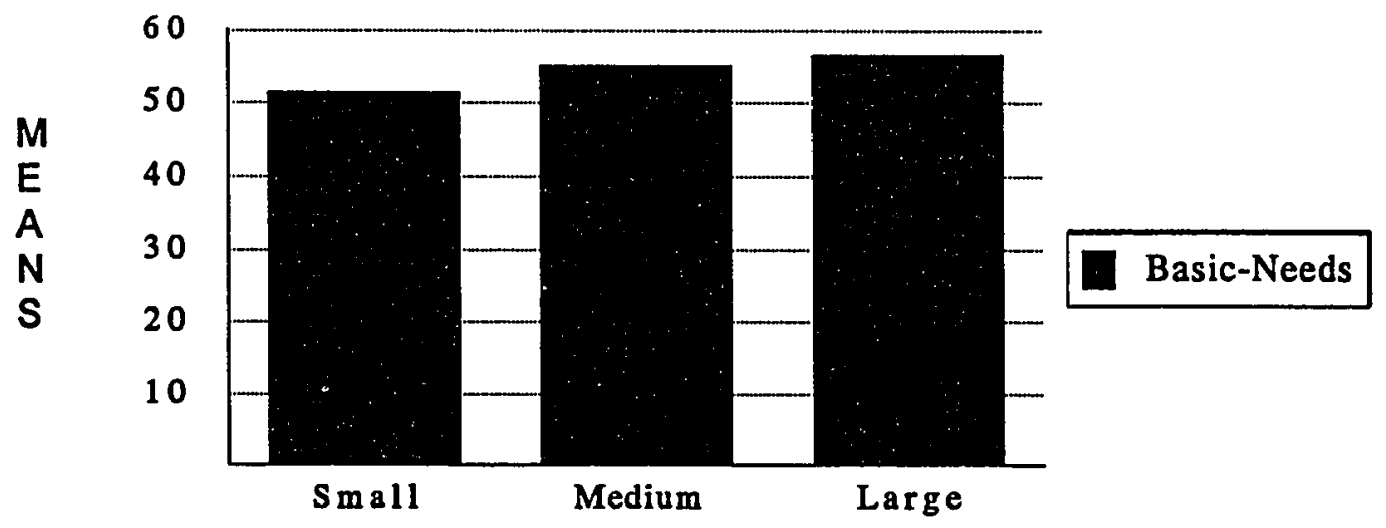

Figure 36. Means by size of school district for basic needs.

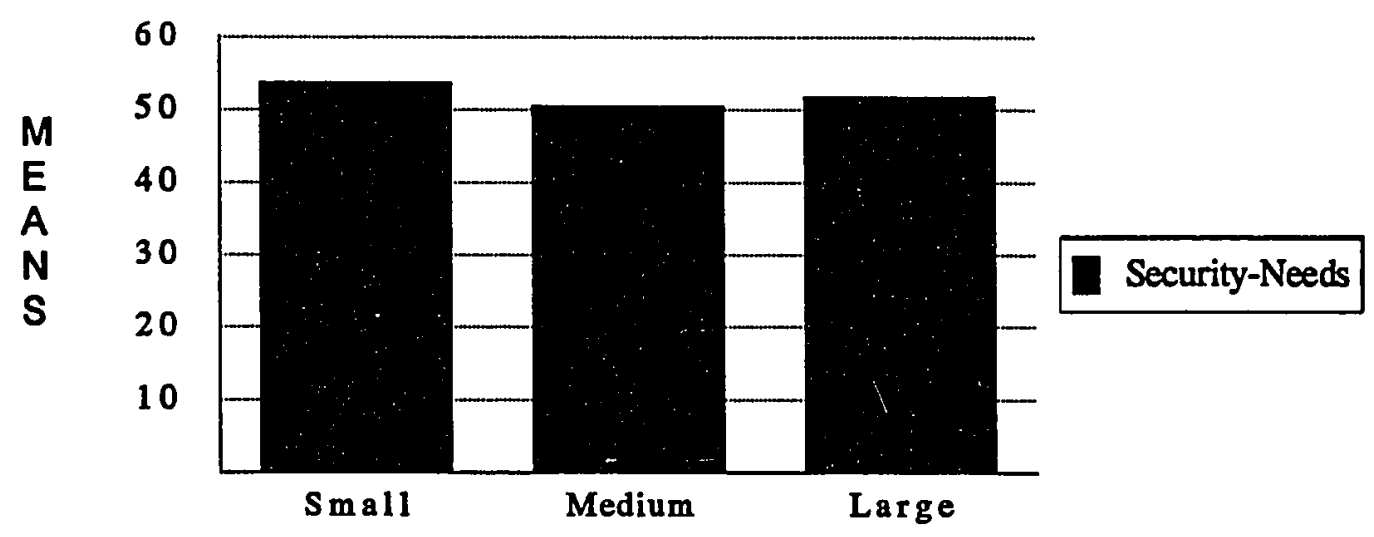

Figure 37. Means by size of school district for security needs. 
The two-way interaction of Gender and Pupil Enrollment also yielded interesting effects. Males in "Small" districts had a higher Security Need score than females (see Figure 38). The Security Need means for males and females in "Medium-sized" districts were nearly the same. Females in the "Large" districts, however, had a higher Security Need mean than the males.

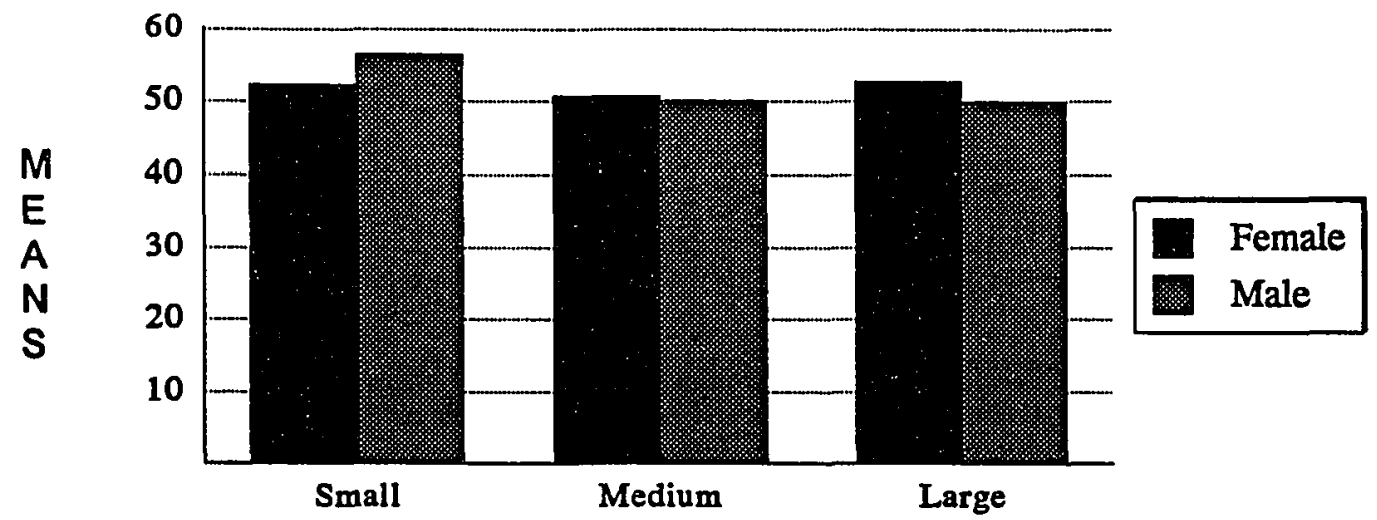

Figure 38. Means by gender and size of school district for security needs.

The last significant effect found through the two-way ANOVA of Gender and Pupil Enrollment by the five Needs Categories was one of Pupil Enrollment on Social Needs. As the size of the district became larger, the Social Need means became smaller (see Figure 39). In other words, teachers in the "Smaller" districts had a higher Social Needs score than teachers in Larger Districts. Teachers in "Smaller" districts, therefore, would be more likely to consider their social needs in deciding whether or not to participate in staff development activities. One could surmise that smaller staffs in smaller districts 
come to expect more interaction with their colleagues than teachers in larger districts, where isolation may be the norm. Support for such a conclusion is bolstered by findings from a study conducted by the National Education Association. The percentage of teachers participating in curriculum or other committee work (collegial interaction) was greater in small and medium-sized school systems than in large systems (NEA, 1992).

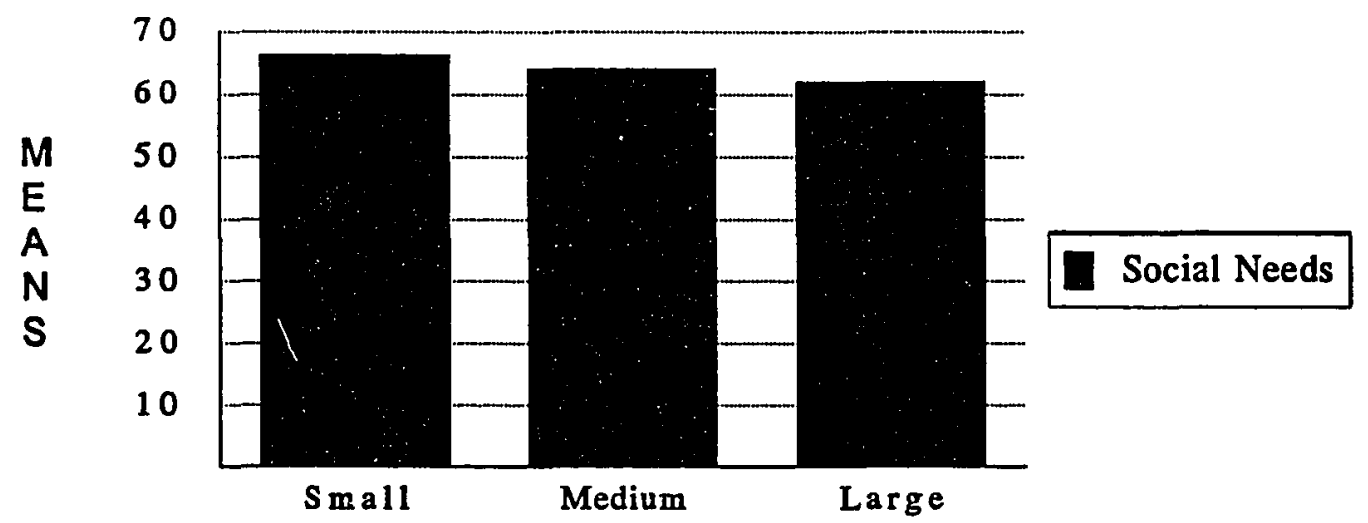

Figure 39. Means by size of school district for social needs.

Gender by Percentage of Household Income Attributable to District Salary. The final variables for which an analysis of variance was conducted were Gender by Percentage of Household Income Attributable to School District Salary. When the multiple regressions conducted earlier indicated that Percentage of Income alone was not a significant predictor of variance, the decision was made to add Gender for a two-way analysis. Since money is commonly considered an incentive for motivating teachers (Frase, Hetzel, \& 
Inman,1987; Olson, 1986), it was thought important to be exhaustive in the analysis of the demographic question involving income.

Teachers were asked the question, "What proportion of your household's total income is attributable to your school district salary?" The five choices of response were: $100 \% ; 75-99 \% ; 50-74 \% ; 25-49 \%$; and less than $25 \%$. Approximately one-fourth of the teachers surveyed derived $100 \%$ of their income from teaching. Nearly half of the teachers derived at least three-fourths of their entire household income from their school district salary. As a group, it might be expected that these teachers would be influenced by the potential for extra pay or advancement on the salary schedule.

Surprisingly, there were no significant Gender differences by Percentage of Income for any of the Need categories. There was, however, no effort made to determine what percentage of either males or females comprised each of the five salary distribution categories listed above. Since the focus of this study was teachers in general rather than a gender specific analysis, no further breakdown by gender was made. This could be a focus for further study.

The only significant main effect or interaction in the analysis was the main effect of Percentage of Household Income on Security Needs. In this area, an unexpected curvilinear relationship was found, in that teachers on either end of the Percentage of Household Income scale had higher Security Need scores than those in the middle. In fact, teachers who derived less than $25 \%$ of their 
household income from teaching had by far the highest Security Need score of all the groups (see Figure 40). Teachers who derived $100 \%$ of their salary from teaching had the second highest Security Need, and the lowest Security Need scores came from teachers receiving $25 \%$ to $99 \%$ of their income from teaching.

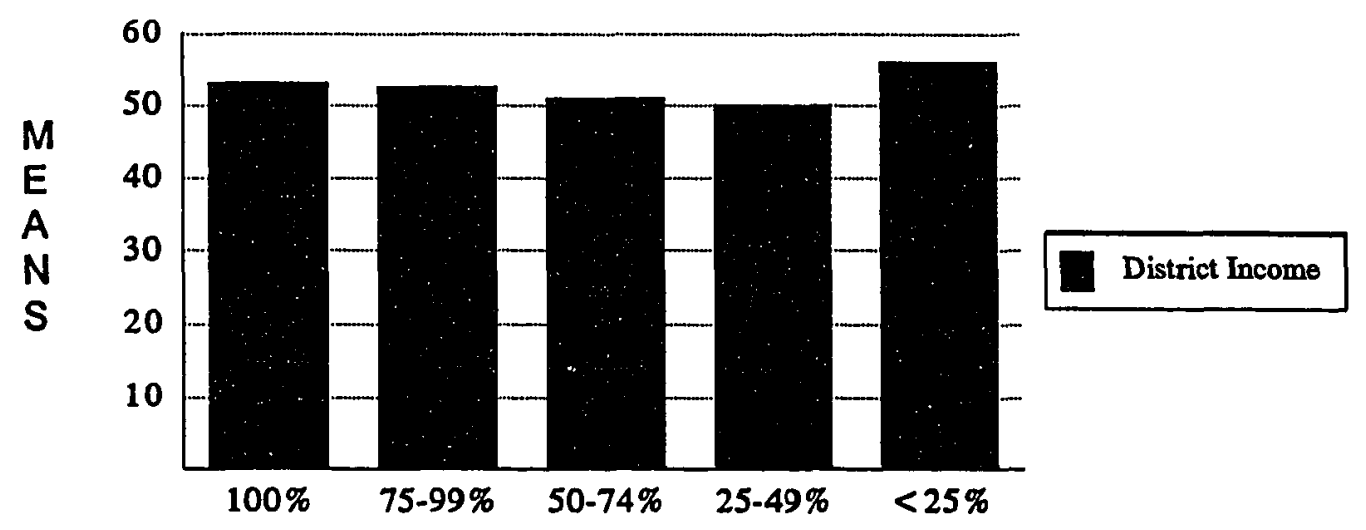

Figure 40. Means by percentage of household income derived from school district salary for security needs.

Percentage of Household Income had no major effect on the incentive structures governing participation in staff development activities. The profiles generated by these subgroups of teachers displayed the same basic pattern that had been established by the total population of teachers. 


\section{SUMMARY OF FINDINGS FROM THE STUDY}

This study was undertaken to identify factors that motivate teachers to participate in furthering their professional development through inservice training. According to Lawler and Porter (1967), individuals are impelled to action in the work setting by a wide variety of reasons and motivators. This study sought to determine the relative motivational strength of certain predetermined incentives based on the Maslow (1954) and Herzberg (Herzberg, et al., 1959) need structures. The study further sought to discern how the incentive structures vary based on a series of variables including gender, size of school district, major work assignment, years of teaching experience and percent of household income attributable to school district salary.

The study was designed to produce a series of profiles, represented by graphs, that would provide visual representations of the relative strength of the various sources of motivation. The contours of the profiles represent the satisfied and unsatisfied motivations/needs of teachers, and create a picture of teachers' orientation toward participating in staff development.

\section{Major Findings}

There were four major findings from the study:

Two Greatest Sources of Motivation. The two greatest sources of motivation for teachers to pursue further professional development were 
Self-Actualization Needs and Social Needs. Although both the Social Needs and the Self-Actualization Needs were strong, the Self-Actualization Need score was by far the highest. This finding revealed that the primary need that prompted teachers in this sample to continue their professional development was the intrinsic motivation of self-actualization. Self-Actualization needs were described in the study as: (a) the personal satisfaction of learning new skills that are relevant to the job; (b) engaging in staff development that is stimulating and challenging; and (c) being able to learn, grow professionally, and become more knowledgeable. Social needs included the following descriptors: (a) opportunities to build positive relationships with colleagues, to socialize, and to share good times; (b) interacting with colleagues, exchanging ideas, and sharing experiences; and (c) colleagues participating and working together as a team.

Three Remaining Need Categories. The study additionally revealed that the remaining three categories of need registered with lesser prominence on the profile. In descending order of need strength were Basic Needs, Status Needs and Security Needs.

Basic Needs was the third highest source of motivation for teachers to participate in staff development activities. The lower score of Basic Needs implied, however, that teachers were not driven to participate in inservice training primarily for the purpose of additional pay. In this study, Basic Needs 
were described in the following terms: (a) receiving extra pay or release time, (b) potential for advancement on the salary schedule, and (c) not requiring more work or cutting into time for personal pleasure.

The fourth Need Category in order of prominence was Status. This lower Status Need score indicated that teachers were not primarily seeking higher status when deciding to pursue professional development activities. The Staff Development Motivation Profile used the following language to describe Status Needs: (a) receiving personal recognition and tangible rewards, (b) providing additional expertise or help in obtaining an advanced degree that would provide personal recognition, and (c) providing an opportunity to demonstrate competence and be recognized by others as being one of the better educators in the group.

Security was the Need category with the lowest score. The relatively low Security Need indicated that this group of teachers did not feel strongly that the continuance of their jobs depended on their participation in inservice training. Security Needs included the following descriptors in the survey instrument: (a) ensuring job security, (b) looking good on evaluations thereby helping to ensure job security, and (c) feeling more secure about my job and more able to cope with changes in my field.

It is important to remember that the Staff Development Motivation Profile produced a series of scores (forming a profile) that were intended to be 
considered in relationship to each other, rather than as individual absolute measures to be treated singly.

Statistically Significant Variables. A third finding from the study was the identification of variables that made statistically significant differences on the need/incentive structures of teachers. Gender was not among the variables that made a significant difference. Both males and females had nearly identical profiles with self-actualization and social needs as the primary sources of motivation. In a study to determine which organizational incentives induce teachers to remain in the profession, Bredeson et al. (1983) also found no significant differences based on gender.

Years of teaching experience made slight differences on Basic Needs and Social Needs. Teachers described as "established professionals" (9-16 years of experience) and "veteran teachers" (17-24 years of experience) had higher Basic Need scores than "newcomer teachers" (0-8 years) or "career teachers" (25+ years). "Newcomer" males showed a slightly higher score than females on Basic Needs. "Veteran" males had an even higher score on Basic Needs than females. "Newcomer teachers," both male and female, scored higher in Social Needs than the other groups.

Major work assignment had an impact on Basic Needs, Security Needs, and Status Needs. Regular Classroom Teachers had a higher Basic Need score than teachers in the "Other" category which consisted of teaching specialists, 
special education teachers, counselors, nurses, etc. By contrast, "Other" category teachers had a higher Security Need than "Regular Classroom Teachers". Status Needs were similarly affected by work assignment. "Other" category teachers had higher Ego/Status Need scores than "Regular Classroom Teachers".

Size of School District effected significant differences on Basic Needs, Security Needs and Social Needs. Basic Needs scores of the total group of males was higher than that of total group females. Previously, in the Gender section, it was reported that there had not been a significant difference in Needs Category scores due to gender. The difference in male and female scores became statistically significant when the total group considered in the analysis dropped from 770 to 729 respondents by virtue of omitting those individuals who did not know the pupil enrollment in their school districts. Differences in Size of School District also generated significant differences in Basic Need scores. As the size of the school district increased, the Basic Need score also increased. Teachers in Large Districts (10,000 or more students) had higher Basic Needs scores than teachers in either Medium (2,001-9,999 students) or Small $(2,000$ or fewer students) districts. Differences in Security Needs were also found. Males in Small Districts had a higher Security Need than females. The Security Needs for males and females in Medium-sized Districts were nearly the same. Females in Large Districts, however, had a higher Security Need score than the males. 
The last significant effect for this category of variable was that as the size of the district became larger, the Social Need scores became smaller. Teachers in the smaller districts had higher Social Needs than teachers in larger districts.

Proportion of Household Income Attributable to School District Salary had a surprisingly small effect on the Need scores of classroom teachers. Neither Gender alone nor the interaction of Gender and Proportion of Household Income produced significant differences in Need scores. Only a main effect of Percentage of Household Income on Security Need scores was found. Teachers who derived all of their income, and those who derived less than one-fourth of their salary, from their teaching jobs had higher Security Need scores than the remainder of the group. The weak effect size, however, helps contradict the common conception, exposed as myth by researchers such as Johnson (1986) and Frase et al. (1982), that teachers are primarily influenced by money.

Despite Variable Differences, Profile Remains Constant. The fourth, and perhaps most significant, finding of the study was that despite the series of subtle differences, found by examining the interaction of variables on the Need Categories, the basic teacher profile remained constant. None of the variables or attributes changed the basic shape of the composite profile created by plotting the total group means for all study respondents. Self-Actualization and Social Needs remained the high points on the graph, and Basic, Status and 
Security Needs remained the low points. The order of prominence of the Needs Categories remained constant throughout all the data manipulations: Self-Actualization Needs, (b) Social Needs, (c) Basic Needs, (d) Status Needs, and (e) Security Needs. The conclusion drawn from this finding is that the major reasons that impelled teachers in this study to pursue additional professional development were self-actualization and social needs. Further, this finding would indicate that the primary motivator for teachers in this study to participate in staff development activities was the intrinsic motivation of self-actualization. Previous studies by Lortie (1975), Heath (1981), and Kottcamp et al. (1986) have also identified intrinsic or psychic rewards as the most powerful motivators for teachers' actions.

\section{IMPLICATIONS OF THE STUDY}

It is clear from the research that the person in charge of the school, the school administrator, has responsibilities that include making decisions based on the best information available, supervising the educational process, encouraging the best teaching possible and improving instruction through the professional growth and development of staff (Duke, 1982; Dwyer et al., 1987; Snyder \& Giella, 1987; Squires et al., 1981).

Motivation studies conducted in recent years have produced some guiding principles for administrators as they engage in personnel enhancement 
activities. For example, considerable evidence exists to suggest that intrinsic rewards are more effective motivators than external rewards such as money (Deci, 1976; Hackman \& Oldham, 1980; Herzberg, 1966; Sergiovanni, 1967; Spuck, 1974). There is also evidence to indicate that the use of external rewards reduces internal motivation (Calder \& Staw, 1975; Daniel \& Esser, 1980; Deci, 1976).

Despite the research evidence to the contrary, however, monetary incentives in the forms of merit pay and career ladders have been heavily promoted in reform plans such as A Nation at Risk (NCEE, 1983) and A Nation Prepared: Teachers for the 21st Century (Carnegie Forum on Education and the Economy, 1986). The major assumption bolstering such pay incentive plans is that money can motivate teachers to improve their classroom performance more effectively than non-financial rewards (Johnson, 1986). According to Olson (1986), cash is perceived as the appropriate response to problems arising from school personnel. Merit pay plans are being promoted despite the fact that the positive effects of monetary rewards compared to other rewards and incentives are questionable and the issue continues to be debated in the professional literature (Frase et al., 1987).

It appears, therefore, that many school administrators, staff development coordinators and other policy makers are operating on information based on myths, half-truths, and otherwise erroneous belief structures about teachers. 
Clearly, additional factual information about the motivations and needs of teachers, such as this study provides, is critical to the decision-making process of administrators.

According to Fenstermacher and Berliner (1984), one area that is in critical need of further research is the motivation factors governing teacher participation in staff development. It is important to know which potential motivators (professional improvement, financial incentives, compliance with administrative mandates) are most important to teachers. It is also worthwhile to consider the combination and relative strength of motivators that interact within an individual or group.

This study sought to provide information about teacher motivation that could be used to assist school administrators and policy makers in devising more effective strategies for increasing teacher participation in staff development activities. Differences in the motivational makeup of different groups of teachers could be used to design incentive structures appropriate to the various segments of the teaching population. Currently, teachers are often treated as a homogeneous group, without regard to gender, years of teaching experience, or other potential differences such as class or ethnicity.

Current efforts to reform education may have far reaching implications for the future of the education profession. Such a reform effort can move forward, basing its progress on informed decisions about principles of human motivation, 
or it can continue to operate on myths and stereotypic beliefs. Responsible decision-making dictates the accumulation of as much factual information as possible.

One premise guiding this study was the belief that researchers and policymakers should identify those incentives that will motivate teachers to improve their professional skills. It was believed that adding to the body of knowledge about the motivators and incentives that teachers consider important could help facilitate the current reform movement and aid in shaping policy decisions about inservice education for teachers. It was further intended that information generated from this study would provide new information about teacher incentives and would inform the decision-making process in the following areas:

1. Planning for Improved Staff Development. By identifying and tapping the incentive structures that motivate teachers to participate in professional development activities, more successful professional growth programs can be developed. Knowing that teachers are primarily seeking to satisfy their Social and Self-Actualization Needs as they pursue staff development activities should provide an important ingredient in the design of staff development programs.

2. Differentiated Planning for the Incentive Needs of Teachers. The findings of this study indicate that the incentive needs of teachers are surprisingly similar regardless of the consideration of a series of demographic 
variables. Rather than focusing on designing incentives appropriate for different segments of the teaching population, it may be important to concentrate attention on the Self-Actualization and Social Needs identified as most prominent for the vast majority of teachers.

3. Policy and Decision Making. School administrators, school boards of education, state departments of education, and legislatures are currently making policy decisions based on incomplete or erroneous information about teacher incentive systems. It is important to the education reform movement to consider information that is derived directly from teachers themselves, rather than from generalized myth. The merit pay system is one recent example of plans based on myths rather than on research. According to Darling-Hammond and Berry (1988), "the failure of the merit pay plan was epitomized by the fact that Florida's 1986 teacher of the year failed to qualify for a bonus" (p. 60).

Current efforts to force teachers to participate in professional growth should be carefully examined for their underlying beliefs about teachers. The findings of this study imply that teachers who are primarily seeking self-actualization from professional development should not have to be forced to participate in these activities.

Finally, informed decision making has become recognized as pivotal to the art of education administration. According to Griffiths, (1959), "All other functions of administration can best be interpreted in terms of the 
decision-making process" (pp. 74-75). In order for school administrators to develop better systems for managing human potential, they need greater insights (more information about) the individuals who make up their work force. Administrators require information from which to make informed decisions. The importance of information-based decision making has been one focus of this study.

\section{RECOMMENDATIONS FOR FURTHER RESEARCH}

\section{Research on Teacher Motivation}

According to Rosenholtz (1984), policy makers who attempt to reform education without observing the lessons taught by research, are in danger of failure. The present school reform movement has not yet reached its conclusion, nor has it reached its goals. Despite the factors mitigating against the use of research information as a basis for creating policy, the importance of learning as much as possible about teachers, their motivations, their needs, their characteristics remains.

The reform reports of the 1980 s all emphasize the importance of a competent teaching force for the task of improving American education (Darling-Hammond \& Berry, 1988). Research indicates that "the best teachers stay in teaching because of intrinsic rewards, although they may be forced to leave because of poor salaries or working conditions" (Johnson, 1986, p. 73). 
Johnson also suggests that inducing teachers to improve their performance in the classroom will probably require "more than improved status, pay or working conditions" (p. 74). Research suggests that it may require the

\begin{abstract}
orchestration of organizational incentives that encourage teachers to think about their work in new ways and commit themselves to new standards and goals...Although, little is yet known about such incentives, it is clear that they are complex, and difficult to manipulate with policy, and warrant further research. (Johnson, 1986, p. 74)
\end{abstract}

Perhaps as additional research information is produced that provides guidance for the development of "organizational incentives" for teachers, policy and practice will begin to rely on the results. As financial resources for education continue to become more limited, the importance of identifying alternative incentives becomes magnified. In an environment of shrinking resources, the questions of what will motivate teachers to improve their skills and how that knowledge can be transformed into practice at the school level become of utmost importance.

\title{
Research on Current Recertification
}

\section{Requirements}

Changes in teacher recertification requirements "have occurred at a breathtaking pace over the last six or eight years, and the cumulative effects will be difficult to assess for several years" (Darling-Hammond \& Berry, 1988, p. 37). In an effort to improve the quality of teaching, more states are requiring teachers 
to participate in additional college coursework or inservice as a condition of teaching certificate renewal. Such practices seem to run counter to Lortie's (1975) research findings that internal rewards are the most powerful motivational forces that attract and retain teachers in the classroom. Even if forced to participate in inservice, intrinsic motivations must guide the learning and improvement of skills. According to Little et al. (1987), "given what we know about human motivation, the likelihood of incorporating staff development learning is much greater when intrinsic motivational opportunities are maximized over external regulation" (pp. 107-108). Elmore and McLaughlin (1988) also pointed out the "ineffectiveness of a command-and-control model of educational reform....External demand is largely ineffective in stimulating adult learning; the motivation to learn new things must come from within" (pp. 41-42).

Contrary to the belief in the need for forced inservice, Little et al. (1987) found that teachers and administrators already demonstrate a firm commitment to improving their own knowledge and practice. In their study entitled $\underline{\text { Staff }}$ Development in California, Little et al. discovered the following:

For every dollar spent by districts and schools directly on formal staff development activities, individual teachers personally contribute 60 cents in volunteer time, with nopresent or future financial compensation. (p. 5)

Despite the relative absence of extrinsic incentives or rewards for improving professional performance, the vast majority of teachers desire more, not less, staff development opportunities. They list "access to new ideas" as their number one motivation for attending conferences or workshops. (p. 6) 
Further research to assess the efficacy of current trends in forced inservice for recertification is needed. Its role in the overall effort to "professionalize" teaching should also be examined.

Research to Generalize the Results of This Study to the Broader Population

Two major questions were left partially unanswered by this study: (a) Do the results of the study (the factors that motivate Washington state teachers to participate in professional development) apply to the broader population of teachers throughout the nation?; and (b) Is the study instrument, based on the Maslow Hierarchy, a valid measure of motivation for all teachers regardless of their cultural, ethnic or class background?

Although evidence does exist to suggest that the results of this study may be representative of the broader population of teachers within the United States, further study may be necessary. The sample of teachers utilized for this study shared several characteristics with the average teacher nationally during the same time period. According to a survey of kindergarten through twelfth grade teacher members of the National Education Association (NEA, 1989), the average years of teaching experience of NEA members in 1987 was 16 years. The average years of teaching experience of teachers in this study was 15 years. Nationally, in $1987,72 \%$ of all teachers were female. This study sample consisted of $64 \%$ female teachers. Finally, the percentage of teachers nationally 
holding a master's degree or higher was $52 \%$ in 1987 . In this study sample, $43 \%$ of the teachers had a master's or higher degree.

In order to more accurately answer the questions of applicability and validity for broader populations, it may be appropriate to replicate this study using a random sample of teachers from several states and optimally from the entire United States. In order to test the theories of Maslow (1954), special attention could be given to states with high populations of culturally or ethnically different teachers.

\section{FINAL RECOMMENDATIONS AND CONCLUDING REMARKS}

Recommendations for School

Administrators

Based on the findings of this study, the following recommendations are made to school administrators and supervisors of staff development:

1. Incentives for encouraging teacher participation in staff development should be designed to address teachers' tendencies to be motivated by the prospect of achieving self-actualization through the training.

2. Incentives structures should reflect the following components of self-actualization: (a) the personal satisfaction of learning new skills that are relevant to the job; (b) engaging in staff development that is stimulating and 
challenging; and (c) being able to learn, grow professionally, and become more knowledgeable.

3. Staff development activities should incorporate opportunities for collegial interaction among teachers.

4. The knowledge that ieachers are motivated by inservice activities that allow them to build positive relationships with peers, exchange ideas, share experiences, and work together as teams should guide the development of programs.

5. When developing incentive structures for staff development, greater reliance should be placed on the research on teacher motivation than on public policy mandates.

6. Site-based decision making tennets should be followed in selecting topics for inservice. Unilateral decisions about "what teachers need" should be minimized.

7. The following models for effective staff development should be examined for specific ideas about designing programs:

Individually quided staff development. The NEA Readings in Educational Research (NEA, 1990) consists of self-directed study groups that read and discuss original research of specific importance to them. Discussion leads to the practical application and incorporation of research findings into the classroom. 
Staff development to alter teachers' knowledge, attitudes and instructional skills. Several examples of training that has proven effective include: Good and Grouws' (1987) description of an elementary school mathematics program; Kerman's (1979) report of a process for improving teachers' interactions with low-achieving students; Robbins and Wolfe's (1987) discussion of a staff development program for helping teachers increase the engaged time and achievement of elementary school students.

Staff in-service that involves teachers in the development or adaptation of curriculum. School improvement plans often utilize this approach to involve the total faculty in a learning process that includes needs assessments, the writing of goals and objectives, development of curriculum, and an evaluation cycle. One such program has been carried out by the Jefferson County (Colorado) School District (Jefferson County Public Schools, 1974)

8. The recommendations and programs described above should be examined in light of the knowledge that there is much yet to be learned about the implementation of effective incentive structures for teachers. All educators have a responsibility to continue learning in this area.

\section{Concluding Remarks}

According to Glickman (1991),

the first task of restructuring-confronting our own professional knowledge-is not easy, but it is likely to produce the courage to 
improve...schools....Calls for the "restructuring" of schools raise questions as to what knowledge should guide our efforts. (p. 4)

Glickman further states that we in education have had the tendency to "pretend not to know what is known" (p. 4). It is this tendency to ignore the research and act in ways which run counter to the proven knowledge that has been dictating the rewards, incentives and mandates surrounding staff development. The lessons that research teaches, however, are clear.

Maslow (1971) counsels that "human nature has been sold short...." (p. 28). People, he believed, have a higher nature and "this higher nature includes the needs for meaningful work, for responsibility, for creativeness, for being fair and just, for doing what is worthwhile and for preferring to do it well" (p. 28). These needs should be utilized to guide the kinds of rewards, incentives and working conditions that organizations establish. The benefits that will flow from such planning include not only personal fulfillment for the individual, but also organizational health and prosperity in the form of quality products or services (Maslow, 1971).

Research also cautions that higher order needs should not be addressed at the expense of basic concerns for salary or working conditions (Frase, et al., 1982; Johnson, 1986; Maslow, 1971). While it may be obsolete to think in terms of rewarding teachers by money alone (Maslow, 1971), it is important to remember that "money does matter, particularly to teachers whose pay falls short of personal needs" (Johnson, 1986, p. 59). Teachers whose basic needs 
are not met are less likely to have the energy or the inclination necessary to pursue higher order rewards (Frase et al., 1982).

Sergiovanni's (1987) Clockworks I mindscape describes how some educational leaders still view teachers: lacking in ambition; unwilling to participate in improving the profession; unwilling to change; viewing teaching as "just a job." In keeping with these attitudes, as of 1988, policy-makers in 32 states require that teachers participate in varying amounts of professional growth before their teaching certificates will be renewed (Darling-Hammond \& Berry, 1988). Such requirements have been imposed despite contradictory research evidence, such as that emanating from a recent study of teacher attitudes toward school reform, which informs us that teachers: (a) are willing to take on new responsibilities and activities, (b) want to stay current in their field, and (c) are willing "to attend teacher-directed workshops in key subject areas" (Harris \& Wagner, 1993, p. 30.) From the results of their study, Harris and Wagner (1993) make the following observation about teachers:

It is evident that these teachers are open to a wide variety of innovation and change. Certainly the singular mark of today's teachers is that they are alerted to change, and are anything but resistant to adapting to new conditions and new challenges. To claim otherwise is a wholly inaccurate representation of teachers in America today. (p. 31)

Clearly, the appropriate foundation for building organizational incentive structures for motivating teachers to participate in professional growth and 
development is outlined in the research. The knowledge base is available for those who wish to expand it, shape it, and utilize it in creative ways that challenge the status quo. The development of successful incentives structures that motivate teachers to improve their skills is important because it has ultimate implications for educational reform and for the improvement of public education.

The results of this study indicate that incentive structures for staff development should be developed to draw heavily upon teachers' tendencies toward seeking self-actualization (the personal satisfaction of learning new skills that are relevant to the job; engaging in staff development that is stimulating and challenging; and being able to learn, grow professionally, and become more knowledgeable) and their desire for social interactions with peers (building positive relationships, exchanging ideas, sharing experiences, and working together as a team). Research informs us that the most effective inservice programs for teachers are designed by considering the needs of the teachers themselves. An integral portion of the design should consist of an opportunity for the collegial exchange of ideas. The challenge in designing new structures must be to "question the regularities," heed the advice provided by research, and act upon "that which is known." 


\section{REFERENCES}

Ainsworth, A. (1976). Teachers talk about inservice education. Journal of Teacher Education, 27(2), 107-109.

Anderson, L., Evertson, C., \& Brophy, J. (1979). An experimental study of effective teaching in first-grade reading groups. Elementary School Journal, 79(4), 193-223.

Barnard, C. I. (1938). The functions of the executive. Cambridge, MA: Harvard University Press.

Berman, P., \& McLaughlin, M. (1978). Federal programs supporting educational change: Vol. 8. Implementing and sustaining innovations. Santa Monica, CA: RAND Corporation.

Blase, J. J. (1987). Dimensions of effective school leadership: The teacher's perspective. American Educational Research Journal, 24(4), 589-610.

Blum, R. E. (1982). Effective schooling practices: A research synthesis. Portland, OR: Northwest Regional Educational Laboratory.

Bock, R. D., \& Jones, L. V. (1968). The measurement and prediction of judgment and choice. San Francisco: Holden-Day, Inc.

Bowles, W. J. (1966, July/August). The management of motivation. Personnel, 40, 16-26.

Boyer, E. (1983). High school: A report on secondary schools. Princeton, NJ: The Carnegie Foundation for the Advancement of Teaching.

Bredeson, P. V., Fruth, M. J., \& Kasten, K. L. (1983). Organizational incentives and secondary school teaching. Journal of Research and Development in Education, 16(4), 52-58.

Bridges, E. M. (1982). Research on the school administrator: The state of the art, 1967-1980. Educational Administration Quarterly, 18 (3), 12-33. 
Brim, J., \& Tollet, D. (1974). How do teachers feel about inservice education? Educational Leadership, 31(6), 521-525.

Brookover, W. B., Gigliotti, R. J., Henderson, R. P., \& Schneider, J. M. (1973). Elementary school social environments and achievement. East Lansing: Michigan State University College of Urban Development.

Brundage, D. H. (1980). Adult learning principles and their application to program planning. Toronto, Ontario: Ministry of Education.

Bruno, J. E., \& Dosch, M. L. (1981). Contributing to the harms of racial isolation: Analysis of requests for teacher transfers in a large, urban school district. Educational Administration Quarterly, 17(2), 93-108.

Buhler, C. (1951). Maturation and motivation. Dialectica, $\underline{5}, 312-361$.

Calder, B. J., \& Staw, B. M. (1975). Self perception of intrinsic and extrinsic motivation. Journal of Personality and Social Psychology, 31(1), 432-43.

Carnegie Forum on Education and the Economy. (1986). A nation prepared: Teachers for the 21st century. New York: Carnegie Foundation.

Champlin, J. (1987). Leadership: A change agent's view. In L. Sheive \& M. B. Schoenheit (Eds.), Leadership: Examining the elusive (pp. 49-63). Alexandria, VA: Association for Supervision and Curriculum Development.

Coombs, C. H., Dawes, R. M., \& Tversky, A. (1970). Mathematical psychology: An elementary introduction. Englewood Cliffs, NJ: Prentice-Hall, Inc.

Cyert, R. M., Simon, H. A., \& Trow, D. B. (1971). Observations of a business decision. In R. M. Cyert \& L. A. Welsch (Eds.), Management decision making. Baltimore: Penguin Books.

Daniel, T. L., \& Esser, J. K. (1980). Intrinsic motivation as influenced by rewards, task interest, and task structure. Journal of Applied Psychology. $\underline{65}(5), 566-573$.

Darling-Hammond, L. \& Berry, B. (1988). The evolution of teacher policy. Santa Monica, CA: RAND Corporation. 
Darling-Hammond, L., \& Sclan, E. (1992). Policy and supervision. In C. D. Glickman (Ed.), Supervision in transition (pp.7-29). Alexandria, VA: Association for Supervision and Curriculum Development.

David, H. A. (1988). The method of paired comparisons. London: Charles Griffin \& Co., Limited.

Deal, T. E. (1987). The culture of schools. In L. Sheive \& M. B. Schoenheit (Eds.), Leadership: Examining the elusive (pp. 3-15). Alexandria, VA: Association for Supervision and Curriculum Development.

Deal, T. E., \& Kennedy, A. A. (1982). Corporate cultures: The rites and rituals of corporate life. Reading, MA: Addison-Wesley.

Deci, E. L. (1976). The hidden cost of rewards. Organizational Dynamics, $4(3), 61-72$.

Duke, D. L. (1982). Leadership functions and instructional effectiveness. Portland, OR: Northwest Regional Educational Laboratory.

Duke, D. L., Showers, B. K., \& Imber, M. (1980). Teachers as school decision makers (Project Report No. 80-A7). Stanford, CA: Institute for Research on Educational Finance and Governance.

Dwyer, D. C. (1985). Contextual antecedents of instructional leadership. Uiban Review, 17(3), 166-188.

Dwyer, D. C., Barnett, B. G., \& Lee, G. V. (1987). The school principal: scapegoat or the last great hope? In L. Sheive \& M. B. Schoenheit (Eds.), Leadership: Examining the elusive (pp. 30-46). Alexandria, VA: Association for Supervision and Curriculum Development.

Dwyer, D. C., Filby, B. G., \& Rowan, B. (1984). Frances Hedges and Orchard Park elementary schools: Instructional leadership in a stable urban setting. San Francisco: Far West Laboratory.

Education Commission of the States. (1983). A survey of state school improvement efforts. Denver, CO: ECS.

Elmore, R. F. \& McLaughlin, M. W. (1988). Steady work: Policy, practice and the reform of education. Santa Monica, CA: RAND Corporation. 
Engleking, J. L. (1987). Attracting and retaining qualified teachers through incentives. NASSP Bulletin, 71 (500), 36-53.

Fenstermacher, G. D., \& Berliner, D. C. (1984). A conceptual framework for the analysis of staff development. Santa Monica, CA: RAND Corporation.

Fiedler, F. E., Chemers, M. M., \& Mahar, L. (1976). Improving leadership effectiveness: The leader match concept. New York: John Wiley \& Sons.

Frase, L. E., Hetzel R. W., \& Grant, R. T. (1982). Promoting instructional excellence through a teacher reward system: Herzberg's theory applied. Planning and Changing, 13 (2), 67-76.

Frase, L. E., Hetzel, R. W., \& Inman, D. (1987). Is there a sound rationale behind the merit pay craze? Teacher Education Quarterly, 14 (2), 90-101.

Galbraith, J. R. (1977). Organization design. Reading, MA: Addison Wesley.

Gellerman, S. (1968). Management by motivation. New York: American Management Association, Inc.

George, M. (1986). Teacher empowerment: Taking it to the limits. San Francisco: Presentation at ASCD Annual Conference.

Glenn, B. C. \& McLean, T. (1981). What works? An examination of effective schools for poor black children. Cambridge, MA: Harvard University, Center for Law and Education.

Glickman, C. (1991). Pretending not to know what we know. Educational Leadership, 48 (8), 4-10.

Good, T., \& Grouws, D. (1987). Increasing teachers' understanding of mathematical ideas through inservice training. Phi Delta Kappan, 68(10), 778-783.

Goodlad, J. (1983). Improving schooling in the 1980's: Toward the non-replication of non-events. Educational Leadership, 40(7), 4-7.

Griffin, G. A. (1983). Implications of research for staff development programs. The Elementary School Journal, 83 (4), 414-426.

Griffiths, D. (1959). Administrative theory. New York: Appleton-Century Crofts. 
Hackman, R. J., \& Oldham, G. R. (1980). Work redesign. Reading, PA: Addison-Wesley.

Hall, G. E., \& Loucks, S. (1978). Teachers concerns as a basis for facilitating and personalizing staff development. Teachers College Record, 80 (1), 36-53.

Hall, J. \& Williams, M. (1967). Work motivation inventory. The Woodlands, TX: Teleometrics International.

Hanson, E. M. (1979). Educational administration and organizational behavior. Boston: Allyn and Bacon.

Harris, L., \& Wagner, R. F. Jr. (1993). Testing assumptions: A survev of teachers' attitudes toward the nation's school reform agenda. New York: The Ford Foundation.

Heath, D. (1981). Faculty burnout, morale, and vocational adaptation. Boston: National Association of Independent Schools.

Hersey, P., \& Blanchard, K. H. (1977). Management of organizational behavior: Utilizing human resources (3rd ed.). Englewood Cliffs, NJ: Prentice-Hall, Inc.

Herzberg, F. (1966). Work and the nature of man. Cleveland: World.

Herzberg, F. (1968, January). One more time: How do you motivate employees? Harvard Business Review, 46, 53-62.

Herzberg, F., Mausner, B., \& Snyderman, B. B. (1959). The motivation to work (2nd ed.). New York: John Wiley \& Sons, Inc.

Herzberg, F., Wiener, Y., Mathapo, J., \& Wiesen, L. E. (1974, June). Motivation-hygiene correlates of mental health: An examination of motivation inversion in a clinical population. Journal of Consulting and Clinical Psychology, 42, 411-419.

Hofstede, G. (1980). Motivation, leadership, and organization: do American theories apply abroad? Organizational Dynamics, $\underline{9}(1), 42-63$.

The Holmes Group (1986). Tomorrow's teachers: A report of the Holmes group. East Lansing, Ml: Author. 
Howes, N. J., \& McCarthy, H. (1982, March). Participative management: A practice for meeting the demands of the eighties. Paper presented at the meeting of the American Educational Research Association, New York.

Innaccone, L. (1946). An approach to the informal organization of the school. In D. E. Griffiths (Ed.), Behavioral science and educational administration. The Sixty-third Yearbook of the National Society for the Study of Education. Chicago: University of Chicago Press.

Jackson, P. W. (1968). Life in classrooms. New York: Holt, Rinehart and Winston.

Janis, I. L., \& Mann, D. (1977). Decision-making. New York: The Free Press.

Jaycox, W., \& Tallman, L. (1967). A study of the motivation of elementary school teachers. Unpublished doctoral dissertation, University of Southern California, Los Angeles.

Johnson, S. M. (1986). Incentives for teachers: What motivates, what matters. Educational Administration Quarterly, 22 (3), 54-79.

Joyce, B., \& Peck, L. (1977). Inservice teacher education project report II: Interviews. Syracuse, NY: Syracuse University.

Kaiser, J. S. (1981). Motivation deprivation: No reason to stay. The Clearing House, 55(1) 35-38.

Kaiser, J. S. (1982). Teacher longevity: motivation or burnout. The Clearing House, 56(1) 17-79.

Kells, P. (1981). Quality practices in inservice education: The developer (1-6). Oxford, OH: National Staff Development Council.

Kerman, S. (1979). Teacher expectations and student achievement. Phi Delta Kappan, 60(10), 716-718.

Knowles, M. S. (1970). The modern practice of adult education. New York: Association Press.

Knowles, M. S. (1978). The adult learner: A neglected species. Houston: Gulf. 
Kottcamp, R., Provenzo, E., \& Cohn, M. (1986). Stability and change in a profession: Two decades of teacher attitudes (1964-1984). Phi Delta Kappan, $\underline{67}(83), 559-567$.

Lambert, L. (1989). The end of an era of staff development. Educational Leadership, $47(1), 78-81$.

Lawler, E. E. (1986). High-involvement management. San Francisco: Jossey-Bass.

Lawler, E. E., III, \& Porter, L. W. (1967). The effect of performance on job satisfaction. Industrial relations: A journal of economy and society, $\underline{Z}(1), 20-28$.

Levine, S. (1988). Promoting adult growth in schools: The promise of professional development. Lexington, MA: Allyn \& Bacon.

Lieberman, A. L., \& Miller, L. (1981). Synthesis of research on improving schools. Educational Leadership $38(7), 583-586$.

Lightfoot, S. (1983). The good high school: Portraits of character and culture. New York: Basic Books.

Lipham, J. M. (1981). Effective principal, effective school. Reston, VA: National Association of Secondary School Principals.

Little, J. W. (1981). School success and staff development: The role of staff development in urban desegregated schools. Boulder, CO: Center for Action Research, Inc.

Little, J. W., Gerritz, W. H., Stern, D. S., Guthrie, J. W., Kirst, M. W., \& Marsh, D. D. (1987). Staff development in California. San Francisco: Far West Laboratory for Education Research \& Development.

Lortie, D. C. (1969). The balance of control and autonomy in elementary school teaching. In A. Etzioni (Ed.), The semiprofessions and their organization. New York: The Free Press.

Lortie, D. C. (1975). Schoolteacher: A sociological study. Chicago: University of Chicago Press. 
Loucks-Horsley, S., Harding, C. K., Arbuckle, M. A., Murray, L. B., Dubea, C., \& Williams, M. K. (1987). Continuing to learn: A quidebook for teacher development. Andover, MA: Regional Laboratory for Educational Improvement of the Northeast and Islands \& Oxford, $\mathrm{OH}$ : National Staff Development Council.

Maslow, A. H. (1954). Motivation and personality. New York: Harper \& Row.

Maslow, A. H. (1965). Eupsychian management: A journal. Homewood, IL: Richard D. Irwin, Inc. \& the Dorsey Press.

Maslow, A. H. (1968). Toward a psychology of being. New York: D. Van Nostrand Company.

Maslow, A. H. (1971). The farther reaches of human nature. New York: The Viking Press.

McCall, C. H. (1982). Sampling and statistics handbook for research. Ames: The lowa State Press.

McGregor, D. (1960). The human side of enterprise. New York: McGraw-Hill.

McLaughlin, M. W., \& Marsh, D. D. (1978). Staff development and school change. Teachers College Record, $\underline{80}(1), 69-94$.

McPherson, G. H. (1972). Small town teacher. Cambridge: Harvard University Press.

Metz, M. I. (1978). Classrooms and corridors: The crisis of authority in desegregated schools. Berkeley: University of California Press.

Miller, R. B. (1966). How to motivate people. Swarthmore, PA: Assignments in Management.

Miner, J. B. (1980). Theories of organizational behavior. Hinsdale, IL: Dryden Press.

Moore, R., \& Hyde, A. A. (1981). Making sense of staff development: An analysis of staff development programs and their costs in three urban school districts. Chicago: Designs for Change. 
Murnane, R. J., \& Cohen, R. (1987). Merit pay and the evaluation problem: why most merit pay plans fail and a few survive. In M. Okazawa-Rey, J. Anderson, \& R. Traver (Eds.), Teaching. Teachers and Teachers Education, (pp. 350-366). Cambridge, MA: Harvard Educational Review.

National Commission on Excellence in Education. (1983). A nation at risk: The imperative for educational reform. Washington, DC: U. S. Department of Education.

National Education Association. (1989). 1987 survey of k-12 teacher members. Washington, DC: National Education Association.

National Education Association. (1990). Readings in Educational Research. Washington, DC: National Education Association.

National Education Association (1992). Status of the American public school teacher: 1990-1991. Washington, D. C.: National Education Association.

Olson L. (1986). Performance pay: New round for an old debate. Education Week, 12 (26), 1-19.

O'Toole, J. (1981). Making America work. New York: Continuum.

Peters, T. J., \& Waterman , R. H., Jr. (1982). In search of excellence. New York: Harper \& Row.

Purkey, S. C., \& Smith, M. S. (1984). School reform: The district policy implications of the effective schools literature. Madison: University of Wisconsin, Center for Education Research.

Robbins, P., \& Wolfe, P. (1987). Reflections on a Hunter-based staff development project. Educational Leadership, 44(5), 56-65.

Rosenholtz, S. J. (1984). Political myths about reforming teaching. Denver, CO: Education Commission of the States.

Sarason, S. (1971). The culture of the school and the problem of change. Boston: Allyn \& Bacon.

Schmidt, G. L. (1976, Spring). Job satisfaction among secondary school administrators. Educational Administration Quarterly, 12. 81-88. 
Sergiovanni, T. J. (1966). Satisfaction and dissatisfaction of teachers: Final report. Urbana: Illinois University.

Sergiovanni, T. J. (1980). A social humanities view of educational policy and administration. Educational Administration Quarterly, 16 (1), 1-19.

Sergiovanni, T. J. (1982). Ten principles of quality leadership. Educational Leadership, 39 (5), 330-336.

Sergiovanni, T. J. (1987). The theoretical basis for cultural leadership. In L. Sheive \& M. B. Schoenheit (Eds.), Leadership: Examining the elusive (pp. 116-127). Alexandria, VA: Association for Supervision and Curriculum Development.

Sergiovanni, T. J., \& Carver, F. D. (1980). The new school executive: A theory of administration. New York: Harper and Row.

Shalaway, L. (1981). "Good news" schools share common characteristics. Educational R. \& D. Report, 4 (2), 3-6.

Sheive, L., \& Schoenheit, M. B. (Eds.). (1987). Leadership: Examining the elusive. Alexandria, VA: Association for Supervision and Curriculum Development.

Sizer, T. (1984). Horace's compromise: The dilemma of the American high-school. Boston: Houghton Mifflin.

Smith, S. C., Mazzarella, J. A., \& Piele, P. K. (Eds.). (1981). School leadership: Handbook for survival. Eugene: University of Oregon, Clearinghouse on Educational Management.

Snyder, K. J., \& Anderson, R. H. (1986). Managing productive schools: Toward an ecology. San Diego, CA: Harcourt Brace Jovanovich.

Snyder, K. J., \& Giella, M. (1987). Developing principals' problem solving capacities. Educational Leadership, 45(1), 38-41.

Sparks, G. M. (1983). Synthesis of research on staff development for effective teaching. Educational Leadership, 41,(3), 65-72.

Sparks, D., \& Loucks-Horsley, S. (1990). Models of staff development. In R. Houston (Ed.), Handbook of research on teacher education (pp.234-250). New York: MacMillan Publishing Co. 
Spuck, D. W. (1974). Reward structures in the public high school. Educational Administration Quarterly, 10(1), 18-34.

Squires, D. A., Huitt, W. G., \& Segars, J. K. (1981). Improving classrooms and schools: What's important. Educational Leadership 39(3), 174-179.

Stallings, J. A., \& Mohlman, G. G. (1981). School policy, leadership style, teacher change, and student behavior in eight schools: Final Report. Washington, DC: National Institute of Education.

Sweeney, J. (1982). Research synthesis on effective school leadership. Educational Leadership, 39(5), 346-352.

Terry, G. R. (1960). Principles of management (3rd ed). Homewood, IL: Richard D. Inwin.

Thomson, S. D. (1980). Editorial: Effective leadership. NAASP Newsletter, 27, (8), 2.

Thurstone, L. L. (1959). The measurement of values. Chicago: University of Chicago Press.

Tyler, L. E. (1963). Tests and measurements. Englewood Cliffs, NJ: Prentice-Hall, Inc.

Vroom, V. H. (1964). Work and motivation. New York: John Wiley.

Walsh, W. B., \& Bitz, N. E. (1990). Tests and assessment. Englewood Cliffs, NJ: Prentice-Hall, Inc.

Washington State Office of the Superintendent of Public Instruction (1985). Statistics: teachers and students. Olympia: Author.

Welte, C. E. (1978). Management and leadership: Concepts with an important difference. Personnel Journal, 57(11), 630-632.

Wickstrom, R. A. (1971). An investigation into job satisfaction among teachers. Unpublished doctoral dissertation, University of Oregon, Eugene.

Wood, F., \& Kleine, P. (1987). Staff development research and rural schools: A critical appraisal. Unpublished manuscript, University of Oklahoma, Norman. 
Wynne, E. (1981). Looking at good schools. Phi Delta Kappan, $\underline{62}(5)$, 377-381.

Yarger, S., Howey, K., \& Joyce, B. (1980). Inservice teacher education. Palo Alto, CA: Booksend Laboratory. 


\section{APPENDIX A}

\section{STAFF DEVELOPMENT AND WORK}

MOTIVATION PROFILE 


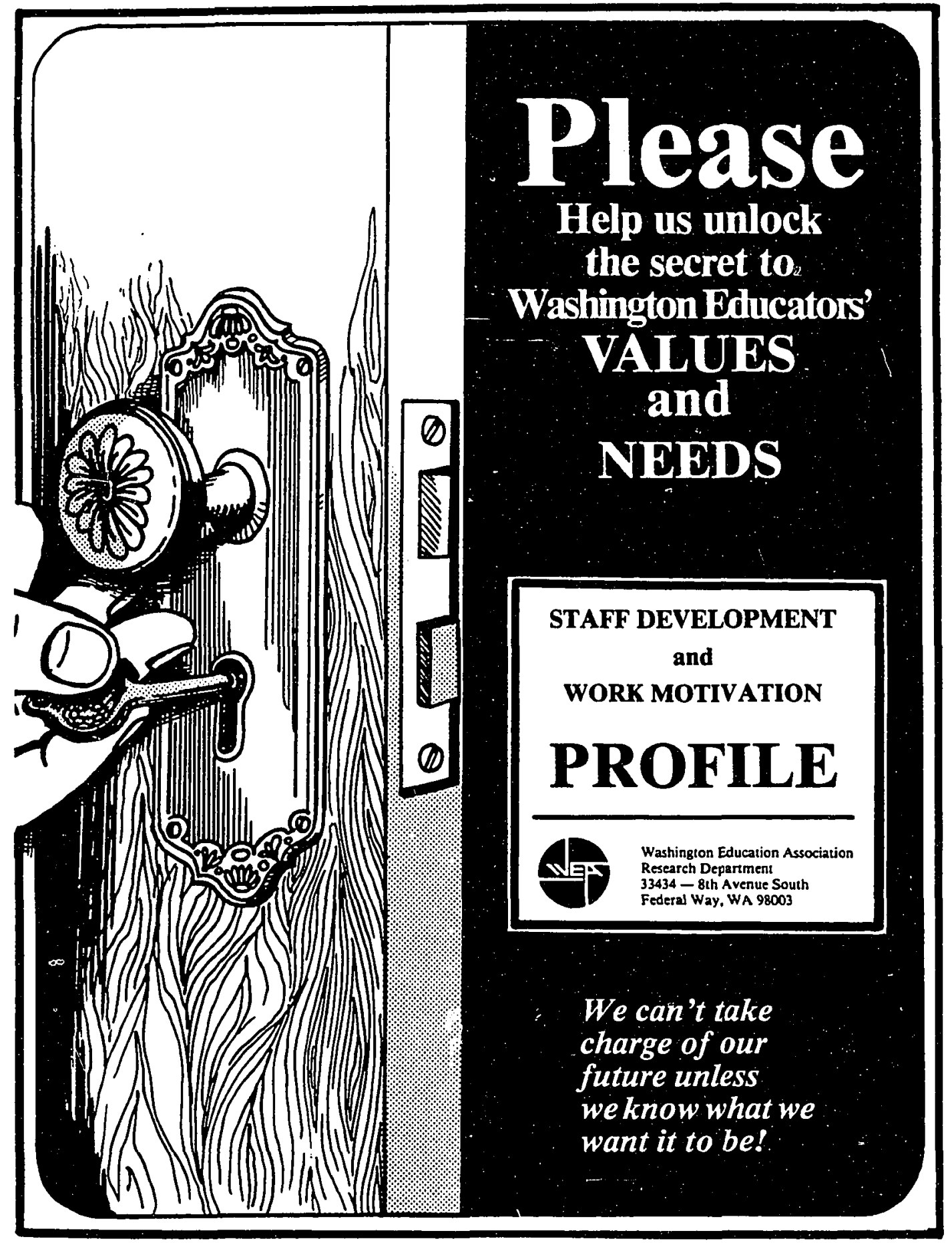


Sit $\mathscr{B}$ ack ...

Relax ...

And Then, Please Read On!

\section{Dear Educator and WEA Member:}

You have been selected to participate in this very important survey designed to find out more about what educators value and need in their professional lives. Your Association wants to know what you see as important considerations in making work-related decisions. Specifically, this survey will help us answer two questions about Washington educators:

What motivates us in our work lives?

What motivates us to participate in staff development activities?

We will use the results of this survey to improve staff development programs, and to make other WEA program areas (lobbying, bargaining, public relations, etc.) more responsive to your needs.

This survey has three sections: (1) a Work Motivation Profile, (2) a Staff Development Motivation Profile, and (3) demographic questions that will yield general statistical information about the survey respondents.

All individual responses will be strictly confidential. Neither your name nor survey number will be associated with your responses in any way. The number that appears on the return address portion of your survey answer sheet is used only to send follow-up requests to non-respondents. The survey results will provide group data only and a summary of the results will be made available to WEA members.

Please allow yourself some quiet, uninterrupted time to devote your attention to responding to this questionnaire.

Have I convinced you to help? I hope so. Return instructions are on the back of the answer sheet. If you have questions about this survey, please call:

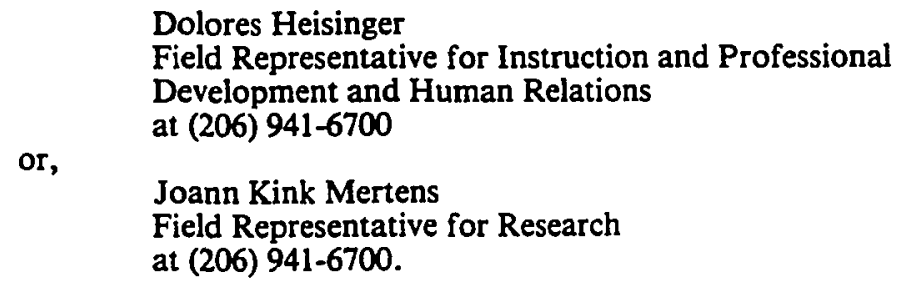

Collect calls will be accepted.

Sincerely,

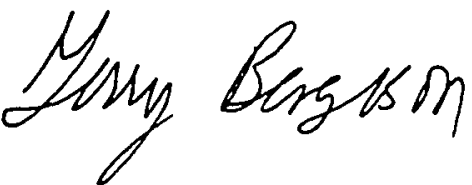

Terry Bergeson

WEA President 


\section{PROFILE INSTRUCTIONS}

In every work situation individuals have a variety of needs and objectives, and are sensitive to how well they are being met.

This survey is designed to assess the needs and values that you and other educators see as important considerations in making decisions about staff development. There are no "right" or "wrong" answers. Rather, the best'response to any item is simply the one which best reflects your feelings-either as you have experienced them or anticipate you would experience them-in the situation described.

Five need types-A, B, C, D, and E-are assessed in this survey, two at a time. For each item you are asked to indicate the extent to which each of two alternative reactions would be characteristic of you. Some alternatives may be equally characteristic of you or equally uncharacteristic. While this is possible, please choose the alternative which is relatively more characteristic of you. For each item, you will have five points that you may distribute between each pair of alternatives. For example, A and B types could be rated in any of the following combinations:

(1) If $A$ is completely characteristic of your feelings and $B$ is completely uncharacteristic, write a " 5 " on your answer sheet under $A$ and $a$ " 0 " under $B$,

(2) If $A$ is very characteristic of your feelings and $B$ is somewhat characteristic, write a " 4 " on your answer sheet under $A$ and $a$ " 1 " under $B$,

- (3) If $A$ is only slightly more characteristic of your feelings than B is, write a " 3 " on your answer sheet under $A$ and $a$ " 2 " under $B$,

(4) Each of the above three combinations may be used in the converse order: for example, should you feel $B$ is slightly more characteristic of your feelings than A, write a " 2 "' on your test sheet under $A$ and $a$ " 3 " under $B$,
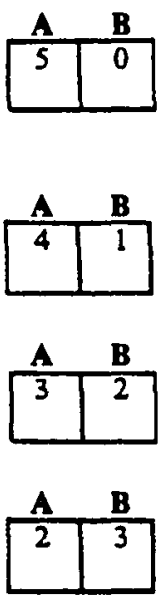

and so on for $A=1, B=4$, or $A=0, B=S$. Thus, there are six possible combinations for responaing to the pair of alternatives presented to you with each item.

Use only whole numbers. Be sure the numbers you assign to each pair total 5.

In general, try to relate each situation in the survey to your own personal feelings. Take as much time as you need to accurately reflect your feelings in your responses.

It may appear to you that this instrument is repetitious. However, you are never answering exactly the same question twice. Different combinations of the same responses are interspersed throughout.

Please remember, in this survey there are no right or wrong answers. It is your feelings and opinions that count here. Attempts to give a "correct" response will distort the meaning of your answers.

Whea marking your responses on the tear-off answer sheet, be sure the number for the response boxes corresponds to the number of the question you are answering. Please tum the page and begin with question 1. 


\section{SECTION 1-WORK MOTIVATION PROFILE}

1. I am likely to commit the most time and energy to my work when:

A. Supplies and materials are up-to-date and plentiful, and the facilities are functional as well as comfortable.

OR

B. It provides good job security and a strong benefits package.

2. If I should become so dissatisfied with my work as an educator that I decide to quit, the most likely cause would be that:

B. My work involved "high risk" factors such as severe student discipline problems, inadequate support services, or inadequate job security.

OR

C. I felt isolated from my colleagues and unable to share ideas and problems, or plan programs together.

3. I believe my morale, motivation, and enthusiasm as an educator would suffer most where:

C. My colleagues were cold, cliqueish, or held grudges against me and others over minor issues.

OR A. My workload was too great and I had little time to adequately prepare, or I had to take an unreasonable amount of work home.

4. For me, the real rewards in working are those which:

E. Are within the nature of the work itself; that it is stimulating, meaningful, and challenging.

OR

A. Provide me with the basics; specifically, a good salary, good working conditions, a nice house and car, etc.

5. I am likely to commit the most time and energy to my work when:

C. There is a real feeling of camaraderie among my colleagues and we all share good times and get OR along well with one another.

D. There are tangible rewards and recognition for one's performance.

6. If I should become so dissatisfied with my work as an educator that I decide to quit, the most likely cause would be that:

OR. The job did not pay well enough to satisfy the needs of my family and me.

B. My work involved "high risk"' factors such as severe student discipline problems, inadequate support services, or inadequate job security.

7. I believe my morale, motivation, and enthusiasm as an educator would suffer most if:

OR

E. I felt that my real skills and abilities were being wasted or were not fully utilized.

D. Other employees with no better skills or abilities than I received recognition and attention for their work when I didn't.

8. For me, the real rewards in working are those which:

D. Reflect my own competence; that is, being recognized by others as one of the more effective educators in my school.

OR

C. Come from the social and professional interaction among educators; that is, the chance to be a valued member of a team.

9. I am likely to commit the most time and energy to my work when:

C. There is a real feeling of camaraderie among my colleagues and we all share good times and get along well with one another.

A. Supplies and materials are up-to-date and plentiful, and the facilities are functional as well as comfortable.

10. If I should becomé so dissatisfied with my work as an educator that I decide to quit, the most likely cause would be that:

C. I felt isolated from my colleagues and was unable to share ideas and problems, or plan programs together.

D. I was degraded or harassed as a person or an educator, or I did not get the respect I deserved. 
11. I believe my morale, motivation, and enthusiasm as an educator would suffer most where:
D. Other employees with no better skills or abilities than I received recognition and attention for their work when I didn't.
C. My colleagues were cold
cold, cliqueish, or held grudges against me and others over minor issues.

12. For me, the real rewards in working are those which:

D. Reflect my own competence; that is, being recognized by others as one of the more ef fective educators in my school.

OR E. Are within the nature of the work itself; that it is stimulating, meaningful, and challenging.

13. I am likely to commit the most time and energy to my work when:

D. There are tangible rewards and recognition for one's performance.

B. It provides good job security and a strong benefits package.

14. If I should become so dissatisfied with my work as an educator that I decide to quit, the most likely cause would be that:

OR

E. I felt I was stagnating professionally or that my work was not a real test of my abilities.

D. I was degraded or harassed as a person or an educator, or I did not get the respect I deserved.

15. I believe my morale, motivation, and enthusiasm as an educator would suffer most where:

A. My workload was too great and I had little time to adequately prepare, or I had to take an unreasonable amount of work home.

OR B. My evaluation was based almost entirely on how well I met performance goals, i.e., student test scores, student achievement levels, etc.

16. For me, the real rewards in working are those which:

B. Are provided by the fringe benefits program; such things as medical, dental and vision insurance. retirement benefits, etc.

D. Reflect my own competence; that is, being recognized by others as one of the more effective educators in my school.

\section{I am likely to commit the most time and energy to my work when:}

OR

B. It provides good job security, benefits, and working conditions.

C. There is a real feeling of camaraderie among my colleagues and we all share good times and get along well with one another.

18. If I should become so dissatisfied with my work as an educator that I decide to quit, the most likely cause would be that:

B. My work involved "high risk"' factors such as severe student discipline problems, inadequate support services, or inadequate job security.

OR E. I felt I was stagnating professionally or that my work was not a real test of my abilities.

19. I believe my morale, motivation, and enthusiasm as an educator would suffer most where:

D. Other employees with no better skills or abilities than I received recognition and attention for their work when I didn't.

OR A. My workload was too great and I had little time to adequately prepare, or I had to take an unreasonable amount of work home.

20. For me, the real rewards in working are those which:

C. Come from the social and professional interaction among educators; that is, the chance to be a valued member of a team.

OR B. Are provided by the fringe benefits program; such things as medical, dental and vision insurance, retirement benefits, etc. 
21. I am likely to commit the most time and energy to my work whea:

E. I can see the fruits of my labor from the standpoint of personal growth and development.

OR

B. It provides good job security, benefits, and working conditions.

22. If I should become so dissatisfied with my work as an educator that I decide to quit, the most likely cause would be that:

D. I was degraded or harassed as a person or an educator, or I did not get the respect I deserved.

OR B. My work involved "high risk" factors such as severe student discipline problems, inadequate support services, or inadequate job security.

23. I believe'my morle, motivation, and enthusiasm as an educator would suffer most if:

E. I felt that my real skills and abilities were being wasted or were not fully utilized.

C. My colleagues were cold, cliqueish, or held grudges against me and others over minor issues.

24. For me, the real rewards in working are those which:

E. Are within the nature of the work itself; that it is stimulating, meaningful, and challenging.

OR C. Come from the social and professional interaction among educators; that is, the chance to be a valued member of a team.

25. I am likely to commit the most time and energy to my work when:

D. There are tangible rewards and recognition for one's performance.

A. Supplies and materials are up-to-date and plentiful, and the facilities are functional as well as comfortable.

26. If I should become so dissatisfied with my work as an educator that I decide to quit, the most llkely cause would be that:

OR

D. I was degraded or harassed as a person or an educator, or I did not get the respect I deserved.

A. The job did not pay well enough to satisfy the needs of my family and me.

27. I believe my morale, motivation, and enthusiasm as an educator would suffer most where:

B. My evaluation was based almost entirely on how well 1 met performance goals, i.e., student test scores, student achievement levels, etc.

OR C. My colleagues were cold, cliqueish, or held grudges against me and others over minor issues.

28. For me, the real rewards in working are those which:

D. Reflect my own competence; that is, being recognized by others as one of the more effective educators in my school.

OR A. Provide me with the basics; specifically, a good salary, good working conditions, a nice house and car, etc.

29. I am likely to commit the most time and energy to my work when:

D. There are tangible rewards and recognition for one's performance.

OR E. I can see the fruits of my labor from the standpoint of personal growth and development.

30. If I should become so dissatisfied with my work as an educator that I decide to quit, the most likely cause would be that:

C. I felt isolated from my colleagues and was unable to share ideas and problems, or plan programs together.

OR E. I felt I was stagnating professionally or that my work was not a real test of my abilities. 
31. I believe my morale, motivation, and enthusiasm as an educator would suffer most where:

D. Other employees with no better skills or abilities than I received recognition and attention for their work when I didn't.

OR

B. My evaluation was based almost entirely on how well I met performance goais, i.e., student test scores, student achievement levels, etc.

32. For me, the real rewards in working are those which:

A. Provide me with the basics; specifically, a good salary, good working conditions, a nice house and car, etc.

OR

B. Are provided by the fringe benefits program; such things as medical, dental and vision insurance, retirement benefits, etc.

33. I am likely to commit the most time and energy to my work when:

C. There is a real feeling of camaraderie in my school among my colleagues and we all share good times and get along well with one another.

OR

E. I can see the fruits of my labor from the standpoint of personal growth and development.

34. If I should become so dissatisfied with my work as an educator that I decide to quit, the most likely cause would be that:

OR

E. I felt I was stagnating professionally or that my work was not a real test of my abilities.

A. The job did not pay well enough to satisfy the needs of my family and me.

35. I believe my morale, motivation, and enthusiasm as an educator would suffer most where:

OR

E. I felt that my real skills and abilities were being wasted or were not fully utilized.

B. My evaluation was based almost entirely on how well I met performance goals, i.e., student test scores, student achievement levels, etc.

36. For me, the real rewards in working are those which:

A. Provide me with the basics; specifically, a good salary, good working conditions, a nice house and car, etc.

OR Come from the social and professional interaction among educators; that is, the chance to be a valued member of a team.

37. I am likely to commit the most time and energy to my work when:

A. Supplies and materials are up-to-date and plentiful, and the facilities are functional as well as comfortable.

OR

E. I can see the fruits of my labor from the standpoint of personal growth and development.

38. If I should become so dissatisfled with my work as an educator that I decide to quit, the most likely cause would be that:

C. I felt isolated from my colleagues, and was unable to share ideas and problems, or plan programs together.

OR

A. My ability to do my job was seriously impacted by factors such as poor heating or air conditioning, inadequate facilities, etc.

39. I believe my morale, motivation, and enthusiasm as an educator would suffer most where:

A. My workload was too great and I had little time to adequately prepare, or I had to take an unrea. sonable amount of work home.

OR E. I felt that my real skills and abilities were being wasted or were not fully utilized.

40. For me, the real rewards in working are those which:

B. Are provided by the fringe benefits program; such things as medical, dental and vision insurance, retirement benefits, etc.

OR E. Are within the nature of the work itself; that it is stimulating, meaningful, and challenging. 


\section{SECTION 2-STAFF DEVELOPMENT MOTIVATION PROFILE}

41. Personally, I believe the real rewards of participating in staff development activities are:

OR

E. The personal satisfaction of learning new skills that are relevant to my job.

D. Receiving personal recognition and tangible rewards for participating.

42. In deciding whether or not to participate in staff development activities, I would be most concerned with the extent to which:

B. Participating would help ensure my job security.

OR C. It would provide an opportunity to build positive relationships with my colleagues, socialize, and share good times.

43. I would be most motivated to participate in staff development if:

E. It were stimulating and meaningful and I felt challenged.

OR A. It did not require more work on my part or cut into the time I would have for my own personal pleasures.

44. Personally, I believe the real rewards of participating in staff development activities are:

C. Interacting with colleagues, exchanging ideas, and sharing experiences.

OR

A. The potential for advancement on the salary schedule.

45. In deciding whether or not to participate in staff development activities, I will be most concerned with the extent to which:

D. It would give me additional expertise or help me obtain an advanced degree for which I would receive personal recognition.

OR E. I would be able to learn, grow professionally, and become more knowledgeable.

46. I would be most motivated to participate in staff developmeat If:

C. My colleagues also participated and we were able to work together as a team.

OR D. It allowed me to demonstrate my own competence and be recognized by others as being one of the better educators in my group.

47. Personally, I believe the real rewards of participating in staff development activities are:

B. That it will look good on my evaluations and thereby help ensure my job security.

OR $E$. The personal satisfaction of learning new skills that are relevant to my job.

48. In deciding whether or not to participate in staff development activities, I would be most concerned with the extent to which:

A. I would receive extra pay or release time.

C. It would provide an opportunity to build positive relationships with my colleagues, socialize, and share good times.

49. I would be most motivated to participate in staff development if:

B. It helped me feel more secure about my job and abie to cope with changes in my field.

OR D. It allowed me to demonstrate my own competence and be recognized by others as being one of the better educators in my group.

50. Personally, I believe the real rewards of participating in staff development activities are:

OR

E. The personal satisfaction of learning new skills that are relevant to my job.

A. The potential for advancement on the salary schedule. 
51. In deciding whether or not to participate in staff development activities, I would be most concerned with the extent to which:

D. It would give me additional expertise or help me obtain an advanced degree for which I would receive personal recognition.

OR B. Participating would help ensure my job security.

52. I would be most motivated to participate in staff development if:

A. It did not require more work on my part or cut into the time I would have for my own personal pleasures.

OR C. My colleagues also participated and we were abie to work together as a team.

53. Personally, I believe the real rewards of participating in staff development activities are:

D. Receiving personal recognition and tangible rewards for participating.

OR A. The potential for advancement on the salary schedule.

54. In deciding whether or not to particjpate in staff development activities, I would be most concerned with the extent to which:

OR

B. Participating would help ensure my job security.

E. I would be able to learn, grow professionally, and become more knowledgeable.

55. I would be most motivated to participate in stoff development if:

C. My colleagues also participated and we were able to work together as a team.

E. It were stimulating and meaningful and I felt challenged.

56. Personally, I believe the real rewards of participating in staff development activities are:

C. Interacting with colleagues, exchanging ideas, and sharing experiences.

OR. Receiving personal recognition and tangible rewards for participating.

57. In deciding whether or not to participate in staff development activities, I would be most concerned with the extent to which:

A. I would receive extra pay or release time.

D. It would give me additional experise or help me work toward an advanced degree for which I would receive personal recognition.

58. I would be most motivated to participate in staff development If:

B. It helped me feel more secure about my job and able to cope with changes in my field.

OR

C. My colleagues also participated and we were able to work together as a team.

59. Personally, I believe the real reward of participating in staff development activities is:

A. The potential for advancement on the salary schedule.

OR B. That it will look good on my evaluations and thereby help ensure my job security.

60. In deciding whether or not to participate in staff development activities, I would be most concerned with the extent to which:

OR

D. I would be able to learn, grow professionally, and become more knowledgeable.

A. I would receive extra pay or release time. 
61. I would be most motivated to participate in staff development if:

B. It helped me feel more secure about my job and able to cope with changes in my field.

OR

E. It were stimulating and meaningful and I felt challenged.

62. Personally, I believe the real rewards of participating in staff development activities are:

OR

B. That it will look good on my evaluations and thereby help ensure my job security.

C. Interacting with colleagues, exchanging ideas, and sharing experiences.

63. In deciding whether or not to participate in staff development activities, I would be most concerned with the extent to which:

OR A. I would receive extra pay or release time.

B. It would help ensure my job security.

64. I would be most motivated to participate in staff deveiopment lf:

D. It allowed me to demonstrate my own competence and be recognized by others as being one of the better educators in my field.

OR

E. It were stimulating and meaningful and I felt challenged.

65. Personally, I believe the real rewards of participating in staff development activities are:

OR

B. That it will look good on my evaluations and thereby help ensure my job security.

D. Receiving personal recognition and tangible rewards for participating.

66. In deciding whether or not to participate in staff development activities, I would be most concerned with the extent to which:

C. It would provide an opportunity to build positive relationships with my colleagues, socialize, and share good times.

OR

E. I would be able to learn, grow professionally, and become more knowledgeable.

67. I would be most motivated to participate in staff development If:

D. It allowed me to demonstrate my own competence and be recognized by others as being one of the better educators in my group.

OR

A. It did not require more work on my part or cut into the time I would have for my own personal pleasures.

68. Personally, 1 belleve the real rewards of participatiag in staff development activities are:

C. Interacting with colleagues, exchanging ideas, and sharing experiences.

OR E. The personal satisfaction of learning new skills that are relevant to my job.

69. In deciding whether or not to participate in staff development activities, I would be most concerned with the extent to which:

C. It would provide an opportunity to build positive relationships with my colleagues, socialize, and share good times.

OR D. It would give me additional expertise or help me obtain an advanced degree for which I would receive personal recognition.

70. I would be most motivated to participate in staff development if:

A. It did not require more work on my part or cut into the time 1 would have for my own personal pleasures.

OR B. It helped me feel more secure about my job and able to cope with changes in my field. 


\section{SECTION 3-DEMOGRAPHIC QUESTIONS}

For questions 71 -78, please enter your responses in the space provided on your answer sheet in the demographic section. Be sure to match the number of the response box to the number of the question you are answering.

71. How many total years combined Washington State and out-of-state full-rime certificated public sehool experience do you have? (Include long-term substitute experience. Combine years of part-time teaching experience to yield full years. For example: 2 years of half-time experience equals 1 year of full-time experience.)

WRITE THE NUMBER OF YEARS IN THE SPACE PROVIDED ON YOUR ANSWER SHEET, Q7I

72. What is your gender?

A. Female

B. Male

73. Which of the following best describes your major work assigameat?
A. Regular classroom teacher
B. Teaching specialist (music, art, reading, librarian)
C. Special education teacher (resource, Chapter I, etc.)
D. Certificated supporn personnel (counselor, nurse. audiologist, etc.)
E. Other

74. Which of the following best identifies your highest earued degree?
A. Vocational degree
B. Bachelors degree
C. Masters degree
D. Doctorate degree
E. Other

75. Do you still quallify for incremental movement on your school district's salary schedule?
A. Yes, I can earn both more experience and more education credit.
B. Yes, but for education increments only (I have as many years of experience as the schedule recognizes).
C. Yes, but for experieace increments only (I have as much education as the schedule recognizes).
D. No, I can't move either way (I have as much, or more, of both education and experience credit as the schedule recognizes).
E. Don't know/not sure.

76. What proportion of your household's totel lncome is attributable to your school district salery?
A. $100 \%$
B. $75-99 \%$
C. $50-74 \%$
D. $25-49 \%$
E. Less than $25 \%$

77. To what grade level(s) are you assigued the majority of your time?
A. Elementary/primary school
B. Middle/junior high school
C. High school
D. Combination of above levels
E. Not applicable

78. What is the approximate pupil enroliment.in the school district in which you work?
A. Small-fewer than 2,000 pupils
B. Medium-from 2,001 to 9,999 pupils
C. Large $-10,000$ or more pupils
D. Don't know/not sure 


\section{PROFILE ANSWER SHEET}

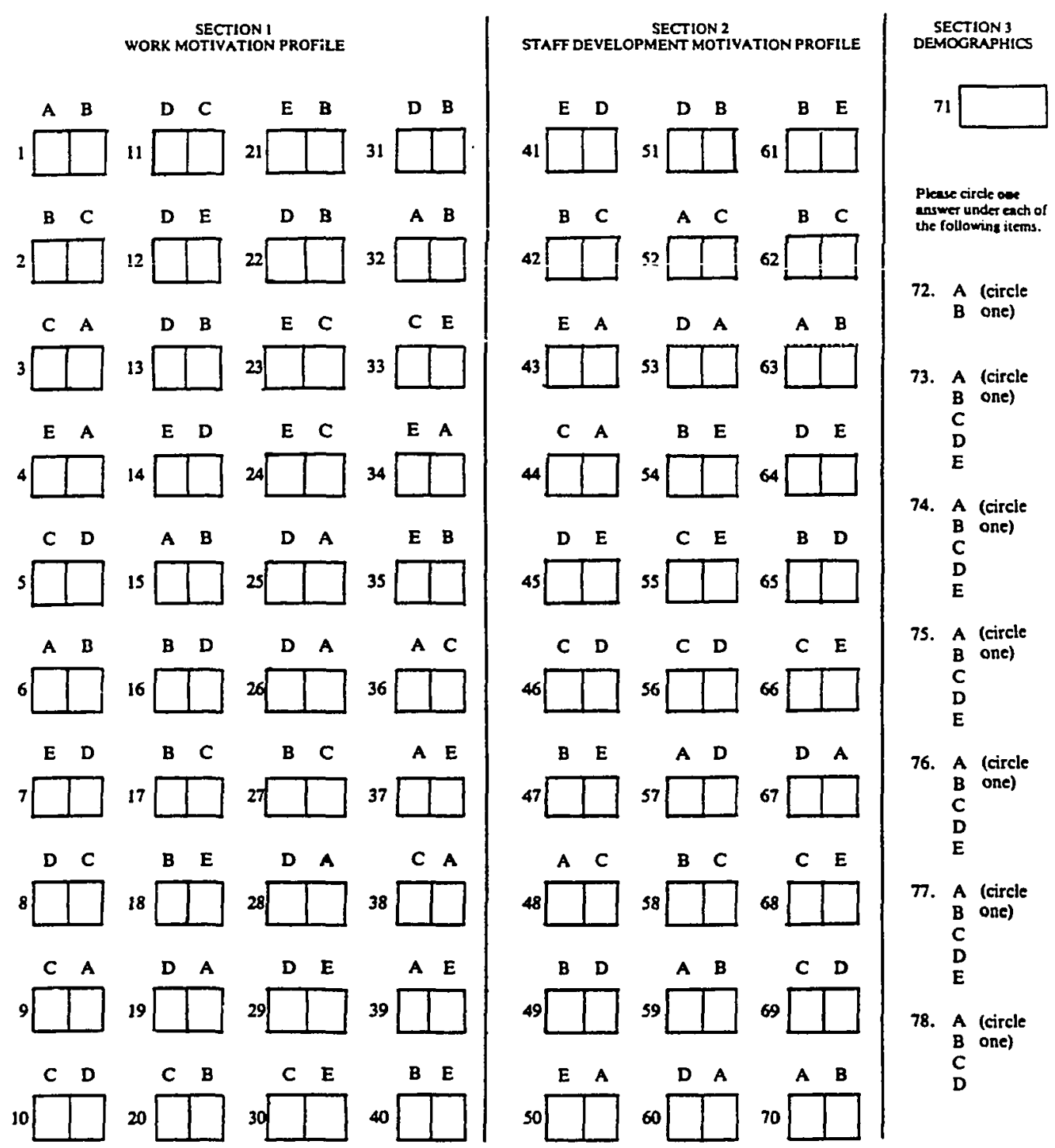

PLEASE SEE REVERSE SIDE FOR RETURN MAIL INSTRUCTIONS. 
COMMENTS:

And finally, please ...

1. Tear off this answer sheet.

2. Go over your answer sheet to be sure you have responded to every item in all three sections.

3. For items in sections 1 and 2 , please be sure the numbers you assign to each pair sum to equal 5 .

4. Fold this answer sheet as indicated and mail it at your earliest convenience.

THANK YOU!

smon
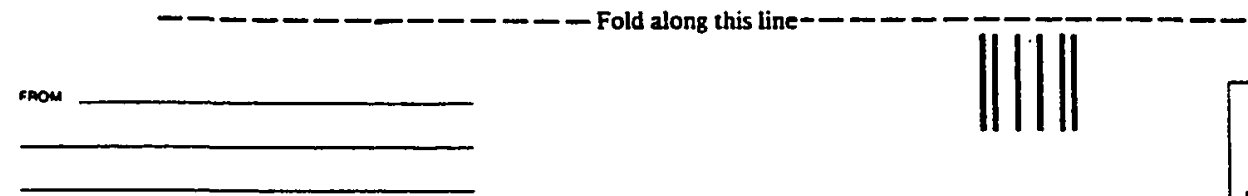

BUSINESS REPLY MAIL FIASTCLASS PERMITNO.427 AUBURN.WA

POSTAGE WILL BE PAID GY ADDRESSEe

WASHINGTON

EDUCATION ASSOCLATION

RESEARCH DEPARTMENT

33434 - 8TH AVENUE SOUTH

FEDERAL WAY, WA 98003-6397

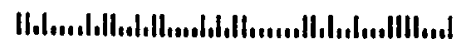


$\stackrel{\text { @ }}{\mathbb{N}}$

Washington Education Association

Research Department

33434 Eighth Avenue South

Federal Way, WA 98003-6397

«实实以・"

To: 


\section{APPENDIX B}

PILOT TEST QUESTIONNAIRE 


\section{PILOT TEST QUESTIONNAIRE}

\section{PLEASE TAKE A MOMENT TO ANSWER THESE QUESTIONS:}

Please circle the appropriate response.

1. The instructions were clear and sufficient.

Strongly

Strongly

Agree

Disagree

$\begin{array}{lllll}1 & 2 & 3 & 4 & 5\end{array}$

2. I had no difficulty understanding the instructions.

$\begin{array}{lllll}1 & 2 & 3 & 4 & 5\end{array}$

3. Were any of the questions particularly confusing?

Yes

No

Which one(s)? Write the number of the question (s).

4. What was your overall reaction to the survey instrument?

5. Do you have any questions about the survey? 
APPENDIX C CODE BOOK 
DATA CODE BOOK

Section 1 - WORK MOTIVATION PROFILE

(first iteration)

LOC. QUEST.\# VAR QUEST. NAMEJDESCRIPTION VAR ISUBGROUP \# TYPE NAME

\begin{tabular}{|c|c|c|c|c|c|}
\hline $\begin{array}{l}01 \\
02 \\
03 \\
04 \\
05 \\
08 \\
07 \\
08\end{array}$ & $\begin{array}{l}\text { 1A(BASIC) } \\
\text { 1E(SAFETY) } \\
\text { 2B(SAFETY) } \\
\text { 2C(BELONG) } \\
3 C(B E L O N G) \\
3 A(B A S I C) \\
\text { 4E(ACTUAL) } \\
\text { 4A(BASIC) }\end{array}$ & $\begin{array}{l}1 \\
2 \\
3 \\
4 \\
5 \\
6 \\
7 \\
8\end{array}$ & $\begin{array}{l}\mathbf{a} \\
\mathbf{b} \\
\mathbf{c} \\
\mathbf{d} \\
\mathbf{e} \\
\mathbf{f} \\
\mathbf{g} \\
\mathbf{h}\end{array}$ & $\begin{array}{l}\text { TIME-ENERGYISUPPLIES } \\
\text { TIME-ENERGYISECURITY } \\
\text { QUIT-ED/HIGH RISK } \\
\text { QUIT-ED/ISOLATED } \\
\text { SUFFER/GRUDGE } \\
\text { SUFFERWORKLOAD } \\
\text { REWARDS/NATURE } \\
\text { REWARDS/BASICS }\end{array}$ & $\begin{array}{l}\text { (SUP1) } \\
\text { (SEC1) } \\
\text { (RISK2) } \\
\text { (ISO2) } \\
\text { (SUFF2) } \\
\text { (LOAD3) } \\
\text { (NATU4) } \\
\text { (BASI4) }\end{array}$ \\
\hline
\end{tabular}

(second iteration)

LOC. QUEST.\# VAR QUEST. NAME/DESCRIPTION VAR ISUBGROUP \# TYPE NAME

\begin{tabular}{llllll}
\hline 09 & 5C(BELONG) & 09 & $\mathbf{i}$ & TIME-ENERGYISUPPLIES & (SUP1) \\
10 & 5D(EGO) & 10 & $\mathbf{j}$ & TIME-ENERGYISECURITY & (SEC1) \\
11 & 6A(BASIC) & 11 & $\mathbf{k}$ & QUIT-ED/PAY & (PAY2) \\
12 & 6B(SAFETY) & 12 & $\mathbf{c}^{*}$ & QUIT-ED/HIGH RISK(a) & (RISKA2) \\
13 & 7E(ACTUAL) & 13 & $\mathbf{1}$ & SUFFERNASTED & (WASTE3) \\
14 & 7D(EGO) & 14 & $\mathbf{m}$ & SUFFERNORKLOAD & (LOAD3) \\
15 & 8D(EGO) & 15 & $\mathbf{n}$ & REWARDS/COMPETENCE & (COMP4) \\
16 & $8 C(B E L O N G)$ & 16 & 0 & REWARDSNALUED & (NALU4)
\end{tabular}

(third iteration)

\begin{tabular}{|c|c|c|c|c|c|}
\hline LOC. & $\begin{array}{l}\text { QUEST. \# } \\
\text { ISUBGROUP }\end{array}$ & $\begin{array}{c}\text { VAR } \\
\#\end{array}$ & $\begin{array}{l}\text { QUEST. } \\
\text { TYPE }\end{array}$ & NAME/DESCRIPTION & $\begin{array}{l}\text { VAR } \\
\text { NAME }\end{array}$ \\
\hline $\begin{array}{l}17 \\
18 \\
19 \\
20 \\
21 \\
22 \\
23 \\
24\end{array}$ & $\begin{array}{l}9 C \text { (BELONG) } \\
9 A(B A S I C) \\
10 C(B E L O N G) \\
10 D(E G O) \\
11 D(E G O) \\
11 C \text { (BELONG) } \\
12 D(E G O) \\
12 E(A C T U A L)\end{array}$ & $\begin{array}{l}17 \\
18 \\
19 \\
20 \\
21 \\
22 \\
23 \\
24\end{array}$ & $\begin{array}{l}i^{*} \\
a^{*} \\
d^{*} \\
p \\
m^{*} \\
e^{*} \\
n^{*} \\
g^{*}\end{array}$ & $\begin{array}{l}\text { TIME-ENERGYICAMARAD(a) } \\
\text { TIME-ENERGYISUPPLIES(a) } \\
\text { QUIT-ED/ISOLATED(a) } \\
\text { QUIT-ED/DEGRADE } \\
\text { SUFFER/RECOGNITION(a) } \\
\text { SUFFER/GRUDGE(a) } \\
\text { REWARD/COMPETENCE(a) } \\
\text { REWARDS/NATURE(a) }\end{array}$ & $\begin{array}{l}\text { (CAMA1) } \\
\text { (SUPP1) } \\
\text { (ISOA2) } \\
\text { (DEG2) } \\
\text { (RECA3) } \\
\text { (SUFFA3) } \\
\text { (COMPA4) } \\
\text { (NATUA4) }\end{array}$ \\
\hline
\end{tabular}


(fourth iteration)

\begin{tabular}{|c|c|c|c|c|c|}
\hline LOC. & $\begin{array}{l}\text { QUEST.\# } \\
\text { ISUBGROUP }\end{array}$ & $\begin{array}{c}\text { VAR } \\
\#\end{array}$ & $\begin{array}{l}\text { QUEST } \\
\text { TYPE }\end{array}$ & NAMESDESCRIPTION & $\begin{array}{l}\text { VAR } \\
\text { NAME }\end{array}$ \\
\hline $\begin{array}{l}25 \\
26 \\
27 \\
28 \\
29 \\
30 \\
31 \\
32\end{array}$ & $\begin{array}{l}\text { 13D(EGO) } \\
\text { 13B(SAFETY) } \\
\text { 14E(ACTUAL) } \\
\text { 14D(EGO) } \\
\text { 15A(BASIC) } \\
\text { 15B(SAFETY) } \\
\text { 16B(SAFETY) } \\
\text { 16D(EGO) }\end{array}$ & $\begin{array}{l}25 \\
26 \\
27 \\
28 \\
29 \\
30 \\
31 \\
32\end{array}$ & $\begin{array}{l}j^{\star} \\
b^{*} \\
q \\
p^{*} \\
f^{*} \\
r \\
s \\
n^{*}\end{array}$ & $\begin{array}{l}\text { TIME-ENERGYIPERF(a) } \\
\text { TIME-ENERGYISECURITY(a) } \\
\text { QUIT-ED/STAGNATE } \\
\text { QUIT-ED/DEGRADE(A) } \\
\text { SUFFERWORKLOAD(a) } \\
\text { SUFFER/EVALUATION } \\
\text { REWARD/FRINGE BENEFIT } \\
\text { REWARD/COMPETENCE(b) }\end{array}$ & $\begin{array}{l}\text { (PERFA1) } \\
\text { (SECA1) } \\
\text { (STAG2) } \\
\text { (DEGA2) } \\
\text { (LOADA3) } \\
\text { (EVAL3) } \\
\text { (FRIN4) } \\
\text { (COMPB4) }\end{array}$ \\
\hline
\end{tabular}

(fifth iteration)

$\begin{array}{llcccc}\text { LOC. } & \text { QUEST. \# } & \text { VAR } & \text { QUEST. } & \text { NAME/DESCRIPTION } & \text { VAR } \\ & \text { ISUBGROUP } & \# & \text { TYPE } & & \text { NAME }\end{array}$

\begin{tabular}{|c|c|c|c|c|c|}
\hline $\begin{array}{l}33 \\
34 \\
35 \\
36 \\
37 \\
38 \\
39 \\
40\end{array}$ & $\begin{array}{l}\text { 17B(SAFETY) } \\
\text { 17C(BELONG) } \\
\text { 18B(SAFETY) } \\
\text { 18E(ACTUAL) } \\
\text { 19D(EGO) } \\
\text { 19A(BASIC) } \\
\text { 20C(BELONG) } \\
\text { 20B(SAFETY) }\end{array}$ & $\begin{array}{l}33 \\
34 \\
35 \\
36 \\
37 \\
38 \\
39 \\
40\end{array}$ & $\begin{array}{l}b^{*} \\
i^{*} \\
c^{*} \\
q^{*} \\
m^{*} \\
f^{*} \\
0^{*} \\
s^{*}\end{array}$ & $\begin{array}{l}\text { TIME-ENERGYISECURITY(b) } \\
\text { TIME-ENERGYICOMARAD(b) } \\
\text { QUIT-ED/HIGH RISK(b) } \\
\text { QUIT-ED/STAGNATE(a) } \\
\text { SUFFER/RECOGNITION(b) } \\
\text { SUFFERWORKLOAD(b) } \\
\text { REWARDSNALUED(a) } \\
\text { REWARDS/FRINGE BENE(a) }\end{array}$ & $\begin{array}{l}\text { (SECB1) } \\
\text { (COMB1) } \\
\text { (RISKB2) } \\
\text { (STAGA2) } \\
\text { (RECB3) } \\
\text { (LOADB3) } \\
\text { NALUA4) } \\
\text { (FRINA4) }\end{array}$ \\
\hline
\end{tabular}

(sixth iteration)

LOC. QUEST.\# VAR QUEST. NAME/DESCRIPTION VAR ISUBGROUP \# TYPE NAME

\begin{tabular}{|c|c|c|c|c|c|}
\hline $\begin{array}{l}41 \\
42 \\
43 \\
44 \\
45 \\
46 \\
47 \\
48\end{array}$ & $\begin{array}{l}\text { 21E(ACTUAL) } \\
\text { 21B(SAFETY) } \\
\text { 22D(EGO) } \\
\text { 22B(SAFETY) } \\
\text { 23E(ACTUAL) } \\
\text { 23C(BELONG) } \\
\text { 24E(ACTUAL) } \\
\text { 24C(BELONG) }\end{array}$ & $\begin{array}{l}41 \\
42 \\
43 \\
44 \\
45 \\
46 \\
47 \\
48\end{array}$ & $\begin{array}{l}t \\
b^{*} \\
p^{*} \\
c^{*} \\
l^{*} \\
e^{*} \\
g^{*} \\
0^{*}\end{array}$ & $\begin{array}{l}\text { TIME-ENERGY/FRUITS } \\
\text { TIME-ENERGYISECURITY(c) } \\
\text { QUIT-ED/DEGRADE(b) } \\
\text { QUIT-ED/HIGH RISK(c) } \\
\text { SUFFERWASTED(a) } \\
\text { SUFFER/GRUDGE(b) } \\
\text { REWARDS/NATURE(b) } \\
\text { REWARDSNALUED(b) }\end{array}$ & $\begin{array}{l}\text { (FRU1) } \\
\text { (SECC1) } \\
\text { (DEGB2) } \\
\text { (RISKC2) } \\
\text { (WASTA3) } \\
\text { (SUFFB3) } \\
\text { (NATUB4) } \\
\text { (NALUB4) }\end{array}$ \\
\hline
\end{tabular}


(seventh iteration)

\begin{tabular}{|c|c|c|c|c|c|}
\hline LOC. & $\begin{array}{l}\text { QUEST. \# } \\
\text { ISUBGROUP }\end{array}$ & $\begin{array}{c}\text { VAR } \\
\#\end{array}$ & $\begin{array}{l}\text { QUEST. } \\
\text { TYPE }\end{array}$ & NAME/DESCRIPTION & $\begin{array}{l}\text { VAR } \\
\text { NAME }\end{array}$ \\
\hline $\begin{array}{l}49 \\
50 \\
51 \\
52 \\
53 \\
54 \\
55 \\
56\end{array}$ & $\begin{array}{l}\text { 25D(EGO) } \\
\text { 25A(BASIC) } \\
\text { 26D(EGO) } \\
\text { 26A(BASIC) } \\
27 B(\text { SAFETY } \\
\text { 27C(BELONG) } \\
\text { 28D(EGO) } \\
\text { 28A(BASIC) }\end{array}$ & $\begin{array}{l}49 \\
50 \\
51 \\
52 \\
53 \\
54 \\
55 \\
56\end{array}$ & $\begin{array}{l}j^{\star} \\
a^{*} \\
p^{*} \\
k^{*} \\
r^{*} \\
e^{*} \\
n^{*} \\
h^{*}\end{array}$ & $\begin{array}{l}\text { TIME-ENERGY/PERF(b) } \\
\text { TIME-ENERGYISUPPLIES(b) } \\
\text { QUIT-ED/DEGRADE(c) } \\
\text { QUIT-ED/PAY(a) } \\
\text { SUFFER/EVALUATION(a) } \\
\text { SUFFER/GRUDGE(c) } \\
\text { REWARD/COMPETENCE(c) } \\
\text { REWARD/BASICS(a) }\end{array}$ & $\begin{array}{l}\text { (PERFB1) } \\
\text { (SUPB1) } \\
\text { (DEGC2) } \\
\text { (PAYA2) } \\
\text { (EVALA3) } \\
\text { (SUFFC3) } \\
\text { (COMPC4) } \\
\text { (BASIA4) }\end{array}$ \\
\hline
\end{tabular}

(eighth iteration)

\begin{tabular}{|c|c|c|c|c|c|}
\hline LOC. & $\begin{array}{l}\text { QUEST. \# } \\
\text { ISUBGROUP }\end{array}$ & $\begin{array}{c}\text { VAR } \\
\#\end{array}$ & $\begin{array}{l}\text { QUEST. } \\
\text { TYPE }\end{array}$ & NAMEJDESCRIPTION & $\begin{array}{l}\text { VAR } \\
\text { NAME }\end{array}$ \\
\hline $\begin{array}{l}57 \\
58 \\
59 \\
60 \\
61 \\
62 \\
63 \\
64\end{array}$ & $\begin{array}{l}\text { 29D(EGO) } \\
\text { 29E(ACTUAL) } \\
\text { 30C(BELONG) } \\
\text { 30E(ACTUAL) } \\
\text { 31D(EGO) } \\
\text { 31B(SAFETY) } \\
\text { 32A(BASIC) } \\
\text { 32B(SAFETY) }\end{array}$ & $\begin{array}{l}57 \\
58 \\
59 \\
60 \\
61 \\
62 \\
63 \\
64\end{array}$ & $\begin{array}{l}j^{*} \\
t^{*} \\
d^{*} \\
q^{*} \\
m^{*} \\
r^{*} \\
h^{*} \\
s^{*}\end{array}$ & $\begin{array}{l}\text { TIME-ENERGY/PERF(c) } \\
\text { TIME-ENERGY/FRUITS(a) } \\
\text { QUIT-ED/ISOLATED(b) } \\
\text { QUIT-ED/STAGNATE(b) } \\
\text { SUFFER/RECOGNITION(c) } \\
\text { SUFFER/EVALUATION(b) } \\
\text { REWARDS/BASICS(c) } \\
\text { REWARDS/FRINGE BENE }\end{array}$ & $\begin{array}{l}\text { (PERFC1) } \\
\text { (FRUA1) } \\
\text { (ISOB2) } \\
\text { (STAGB2) } \\
\text { (RECC3) } \\
\text { (EVALB3) } \\
\text { (BASIC4) } \\
\text { (FRINB4) }\end{array}$ \\
\hline
\end{tabular}

(ninth iteration)

\begin{tabular}{|c|c|c|c|c|c|}
\hline LOC. & $\begin{array}{l}\text { QUEST. \# } \\
\text { ISUBGROUP }\end{array}$ & $\begin{array}{c}\text { VAR } \\
\#\end{array}$ & $\begin{array}{l}\text { QUEST. } \\
\text { TYPE }\end{array}$ & NAME/DESCRIPTION & $\begin{array}{l}\text { VAR } \\
\text { NAME }\end{array}$ \\
\hline $\begin{array}{l}65 \\
66 \\
67 \\
68 \\
69 \\
70 \\
71 \\
72\end{array}$ & $\begin{array}{l}\text { 33C(BELONG) } \\
\text { 33E(ACTUAL) } \\
\text { 34E(ACTUAL) } \\
\text { 34A(BASIC) } \\
\text { 35E(ACTUAL) } \\
\text { 35B(SAFETY) } \\
\text { 36A(BASIC) } \\
\text { 36C(BELONG) }\end{array}$ & $\begin{array}{l}65 \\
66 \\
67 \\
68 \\
69 \\
70 \\
71 \\
72\end{array}$ & $\begin{array}{l}i^{*} \\
t^{*} \\
q^{*} \\
k^{*} \\
i^{*} \\
h^{*} \\
0^{*}\end{array}$ & $\begin{array}{l}\text { TIME-ENERGY/COMARAD(c) } \\
\text { TIME-ENERGY/FRUITS(b) } \\
\text { QUIT-ED/STAGNATE(c) } \\
\text { QUIT-ED/PAY(b) } \\
\text { SUFFERWASTED(b) } \\
\text { SUFFER/EVALUATION(c) } \\
\text { REWARDS/BASICS(b) } \\
\text { REWARDSNNALUED(c) }\end{array}$ & $\begin{array}{l}\text { (COMC1) } \\
\text { (FRUB1) } \\
\text { (STAGC2) } \\
\text { (PAYB2) } \\
\text { (WASTB3) } \\
\text { (EVALC3) } \\
\text { (BASIB4) } \\
\text { (NALUC4) }\end{array}$ \\
\hline
\end{tabular}


(tenth iteration)

\begin{tabular}{|c|c|c|c|c|c|}
\hline Dc. & $\begin{array}{l}\text { QUEST. \# } \\
\text { ISUBGROUP }\end{array}$ & $\begin{array}{c}\text { VAR } \\
\#\end{array}$ & $\begin{array}{l}\text { QUEST. } \\
\text { TYPE }\end{array}$ & NAME/DESCRIPTION & $\begin{array}{l}\text { VAR } \\
\text { NAME }\end{array}$ \\
\hline $\begin{array}{l}73 \\
74 \\
75 \\
76 \\
77 \\
78 \\
79 \\
80\end{array}$ & $\begin{array}{l}\text { 37A(BASIC) } \\
\text { 37E(ACTUAL) } \\
\text { 38C(BELONG) } \\
\text { 38A(BASIC) } \\
\text { 39A(BASIC) } \\
\text { 39E(ACTUAL) } \\
\text { 40B(SAFETY) } \\
\text { 40E(ACTUAL) }\end{array}$ & $\begin{array}{l}73 \\
74 \\
75 \\
76 \\
77 \\
78 \\
79 \\
80\end{array}$ & $\begin{array}{l}a^{*} \\
t^{*} \\
c^{*} \\
u \\
f^{*} \\
i^{*} \\
\mathbf{s}^{*}\end{array}$ & $\begin{array}{l}\text { TIME-ENERGYISUPPLIES(c) } \\
\text { TIME-ENERGY/FRUITS(b) } \\
\text { QUIT-ED/ISOLATED(c) } \\
\text { QUIT-ED/HEATING } \\
\text { SUFFERMORKLOAD(c) } \\
\text { SUFFERWWATED(c) } \\
\text { REWARDS/FRINGE BENE(c) } \\
\text { REWARDS/NATURE(c) }\end{array}$ & $\begin{array}{l}\text { (SUPC1) } \\
\text { (FRUC1) } \\
\text { (ISOC2) } \\
\text { (HEAT2) } \\
\text { (LOADC2) } \\
\text { (WASTC3) } \\
\text { (FRINC4) } \\
\text { (NATUC4) }\end{array}$ \\
\hline
\end{tabular}

Section 2 - STAFF DEVELOPMENT AND MOTIVATION PROFILE

(first iteration)

\begin{tabular}{|c|c|c|c|c|c|}
\hline LOC. & $\begin{array}{l}\text { QUEST.\# } \\
\text { ISUBGROUP }\end{array}$ & $\begin{array}{c}\text { VAR } \\
\#\end{array}$ & $\begin{array}{l}\text { QUEST. } \\
\text { TYPE }\end{array}$ & NAME/DESCRIPTION & $\begin{array}{l}\text { VAR } \\
\text { NAME }\end{array}$ \\
\hline $\begin{array}{l}81 \\
82 \\
83 \\
84 \\
85 \\
86\end{array}$ & $\begin{array}{l}\text { 41E(ACTUAL) } \\
\text { 41D(EGO) } \\
\text { 42B(SAFETY } \\
\text { 42C(BELONG) } \\
\text { 43E(ACTUAL) } \\
\text { 43A(BASIC) }\end{array}$ & $\begin{array}{l}81 \\
82 \\
83 \\
84 \\
85 \\
86\end{array}$ & $\begin{array}{l}a a \\
b b \\
c c \\
d d \\
e e \\
f f\end{array}$ & $\begin{array}{l}\text { PERSONALLYNEW SKILLS } \\
\text { PERSONALLY/RECEIVING } \\
\text { IN DECIDING/ENSURE SEC } \\
\text { IN DECIDING/GOOD TIMES } \\
\text { MOTIVATED/STIMULATE } \\
\text { MOTIVATED/PLEASURES }\end{array}$ & $\begin{array}{l}\text { (SKIL11) } \\
\text { (PREC11) } \\
\text { (ENSE22) } \\
\text { (GT22) } \\
\text { (STIM33) } \\
\text { (PLEAS33) }\end{array}$ \\
\hline
\end{tabular}

(second iteration)

\begin{tabular}{|c|c|c|c|c|c|}
\hline LOC. & $\begin{array}{l}\text { QUEST. \# } \\
\text { /SUBGROUP }\end{array}$ & $\begin{array}{c}\text { VAR } \\
\#\end{array}$ & $\begin{array}{c}\text { QUEST } \\
\text { TYPE }\end{array}$ & NAME/DESCRIPTION & $\begin{array}{l}\text { VAR } \\
\text { NAME }\end{array}$ \\
\hline $\begin{array}{l}87 \\
88 \\
89 \\
90 \\
91 \\
92\end{array}$ & $\begin{array}{l}\text { 44C(BELONG) } \\
\text { 44A(BASIC) } \\
\text { 45D(EGO) } \\
\text { 45E(ACTUAL) } \\
\text { 46C(BELONG) } \\
\text { 46D(EGO) }\end{array}$ & $\begin{array}{l}87 \\
88 \\
89 \\
90 \\
91 \\
92\end{array}$ & $\begin{array}{l}\text { gg } \\
\text { hh } \\
\text { ii } \\
\text { ji } \\
\text { kk } \\
\text { II }\end{array}$ & $\begin{array}{l}\text { PERSONALLYIINTERACTING } \\
\text { PERSONALLY/POTENTIAL } \\
\text { IN DECIDING/EXPERT } \\
\text { IN DECIDING/LEARN } \\
\text { MOTIVATED/TEAM } \\
\text { MOTIVATED/GROUP }\end{array}$ & $\begin{array}{l}\text { (INTER11) } \\
\text { (POT11) } \\
\text { (EXP22) } \\
\text { (LEARN22) } \\
\text { (TEAM33) } \\
\text { (GROU33) }\end{array}$ \\
\hline
\end{tabular}


(third iteration)

\begin{tabular}{|c|c|c|c|c|c|}
\hline LOC. & $\begin{array}{l}\text { QUEST.\# } \\
\text { ISUBGROUP }\end{array}$ & $\begin{array}{c}\text { VAR } \\
\#\end{array}$ & $\begin{array}{l}\text { QUEST. } \\
\text { TYPE }\end{array}$ & NAME/DESCRIPTION & $\begin{array}{l}\text { VAR } \\
\text { NAME }\end{array}$ \\
\hline $\begin{array}{l}93 \\
94 \\
95 \\
96 \\
97 \\
98\end{array}$ & $\begin{array}{l}\text { 47B(SAFETY) } \\
\text { 47E(ACTUAL) } \\
\text { 48A(SAFETY) } \\
\text { 48C(BELONG) } \\
\text { 49B(SAFETY) } \\
\text { 49D(EGO) }\end{array}$ & $\begin{array}{l}93 \\
94 \\
95 \\
96 \\
97 \\
98\end{array}$ & $\begin{array}{l}\mathrm{mm} \\
\mathrm{aa} \\
\mathrm{nn} \\
\mathrm{dd} \\
00 \\
l^{\star}\end{array}$ & $\begin{array}{l}\text { PERSONALLY/GOOD } \\
\text { PERSONALLYNEW SKILL(a) } \\
\text { IN DECIDING/RELEASE } \\
\text { IN DECIDING/GOOD TIME(a) } \\
\text { MOTIVATED/COPE } \\
\text { MOTIVATEO/GROUP(a) }\end{array}$ & $\begin{array}{l}\text { (GOOD11) } \\
\text { (SKILA11) } \\
\text { (REL22) } \\
\text { (GTA22) } \\
\text { (COPE33) } \\
\text { (GROA33) }\end{array}$ \\
\hline
\end{tabular}

(fourth iteration)

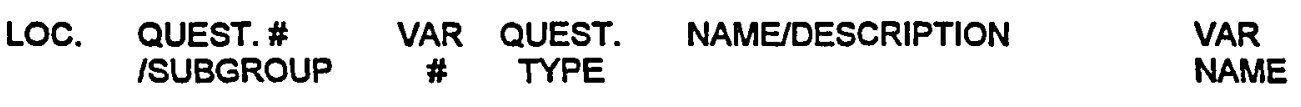

\begin{tabular}{|c|c|c|c|c|c|}
\hline $\begin{array}{l}99 \\
100 \\
101 \\
102 \\
103 \\
104\end{array}$ & $\begin{array}{l}\text { 50E(ACTUAL) } \\
\text { 50A(BASIC) } \\
\text { 51D(EGO) } \\
\text { 51B(SAFETY) } \\
\text { 52A(BASIC) } \\
\text { 52C(BELONG) }\end{array}$ & $\begin{array}{l}99 \\
100 \\
101 \\
102 \\
103 \\
104\end{array}$ & $\begin{array}{l}a a^{*} \\
h h^{*} \\
i^{*} \\
c c^{*} \\
f^{*} \\
k k^{*}\end{array}$ & $\begin{array}{l}\text { PERSONALLY/NEW SKILL(b) } \\
\text { PERSONALLYIPOTENTIAL(a) } \\
\text { IN DECIDING/EXPERTISE(a) } \\
\text { IN DECIDING/ENSURESE(a) } \\
\text { MOTIVATED/PLEASURES(a) } \\
\text { MOTIVATED/TEAM(a) }\end{array}$ & $\begin{array}{l}\text { (SKILB11) } \\
\text { (POTA11) } \\
\text { (EXPA22) } \\
\text { (ENSEA22) } \\
\text { (PLEAA33) } \\
\text { (TEAMA33) }\end{array}$ \\
\hline
\end{tabular}

(fifth iteration)

\begin{tabular}{|c|c|c|c|c|c|}
\hline LOC. & $\begin{array}{l}\text { QUEST. \# } \\
\text { ISUBGROUP }\end{array}$ & $\begin{array}{c}\text { VAR } \\
\#\end{array}$ & $\begin{array}{l}\text { QUEST. } \\
\text { TYPE }\end{array}$ & NAME/DESCRIPTION & $\begin{array}{l}\text { VAR } \\
\text { NAME }\end{array}$ \\
\hline $\begin{array}{l}105 \\
106 \\
107 \\
108 \\
109 \\
110\end{array}$ & $\begin{array}{l}\text { 53D(EGO) } \\
\text { 53A(BASIC) } \\
\text { 54B(SAFETY) } \\
\text { 54E(ACTUAL) } \\
\text { 55C(BELONG) } \\
\text { 55E(ACTUAL) }\end{array}$ & $\begin{array}{l}105 \\
106 \\
107 \\
108 \\
109 \\
110\end{array}$ & $\begin{array}{l}\mathrm{bb}^{*} \\
\mathrm{hh}^{*} \\
\mathrm{cc}^{*} \\
\mathrm{j}^{*} \\
\mathrm{kk}^{*} \\
\mathrm{ee}^{*}\end{array}$ & $\begin{array}{l}\text { PERSONALLY/RECEIVING(a) } \\
\text { PERSONALLY/POTENTIAL(b) } \\
\text { IN DECIDING/ENSURESE(b) } \\
\text { IN DECIDINGILARN(a) } \\
\text { MOTIVATED/TEAM(b) } \\
\text { MOTIVATED/STIMULATE(a) }\end{array}$ & $\begin{array}{l}\text { (PRECA11) } \\
\text { (POTB11) } \\
\text { (ENSEB22) } \\
\text { (LEARA22) } \\
\text { (TEAMB33) } \\
\text { (STIMA33) }\end{array}$ \\
\hline
\end{tabular}


(sixth iteration)

\begin{tabular}{|c|c|c|c|c|c|}
\hline LOC. & $\begin{array}{l}\text { QUEST. \# } \\
\text { ISUBGROUP }\end{array}$ & $\begin{array}{c}\text { VAR } \\
\#\end{array}$ & $\begin{array}{l}\text { QUEST. } \\
\text { TYPE }\end{array}$ & NAMEIDESCRIPTION & $\begin{array}{l}\text { VAR } \\
\text { NAME }\end{array}$ \\
\hline $\begin{array}{l}111 \\
112 \\
113 \\
114 \\
115 \\
116\end{array}$ & $\begin{array}{l}\text { 56C(BELONG) } \\
\text { 56D(EGO) } \\
\text { 57A(BASIC) } \\
\text { 57D(EGO) } \\
\text { 58B(SAFETY) } \\
\text { 58C(BELONG) }\end{array}$ & $\begin{array}{l}111 \\
112 \\
113 \\
114 \\
115 \\
116\end{array}$ & $\begin{array}{l}g^{*} \\
\mathrm{bb}^{*} \\
\mathrm{nn}^{*} \\
\mathrm{ii}^{*} \\
00^{*} \\
\mathrm{kk}^{*}\end{array}$ & $\begin{array}{l}\text { PERSONALLYINTERACT(a) } \\
\text { PERSONALLYIRECEIVING(b) } \\
\text { IN DECIDING/RELEASE(a) } \\
\text { IN DECIDING/EXPERTISE(b) } \\
\text { MOTIVATED/COPE(a) } \\
\text { MOTIVATEDITEAM(c) }\end{array}$ & $\begin{array}{l}\text { (INTEA11) } \\
\text { (PREC11) } \\
\text { (RELA22) } \\
\text { (EXPB22) } \\
\text { (COPA33) } \\
\text { (TEAC33) }\end{array}$ \\
\hline
\end{tabular}

(seventh iteration)

\begin{tabular}{|c|c|c|c|c|c|}
\hline LOC. & $\begin{array}{l}\text { QUEST. \# } \\
\text { ISUBGROUP }\end{array}$ & $\begin{array}{c}\text { VAR } \\
\#\end{array}$ & $\begin{array}{l}\text { QUEST. } \\
\text { TYPE }\end{array}$ & NAME/DESCRIPTION & $\begin{array}{l}\text { VAR } \\
\text { NAME }\end{array}$ \\
\hline $\begin{array}{l}117 \\
118 \\
119 \\
120 \\
121 \\
122\end{array}$ & $\begin{array}{l}\text { 59A(BASIC) } \\
\text { 59B(SAFETY } \\
\text { 60D(EGO) } \\
\text { 60A(BASIC) } \\
\text { 61B(SAFETY } \\
\text { 61E(ACTUAL) }\end{array}$ & $\begin{array}{l}117 \\
118 \\
119 \\
120 \\
121 \\
122\end{array}$ & $\begin{array}{l}\mathrm{hh}^{*} \\
\mathrm{~mm} \\
\mathrm{ji}^{*} \\
\mathrm{nn} \\
\mathrm{OO}^{*} \\
\mathrm{ee}\end{array}$ & $\begin{array}{l}\text { PERSONALLY/POTENTIAL } \\
\text { PERSONALLY/GOOD(a) } \\
\text { IN DECIDING/LEARN(b) } \\
\text { IN DECIDING/RELEASE(b) } \\
\text { MOTIVATED/COPE(b) } \\
\text { MOTIVATED/STIMULATE(b) }\end{array}$ & $\begin{array}{l}\text { (C)(POTC11) } \\
\text { (GOOA11) } \\
\text { (LEARB22) } \\
\text { (RELB22) } \\
\text { (COPB33) } \\
\text { (STIMB33) }\end{array}$ \\
\hline
\end{tabular}

(eighth iteration)

\begin{tabular}{|c|c|c|c|c|c|}
\hline LOC. & $\begin{array}{l}\text { QUEST. \# } \\
\text { ISUBGROUP }\end{array}$ & $\begin{array}{c}\text { VAR } \\
\#\end{array}$ & $\begin{array}{l}\text { QUEST. } \\
\text { TYPE }\end{array}$ & NAME/DESCRIPTION & $\begin{array}{l}\text { VAR } \\
\text { NAME }\end{array}$ \\
\hline $\begin{array}{l}123 \\
124 \\
125 \\
126 \\
127 \\
128\end{array}$ & $\begin{array}{l}\text { 62B(SAFETY } \\
\text { 62C(BELONG) } \\
63 A(B A S I C) \\
63 B(\text { SAFETY } \\
\text { 64D(EGO) } \\
\text { 64E(ACTUAL) }\end{array}$ & $\begin{array}{l}123 \\
124 \\
125 \\
126 \\
127 \\
128\end{array}$ & $\begin{array}{l}\mathrm{mm}^{*} \\
\mathrm{gg} \\
\mathrm{nn} \\
\mathrm{cc}^{*} \\
\mathrm{II}^{*} \\
\mathrm{ee}^{*}\end{array}$ & $\begin{array}{l}\text { PERSONALLYIGOOD(b) } \\
\text { PERSONALLYIINTERACT(b) } \\
\text { IN DECIDING/RELEASE(c) } \\
\text { IN DECIDING/ENSURE SE(c) } \\
\text { MOTIVATED/GROUP(b) } \\
\text { MOTIVATED/STIMULATE(c) }\end{array}$ & $\begin{array}{l}\text { (GOOB11) } \\
\text { (INTEB11) } \\
\text { (RELC22) } \\
\text { (ENSC22) } \\
\text { (GROB33) } \\
\text { (STIMC33) }\end{array}$ \\
\hline
\end{tabular}


(ninth iteration)

\begin{tabular}{|c|c|c|c|c|c|}
\hline LOC. & $\begin{array}{l}\text { QUEST. \# } \\
\text { ISUBGROUP }\end{array}$ & $\begin{array}{c}\text { VAR } \\
\#\end{array}$ & $\begin{array}{c}\text { QUEST } \\
\text { TYPE }\end{array}$ & NAME/DESCRIPTION & $\begin{array}{l}\text { VAR } \\
\text { NAME }\end{array}$ \\
\hline $\begin{array}{l}129 \\
130 \\
131 \\
132 \\
133 \\
134\end{array}$ & $\begin{array}{l}\text { 65B(SAFETY) } \\
\text { 65D(EGO) } \\
\text { 66C(BELONG) } \\
\text { 66E(ACTUAL) } \\
\text { 67D(EGO) } \\
\text { 67A(BASIC) }\end{array}$ & $\begin{array}{l}129 \\
130 \\
131 \\
132 \\
133 \\
134\end{array}$ & $\begin{array}{l}\mathrm{mm} \\
\mathrm{bb}^{*} \\
\mathrm{dd}^{*} \\
\mathrm{ij}^{*} \\
\mathrm{ll}^{*} \\
\mathrm{ff}^{*}\end{array}$ & $\begin{array}{l}\text { PERSONALLY/GOOD(c) } \\
\text { PERSONALLY/RECEIVING(c) } \\
\text { IN DECIDING/GOOD TIME(b) } \\
\text { IN DECIDINGLEARN(c) } \\
\text { MOTIVATED/GROUP(c) } \\
\text { MOTIVATED/PLEASURE(b) }\end{array}$ & $\begin{array}{l}\text { (GOOC11) } \\
\text { (PRCC11) } \\
\text { (GTB22) } \\
\text { (LERNC22) } \\
\text { (GROC33) } \\
\text { (PLEAB33) }\end{array}$ \\
\hline
\end{tabular}

(tenth iteration)

LOC. QUEST. ISUBGROUP

VAR QUEST.

NAME/DESCRIPTION

VAR

\# TYPE

NAME

\begin{tabular}{|c|c|c|c|c|c|}
\hline $\begin{array}{l}135 \\
136 \\
137 \\
138 \\
139 \\
140\end{array}$ & $\begin{array}{l}\text { 68C(BELONG) } \\
\text { 68E(ACTUAL) } \\
\text { 69C(BELONG) } \\
\text { 69D(EGO) } \\
\text { 70A(BASIC) } \\
\text { 70B(SAFETY) }\end{array}$ & $\begin{array}{l}135 \\
136 \\
137 \\
138 \\
139 \\
140\end{array}$ & $\begin{array}{l}g g^{*} \\
a^{*} \\
d^{*} \\
i^{* *} \\
f^{*} \\
00^{*}\end{array}$ & $\begin{array}{l}\text { PERSONALLY/NTERACT(c) } \\
\text { PERSONALLYINEW SKILL(C) } \\
\text { IN DECIDING/GOOD TIME(c) } \\
\text { IN DECIDING/EXPERTISE(c) } \\
\text { MOTIVATED/PLEASURE(c) } \\
\text { MOTIVATED/COPE(c) }\end{array}$ & $\begin{array}{l}\text { (INTEC11) } \\
\text { (SKILC11) } \\
\text { (GTC22) } \\
\text { (EXPC22) } \\
\text { (PLEAC33) } \\
\text { (COPC33) }\end{array}$ \\
\hline
\end{tabular}

Section 3 - ADDITIONAL CODING

LOC. QUEST \# VAR\# VAR-NAME CODING

\begin{tabular}{|c|c|c|c|c|}
\hline $1-140$ & $1-70$ & $1-140$ & (varies) & $\begin{array}{l}0=\text { COMPLETELY UNCHARACT. } \\
\text { 1=SOMEWHAT CHARACT. } \\
\text { 2=SLIGHTLY LESS CHARACT. } \\
\text { 3=SLIGHTLY MORE CHARACT. } \\
\text { 4=VERY CHARACTERISTIC } \\
\text { 5=COMPLETELY CHARACT. }\end{array}$ \\
\hline $141-2$ & 71 & 141 & YEARS & $\#=N U M B E R$ OF YEARS \\
\hline 143 & 72 & 142 & SEX & $\begin{array}{l}1=\text { FEMALE } \\
2=\text { MALE }\end{array}$ \\
\hline 144 & 73 & 143 & WORK & $\begin{array}{l}1=\text { REG. CLASSROOM TEACHER } \\
2=\text { TEACHING SPECIALIST } \\
\text { 3=SPECIAL EDUC. TEACHER } \\
\text { 4=CERT. SUPP. PERSONNEL } \\
5=0 \text { THER }\end{array}$ \\
\hline
\end{tabular}


$145 \quad 74$

146

75

145

$147 \quad 76$

146

148

77

147

$149 \quad 78$
DEGREE

$1=$ VOCATIONAL DEGREE 2=BACHELORS DEGREE

3=MASTERS DEGREE

4=DOCTORATE DEGREE 5=OTHER

SALARY $\quad 1=Y E S-M O R E$ EXP \& ED CREDIT $2=Y E S-O N L Y$ ED INCREMENTS $3=Y E S-O N L Y$ EXP INCREMENTS 4=NO-CANT MOVE 5=DON'T KNOW-NOT SURE

INCOME $\quad 1=100 \%$

$2=75 \%-99 \%$

$3=50 \%-74 \%$

$4=25 \%-49 \%$

5=LESS THAN $24 \%$

GRADE $1=$ ELEMENTARYIPRIMARY

2=MIDDLE/JUNIOR HIGH

$3=H I G H$ SCHOOL

$4=$ COMBINATION OF LEVELS

5=NOT APPLICABLE

PUPILS $\quad 1=S M A L L-L E S S$ THAN 2000

2=MEDIUM-2001 TO 9999

3=LARGE-10000 OR MORE

4=DONT KNOW - NOT SURE 